\title{
Turkana livelihood strategies and adaptation to drought in Kenya
}

\author{
Richard Otieno Juma
}

\begin{abstract}
A thesis
submitted to the Victoria University of Wellington in fulfilment of the requirements for the degree of

Doctor of Philosophy in Development Studies
\end{abstract}




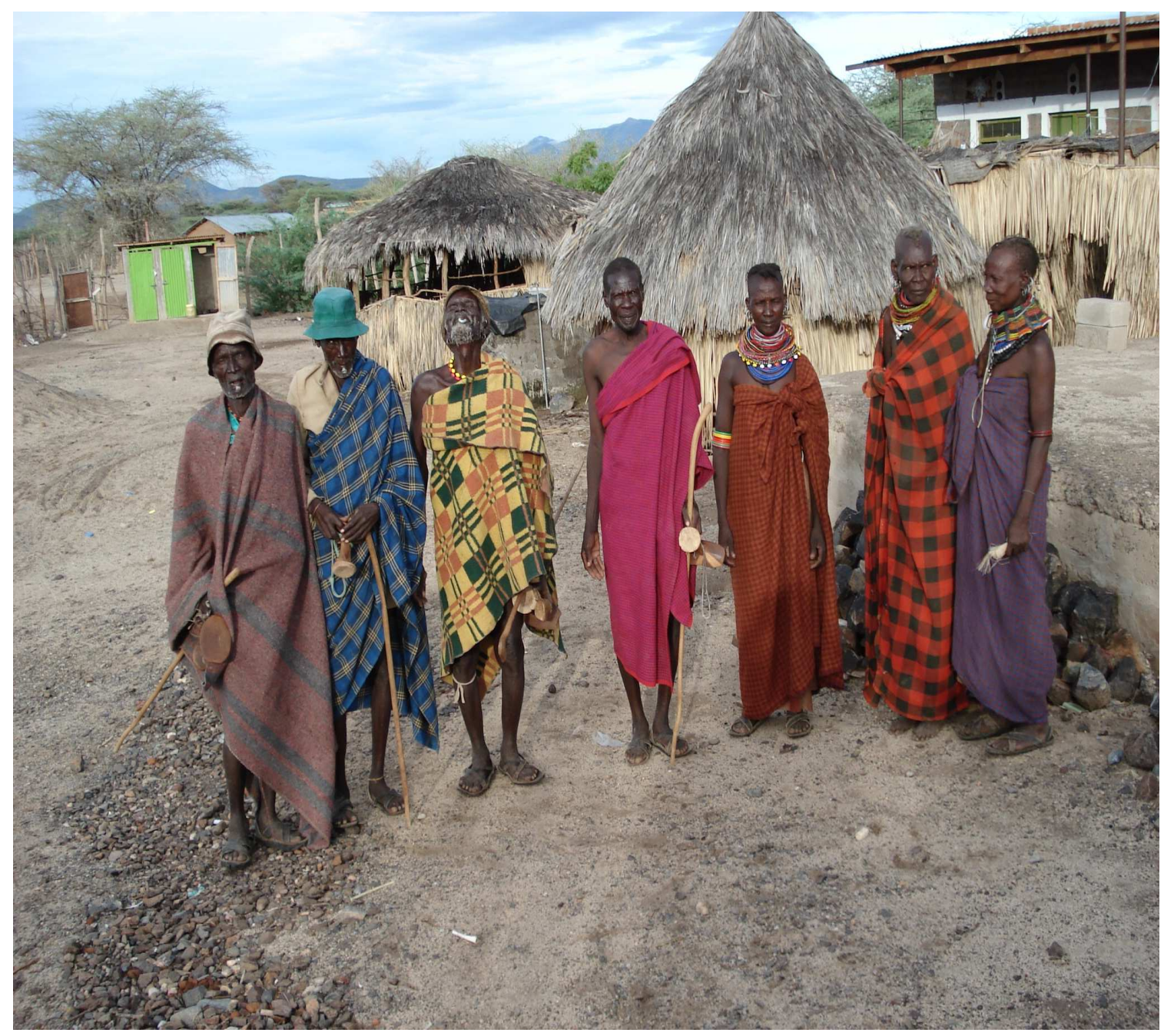

Dedicated to the Turkana people 


\section{Abstract}

Drought and famine in Sub-Saharan Africa are among the leading contributory causes of vulnerability in pastoral communities. Therefore, understanding pastoral vulnerability to drought and famine, and their indigenous adaptive strategies, is critical for mitigation planning.

This study draws on the experience of Turkana pastoralists living in the Turkana District in the arid zone of north-western Kenya, an area with a long history of food insecurity. The study looks at the problem of drought and famine from a historical perspective in order to bring into context contemporary adaptive strategies. Special attention is focused on understanding the inherent potential of the Turkana people to change their own livelihoods within their respective social and economic milieu in response to drought and famine, with a view to understanding the implications of these indigenous responses to adapt to drought in this region in the future. Specifically, the study analyses the types of social networks which were activated during the 2005-2006 drought and famine which hence, over time have shaped the adaptation of the Turkana people's livelihood strategies. The sustainable livelihood approach was deemed appropriate to the focus of this research in that it provided the framework for an indepth exploration of how Turkana people survive during crises.

The fieldwork was carried out for six months between February and July 2007. A sample of 80 household heads and eight key informants were randomly selected. Documentary review, observation and informal interviews, key informant interviews, a household survey, and case histories and mapping were used to obtain data. Data were analysed both qualitatively and quantitatively. The major findings were: firstly, that Turkana people apply a perceptual filter to their crises before finding a relevant livelihood strategy; secondly, that the Turkana possess a 
repertoire of adaptive strategies which stand out in relief and draw on social networks as an insurance system. The dominant modes of networks identified during the 2005-2006 drought and famine consisted of trading, reciprocity, migration, splitting families and the search for allies. For example, families were split with some members sent away to relatives, friends, and school in order to ease the consumption pressure on available household food resources. The process thus helped to slough off population from the pastoral sector. The allies sought out included traders, kinsmen, affine, bond friends, neighbours and school; and thirdly, that adaptability in the Turkana district is a function of the physical, social, and economic environment. For instance, the Ngibelai, who inhabited a more hostile and isolated rural environment suffered more severely, while the Ngisonyoka of the richer urban environment escaped almost unscathed since their adaptive strategies aimed at augmenting existing domestic food supplies by looking for non-pastoral food sources. Finally, the study concludes that, since the drought and famine problem in the Turkana District is an indication of what might become a wider problem throughout Kenya; the challenge for the Turkana people and the Kenyan government is to plan for a sustainable adaptive strategy based on indigenous initiatives.

Key words: Drought, famine, Turkana, livelihood strategies, adaptive strategies, social networks. 


\section{Acknowledgement}

This work was carried out in the School of Geography, Environment and Earth Sciences of Victoria University of Wellington. However, it would never have been completed without the support and assistance of many dedicated individuals and some organisations both inside and outside the School, not all of whom can be mentioned here.

First of all, I would like to acknowledge my deepest sense of both personal and professional gratitude to my primary supervisor, Professor John Overton, who has supervised this $\mathrm{PhD}$ thesis with invaluable enthusiasm. His valuable advice and insightful criticism over the whole thesis have been of the utmost significance in the course of my study. Similarly, without his encouragement, I would have found it very difficult to move forward. My thanks are due also for his countless readings of the manuscript over and again over the nights and weekends during the past three years. I am also incredibly appreciative to my co-supervisor, Associate Professor John McKinnon, for inspiration and professional guidance both while in the field and in the writing process. I have learnt more from him than can ever be contained in this thesis. Special thanks to Professor Vijay Naidu, and Dr. Diane O'Rourke without whom I would never have begun this project. It was their encouragement that originally inspired me to undertake scientific research.

This research has been funded by NZAID. I am deeply grateful for their generous support. I acknowledge my organization Jomo Kenyatta University which gave me study leave to undertake this research.

I would like to thank the Turkana pastoralists of Morulem and Lokichar

villages in the Turkana District. Despite the fact that they make a living under extreme circumstances, where drought, famine, and lack of 
resources constrain their livelihoods, they welcomed and shared their information with me. I am forever indebted to all of them.

I would like to thank all members of academic staff, and non-teaching staff at the School of Geography, Environment and Earth Science for providing an invigorating academic and social setting. Special thanks to my $\mathrm{PhD}$ colleagues especially my "fellow combatants" Alok, Shukri, and Dona. Thanks also go to audiences who attended my seminar, and anonymous reviewers of articles laying the foundation of this thesis.

I would like to express my sincere gratitude to my family especially my wife Quin, and children, Beverly, Maxine and Tessie whose love, unfailing encouragement, understanding, continuing support and prayers have always been a sort of spiritual dynamics propelling me through every difficult moment during my study. Things were not always easy and certain obstacles prevented us from doing what we would have done.

Finally, my years of childhood and adolescence prepared me well for what I have been able to achieve here. I cannot adequately express my gratitude to my parents Stephen Juma and Mary Adhiambo for their unstinting kindness, love, support, encouragements, help, and care at every turn of the road. It was they who cultivated in me the gifts that have enabled me to bring this work to completion. I would also like to thank my brothers Laurence Juma and Benard Ochieng, and sister Milka Akinyi for their moral and practical support. 


\section{Table of contents}

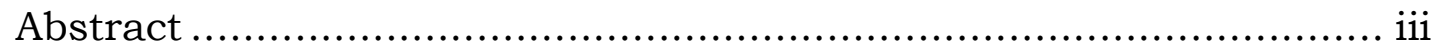

Acknowledgement ............................................................. v

Table of contents ......................................................... vii

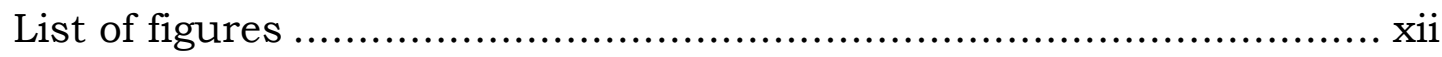

List of tables ...................................................................

CHAPTER 1 INTRODUCTION ................................................. 1

1.1 Historical background to drought and famine in pastoral lands in sub-Saharan Africa ................................ 1

1.2 The drought problem - a concern for African pastoralists .......... 6

1.3 Research problem: critical gap in response to drought and famine in the Turkana District, Kenya .............. 10

1.4 Social networks and rural livelihoods ................................ 21

1.5 Social networks and pastoral livelihoods............................ 23

1.6 Justification of the study .............................................. 31

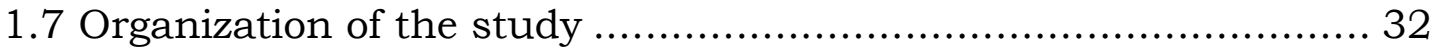

1.8 Chapter summary and hypotheses ................................... 33

CHAPTER 2 THEORETICAL FRAMEWORK OF THE STUDY .............. 35

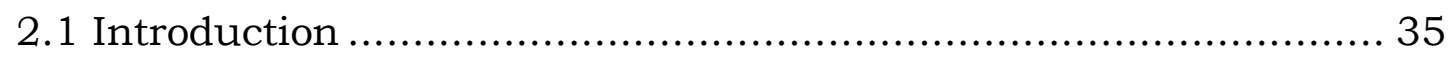

2.2 Emergence of the sustainable livelihoods approach................. 37

2.2.1 Principles and concepts of sustainable livelihoods approach applicable to this study .................................. 39

2.2.2 Explaining the sustainable livelihoods approach framework .................................................. 44

2.2.3 Critique to sustainable livelihoods approach framework ........................................... 45

2.3 Symbolic interaction theory and adjustments ..................... 47

2.4 Social exchange theory .......................................... 49

2.5 Turkana pastoralists' adjustment scheme 
during crises - a conceptual framework.................................... 51

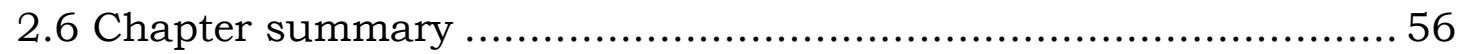

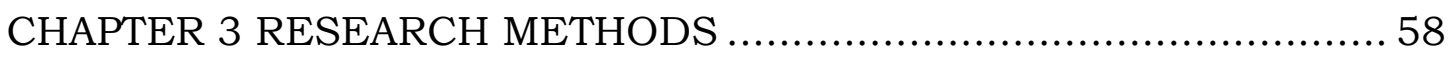

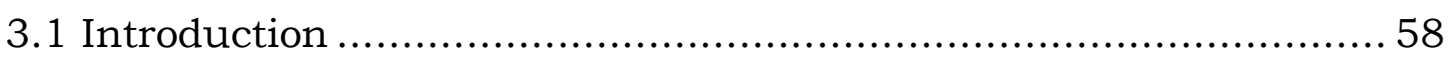

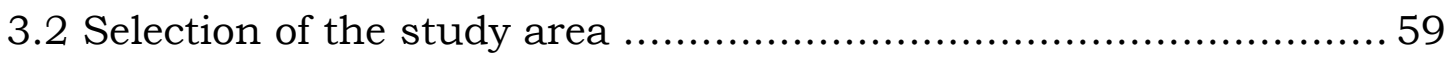

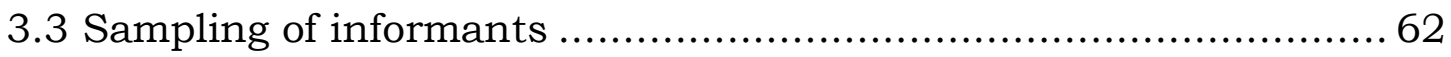

3.4 Data collection techniques and their limitations ........................ 65

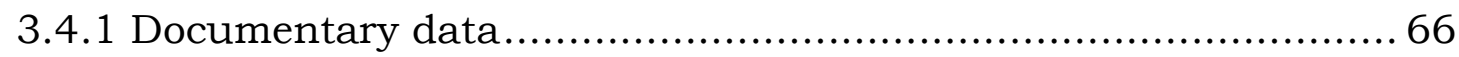

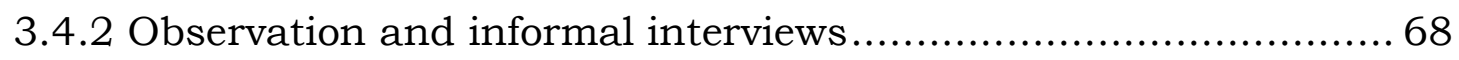

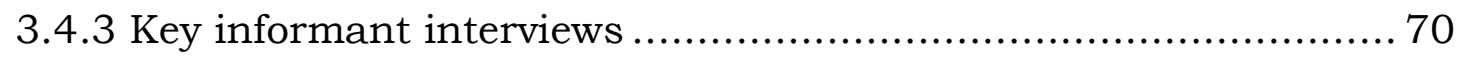

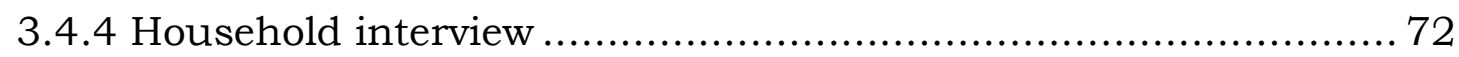

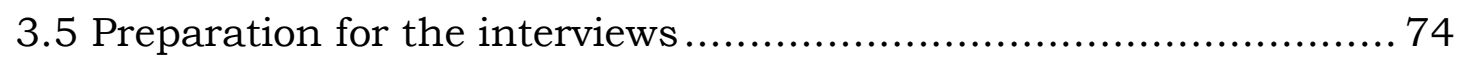

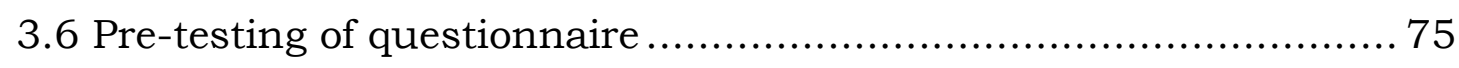

3.7 Household interview schedule

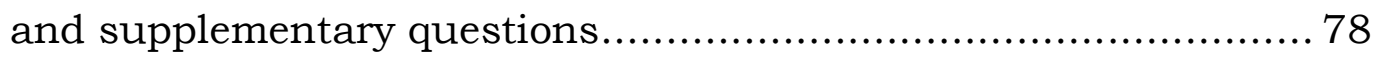

3.8 Reliability of household interview data ..................................... 79

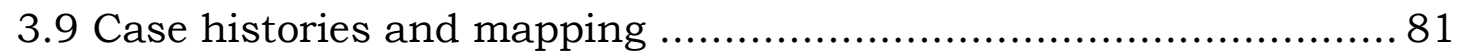

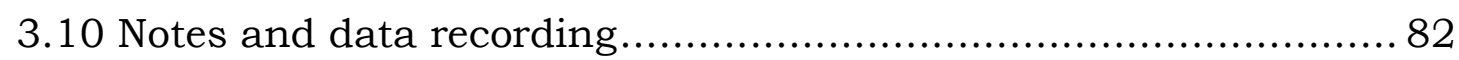

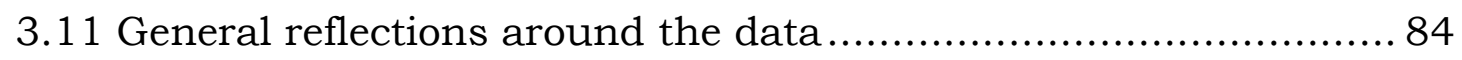

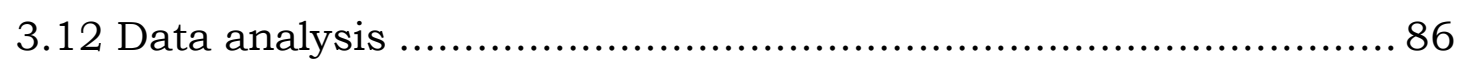

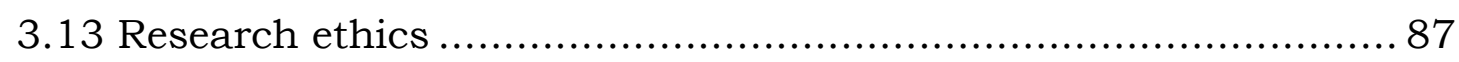

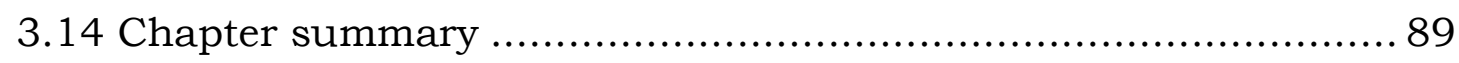

CHAPTER 4 RESEARCH REGION: HISTORY, CHARACTERISTICS, AND

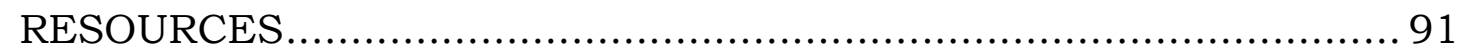

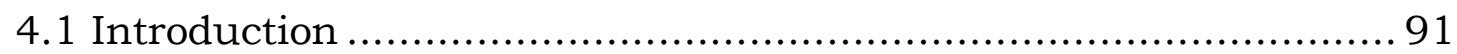

4.2 Brief historical background of the Turkana people ....................... 93

4.3 General description of the Turkana District ................................ 96

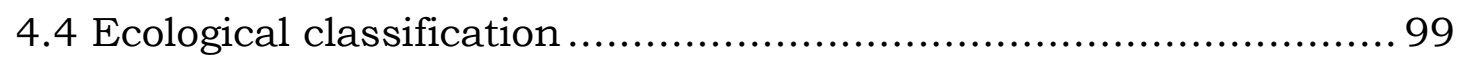

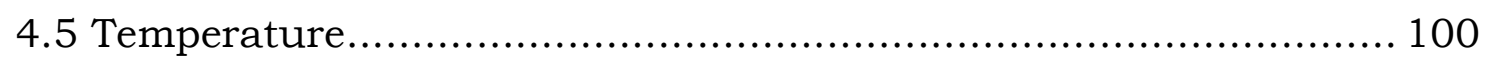

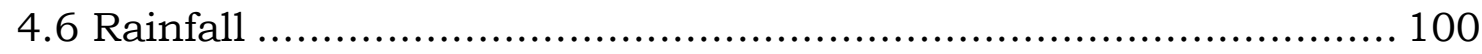




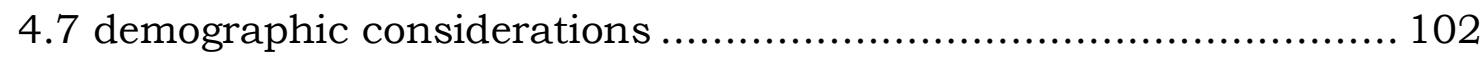

4.8 livelihood platform in the Turkana District ............................... 103

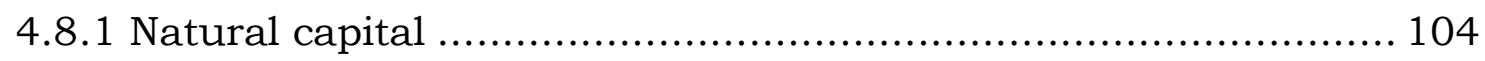

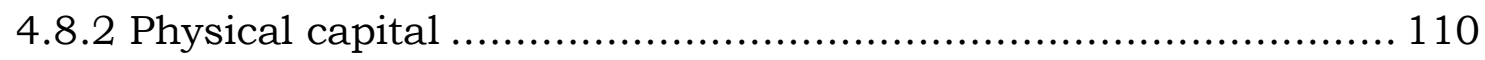

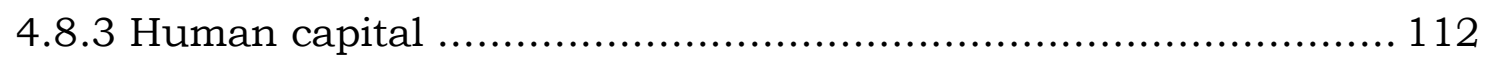

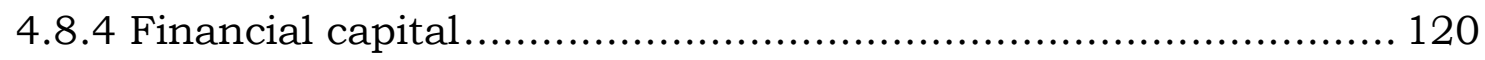

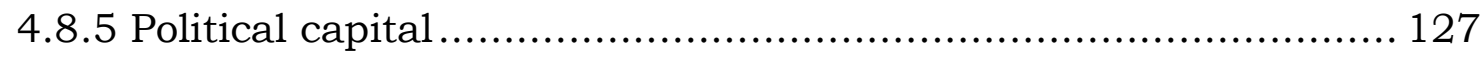

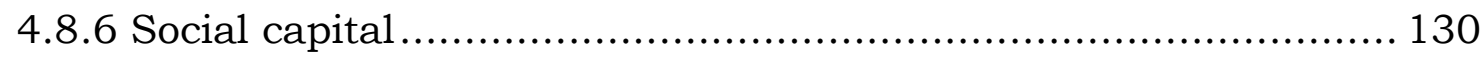

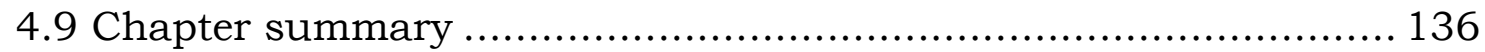

CHAPTER 5 VULNERABILITY CONTEXT IN THE TURKANA DISTRICT 138

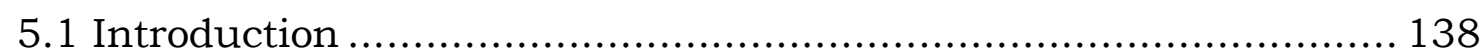

5.2 Factors asserting pressure on the Turkana livelihood system........ 142

5.2.1 Drought and famine occurrence .......................................... 142

5.2.1.1 Phases of drought and effects in Turkana ............................ 144

5.2.2 History of negative policy environment................................ 147

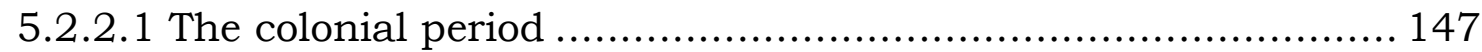

5.2.2.1.1 The era of engolekume, 1888-1963 ................................. 147

5.2.2.1.2 The period of apetaret, 1901-1924 ................................. 149

5.2.3.1.3 Imperialism and land use system.................................... 153

5.2.3.1.4 Famine amelioration measures ....................................... 156

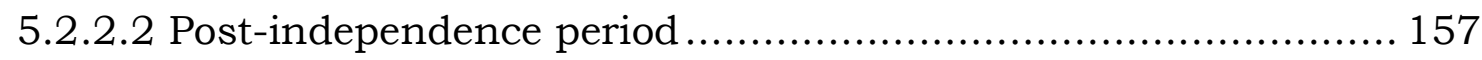

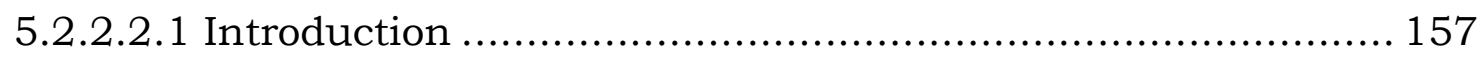

5.2.2.2.2 Inappropriate government policies for pastoral areas .......... 158

5.2.2.2.3 Food security measures in turkana.................................... 160

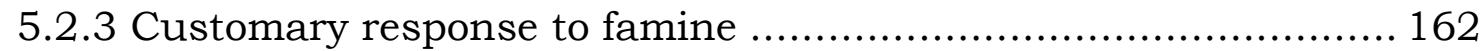

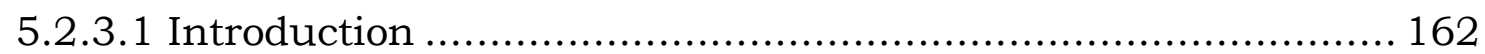

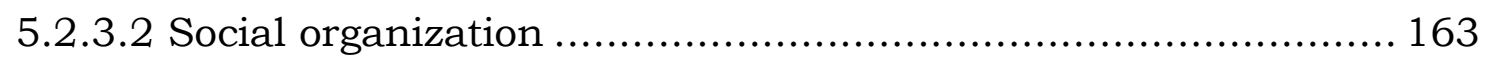

5.2.4 The legality in the traditional turkana society ......................... 174

5.2.5 The religious practice among the turkana .............................. 176

5.2 .6 Chapter summary ….................................................... 177 
CHAPTER 6 2005-2006 DROUGHT IMPACTS, PERCEPTION AND RESPONSE: FIELDWORK EVIDENCE.................................... 181

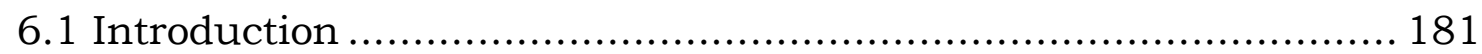

6.2 Effects of 2005-2006 droughts..................................... 182

6.2.1 Livestock losses in the household ................................... 183

6.2.2 Human losses in household...................................... 190

6.3 Perception and contemporary cultural interpretation of drought incidences .............................................. 191

6.4 Identity crisis ......................................................... 198

6.5 Response to 2005-2006 droughts ....................................... 199

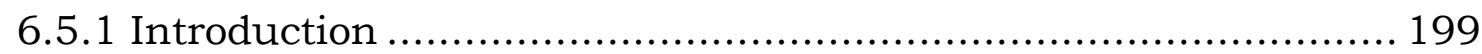

6.5.2 Trade ties and symbiosis ......................................... 201

6.5.3 Splitting herds and families ...................................... 203

6.5.4 Pooling resources ................................................. 207

6.5.5 Reciprocity and exchange ........................................ 209

6.6 Geographical dispersal of bond friends of all the respondents ...... 213

6.7 Taxonomy of Turkana social ties during crises........................ 218

6.8 Chapter summary .................................................... 220

CHAPTER 7 FACTORS THAT IMPINGE ON ADAPTABILITY IN THE

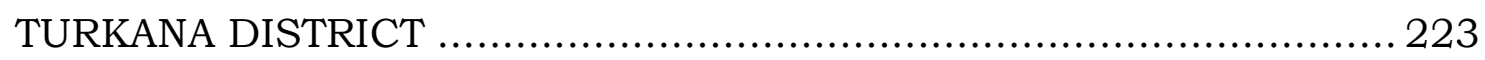

7.1 Introduction ....................................................... 223

7.2 Impact of 2005-2006 droughts on

Morulem and Lokichar residents ........................................ 224

7.2.1 Livestock losses at Morulem and Lokichar villages ................. 224

7.2.2 Changes in the distribution of wealth ............................. 228

7.3 Impact of 2005-2006 famine on

Morulem and Lokichar residents ........................................ 235

7.3.1 Human deaths in the households of Morulem and Lokichar villages .................................... 235

7.4 Impediments to adaptability during the 2005-2006 droughts....... 236 7.5 Chapter summary ................................................... 241 


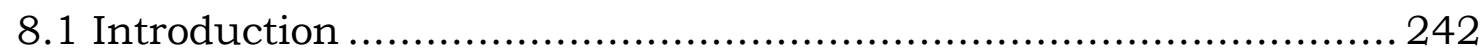

8.2 Theoretical implications............................................ 242

8.3 Methodological aspects ............................................. 244

8.4 Summary of the findings .......................................... 245

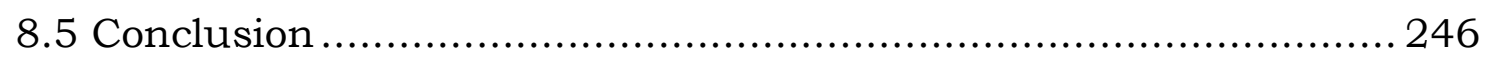

8.6 Policy implications.................................................. 248

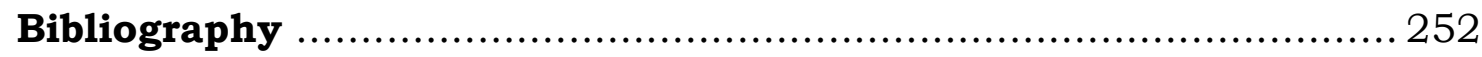

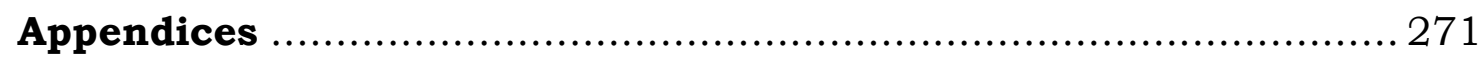

Appendix 1 Household profile........................................... 271

Appendix 2 Household schedule ........................................ 272

Appendix 3 Key informants schedule ..................................... 275

Appendix 4 Mutually intelligible words

in ngaturkana and luo languages........................... 276

Appendix 5 Gender and the division of labour among the Turkana ..... 277 Appendix 6 Ethics approval: no 138/2006.............................. 278

Appendix 7 Introductory letter from supervisor.......................... 271

Appendix 8 Information sheet to participants ............................ 280

Appendix 9 Pre- and post - the 2005-2006 drought

family herds at Morulem village ................................ 281

Appendix 10 Pre- and post - the 2005-2006 drought

family herds at Lokichar village 282 


\section{List of figures}

Figure1 Map of Turkana the study area and its location

within Kenya

Figure 2 Geographical distribution of the pastoralist

groups and their neighbours in northern Kenya

Figure 3 A framework for micro-policy analysis

of rural livelihoods 43

Figure 4 A framework for analyzing Turkana pastoralist's adaptation to dryland situation with special response to drought........ 54

Figure 5 Total households in each village and sample size

Figure 6 Map of Turkana showing the physical features,

and the neighbouring peoples....

Figure 7 Population projections by sex in

the Turkana district, 1999-2008 103

Figure 8 Soils in Turkana ................................................ 106

Figure 9 Turkana woman looking for water............................... 107

Figure 10 Charcoal for sale in Turkana ................................... 110

Figure 11 Investment of capital from a male perspective ................... 126

Figure 12 A dispute over bride-wealth before a wedding.................. 132

Figure 13 Married Turkana women..................................... 133

Figure 14 Factors influencing migration to and

from settlements in Turkana ................................... 145

Figure 15 Events in the build up to drought

related stress in Turkana ......................................... 146

Figure 16 Turkana homestead. note the cattle kraal in the centre...... 165

Figure 17 Territorial sections in Turkana by 1900 ......................... 171

Figure 18 Livestock losses ............................................. 184

Figure 19 Interpretation of the causes of drought ....................... 193

Figure 20 Comparison of school enrolment at Lokichar primary school, prior and during 2005-2006 drought ................... 207

Figure 21 Bond friends' location for three Morulem residents ............ 218 
Figure 22 Percentage loss in livestock per household,

at Morulem and Lokichar villages ................................... 227 


\section{List of tables}

Table 1 Education status in the Turkana District

Table 2 Population projections for selected

age groups, 1999-2008.

Table 3 Livestock numbers in the

Turkana District, 1948 and 2002

Table 4 Major historical droughts and famines,

names and descriptions among the Turkana

Table 5 Pre-drought livestock numbers...

Table 6 Post-drought livestock numbers .

Table 7 Livestock survival/death rates

Table 8 Mortality in the surveyed households

Table 9 Lokichar school enrolment per sex,

during $2004-2005$

Table 10 Total enrolment per year of study at Lokichar primary school 206

Table 11 Gifts exchanged by Turkana households

during the 2005-2006 drought and famine

Table 12 Location of exchange friends of 84

sample respondents of Lokichar and Morulem village

Table 13 Turkana social network tie taxonomy during crises

Table 14 Livestock losses per household

for Morulem and Lokichar residents

Table 15 Wealth categories under normal circumstances in the Turkana District.

Table 16 Pre- and post-drought wealth statuses

of Morulem and Lokichar residents

Table 17 Human losses in the household

at Morulem and Lokichar

Table 18 Sources of food for the respondents. 238 


\section{Chapter 1 INTRODUCTION}

\subsection{Historical background to drought and famine in pastoral lands in Sub-Saharan Africa.}

Sub-Saharan Africa contains one-half of the world's pastoral people (Fratklin 2001). These pastoralists live in the marginal areas of the continent often with variable rainfall both in space and time resulting in low resource base or uneven and unpredictable levels of forage productivity. This environment offers limited opportunities for subsistence activities apart from keeping livestock (Lamprey and Yusuf 1981; Le Houerou 1980; Little, Mahmood, and Coppock 2001). The people raise domestic animals including cattle, camels, goats, sheep and donkies, which are used for milk, meat, blood, transport and trade.

Despite environmental challenges, African pastoralists practiced a relatively resilient and ecologically sound mode of production during the pre-colonial times (Bovin and Manger 1990; Gulliver 1951). Pastoralists were able to cope with ecological stresses by different strategies within their social networks, for example, diversification of activities, dispersion of animal and human groups, and forms of redistribution and reciprocity (Bonte 1975; Davies 1996; Gulliver 1951). Today, however, land degradation and competing land use practices put pastoral resiliency into jeopardy. The scenario is such that pastoralists appear trapped between the advance of the desert and the onslaught of cultivators, agro-business concerns, ranchers and wild game conservationists. Several authors (Dietz and Salih 1997; Dietz 1987b; Glantz 1987; Haagsma and Hardeman 1998; Little 1984), also observe that the role of the state during the colonial and post-independence administrations and the historical processes of impoverishment and economic stagnation have given rise to an interesting phenomenon where pastoralists currently find themselves faced with serious adjustment problems caused by recurrent drought, diseases and famines. But the pertinent and persistent question is: Can pastoralists adapt to their changing environment? 
For instance, at the advent of colonialism, pastoralists were considered to be born hostile, aloof and unreceptive (Baxter and Hogg 1990; Omosa 2003; Republic of Kenya 1992). The colonial administrators saw pastoralism as an undesirable form of land use and wanted to bring pastoralists within the orbit of the state as obedient taxpayers. The colonial policies also aimed at pacification of pastoralists. For example, in East Africa, the colonial administration denied the power and legitimacy of existing pastoral institutions. This was done through a reduction in livestock numbers, importing new breads and providing permanent reserves. The objective was to establish meat producing centres. These intervention policies had negative effects on pastoralists' livelihoods, as improved animal health resulted in an increase in livestock that led to the overuse of common resources such as water. The provision of permanent watering points changed former migratory patterns, leading to large concentrations of livestock in areas that were previously not used for dry season grazing (Umar 1994).

The colonial governments also viewed African pastoralism as an obstacle to development (Hendrickson, Armon, and Mearns 1998). They imposed boundaries in pastoral areas and this accelerated hostility to local societies, and constrained their existing interactions and networks. The colonial policies also favoured sedentary agriculture and ranching strategy. This policy of taking land from pastoralists appeared to have seriously undermined the pastoral economy. For example, in West Africa, the colonial policies were aimed at the powerful pastoral societies of the Sahara and the Sahel. The long conflict between nomadic pastoralists and sedentary agriculturalists was resolved in favour of the cultivators. In Niger, the colonial regime from 1930 to 1950 aimed at developing groundnut cultivation for the market. This led to expansion of cultivated areas that compressed pasture in pastoral lands (Sutter 1982). Tanzania under German colonialism evicted the Maasai from rich grazing land around the base of Mount Kilimanjaro and opened the areas for white 
settlers and indigenous farmers. Similarly, in Kenya, colonial intrusion cut Maasai land in half with an international boundary between British Kenya and German Tanganyika in 1885. Treaties in 1904 and 1911 allowed the British to push the Kenyan Maasai south of the Mombasa-Uganda railroad (which passes through Nairobi) into a single reserve in southern Kenya later administered as Kajiado and Narok districts ${ }^{1}$. The Maasai lost their prime water and grazing lands for European ranches, particularly near Nairobi around the Ngong Hills and Lakes Naivasha and Nakuru. The Maasai were also excluded from 60 percent of their dry season pastures and drought reserves highlands of Laikipia (Spear and Waller 1993).

In Somalia, the colonial government took control of the livestock sector, limiting pastoralists' access to pastures and watering points. In Ethiopia's Awash River basin, home to pastoral communities, land was taken over in the 1950 s and converted for irrigated agricultural production. The colonial policies on development of the Awash basin led to eviction of pastoralists from their land to give way for the establishment of large state farms to produce cotton and sugarcane. The shrinkage of grazing areas meant a decline of the pasture quality, water resources, and productive and reproductive capacity of domestic herds. Circumscribing grazing lands which offered greatest strategic value for subsistence also meant a destruction of basic pre-requisites for pastoral existence (Flood 1976).

During the post-independence period, Sub-Saharan African governments continued with the colonial policies of suppression. They adopted a modernization theory. Some of the tenets of the modernization theory were privatization and individualism. The national governments lured by the investments and aid from the international donor community, have increasingly curtailed pastoral livestock production on communally held lands and promoted expansion of export and local market agriculture including beef and dairy marketing, as private land owners are assumed to

\footnotetext{
${ }^{1}$ A district is the second largest administrative unit in Kenya.
} 
better conserve their resources. Sen (1981) argued that there is evidence of discrimination against the pastoral communities, and a firm suggestion that the Sahelian governments are closely tied to (and more responsive to the needs of the majority of sedentary communities. For instance, in Sudan, the state gave priority to large public and private schemes based on political influence at the expense of pastoralists and other small-scale land users. The Sudanese government designed and implemented programmes to settle nomads and thus exposed them to urban centres, where they could be involved in the exchange market. By this policy, nomads were forced to change their livestock keeping from sheer subsistence to exchange mode of production (Babiker 2007). As a result, nomads became more vulnerable to the dictates of the market environment. In Tanzania, cultivation was extended to the pastoral areas. For instance, in 1980s the Tanzanian Government, with assistance from the Canadian International Development Agency (CIDA) sponsored a large wheat cultivation project around mount Hanang, displacing Barabaig herders from 10,000 hectares of their land. This led to the degradation of common pastoral resources as Barabaig pastoralists could no longer practice their complex system of land use that involves movement (Lane 1996).

A similar predicament to that of the Barabaig pastoralists befell the pastoral Turkana, Maasai, and Samburu of Kenya in the postindependence period. The Kenya government concentrated on the development of higher potential agricultural areas to the detriment of pastoral areas. This led to high population growth and land shortage in high potential agricultural areas. This encouraged the migration of cultivators onto marginal lands, depriving pastoralists of access to their dry season areas, and making them more vulnerable to drought. Exclusion of pastoralists from drought reserves (as a consequence of such areas being set aside for wildlife and tourism and cultivation) has drastically altered the pattern of pastoral land use. Losses of such dry season ranges 
results in increased deterioration of the remaining fragile lands (Republic of Kenya 1992) $)^{2}$.

In the light of the above discussion, it is clear that the policies during colonial and post independence periods weakened internal management and leadership capabilities of pastoral societies. Development initiatives undermine the traditional management system, based on communal rangelands, and push pastoralists into different forms of privatization. These private holdings reduce the size of their rangelands and makes access to distant dry-season and drought reserve pastures difficult. The growing population pressure in pastoral areas contributes to degradation of grazing lands and consequent overgrazing. In addition, Sub-Saharan African governments seek to settle the pastoralists so that they could be controlled and taxed. Most livestock development projects stress the need to supply meat to urban centres and thus concentrate on raising cattle rather than goats and camels. While this strategy may have been beneficial to urban consumers, shifting livestock preference from drought-resilient animals to species that are more prone to suffer during droughts put pastoral people increasingly at risk.

Therefore, the colonial and post independence policies in Sub-Saharan Africa resulted in the disruption of the ecological balance and pastoral flexibility, and accelerated deterioration of natural resources. It then led to an increasing number of conflicts over available resources, and affected the resilience of pastoral systems, thus rendering pastoralists more vulnerable to environmental hazards such as drought.

\footnotetext{
2 Vulnerability has been extensively discussed in literature (Blaikie, Cannon, Davis, and Wisner 1994; Chambers 1989; DFID 2004; Ellis 2003). Adger and Kelly (1999) refer to vulnerability as the potential to be adversely affected by an event or change. My study refers to the social vulnerability i.e the capacity of individuals or communities to respond to physical impacts.
} 


\subsection{The drought problem - a concern for African pastoralist.}

We do not have one definition of drought. Drought is a relative term that can mean different things to people from different backgrounds and with different view points. What is drought in one place may not be drought in another place. Even in the same region, what one farmer considers as drought, the other farmer may view as normal. UNDP (2000) defines drought as a sustained period of deficient precipitation with a low frequency of occurrence. In the context of pastoral settings, drought implies two or more consecutive years when rainfall is less than 75 per cent of the long-term average (Coppock 1994). However, following Nikola (2006), drought is defined in this study as lack of rainy season that is repeated consecutively for three seasons in a row leading to loss of pastures and death of livestock. It is important to stress here that it is a loss of dry season pastures, because according to my respondents, it is only in such conditions that their animals begin to starve and die.

Drought is not a new phenomenon in Sub-Saharan African pastoral lands. Climatologist Glantz (1987: 38) states: “drought is a part of (Africa's) climate and not apart from it". Historically, pastoral areas have suffered numerous such disasters. It has been documented that in Sub-Saharan Africa, eight major droughts have occurred in the last four decades: 1965/66, 1972/74, 1981/84, 1986/87, 1991/92, 1994/95, 1999/2001 and 2005/06 (Nikola 2006). These conditions reduce forage production and water supplies, thus placing serious pressure on the livestock industry (UNDP 2000; UNSO 1999). Although these drought problems are increasingly apparent, many countries in Sub-Saharan Africa lack clearly defined long-term plans especially for pastoral areas where generally speaking, development has not been a national priority (Hogg 1987). For instance, during 1968-1973, drought increased dramatically in the Sahelian countries (Senegal, Mauritania, Mali, Nigeria, Chad, and Sudan). This pointed to the vulnerability of pastoral production systems to 
prolonged droughts as herders ${ }^{3}$ lost up to 80 percent of their small stock and 50 percent of the 10 million cattle in the region, both to starvation and infectious diseases (Gudrum and Ander Hjort 1976). This also resulted in a famine $^{4}$ which claimed at least 100,000 human lives in the Sahel and another 100000 in Ethiopia (Wisner 1977). These disasters opened peoples' eyes, and, as a way to stem future disasters and make pastoralism more resilient, resulted in an upsurge in drought management studies (White 1974).

This need to study and find new ways of improving pastoralists' adaptive capacities does not exclude Kenya. ${ }^{5}$ This is basically because Kenya's arid and semi-arid lands (ASAL), inhabited by more than 3 million pastoralists, incorporate as much as 88 percent of the country's land surface, and carry approximately 50 percent of its livestock (Republic of Kenya 2002). They are drought prone areas of the country and seem to have a regular timetable of natural disasters. They are hit hardest whenever there is a national drought which occasions shortfall in food production.

Evidence suggests that Kenyan nomads are just as vulnerable to droughts as the people of the Sahel and Ethiopia. For instance, during 1960-1961 droughts, Maasai nomads lost between 300,000-400,000 cattle. This was estimated to be between $65-80$ per cent of their total herds. Many Maasai nomads were therefore left stockless and hungry (Dahl and Hjort 1976). The nomadic Turkana suffered equally badly at that time and lost two

\footnotetext{
${ }^{3}$ Cattle keepers and herders are terms that will be used interchangeably in this thesis.

${ }^{4}$ It is not easy to tell when a famine breaks out unless there is mass starvation, as happened in the Sahel (1971-1974). Devereux (1993) in his book Theories of famine, brings to light the various perceptions of the famine phenomenon. In reviewing several famine approaches and theories, as well as case studies, he identifies three dictionary descriptions of famine, e.g. food shortage, severe hunger, and excessive mortality. This study draws from Devereux's (1993) definition of famine, and formulates a general working definition of famine for this study as a period of low food supplies affecting part or whole of the community resulting in persisting hunger and a considerable elevation of community death ratio attributable at least in part to deaths from starvation.

5 In this study, adaptability is taken either as an individual's ability to cope or adjust effectively to the effects of drought or as the drought management capability of the individual. See further discussion in chapter 2 .
} 
thirds of their livestock. According to Dames (1964), 10,000 Turkana pastoralists were registered as destitute and had to be fed by the government in famine relief camps.

During the 1971-1974 drought, the Kenya nomads once again suffered heavy losses, and the subsequent famines were compounded by an outbreak of cholera and high incidence of malnutrition, tuberculosis, meningitis, and measles (Wisner 1977). The young, the old, the sick and the weak suffered most severely. Wisner records 768 cholera cases in 1971 and 402 in 1974. He suspects that 50 percent of those reported could have died from the combination of famine and diseases. This was followed by the 1979-1980 droughts which hit the northern part of Kenya particularly hard and obliged many herders to give up pastoralism as a way of life at least temporarily. More than 90 of cattle, nearly 80 of small stock, and 40 of camels died in Turkana (Hogg 1982). The 1990-1992 droughts also had bad effects on nomads' livelihood and forced them to move to relief camps. As a result, external food assistance became more fully integrated into the nomads arsenal of survival strategies, although at the great cost of dependence on outsiders (Bush 1995).

During the 2005-2006 droughts, Turkana pastoralists were among the hardest-hit victims in Kenya. Experts who had been watching the crisis in northern Kenya described it in one report as a "pervasive pre-famine condition" (Daily Nation 5th June 2006: 1). This condition was extremely costly to the Turkana people. It had a devastating impact on their livelihoods and changed the resource flows critical for their livelihood sustainability. It triggered a humanitarian crisis in which famine, disease, chronic poverty and loss of human life are all too evident. Access to food was reduced and costs of obtaining food increased. This sequence of events was facilitated by the fact that fewer animals were available for sale, and less milk was available for consumption and sale. Social costs were the most devastating. Famished children were highly susceptible to 
disease infection as they became victims of various diseases such as exophthalmia (acute vitamin A deficiency). A brief assessment conducted by the United Nations Children Fund (UNICEF) in Turkana indicated that 25 per cent of the population suffered from malnutrition, that a large number of livestock died, and that a number of people dropped out of pastoralism and either now depend on food aid or have settled in periurban areas in search of employment (UNICEF 2006).

With specific reference to recurrent drought problems in Africa, Glantz (1987) in his study proposed that livelihood intervention efforts in Africa should take drought into account as an expected event, and that for intervention programs to be viable, they must be designed with the ability to cope with the stress associated with drought. While supporting this line of thought, O'Leary (1990) and World Bank (1995) in their findings, recommended that since drought stress has continuously caused longterm economic disruption in African arid and semi-arid lands, occupied by pastoralists, a proper formulation of sustainable livelihood intervention policy should begin with an understanding, and analysis of local perceptions of drought, and the indigenous knowledge of drought mitigation. However, Kenya could be said to be ahead of many African states in having a National Food Policy drawn as a result of the harsh lessons learnt from the 1979-1980 drought and famine. But the document is not the final treatise of Kenya's food security question. The time when all Kenyans will have access to adequate food intake is nowhere near. 


\subsection{Research problem: Critical gap in response to drought and famine in the Turkana district, Kenya.}

This study broadly explores how Turkana ${ }^{6}$ pastoralists $^{7}$ are able to sustain their livelihoods in increasingly arid conditions, and the most appropriate ways in which their livelihood strategies can be enhanced. The Turkana people represent an interesting example of how pastoralists adapt to arid environments and cope with a number of adversities that are profoundly affecting their livelihoods. These pastoralists are an ethno-linguistic group identified as a paranilotic ${ }^{8}$ people who speak one language, Ngaturkana, and by 2006, were estimated to number approximately 568,020. ${ }^{9}$ Like the majority of pastoralists in Africa, Turkana pastoralists' have traditionally led a lifestyle geared towards subsistence production. Their principal asset and the primary source of their sustenance is livestock. They keep cattle, sheep, goats, camels, and donkeys, and their staple food is meat, milk, and blood (Republic of Kenya 2002). Their culture revolves around flexible movement of livestock in response to sparse, erratic rainfall, ephemeral vegetation, water and security needs. They have traditionally adapted to an ecological niche in the Northwestern part of Kenya known as the Turkana District (see Figure 1).

\footnotetext{
6 Turkana is the name of both a tribal group of people, and the geographical area (Turkana District) they inhabit in Northwestern Kenya. Turkana people call their area eturkan meaning Turkanaland (Lamphear 1992).

7 This study adapts Nikola's (2006) definition of pastoralists as cattle keepers who reside in areas which receive less than $400 \mathrm{~mm}$ of rainfall per year with a length of growing period of 0 to 75 days and where cropping is not practised, and derive more than 50 per cent of their livehood from livestock rearing through opportunistic tracking on communal lands.

${ }^{8}$ See chapter 4 for detailed discussion of the origin of the Turkana people.

9 The last population census in Kenya was taken in 1999. It was estimated that the population of the Turkana District would increase from 450,860 persons in 1999 to 568,020 persons by 2006 (Republic of Kenya 2002: 18).
} 
Figure 1: Map of Turkana the study area and its location within Kenya.

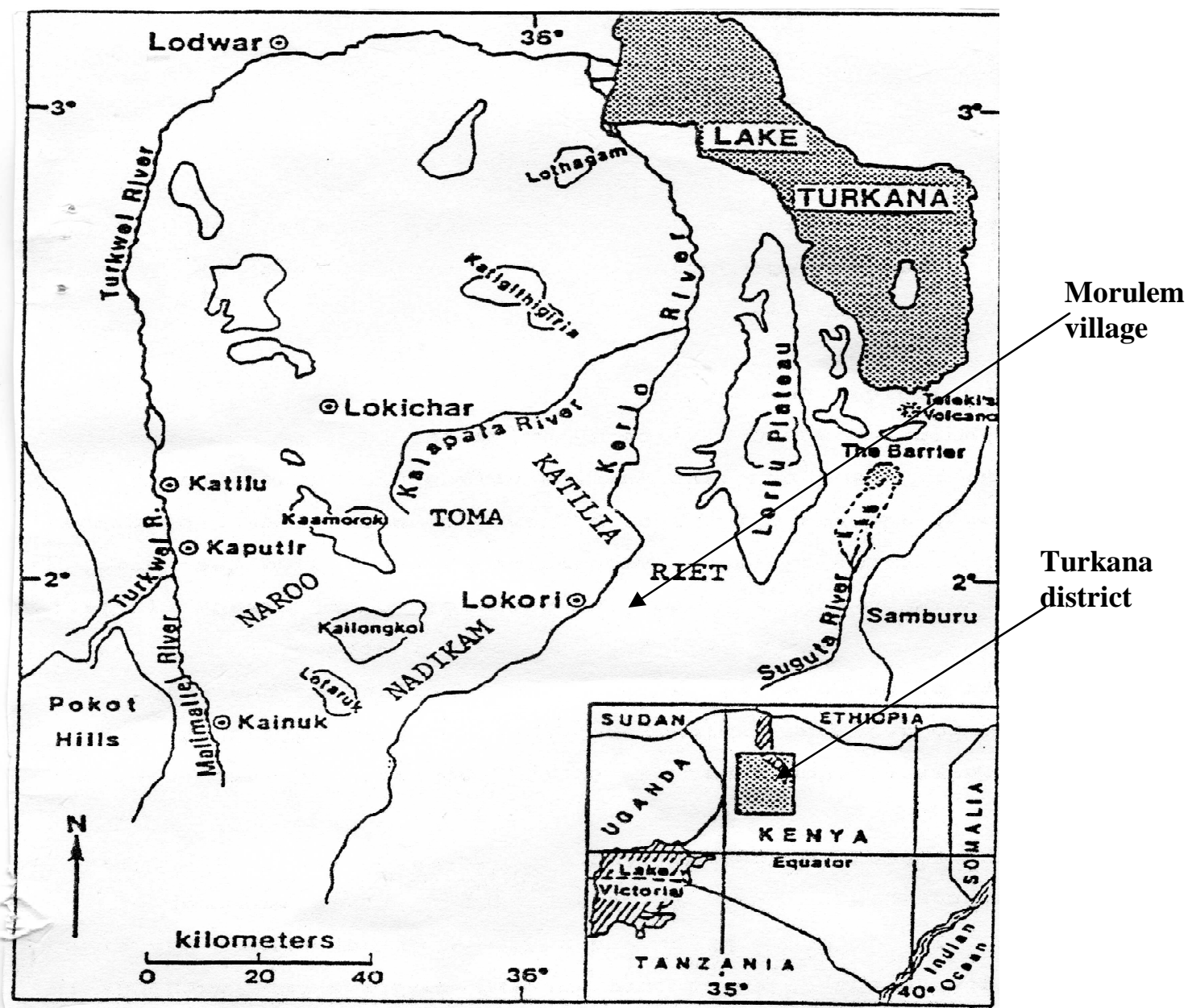

Source: (Hoffman and Oliver-Smith 2002: 218).

The Turkana District is a sprawling arid land and has long been considered a difficult place to survive. From the earliest oral and recorded history ${ }^{10}$, it is evident the people of the District have experienced cycles of droughts and consequent famines resulting in acute shortages of food and water for both humans and livestock (Ellis, Gavin, McCabe, and Swift 1987; Gulliver 1955; McCabe 1990; Republic of Kenya 2002; UNICEF 2006). The early European observers were appalled by the arid conditions. From the earliest days of British colonial administration, Turkana was considered "a district of burning desert of sand and stones with hardly a

10 See chapter 5 for a chronology of drought and famine occurrences in the Turkana District. 
blade of grass anywhere, harsh and uninviting by any standards" (Barber 1968: 69). According to Gulliver (1955: 16), the area is "notably harsh and difficult". Dyson-Hudson (1984: 262-263) described it as an "immature ecosystem characterized by instability", and Robinson (1985: 29) described it as consisting of "vast waterless, desolate and scorching plains".

Generally, drought has introduced extreme instability into the lives of Turkana people and raised their inherent vulnerability to an unsustainable level, and to more aberrant forms of uncertainty for which they cannot plan. It has been documented that drought, among other factors, is the major cause of poverty in the Turkana District (Republic of Kenya 2002: 20). According to district rankings on food poverty among 75 rural districts in Kenya, Turkana is the third highest with more than 74 per cent of their population living below the poverty line (Republic of Kenya 2002: 20). This magnitude of poverty was made even worse by the recent prolonged drought of 2005-2006 and its devastating impact on all sectors of the economy.

Due to the harsh nature of the Turkana District and the fact that Turkana people frequently face food insecurity, measures are necessary for assisting their survival. But famine prevention measures in the Turkana region, as in other pastoral areas in Kenya, has not been a foundation for the political legitimacy of Kenya's ruling classes as it has been in the urban areas and, at crucial political moments preceding elections, in the central highlands (De Waal 1997). Consequently, little has been done by the Kenya government to tackle the structural causes of famine in the Turkana district (Hendrickson, et al. 1998). Hitherto the Kenya government's only response to ameliorate the problems of food shortages in the Turkana District has been the provision of famine relief food. The British distributed relief food in the Turkana District as early as 1932 (Hogg 1982). This provision of relief food, though initially seen as a 
temporary assistance to impoverished pastoralists to make up for a shortterm loss of self reliance, is now being treated as a permanent program.

For instance, during the prolonged drought of 2005-2006, the national food reserves in Kenya had been seriously drained, and there was widespread food insecurity in the country. Turkana pastoralists had to fend for themselves for nearly a year after the drought struck in early 2005, and its devastating effects began to take their toll. This food crisis provided an opportunity for the Kenyan government to tap local peoples' indigenous practices and design a sustainable system of livelihood protection. But it later turned out that the Kenya government and the international donor community could only import large quantities of food aid to give to Turkana people in order to avert the crisis.

However, this was a palliative measure or 'a crisis management' strategy that resulted in the common practice of depending on external aid, rather than addressing the underlying problems of food insecurity in the Turkana District. I believe that this livelihood intervention policy was partly based on historical stereotypical views, myths, faulty assumptions, pure prejudice, and images of African pastoralists and their environment held by government officials, and aid and development workers (Baxter and Hogg 1990; Hendrickson, et al. 1998; Leach and Mearns 1996). These views represent African pastoralists as primitive, arrogant, warlike, economically irrational, unresponsive to development, destructive to the environment, people who end up creating problems, as they can neither anticipate the consequences of a crisis such as drought and famine, nor develop appropriate livelihood strategies. These views also see African pastoralists as helpless victims in need of assistance. ${ }^{11}$ These stereotypes, while colonial in nature, have persisted to the present day and identify pastoralism itself as the primary source of herders' misfortunes

\footnotetext{
${ }^{11}$ Refer to chapter 5 for detailed discussion of stereotypical views about pastoralists, and Turkana in particular.
} 
(Hendrickson, et al. 1998). By and large, these assumptions about the nature of the African pastoralists and their limited production ability has led to the production based view that regular food shortages in the Turkana district are mainly caused by production failure (Republic of Kenya 2002). However, Cornwall and Scoones (1993) have argued that a production based view can only promote the policy of estimation of food requirements and improvement of food supply, but cannot lead to an appreciation of indigenous strategies for coping with food insecurity. According to Levile and Crosskey (2006: 8) "what has been lacking for years is adequate attention to pastoral areas, a proper understanding of the needs and potential of the pastoral communities, coupled with inadequate investment". I assert here that the Turkana people should be described in terms of their potential capacity to cope with uncertainties, risks or crises, rather than in terms of what they lack. In Sudan, for example, an analysis of humanitarian response to the 1984-1985 drought and famine showed how most people affected by drought and famine survived not because of aid, but due to their own resourcefulness and survival skills (De Waal 1989).

As we well know, famine relief food supplies are a stop-gap measure in the struggle to keep victims alive. I argue further that though external support is necessary in extreme situations because the livelihoods of Turkana people are dominated by risk and uncertainty, the Turkana people do not see themselves as so needy as to have their livelihoods ${ }^{12}$ reconstructed. My respondents claimed that external agencies have time and time again missed the opportunity to understand their production system, work with them within their traditional setting, and together chart permanent solutions to food insecurity problems. External intervention programs designed to supply famine relief fail to take into account existing realities. Mbithi and Wisner (1972) argues that a relatively low cost and high benefit approach in dealing with drought problems in Kenya is to build upon the

\footnotetext{
12 This information was obtained from both key informants and household heads.
} 
local patterns of adjustment to drought which have grown up in the different ecological zones of the country; fostering those which seem to be effective. According to Korten (1995: 5) a sustainable livelihood is not like a substance which can be borrowed from outside - real livelihood sustainability cannot be purchased with foreign aid or assistance, and rather it depends on people's ability and interest for using the local resources efficiently. Cernea emphasizes people's importance in livelihood sustainability as "people are ... and should be ... the starting point, the centre and the end goal of each livelihood intervention" (Cernea 1985: ix, emphasis added). Chambers (1983) maintains that there is a need for local participation for solving poverty ${ }^{13}$ issues because the people in the community can define criteria for well-being and the key elements of deprivation as they appear in the local context ${ }^{14}$. It is argued here that Turkana people should not be treated as passive recipients of livelihood intervention programs but play an active role in what is done for them. Famine relief efforts are a more intrusive external influence that creates dependency, exacerbate inequality, and undermine and erode the intrinsic capacity of the Turkana people to buffer environmental disturbances, such as drought (Gore 1994; Hendrickson, et al. 1998; Hogg 1987; McCabe 1990; Oba 1992). Any intervention that focuses on saving lives which neglects the possibility that the basis of livelihoods may be undermined risks tackling the symptoms rather than addressing the causes of destitution.

There is a gap between external ideologies and local practice which impacts disadvantageously on sustainable livelihoods in the Turkana district. As Zoomers (1999) has recently suggested for the Andes, one important reason external interventions fail is probably that they simply misperceive the way local people get by and get things done. According to my respondents, livelihood intervention programs in the Turkana District

13 Cited in Ellis (2000).

${ }^{14}$ For detailed analysis of people-centred development (Acharya 1997; Oakley 1991; Schumacher 1997). 
would be more sustainable and constructive if they were more sensitive to the origins, dynamics, and differential experience of local people, and paid more attention to the challenges of minimizing risks and coping with crises. Intervention projects should therefore build on local practices by identifying what Turkana people have rather than what they don't have, and strengthen local inventive solutions, rather than substitute for, or undermine them.

The prominence of my interest in undertaking this research originates with three experiences: First, while working in rural Turkana District as a government officer in 1999, the annual drought, enormous suffering, and ensuing famine made me feel that something needed to be done to change things for the better, to enhance the Turkana people's resilience to drought, and see the end of media coverage that documented their sorrow and misery. I began to realize that the Turkana's own capacity to recover from drought depends on their ability to draw on their network of social relations for help, and that the more people with whom one has close relations, the better. Their social networking acts as an informal safety net ${ }^{15}$ which promotes social stability. The safety net function of networks is crucial to understanding the Turkana's ability to cope with economic or physical shocks to their livelihood.

Secondly, Soja, (1968), in his book 'The Geography of Modernization in Kenya', taught me that during the pre-colonial past, many nomadic communities such as the Turkana were not vulnerable to calamities (crises) as they were wealthy, well-fed and politically powerful. Turkana herders constantly switched back and forth between a range of livelihood activities depending on whether conditions were good or bad. They mobilized a set of livelihood strategies ${ }^{16}$ which they resorted to in times of

\footnotetext{
15 My study adopts Devereux (2001) definition of safety net as non-market transfers of goods and services between households.

16 See Corbett (1988) for a description of the sequential phases that characterise coping behaviour following a disaster such as drought.
} 
stress (Soja 1968). The ability to cope even under challenging and changing environments in the past implied that there is much wisdom held by the Turkana people that need to be understood. It is therefore worthwhile to ask ourselves what their indigenous livelihood strategies were, and investigate why people who had previously sustained their livelihood in the absence of outside intervention are currently suffering ecological and economic stress.

Thirdly, the function of social capital in mediating economic change effects on Turkana households ${ }^{17}$ by providing (or constraining) access to other resources, coping mechanisms, or adaptive strategies makes it a crucial but formerly neglected area of analysis. Its contribution to famine alleviation has also not been extensively documented. Most studies deal with generalities which mask coping and adaptive responses (Barton, J. Morton, and C. Hendy 2001; Gulliver 1951, 1955; Hogg 1986; Oba 2001). The need for a detailed study is overdue. Furthermore, contemporary economic analysis of coping mechanisms or livelihood strategies helps us understand the impact of crises only in terms of factors like wealth, mobility, education, life style, and gender. Though important, if the mediating role of social relations is neglected, these factors do not explain why one coping strategy is pursued over another. Moreover, these other factors provide little normative insight for purposes of formulating relevant livelihood policy for pastoral areas.

This thesis fills this gap by focusing specifically on those behavioural patterns which emerged in the process of adjustment to stem the negative effects of the 2005-2006 drought and famine in the Turkana District. It is assumed that such behaviours remain dormant in times of plenty, and become observable only in times of need. They emerge only in response to calamities: more specifically drought, and one of its consequences, famine. The critical questions this study sets to answer are: What are the

\footnotetext{
${ }^{17}$ Refer to chapter 3 for a clear definition of the term 'household'
} 
indigenous livelihood strategies deployed by the Turkana people to cope with crises in general, and in the 2005-2006 drought and famine in particular? How do they cope on their own without support from outside the community? And how do local practices and indigenous knowledge contribute or not to the challenge of maintaining sustainable livelihoods?

In this thesis, it is argued that a new approach needs to be taken to understanding Turkana pastoralists livelihoods - one that recognises the Turkana people's social networks as a fundamental component of crisis management with a view to conceptualising how, in practice, effective adaptation measures can built on indigenous social capital ${ }^{18}$. This new perspective reflects a paradigm shift in livelihood intervention thinking followed in the 1980s which proposed externally imposed, often blueprint solutions, and marks a shift towards a more iterative approach between external donors' prescriptions and local people's own potential. It advocates acknowledgement and understanding of the ways in which Turkana people manage and change their own livelihood strategies in response to stress and uncertainties. Potentially, it implies a new dimension to rural development which builds on the Turkana people's own successes and enables them to avoid - or find alternatives to - some of the deleterious effects of unsustainable changes in their livelihood.

As will be explored throughout this thesis, Turkana people's networking behaviour is an attempt to create or strengthen social ties that can be used to mitigate environmentally stressful periods of time such as drought. These networks form pathways that determine access and rights to livelihood resources or 'capital' (natural, economic, physical, human and social), and are critical to the maintenance of different livelihood

\footnotetext{
18 Social capital is the social resources (networks, social claims, social relations, affiliations, associations and mutual trust) (DFID 1994; Scoones 1998). This study uses these elements interchangeably.
} 
strategies $^{19}$ and achievement of sustainable livelihoods. The idea is not new. An earlier study by Gulliver (1955) established that in the precolonial period social relations among Turkana pastoralists were a critical part of the production system.

Theoretically, the study seeks to investigate and explain two basic components of the adaptive phenomenon. First, the specific types of social networks ${ }^{20}$ activated during the 2005-2006 drought and famine in the endeavour to survive ${ }^{21}$. However, how to identify these relationships is a real challenge. Nomadism presents several problems for a standard network analysis approach (most network analysts have studied settled communities). It is not possible to delineate a herd owner's total network of social relations since it would take a lifetime to come into contact with all the people who are part or potentially apart, of a nomadic social network. For example, in Turkana, a person's residence frequently and irregularly changes. The qualities of an individual's social ties vary both in number and temporarily through the course of the year, and throughout a lifetime. To overcome this problem, I place more emphasis on the quality of specific relationships rather than the quantity, and focus only on those social relations that emerged during the 2005-2006 droughts and famine, and allowed the Turkana people to implement their livelihood strategies to good effect, and hence towards the sustainability of their livelihood.

Secondly, it is important to examine the social and economic determinants of adaptability 22 . Toulmin (1986) has argued that people's responses to food insecurity are often differentiated by socio-economic factors, and that this determines a range of coping options at a household's disposal. This

\footnotetext{
19 Strategies are referred to here as thoughts, plans, or behaviours that Turkana people employ in their attempts to utilise scarce resources.

${ }^{20}$ I use the concept 'network' because it allows me to focus on friendship ties of particular individuals who provide each other a type of resource security during environmentally stressful times. This will be key to the discussion in chapter 6 .

21 I use the term 'survive' because, during difficult periods (i.e the dry season and especially drought) life in Turkana is oriented toward survival.

22 See chapter 7 for detailed discussion.
} 
argument is supported by Pottier (1993) who observes that periodic or chronic food stress does not cause all members of a population to be similarly or equally affected. The dryland areas may share common characteristics and occupying populations may experience similar problems, but livelihood sustainability levels may differ greatly depending on the availability of socio-economic resources. It is argued here that for us to discuss the policy issues emanating from this study more meaningfully, we should not only address livelihood responses per se, but also the socio-economic factors which promote or impede local responses to drought and famine in the Turkana District. It is only with such knowledge that we can make intelligent and informed suggestions about what outsiders can do to help without undermining Turkana initiatives.

The research undertaken in the preparation of this thesis was predicated on the idea that to make such a critical analysis and improve policy formulation, it was necessary to look at more than one community. The effects of the 2005-2006 droughts and famine were not the same in all areas of the Turkana District, but within the time and resource constraints placed on a PhD exercise, it was only possible to carry out research in two contrasting Turkana villages reportedly hardest hit by the 2005-2006 drought and famine. The two sites, Morulem (rural) and Lokichar (urban) were selected with an understanding that the data collected would enable me to document the response differences to drought and famine followed by each community (see the location of the two study areas in Figure 1). Data were obtained through documentary review, in-depth key informant interviews, household survey and case histories. A random sampling method was used. In Morulem, I interviewed 45 household ${ }^{23}$ heads and 5 key informants while in Lokichar, I interviewed 35 household heads and 3 key informants. The success of this is reported in chapters 3, 6 and 7 .

\footnotetext{
${ }^{23}$ Refer to chapter 3 for a fuller discussion of the term 'household'
} 
Therefore, the main goal of this study is to bring the views of the Turkana people into centre stage and demonstrate that the drought and famine relief response can be constructed on a new model of analysis based on an in-depth understanding of local people's indigenous behaviours. The observations they make regarding their livelihoods provides a way out of the current impasse associated with recurrent vulnerability to drought in the Turkana District.

\subsection{Social networks and rural livelihoods}

The concept of social networking has been well described in both sociological and anthropological literature (Davern 1997; Putnam 1993). In order to understand how the concept works for Turkana households facing a crisis, this thesis will refer to writings of various authors: Davern (1997) defines a social network as a series of direct and indirect ties from one actor to a collection of others, regardless of whether the central actor is an individual or an aggregation of individuals (households); Moser (1998) defines it as reciprocal relationships which are based on kin and place of origin; Dasgupta (2000) describes it as the embodiment of social capital ${ }^{24}$; Ellis (2000) focuses on social networks formed by personal or family relationships that typically consist of near or remote kin as well as close family. The family are spread out over a diverse range of areas and can respond when past favours need to reciprocated; and for Johnson (1999), networks are links to the past, present, and future. Johnson argues that a network perspective allows one to cut across kin categories and focus on the links between active and inactive relationships and that it is a connection to people who can provide material assistance to those facing a crisis such as when there is food insecurity 25 . For the purpose of this study and as part of our understanding of how Turkana people make a

25 Further definitions (Dershem and Gzirishvili 1998; DFID 1994; Ellis 2000; Putnam 1993; Scoones 1998) 
living in an increasingly difficult, arid environment, the concept of reciprocity forms the most important part.

Empirical evidence from studies across Sub-Saharan Africa and other parts of the world suggests that social networking plays an integral (or critical) role in sustaining rural livelihoods. According to Collier (1998), social interaction can generate durable externalities that include knowledge about other agents, knowledge about the world, and benefits of collective action. Johnson (1997), in his study, found out that social networking can be used in acquiring economic capital (money and materials), human capital (labour and knowledge), and natural capital (land and water), and is hence important for livelihood sustainability. In central Mali, it was observed that social networks act to spread risk and enhance coping with crisis for member households. Both kinship and village-level associations were found to facilitate important non-market transfer of food and labour (Adams 1993). Derhem and Gzirishvili (1998), while studying the relationship between social networks and economic vulnerability of households in Georgia, found that those households with larger support networks define themselves as less vulnerable in contrast to less fortunate households with fewer social support networks. Jacoby and Skoufias (1998) provide evidence that poor households draw on interhousehold transfers and informal credit markets to smooth seasonal fluctuations in income. Moser (1998) shows how declining extended family support systems are a major source of vulnerability for the poor. Agarwal (1991), while studying livelihood adaptation in India during drought years and other years of exceptional stress, pointed out that people utilize social networks and informal credit networks to overcome shortages. There is extensive literature on the critical role of social capital or networks of trust and reciprocity, which need not be discussed here at length. Interested readers may be referred to the writings of the following: Adger (2000); Bigsten (1996); Cross and Mngadi (1998); Dershem and Gzirishvili (1998); 
Devereux and Naeraa (1996); Hussein and Nelson (1998); Kandiyoti (1998); and Werner (1998).

\subsection{Social networks and pastoral livelihoods.}

Despite the importance of social networks in pastoral livelihoods in SubSaharan African countries, it has not been given a high profile in recent literature (Danny de Vries, Leslie, and McCabe 2006; Johnson 1999). This extends to aid agencies. In fact my respondents argued that their networking behaviour was deliberately ignored in the formulation of relevant livelihood policies in their area. They claimed that the cultivation and maintenance of social relations is a planned livelihood strategy and a way of dealing with livelihood shocks, and refers specifically to non-market transfers of goods and services between households. Respondents explained that an individual's network consists of people who share food, exchange livestock, discuss future plans, share information, make decisions and engage in mutually affectionate labour.

In history, the role of social networking in pastoral livelihoods is well known. Earlier ethnographers studying African pastoralists acknowledged the central role played by social relations in pastoral livelihood sustainability (see Evan-Pritchard (1940) the Nuer; Gulliver (1951, 1955) in Turkana; Lewis (1961) among the Somalis; Jacobs (1965) in Maasailand; Spencer $(1965,1973)$ in Samburu; Dyson-Hudson (1966) in Karamoja). It has been documented that during the pre-colonial period, the groups worst affected by raids, diseases or droughts were forced to seek assistance from neighbouring tribes. In such occasions, Karamajong went to seek food from the Pokot (Dietz 1987b), while the Turkana went into the Dassenetch country (Sobania 1992), where the Dassenetch allowed the Turkana refugees to cultivate food on the Omo River delta and along the lake shore. These relationships were built over many generations. 
In his study, Philip Salzmann (1981: 32-38) pointed out that pastoralists have never been single-minded people who know only one thing: livestock husbandry. Rather, they have always been multi-interest 'foxes' who pursue many ends in which social networks play an integral role. Dan Aronson supports this line of thought and argues that pastoralists operate multi-resource economies:

Throughout their history pastoralists have engaged in a multiplicity of economic activities, making use of a wide diversity of resources within their reach and often modifying their animal production to the demands of other pursuits. Above all, they farm, trade, handcraft, involve in collection of firewood and charcoal burning, and they used to raid and make war on their own or others (Aronson 1980: 173-184).

According to Turkana oral traditions, the non-pastoral pursuits gained prominence in times of hardship when pastoral yields declined to below subsistence level. For instance, during hardship, Turkana people in northern territories would engage more actively in trade with the people of lower Omo, Southern Sudan and Northern Eastern Uganda. From this trade, they procured an assortment of goods including maize meals, sorghum, beans and tobacco. The lower Omo, however was their principal source of sorghum. Turkana oral traditions record that in this trade:

Sometimes the Turkana would drive cattle up there and sometimes the Melire would bring bags of sorghum down here. In either case, people would go to the Kraals of the people they know. If their daughters had been married by men of other tribe, they would go to the kraals of their sons-in law (Lamphear 1982: 18).

During the famine of the 1880s and 1890s, which was caused by series of calamities including rinderpest, drought, small pox, malaria, and cholera, nomads had to develop coping strategies to survive the crisis. At this time, there were famines everywhere except among the Turkana who escaped unscathed. This apparently was because the Turkana traded with their 
neighbours, such as the Samburu, and Swahili traders from the coast. They traded cattle, goats, sheep, and leather skins, and bought millet, maize, maize-meal, tobacco, cloth, iron work (spears and knives), cooking pots, and articles for ornamentation (beads, ostrich eggs and feathers). Most of their material culture was indigenous, made from wood and leather (Fedders and Salvadori 1977). However, Dyson Hudson and McCabe (1985), and Lampheear $(1988,1992)$ document that during this time, the Turkana people herded their cattle on isolated mountain massifs, while the goats and camels, not susceptible to rinderpest, were herded on the surrounding plains. But not all nomads in Kenya were so lucky. Writing about the pastoral Maasai, the historian Godfrey Muriuki tells us:

The various disasters that overtook the Maasai pastoralists e.g. the cattle epidemic, smallpox, and wars culminated in a large scale influx of refugees into Kikuyuland. In fact, these phenomena were not confined to the Kikuyuland alone; throughout the century, Maasai refugees are known to have settled among the Taveta, the Chagga, the Arusha and Luhya. Moreover, an arrangement whereby women and children could be pawned in times of misfortune existed, as it did among the Ashanti and the Dahomey of West Africa. Desperate Maasai families left their children and women in the hands of the Kikuyu in exchange for foodstuffs hoping to ransom them in better times. No stigma was attached to the pawning as the system was commonly practiced by the Akamba, the Kikuyu and other Mount Kenya peoples during famine times. In any case, it fulfilled an important function by ensuring that a family did not starve. Pawnship was certainly not regarded as slavery, indeed it was a stage toward full adoption (Muriuki 1974: 85).

Another historian, William Ochieng, records that impoverished Maasai warriors fled their land and became paid mercenaries, and fought in the armies of the Kikuyu, the Kamba, and the Luhya (Ochieng 1985).

A study conducted by George Henriksen (1974) on the ecological problems in Turkana during 1971 drought indicates that the Turkana, who were 
themselves non-pastoralists like civil servants, teachers, politicians, businessmen, etc took advantage of their privileged position to accumulate large herds. They did this because pastures were communally owned and free, thus making livestock keeping the most profitable form of capital investment. They used the patron-client relationship based on traditional kinship ties to recruit cheap labour. During drought and famine, they buy off the poor and thus perpetuate inequality. According to this line of thought, the rich who were themselves 'non-pastoralists' were the immediate cause of the overstocking and overgrazing problems in Turkana (Henriksen 1974).

In his study of the Gabbra pastoralists' adjustments to drought and the famine of the 1890s, Robinson (1980) records farming, long distance trade, hunting and gathering, reciprocal gifts, paid employment within the community, and, in extreme cases, the sale of female children in exchange for food. Farming and trade were of particular interest for this study as they were low cost but high-benefit adjustment choices for the famished Gabbra. Those who settled down to farming (temporarily) did so among the agricultural Konso of southern Ethiopia where they settled as migrants.

The Konso live in the well-watered highlands of southern Ethiopia. They grow sorghum, wheat, barley, maize, potatoes, vegetables, coffee and cotton. They also keep donkeys and a few cattle, sheep and goats at the lower altitudes. Theirs is a market-oriented economy (Kluckson 1962). The Konso and Gabbra had a friendly relationship which to survive the Gabbra leaned on heavily for survival during the famine of the 1890s. The Gabbra settled among the Konso as immigrants and bought cattle, sheep, and goats. When the pastures were restored, they returned to Gabbra country and re-entered the mainstream of pastoral life (Robinson 1980).

Trade was the most interesting mode of adaptation. Traditionally the Gabbra held trade in low esteem, nearly as low as hunting or as the 
occupation of the poor (Robinson 1980). During the famine of the 1890s, the famished Gabbra were forced to stoop to both hunting and trading. They hunted elephants for ivory which they then sold to the Somali traders, and from this trade in ivory, they accumulated large herds (see Figure 2 for where the Gabbra and the Somali pastoralists inhabit). It is said that the trade was lucrative for one good pair of tusks fetched 30 head of cattle from the Somalis (Robinson 1980)

Figure 2: Geographical distribution of the pastoralist groups and their neighbours in Northern Kenya.

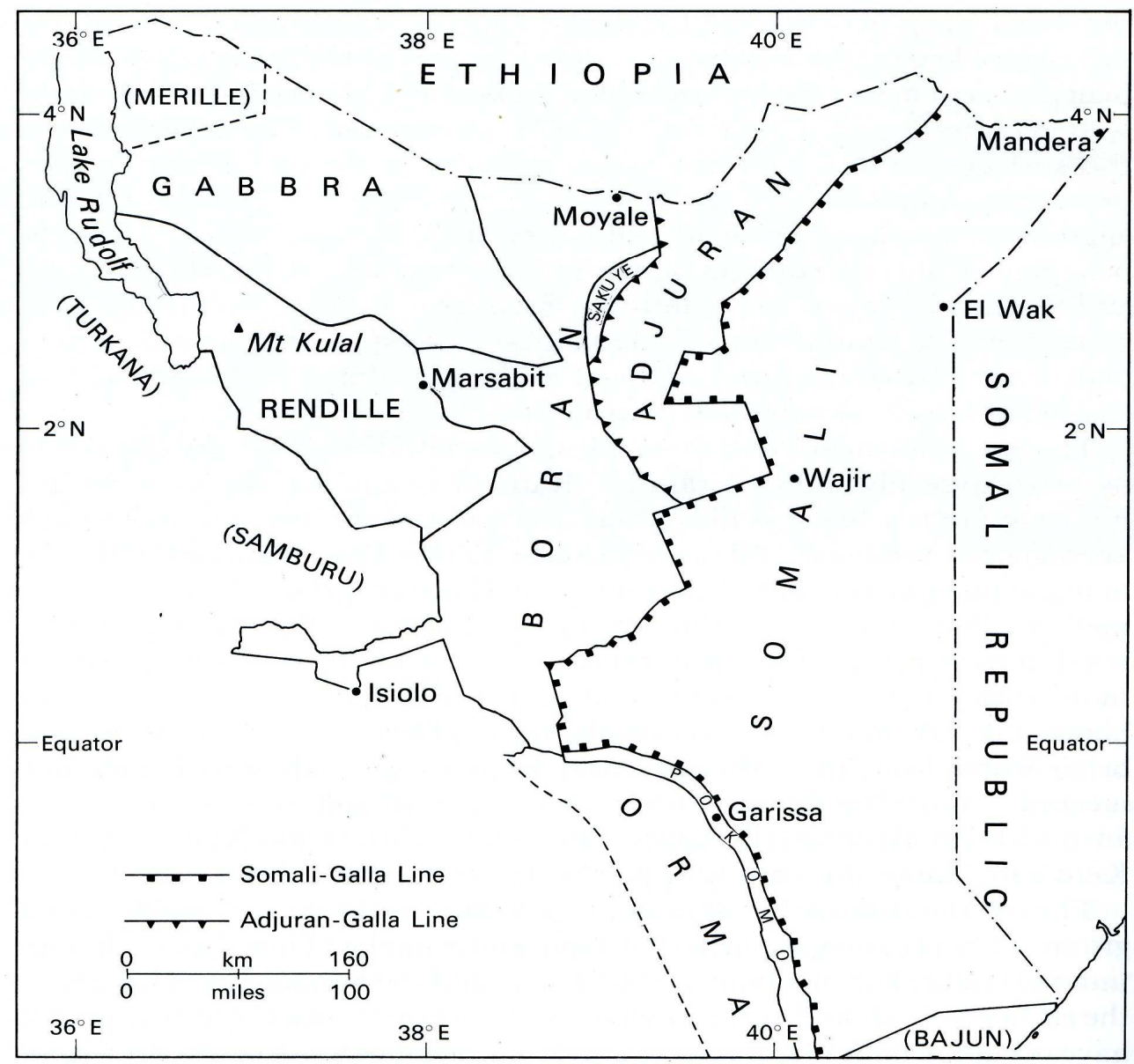

Source: (Morgan 1973: 216).

The lasting economic effect of the eco-stress in the Gabbra pastoral economy was the shift from a predominantly cattle-based economy to a 
camel-based economy. The rinderpest had killed nearly 90 per cent of their cattle and spared the camels. This, to the Gabbra, meant that cattle were weak and therefore less secure as a source of subsistence than hardy camels (Robinson 1980: 16-17).

Among the Wollo of Ethiopia, survival strategies included bartering animals. In times of drought and famine, the Wollo pawned female animals such as goats and sheep for grain. The grain owner would get collateral security, and was entitled to an offspring of the animal, if it calved in his custody. The owner of the animal got grain, and his animal would survive the drought situation. The pawning of animals for grain among the Wollo took place between the pastoral Wollo and the Borana peasants. During the drought of 1975 and 1980 in Ethiopia, the Wollo in northeast, pawned animals for grain with the Borana peasants in the southeast (Rahmato 1991).

The evidence in the literature suggests that the outright gifting of food to famished families plays an important role in sustaining households, but is never enough to weather a prolonged food crisis. Neville Dyson-Hudson, for instance, reports that among the Karamajong, the poor could be fed only if they were few in number: when their numbers swelled, they had to fend for themselves or perish (Dyson-Hudson 1966).

Campbell (1984), while studying responses to drought in Maasailand in Kenya, argued that the mutual claims to ownership of livestock made it possible to keep some cattle outside the area under threat of famine and ensured their survival. Following recovery, livestock were redistributed among (semi) destitute clan members giving them the opportunity to reestablish their herds. Campbell points out that fallback activities have also been common among pastoralists living in areas periodically affected by famine. For pastoralists, this means economic activities outside the pastoral sector such as agriculture, fishing, and hunting. Other actions 
are aimed to directly reduce pressure on household resources such as sending children to other relatives for schooling, purely to benefit from special feeding programs.

Ellis, Gavin, McCabe, and Swift (1987) discuss the adjustment strategies of Turkana pastoralists during the 1979-1980 droughts. From the literature they review, responses tend to correspond with the worsening conditions of the ground. Oba (2001) has recently advanced a similar hypothesis following his literature review on how seven major pastoral groups in the northern part of Kenya cope with difficulties.

When a pre-disaster 'drought threat' period ${ }^{26}$ is anticipated or detected at an early stage, nomads begin to move herds to dry season pastures earlier than usual and the livestock remain there as long as the drought lasts. ${ }^{27}$ This involves selective access to cross sub-sections and cross border rangelands. In the second phase, family herds are divided into smaller but specialized units. Those with long watering intervals are moved further away from the wells than those requiring more frequent watering. Young men scatter in every direction with these small units in search of fresh pastures and water. Thus, mobility is intensified. Young herders go to kinsmen and friends to beg for access to grazing land. According to Ellis, Gavin, McCabe, and Swift (1987), due to relatively good relationships between the various Turkana sub-sections, access to rangelands belonging to neighbouring sub-sections is much more easily achieved than the access to areas belonging to neighbouring and often rival groups. However, in some cases, peace pacts are negotiated through the mediation of clan elders to ensure safe passage and utilization of rangelands across district or national boundaries (Lamphear 1992).

\footnotetext{
26 During this time, although drought threat is evident or the drought is in its early stages, economic stress has not yet occurred.

27 These strategies both relate to assets and production. Land resources are seen here as assets access which leads to production of livestock. Mobility is regarded as a strategy which foceses on exploiting environmental resources available as livestock resource.
} 
During a 'drought stress' threat period 28 a herd owner may have to reduce the number of people dependent on the livestock for food. The women, children and the elderly are moved out of their homesteads and sent away to live with kinsmen and allies in towns and the farming villages. This enables herders to migrate further away from home in search of forage and water. It also helps to slough off the number of people dependent on pastoral production, and thus saves milk for calves. This helped to improve the survival rate of calves. Systematic culling and sale of livestock also helped keep livestock numbers down as well as generating a cash income they could use to buy food (Gulliver 1951).

Apart from relying on kinsmen for food, the nomads would trade, farm and take up wage employment temporarily as they waited for rains to restore the pastures and allow them to return to full-time pastoralism. These strategic responses have also been documented in recent research carried out by Barton, Morton and Hendy (2001).

In summary, this sample selection of adjustment mechanisms brought into play by the Turkana, Maasai, Gabbra, Somali, Rendile, Konso, Wollo, Borena, and Karamajong pastoralists highlights a number of the salient features of adaptability: firstly, the adjustment choices are easier to observe during periods of hardship; secondly, the adjustments may vary from one society to another but they possess one factor in common in that they are creative behaviours; and finally, pastoralists predominantly utilize their social relationships to gain access to economic opportunities which enables them to obtain additional food supplies to top up their food reserves during crises.

${ }^{28}$ During this period, drought stress is becoming evident, with an impact on the economy. 


\subsection{Justification for the study.}

The rationale of this particular study is threefold:

As they depend almost solely on natural resources, nomad livelihoods are endemically exposed to many uncertainties. For example, the vegetation cover of pastures in non-equilibrium contexts like African drylands depends on unpredictable variations in rainfall and other climatic factors (Scoones 1994). Accordingly, nomads react to these uncertainties (crises) by employing different livelihood mechanisms. It is thus interesting to explore how Turkana people deal with such uncertainties (namely drought) within their social networks. This knowledge would therefore enhance our theoretical and empirical understanding of the Turkana nomads' indigenous ways of coping with drought and famine today, as representative of what ways nomads follow under similar circumstances universally.

Secondly, the findings should enable us to identify key variables in the patterns of local adjustments which might be supported, modified or enhanced to develop long-range drought and famine management mechanisms. The planning of low-cost, but high-benefit, approaches to cope with droughts require that they be built on patterns of local adjustment. Therefore, the knowledge gained through this research will help to evaluate the appropriateness of the existing approach to intermediation in Turkana and whether enough effort has been made to identify alternative approaches.

Finally, this is a small-scale study whose findings could add to the existing literature on human adaptation to droughts. As we expand and enrich our knowledge of adaptation, it should be possible to design new methods that would not only enable pastoralists to cope with droughts but also to enhance our conception of their livelihoods, which may help us to rethink 
concerning the nature and content of external livelihood interventions, so that they are more consonant with the diverse ways in which pastoralists make their livings and build their worlds. This becomes even more crucial in the current situation in Sub-Saharan Africa where droughts are becoming both more frequent and severe than previously. When coupled with a general decline in food production, the urgency of the task becomes imperative.

\subsection{Organization of the study.}

The study is divided into eight chapters. Chapter 1 sets the scene for subsequent chapters by: providing some background information about the topic; introducing the context within which the research is based; and exploring the debates on the topics relevant to the research. The research questions, justification, and hypotheses are also provided. Chapter 2 looks at the theoretical framework underpinning this research. The livelihood approach is introduced in a way that is holistic and people focused. Due to its limitation, two other theories, the symbolic interaction theory and the social exchange theory, are introduced to modify it. Finally, the applicability of the three approaches to the study is discussed. Chapter 3 discusses the research methodology. The methodological approach further points at the sampling method and data collection techniques that have been used in the field. The data analysis technique is described, and some of the general problems and issues I came up against and had to overcome during the fieldwork are noted. Chapter 4 describes the general setting of the study area such as background information pertaining to the ecological conditions of the area the Turkana people occupy, the population, and the socio-economic aspects. The major findings of the study based on the research questions are then presented in chapter 5 to 8. The overview of the vulnerability context in the Turkana District is presented in chapter 5. Chapter 6 provides a discussion of the 2005-2006 drought and famine in the Turkana district. Accordingly, attention is 
placed on the contribution of social networks in livelihood sustainability. Chapter 7 discusses factors that impinge on adaptability in the Turkana District. Chapter 8 summarises the study, providing a conclusion and policy implications of the study.

\subsection{Chapter summary and hypotheses.}

In this chapter, the following research questions were established: What are the indigenous livelihood strategies deployed by the Turkana people to cope with crises both in general, and in the 2005-2006 drought and famine in particular? And how do they cope on their own without support from outside the community? How do local practices and indigenous knowledge contribute, or not, to the challenge of maintaining sustainable livelihoods? The concept of social networking is used to focus on the dynamics of the Turkana people's livelihood during a crisis. To set the scene for the discussion of the research problem, an overview was provided of the wider context in which the colonial and post independence government policies in Sub-Saharan Africa impoverished and increased pastoralist's vulnerability to calamities. This was followed by a selected review of the literature on how various pastoralists adjust to the challenge of the impending crises such as migrating, splitting families, and so forth, depending on the configuration of their social relations.

A preliminary observation arising from the literature review is that typical adaptive responses result in behaviours that take on exaggerated form in times of economic hardship. The review reveals that East African pastoralists possess a repertoire of adaptive strategies which they call into action during drought and famine. The adaptive responses are guided by a detailed knowledge of what environmental, physical, and social resources are available and how they might contribute to their survival in times of need. Survival then depends greatly on the group or individual capacity to access potential means of support in the social and economic world 
around them, as will be illustrated in Chapter 2. The knowledge gained in this chapter leads to the formulation of two hypotheses as follows:

i) Drought and famine stimulate the search for potential allies. ${ }^{29}$

ii) The social and economic resources accessible to famished Turkana nomads determine the range and scope of adaptive responses. ${ }^{30}$

Therefore, the following chapter provides a detailed discussion of the theoretical framework of the study.

${ }^{29}$ As will be discussed in the next chapter, this study consider potential allies to include kinsmen, neighbours, bond-friends, the state, missionaries, traders, employers, pastoral and non-pastoral neighbours.

30 Hypotheses 1 and 2 are extensively discussed in chapter 6 and 7 respectively. 


\section{CHAPTER 2 THEORETICAL FRAMEWORK}

\subsection{Introduction.}

The previous chapter introduced and provided an overview of how pastoralists in Sub-Saharan Africa survive during food crises. It drew from the experience of Turkana pastoralists living in the arid part of Northwestern Kenya. The 2005-2006 droughts and famine crisis in the Turkana region is a recent case in point. Its disturbing role in undermining the economic base of the Turkana people and subsequent increase in overall food insecurity was acknowledged. In this chapter, it is strongly argued that the idea of famine relief support whenever famine breaks out in the Turkana region is 'a top down' approach which considers that livelihood sustainability can only come from outside and not from within. Therefore, there is need for an alternative approach to the study of Turkana people's livelihoods that starts with local peoples own practices. Thus, the focus in this chapter shifts from the broad and the general to the local and the particular, allowing an understanding of differing indigenous responses at the local level. It is considered here that understanding the Turkana people's indigenous livelihood responses during crises and its implication to policy requires a properly conceived holistic framework. Within this broader framework, this study places special attention on one of the five assets identified as constitutive of livelihood strategies in the Turkana District: Social capital. The reason for choosing this particular asset is two-fold: First, as discussed in Chapter one, social capital among the Turkana people inheres in types of relationships that allow access, and is thus a critical precursor to the possible access of. ${ }^{31}$. Second, social capital as a livelihood asset in the Turkana District is probably the least tangible, and therefore, the least understood.

\footnotetext{
31 De Han and Zoomers (2005) argue that access is the key in conceptualization of livelihoods and, therefore, the key to unravelling poverty. Carney (1998) concurs that social capital is an important asset required for generating a means of livelihood.
} 
The sustainable livelihoods approach is central to this discussion. It provides an important insight and a strong starting point to understanding the dynamics of Turkana pastoralists' livelihoods as it places a lot of emphasis on ownership of, or access to, assets which the Turkana people could use to construct their own routes out of food insecurity problems. The approach incorporates a view that integrates social capital ${ }^{32}$ directly into household livelihood analysis. But for the purpose of this thesis, the sustainable livelihood approach is too general and lacks the specificity to carry a detailed analysis of all the issues critical to understanding Turkana people's livelihood strategies. To improve its theoretical depth and make it more powerful analytically, this study draws from two other approaches: symbolic interaction theory and social exchange theory. These theories were incorporated on the basis of their applicability to the research problem and add an important dimension to the study. The three theories also share some features and highlight several variables which are critical to understanding capacities and ways in which Turkana people cope with drought and famine.

Initially, these three theories will be reviewed separately in order to operationalize and improve their theoretical depth. Finally, with special emphasis on drought, a framework will be formulated to analyse Turkana pastoralists' adaptation to the constraints imposed by dryland conditions. The framework illustrates an alternative scenario, by highlighting the positive aspects of the livelihood situation in the Turkana District by looking at what is possible, rather than, negatively, at how desperate things are.

32 The incorporation of social resources within the sustainable livelihood approach relates to the earlier work of Amartya Sen (Sen 1981; Sen 1985). 


\subsection{Emergence of the sustainable livelihood approach.}

As an academic discourse, the concept of sustainable livelihood approach became prominent in the middle of the 1980s as a reaction to the 'basic needs' development discourse of the 70's, and the 'top down' approaches that had been dominant within the development discourse for some time (Ellis 2000; Scoones 1998). Robert Chambers was one of the strongest critics of the 'top down' approach, and emphasised the need for enhanced focus on actors of development - the poor people themselves (Chambers 1983). The idea was to replace the 'top down' approach with action from below. The approach developed alongside other fields and approaches in the 1980s, and Chambers argues that "the sustainable livelihood thinking was formed by fusing the best environment, development, and livelihood thinking" (Chambers 1987: 5). This implies, respectively, a focus on sustainability, productivity and poor people's livelihoods.

Various understandings of the concept are used. At its most basic, a 'livelihoods approach' is simply one that takes as its starting point the actual livelihood strategies of a people. Instead of starting with a grand theory, it looks at where people are and situated, what they have and what their needs and interests are (Chambers 1983). Modified interpretations of the livelihood approach are described by various authors and organisations (Cahn 2002; DFID 2001; Ellis 2000; Scoones 1998). Two widely used definitions of livelihoods are:

A livelihood comprises the capabilities, assets (including both material and social resources) and activities required for a means of living. A livelihood is sustainable when it can cope with and recover from stresses and shocks, maintain or enhance its capabilities and assets, while not undermining the natural resource base (Scoones 1998: 5).

A livelihood comprises the assets (natural, physical, human, financial and social capital), the activities, and 
the access to these (mediated by institutions and social relations) that together determine the living gained by the individual or household 33 (Ellis 2000: 10).

It is difficult to discuss sustainable livelihoods or sustainability as such, without touching upon the concept of 'sustainable development'. The World Commission of Environment and Development (WCED) introduced this concept in 1987 in its well known publication 'Our Common Future' which emphasised the importance of the link between poverty and environment. WCED defined sustainable development as "Development that [...] meets the needs of the present without compromising the ability of future generations to meet their needs" (World Commission on Environment and Development (WCED) 1987). The term 'sustainable livelihoods' first appeared in a report in 1987, also prepared by the WCED, and became incorporated into their policy on sustainable agriculture (Cahn 2002). The concept of livelihoods was incorporated into Local Agenda 21 at the UN Conference on Environment and Development in Rio in 1992 (Schafer 2002).

As an idea, sustainable livelihood approach has been gaining increasing currency in recent years and its emergence is now seen as fundamental to poverty reduction approaches around the world (International Institute for Sustainable Development (IISD) 2003). It has two major dimensions, which are both essential for rural livelihoods, namely the environment or ecology, and the social dimension. The former is concerned with the sustainability of the natural resource base, on which most rural livelihoods rely. According to Scoones (1998: 6), some authors define this as "the ability of a system to maintain productivity when subject to disturbing forces, be it stress or shock", and further defines the social dimension as relating to livelihood adaptation, vulnerability and resilience, and the ability of a

\footnotetext{
33 According to (Ellis 1998: 6) "a household is conceived as a social group that resides in the same place, shares the same meals and makes joint or co-ordinated decisions over resource allocations and income pooling". The Turkana people's own definition of household is provided in Chapter 3 where the methods used in collecting the data are discussed in detail.
} 
livelihood to cope with and recover from stresses and shocks. According to the social dimension, the sustainable livelihood approach demonstrates that poverty reduction requires an understanding of how rural livelihoods are conducted and sustained, as the ability to move out of poverty, reflects the capabilities and assets and/or lack thereof available to the poor (Ellis 2000). This includes material assets such as access to land, other natural resources, financial capital and credit, tools, inputs into productive activities, and others. It also reflects human capabilities (the knowledge and skills of the family); social and political factors such as contact networks and the openness of government institutions (Ellis 2000). Moreover, by understanding the dynamics of rural people's livelihoods, we can begin to understand how they will be affected by shocks such as drought impacts, how they might respond with the resources they have, and how these conditions can be reflexively built to develop more successful coping strategies. The analysis of the Turkana livelihood situation, as contained in this thesis, relates to the social dimension which hence adopts the Ellis (2000) approach.

\subsubsection{Principles and concepts of sustainable livelihood approach applicable to this study.}

The concept of sustainable livelihood approach provides a useful guideline for understanding survival strategies that households and individuals adopt during a crisis. The main guiding principles identified in the livelihood literatures which are relevant to my study are: Firstly, that Sustainable livelihood approach literature categorizes the main livelihood strategies which households pursue into three broad groups:

i) Agricultural intensification, which refers to the strategies based on exploitation of natural resources (e.g. food crops, cash crops, livestock) including income from agriculture

ii) Livelihood diversification which occurs when rural households construct a diverse portfolio of activities and social support capabilities for survival 
in order to improve standard of living (Ellis 1998). This includes expansion of income from different sources (farm or off-farm).

iii) Migration: when one or a few family members leave and earn money somewhere else and contribute to the household economy. Migration can be seasonal, circular or permanent.

Two of these livelihood strategies (e.g. livelihood diversification and migration) fit quite well in the analysis of how the Turkana people adapt their livelihoods during a crisis as they represent strategies that are used to cope with drought and famine in the Turkana District. The Turkana people are known to have diversified their livelihood activities even during the pre-colonial period by engaging in agriculture, fishing, and hunting and gathering 34 .

Secondly, Ellis' (2000) definition of the sustainable livelihood approach places more emphasis on the social factors ${ }^{35}$ as crucial elements to understanding the implications of household livelihood strategies. This assertion is applicable to the Turkana situation because food production in the study area is primarily, although not exclusively, reliant on local people's social networks.

Thirdly, while acknowledging that social structures and processes at a macro level in society have an important impact on livelihoods, they are not the only critical factors. The macro level has to be linked to the micro level where actors operate and individuals and households take action for changes to take place. ${ }^{36}$ Using the sustainable livelihood approach in this analysis, these different aspects are incorporated. Fourthly, following Ashley and Carney (1999), this study favours a sustainable livelihood approach which focuses on the household and its assets as a unit of social

\footnotetext{
${ }^{34}$ See the discussion in Chapter 5.

35 The question of social resources in livelihood analysis is a critical issue in understanding livelihood situation in the Turkana district (See Chapters 4, 5 and 6 for detailed discussion).

${ }^{36}$ Long is one of the proponents of actor oriented approach (Long 2001, 2002)
} 
change and development. Here, it implies that looking at what people actually have, their strengths and capabilities, is more valuable than looking at their needs or what they don't have. It is a way of thinking about objectives, range and priorities for development, in order to enhance progress in poverty reduction. It is a pro-poor approach aimed at helping poor people achieve enduring improvement against the indicators of poverty (Ashley and Carney 1999). Fifth, the sustainable livelihood approach places people and their priorities at the centre of the analysis (Ashley and Carney 1999). This approach therefore creates an understanding of poor people's perspectives on the world and their situation, understanding their priorities and uncovering what they perceive to be the opportunities for and constraints to achieving a sustainable livelihood (Chambers 1983, 1987). In this study, the Turkana people's perception and definition of their situation is considered as well as the meaning they give to their situation. Sixth, the holistic character of the Sustainable livelihood approach entails an inter-disciplinary and intersectoral focus (Freeman, Ellis, and Allison 2004 ). By focusing on the entirety of the factors influencing the households, the sustainable livelihood approach differs from other approaches to developments which focus on aggregated objectives and indicators. The framework therefore provides the basis for examination of the livelihood strategies in a wider perspective and gives room for a consideration of diverse factors influencing livelihood sustainability in my study area. Finally, the sustainable livelihood approach used here recognises the importance of resilience, adaptability, and sustainability (Scoones 1998: 6). Adaptability is the focus of this study.

To gain a better understanding of livelihood process and analysis, Ellis (2000) has developed a rural livelihoods analytical framework. It considers a wide range of factors determining the livelihood strategies of people in a particular setting and focuses on livelihood sustainability. It is structured mainly for coming to grips with the complexity of livelihoods, 
understanding influences on poverty and identifying where interventions can best be made to help poor people reduce poverty. The framework has been applied widely by development agencies, donors, and other organizations in formulating policies, informing strategic thinking and guiding participatory planning (Ashley and Carney 1999: 10).

Ellis' (2000: 30) framework is presented here as Figure 3. This is a version of the 'assets-mediating process-activities' framework. The framework identifies entry points and critical processes, and assists with prioritising catalysts for change. Readers may think that it is difficult for such a diagram to capture the dynamics of livelihood systems that, in practice, involve numerable feedback mechanisms and complex interactions between components. Here, the diagram is used as a pragmatic heuristic device to organise ideas into manageable categories. Dynamic interactions are therefore under emphasised and boldly implied, rather than stated in the framework. 
Figure 3: A framework for micro-policy analysis of rural livelihoods. ${ }^{37}$

\begin{tabular}{|c|c|c|c|c|c|}
\hline A & B & $\mathrm{C}$ & $\mathrm{D}$ & E & $\mathrm{F}$ \\
\hline $\begin{array}{l}\text { Livelihood } \\
\text { platform }\end{array}$ & $\begin{array}{l}\text { Access modified } \\
\text { by }\end{array}$ & $\begin{array}{l}\text { In context } \\
\text { of }\end{array}$ & Resulting in & Composed of & With effects on \\
\hline $\begin{array}{l}\text { Assets: } \\
\text { Natural } \\
\text { capital, } \\
\text { physical } \\
\text { capital, } \\
\text { Human } \\
\text { capital, } \\
\text { financial } \\
\text { capital, social } \\
\text { capital. }\end{array}$ & $\begin{array}{l}\text { Social relations: } \\
\text { Gender, } \\
\text { Class, } \\
\text { Age, } \\
\text { Ethnicity. } \\
\\
\text { Institutions: } \\
\text { Rules and } \\
\text { customs, Land } \\
\text { tenure, markets in } \\
\text { practice. }\end{array}$ & $\begin{array}{l}\text { Trends: } \\
\text { Population } \\
\text { Migration, } \\
\text { Technical } \\
\text { change, } \\
\text { Relative } \\
\text { prices, } \\
\text { Macro } \\
\text { policy, } \\
\text { National } \\
\text { economics } \\
\text { trends, } \\
\text { World } \\
\text { economic } \\
\text { trends. }\end{array}$ & $\begin{array}{l}\text { Livelihood } \\
\text { strategies }\end{array}$ & $\begin{array}{l}\begin{array}{l}\text { Natural } \\
\text { resource based } \\
\text { activities: }\end{array} \\
\text { Collection, } \\
\text { cultivation } \\
\text { (food), } \\
\text { Cultivation } \\
\text { (non-food), } \\
\text { livestock, Non- } \\
\text { farm NR. } \\
\text { Non natural } \\
\text { resource based } \\
\text { activities } \\
\text { Rural trade, } \\
\text { rural } \\
\text { manufacture, } \\
\text { remittances. }\end{array}$ & $\begin{array}{l}\text { Environmental } \\
\text { sustainability: } \\
\text { Soil and land } \\
\text { quality, } \\
\text { Water, } \\
\text { Rangelands, } \\
\text { Forests, } \\
\text { Biodiversity. }\end{array}$ \\
\hline
\end{tabular}

Source: Ellis (2000: 30). Adapted from Scoones (1998: 4) and Carney (1998: 5).

37 The framework originates from work on vulnerability and famines (Davies 1996; Swift 1989); livelihood system approaches to gender analysis (Grown and Sebstad 1989); analysis of poverty-environment interactions (Reardon and Vosti 1995); asset vulnerability approach to urban poverty reduction (Moser 1998); and research on sustainable rural livelihoods (Bebbington 1999; Scoones 1998). 


\subsubsection{Explaining the sustainable livelihood approach framework.}

One of the key components of Ellis' framework, shown in Figure 3, is assets. Ellis regards the "asset status of poor individuals as fundamental to understanding the options open to [the rural poor], the strategies they adopt for survival and their vulnerability to adverse trends and events" (Ellis 2000:28). The assets can be understood as the tangible and intangible resources that the household is in possession of through ownership, control, claim or accession by other means, and can be used directly or indirectly to generate livelihoods. The greater and more varied the asset base, the higher and more durable the level of sustainability and security of livelihoods. Assets can be divided into different forms of 'capital'. The categories of assets that are used by Ellis are natural, physical, human, financial, and social capital. Natural capital refers to natural resource stocks such as land, water, trees, pasture, and wildlife, and environmental services such as hydrological cycle and pollution sinks, from which resource flows and services useful for livelihoods are derived (DFID 2001; Ellis 2000; Scoones 1998). The productivity of these resources may be degraded or improved by human management (DFID 2001; Ellis 2000). Physical capital is that capital created by the economic production processes. It includes infrastructure such as roads, canals, electricity supply, and water supply; and also producer goods such as tools and machinery. Financial capital ${ }^{38}$ consists of stocks of money or other savings in liquid form. It also includes access to credit and easily disposed assets such as livestock, (ibid). Human capital is constituted by the quantity (number of productive individuals) and quality (what these individuals know and how hard they are able to work) of labour available at the household level; therefore it is determined by household size, and also by the education, skills, and health of household members. Social capital is the social resources such as contact networks, social claims, social relations, affiliations, associations, and mutual trust, upon which people

\footnotetext{
${ }^{38}$ Scoones (1998) labeled financial and physical capitals together as economic capital
} 
draw when pursuing different livelihood strategies requiring coordinated actions (Scoones 1998; Ellis 2000; DFID 2001).

The access to these assets is influenced by (1) social relations as class, ethnicity, gender etc., (2) institutions, which refers to formal and customary rules, conventions, and codes of behaviour, and (3) organisations, implying groups of individuals bound by some common purpose to achieve certain objectives. These endogenous factors are further affected by exogenous factors such as trends and shocks. The modified assets exist in a specific context, which form the livelihood strategies of a household. These livelihood strategies are sets of activities that are pursued by households to generate means of survival (Ellis 2000). Strategies are categorized differently by various scholars. For example, Ellis (2000) has classified strategies according to the nature of the resources used into natural and non-natural resource based activities, while Scoones (1998: 4) identified three broad livelihood strategies: agricultural (intensification of existing agricultural activities) diversification by adopting additional productive activities; and migration to develop productive activity elsewhere. It is important to note that these are not exclusive, and may be combined in practice.

These livelihood strategies determine the household's livelihood security, measured, for instance, by income level, seasonality, and degree of risk. The individual strategies, and thereby the activities occupying the household, also affect the environmental sustainability of the households' resources and the surrounding which they depend on (Ellis 2000).

\subsubsection{Critique of the Sustainable livelihood approach framework.}

Although the sustainable livelihood approach framework assists in situating an analysis of Turkana people's livelihood strategies within the wider context of change, this study subjects it to a critique. A major 
weakness of the sustainable livelihood approach is that it is extremely broad and general, and covers aspects from the micro to the macro level by taking into consideration many factors affecting the livelihoods of poor people. Hence it may not be able to analyse the dynamics of relationships that emerge during calamities in the Turkana District in the endeavour to survive. For example, in the Turkana region, some livelihood behaviours remain dormant in times of plenty and become observable in exaggerated forms only in times of need. The sustainable livelihood approach may not systematically analyze this behaviour change in a satisfactory manner. Evidence in the literature, as discussed in Chapter 1, indicates that East African pastoralists depend on reciprocity and symbiotic relationships during a livelihood crisis. The sustainable livelihood approach framework does not easily highlight and critically analyse these variable aspects within its framework. The sustainable livelihood approach illustrates the major livelihood strategies (e.g. diversification, agricultural intensification, and migration), and the context in which they are applied does not have the capacity to show how and why people would choose those strategies. The Turkana people's choice of a livelihood strategy during a crisis normally depends on their own perception or definition of their environment or situation, and the meaning the various strategies have for them. These issues seem to be beyond the scope of the sustainable livelihood approach. Cahn (2002) noted that it is unrealistic for Ellis (2000) to present the livelihood framework as linear, with no feedback or other relationships. This argument is applicable to this study because the way Turkana people achieve and maintain their livelihoods during a crisis has a feedback mechanism. These points are, however, met to a certain degree by the symbolic interaction theory and the social exchange theory. 


\title{
2.3 Symbolic interaction theory and Adjustments.
}

Social scientists who studied adjustment behaviours during earlier period of drought and famine extended livelihood analysis into the field of social psychology. This was necessary because, as Ben Wisner had noted:

\begin{abstract}
Man (...) does not act directly from his surroundings but rather indirectly through a perpetual and cognitive filter composed of elements of culture, personalities, childhood experience, recent experience, and even immediate bodily states (Wisner 1977: 119).
\end{abstract}

This approach views adjustment behaviour as taking place within a social context and influenced by taboos, ideology, group values as well as individual perceptions. It builds heavily on the symbolic interactionist theory.

Symbolic interactionist theory is a paradigm developed from the original work of the psychologist Mean (1964). The leading scholars of symbolism have been Blumer (1969) and Schutz (1970).

The basic tenets of the symbolic interactionist theory are that human beings act towards things on the basis of the meanings those things have for them in the course of interaction, and that definitions typically undergo revision and reconstruction in the process of interaction itself. The core of the theory is that in a changing situation, behaviour is never random and purposeless, but selective and purposeful. Unfamiliar environments call for their definition by the interacting individual to shape the frame of his act. Sheldon Stryker summarizes the theory in these lines.

When one enters a situation in which his behaviour is problematic, that is, in which pure habit will not suffice, he must find some way to represent that situation to himself in symbolic terms. If he is not to behave randomly, if he is not to select arbitrarily from 
range of acts in his repertoire of possible actions, he must, in short, define the situation. The products of his behaviour are definitions of the situation (Stryker 1973: 515-516).

Thus, humans live in a symbolic, physical, biological, and social world which acts as a stimulus to shape their behaviour. The concepts of 'role' and 'expectations' are crucial to this theory. As a person enters into an interacting system, he or she assumes a certain status position (role) and assigns certain other roles to members of their group, and by so doing invokes role expectations.

For people hungry enough, says Stryker, what may previously have been defined as inedible may be redefined as food and found quite nourishing. People have to redefine the changing situation as a basis for the rational selection of adjustment choices (Stryker 1973). Therefore, what people do in a crisis, then depends on how hard hit they are and the choices available to them.

In their detailed study of the Polish migrant families in America, Thomas William and Znanieki Florian found that Poles adjusting themselves to the new environment abroad had to give the situation in which they found themselves a definition which in the process moulded their adaptive behaviours (William and Znanieki 1974). This example ties in quite well with this study of responses to drought and famine in Turkana. From field data, Turkana pastoralists' adjustment behaviours take place within individual or group context. Therefore, their awareness and interpretation of the change situation is taken as the basis of their innovative behaviour. The situation definition gives individual or group consensus on the parameters of allowable adjustment choices. Evidence in the literature, as discussed in Chapter 1, indicates that pastoralists' collective awareness of the economic hardship permits and even 'legitimizes' otherwise anti-social conduct such as hunting, farming, taking up paid (wage) employment, 
begging, and the pawning of women and children. These are definitely unusual behaviours, which, under normal pastoral conditions, are not allowed.

Although the symbolic interaction theory expands the analysis of adjustment behaviour, it does not capture certain aspects of pastoralists' adjustment strategies, like reciprocity and symbiosis, which is the focus of this study. These aspects are addressed by the social exchange theory.

\subsection{Social exchange theory.}

Reciprocity is perhaps best explained by the social exchange theory of Homans (1961) and Blau (1964).

The social exchange theory is a utilitarian scheme for the study of human behaviour. It assumes that people always behave rationally to maximize gain. It emphasizes the fact that people behave according to anticipated rewards, and, where faced with competing choices, they will choose the option which carries the higher rewards. The rewards could be material things, or they could be purely social and psychological such as acceptance, prestige, sympathy, praise or esteem.

As in all situations of social interaction, ideology (shared values), beliefs, goals, and expectations are the motivating factors. Motivation to act derives out of the probability that the interacting individual's goals will be realized, or interests served.

In pastoral communities, reciprocity is an important insurance system. ${ }^{39}$ It is established and maintained by the constant exchange of livestock gifts. Danny de Vries, et al. (2006) maintains that pastoralists hoard stock to

39 This study adopts Wlaker and Jodha (1986) definition of insurance as a deliberate household strategy to anticipate failures in individual income streams by maintaining a spread of activities. 
enable them to oil reciprocal partnerships through the distribution of livestock gifts. Oba (2001) says that a Samburu man builds up his own affinal and bond partnerships which make up a network within which reciprocal interests are shared. Perhaps one of the most detailed accounts of reciprocity as an insurance system is that in Philip Gulliver's (1955: 196-222) Turkana ethnography, 'Family herds': A study of the two pastoral tribes in East Africa, the Jie and Turkana. In this book, Gulliver carries out a comparative study on pasture, water use, marriage, family life, and stock associateship ${ }^{40}$.

The tilia institution among the Pokot of Kenya is another good example of a pastoral insurance system. Harold Schneider writes:

A tilia partnership assumes many of the characteristics of clan ties. The partners support each other in the disputes, exchange small gifts such as goats, beer, and ornaments, and generally assume an intimate attitude toward each other (Scheneider 1957: 284).

On symbiosis, Kroeber (1948) once pointed out that pastoralism emerges as a sub-culture with ties linking it to sedentary populations, and that this is one of its distinctive characteristics. For their own survival, pastoralists develop inter-dependence relationships with neighbouring agricultural communities. Other studies lend supportive evidence to this pastoralsedentary interdependence thesis. Oba (2001) claims that pastoral Borana and Gabbra need each other for their survival. These relationships benefit both parties and are most vigorously exploited in times of need.

Similarly, pastoral relationships exist between the Turkana and the Dassanetch, the Samburu and the Turkana, the Gabbra and the Somali: all need each other for survival. Paul Spencer's (1973) book, Nomads in Alliance gives illustration of this. The study reviewed the Randille camelbased pastoral economy as weak, unable to grow, and therefore vulnerable

\footnotetext{
40 See detailed notes on Gulliver's (1955) work in Chapters 4 and 5
} 
to stress, especially to rapid population growth. The society periodically ejects surplus labour which is then absorbed by the buoyant and resilient cattle-based Samburu economy. In the process, an intermediate economy of the Arial people has developed. The Arial are of mixed Samburu and Rendille blood, and their economy is based on mixed cattle and camel.

Elliot Fratkin (1991), while agreeing with Spencer on the symbiotic dependency between the Samburu and the Rendille, seems, however, to suggest that it is the Samburu cattle-based economy that is weak due to pressure on hilly grassland pastures. In this case, a number of Samburu opt out of the predominantly cattle based economy and into a mixed cattle and camel economy, to enable them to survive on the lowlands, which favour camels and some cattle. Thus, the drought-resilient Rendille camelbased economy bolsters up the Samburu cattle-based economy. However, whichever is the case, the fact remains that pastoral communities are interdependent, one enhancing the survival chances of the other. It is a two way relationship that is mutually beneficial. However, what is the implication of these three theories (sustainable livelihood approach, symbolic interaction theory, and social exchange theory) to Turkana people's adaptive strategies during crises?

\subsection{Turkana pastoralists' adjustment scheme during crises - a conceptual framework.}

To better understand how Turkana pastoralists adjust to crises, a framework is presented here in Figure 4. It draws from the general literature discussed in the previous chapter, and from my personal knowledge of the Turkana situation. Theoretically, this has meant incorporating the sustainable livelihood approach, the symbolic interaction theory, and the social exchange theory. The model has been used to analyze Turkana pastoralists' adaptation to dryland situation with special attention to drought, and to one of its consequences - famine, and also to refine the current livelihood approaches to crisis response in the Turkana 
District. It is pointed out in this model that Turkana people's livehood during crises needs to be understood in terms of two issues: access and transformation of assets ${ }^{41}$ for a better livelihood; and capabilities of the local people to make their living more meaningful.

As discussed in the previous chapter, this thesis dedicates special attention to the significance of social networks as a mediator through which Turkana people are able to widen their access to other resources during crises. Therefore, the framework portrays the critical role of social networks in the Turkana pastoral livelihood configuration during crises in general, and during drought and famine in particular.

While focusing on drought and famine crises in this framework, the study begins with the hypothesis that famine in Turkana district is the result of interactions of various determinants. Drought is one of these, but to stimulate an appropriate policy response that will reduce food insecurity and strengthen the Turkana people's own capacity to cope with difficulties, drought must be understood in a broad context of vulnerability (see Figure 4). Here, the phrase 'vulnerability context' draws attention to the complex configuration of influences that are, directly or indirectly, responsible for many of the hardships faced by the Turkana people ${ }^{42}$. Therefore, the context is the external environment in which Turkana people exist, and widely condition access to assets and livelihood strategies.

According to the livelihood framework suggested by DFID (2004), vulnerability consists of trends (population, resource, technological change etc), shocks (natural shocks, economic shocks, and conflict), and seasonality (of prices, health, and employment). On the other hand, Scoones (1998) observes that vulnerability covers a range of historical and current socio-economic trends, such as policy setting, politics, history,

41 The terms "asset" and "resource" are used interchangeably.

42 As discussed in Chapter 1, vulnerability is determined by the (in) capacity of the Turkana people to cope with seasonal variations, shocks, risks, and trends. 
climate, and socio-economic conditions. Recent studies in the Turkana District shed more light on the major causes of vulnerability in that particular area and supports Scoones (1998) line of thought. According to Swift (1985) and the Turkana District Contingency Unit (1992), the main constraints that are said to facilitate famine are cattle raids from the neighbouring communities, livestock diseases and climatic factors. As will be discussed in Chapters 4 and 5, the historical context which encompasses the origin and culture that constitutes the identity of the Turkana people, and their marginalization through colonial and post colonial periods is important to their livelihood situation. Therefore, this study assumes the context given by Scoones (1998). ${ }^{43}$

Generally, in this framework (Figure 4), drought among other factors is seen to change the resource flows critical for livelihood sustainability in the Turkana District by profoundly disrupting the local people's assets or resources. Practically, the focus of this study centres on the idea that Turkana people, either as individuals or groups, do not think of their livelihood strategies immediately as crisis strikes. They first define the problem they face on the basis of their world view (e.g. values, norms, taboos, and roles), and give it a specific meaning before adopting a relevant livelihood strategy.

The literature on livelihoods distinguishes between 'coping', which involves temporary adjustments to livelihoods in the face of crisis, but does not necessarily bring a change in livelihoods, and 'adaptation' which involves a longer term shift in the conventional practices and informal or formal rules pursued by households and communities inorder to secure their livelihoods and to minimize the risk of lives (Scoones 1998; Sinclair and Ham 2000). According to De Waal (1994), it is the local coping strategies

\footnotetext{
43 The context given by Scoones (1998) forms the basis for the consideration of a wide range of factors which have impacted negatively on the Turkana people's livelihood. These factors are extensively discussed in Chapters 4 and 5.
} 
that are the most important component in people's survival in many crisis situations. However, my respondents, Turkana people, argued to the contrary that since they are aware that they live in a highly vulnerable system, they are more likely to pursue adaptive strategies, rather than coping strategies, while seeking all available options.

Figure 4: A framework for analyzing Turkana pastoralists' adaptation to a dryland situation with special response to drought.

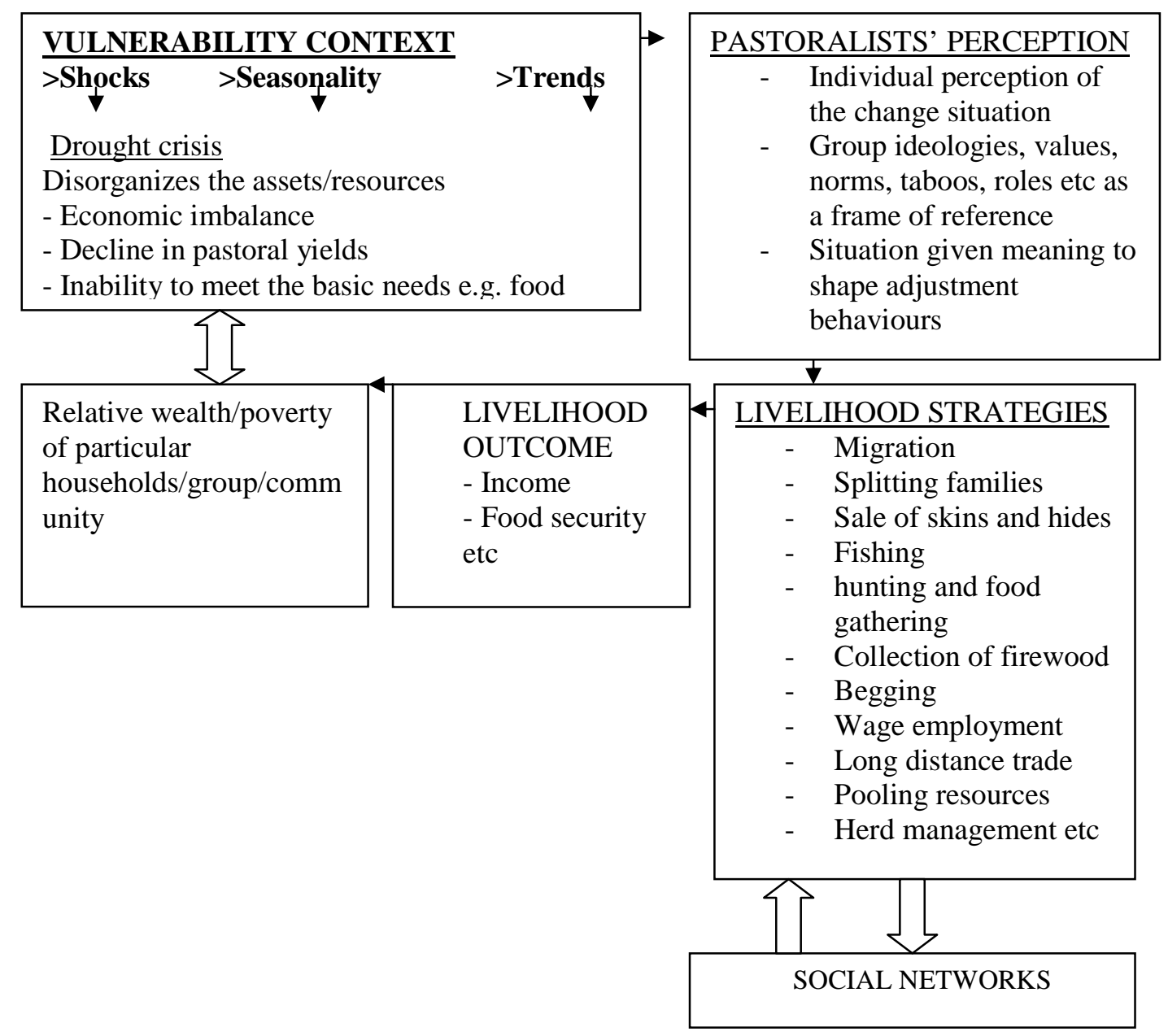

Source: Author 2009.

Ellis (2000) observed that adaptive strategies determine the household's livelihood outcome, that is, the goals that people are trying to achieve through their livelihood pursuits. The outcomes contribute to the 
livelihood security and sustainability of natural resources (DFID 2001; Scoones 1998). Outcomes, conditioned by the assets status and the mediating process, result in positive or negative effects on the poverty status of the household; it is possibly feedback on assets and hence the further development of livelihood strategies. For instance, in the Turkana District, as represented in the framework, the economic relationship between livelihood strategies and livelihood outcomes ${ }^{44}$ during crises has either positive or negative effects on the wealth or poverty status of Turkana households.

The framework further highlights the way in which this economic relationship between livelihood strategies and livelihood outcomes in the Turkana District occurs. The idea is to identify opportunities for strengthening the Turkana people's own capacities. It draws from local people's own views that the relationship is predominantly embedded in various types of social networks being activated during crises. Respondents emphasized that utilizing social networks ${ }^{45}$ as an insurance system during crises increases their resiliency and adaptability towards natural hazards such as drought.

The literature reviewed in chapter one reveals that in the past, several types of social relationships used to be exploited by pastoralists for survival in times of an economic hardship. They were kinsmen, affines within the pastoral communities, reciprocal partnerships, symbiotic relationships with neighbouring agricultural or non-pastoral communities,

\footnotetext{
${ }^{44}$ Understanding all the potential outcomes (and Turkana people's objectives regarding their desired outcomes) is potentially a huge task that would require a substantial amount of time on the part of the researcher and the informants. Therefore, it was beyond the scope of this study to investigate the livelihood outcomes of various Turkana households though important to be shown in the framework for the reader to see the feedback mechanism. My study limits itself only to identifying and analyzing the various types of networks activated during 2005-2006 drought and famine in the endeavor to survive.

45 In this thesis, a social network is seen as a mediator. The phrase "to facilitate individual and community action" in Halpern's (2005: 7) definition makes the social network a mediator.
} 
and finally, relationships with outsiders such as traders, state officials, missionaries, employers, and the sedentary population in general. These are the kind of social ties that form the core of my analysis, while discussing the 2005-2006 drought and famine in the Turkana District. 46

Therefore, this is a holistic framework which builds on the Turkana people's strengths to address food insecurity during crises. It has the potential to provide a sounder analytical basis on which to ground interventions, given the problem associated with simple focus in the delivery of famine relief food in response to immediate life-saving needs in the Turkana District. The framework is more nuanced and informs both my study and theoretical debates about food insecurity in pastoral areas in general, and Turkana District in particular.

\subsection{Chapter summary.}

The discussion in this chapter has explored the theoretical framework in which the relationship between food insecurity and Turkana household responses in terms of livelihood adjustments are to be examined. A framework for the analysis of livelihood strategies, as formulated by Ellis (2000) forms the basis and provides a strong starting point and a wider context for analyzing both the changes that have taken place in Turkana and the manner in which these have influenced livelihood strategies in relation to both livelihood security and environmental sustainability. The focus in this approach, however, is an understanding of what Turkana people have (or have access to), and how they use what they have to construct their livelihoods. Therefore, the sustainable livelihood approach both guided the identification of relevant factors affecting livelihoods in the study area, as well as structuring the analysis. However, an important process on how the Turkana people earn a living during crises is

\footnotetext{
${ }^{46}$ Data analysis in Chapters 6 and 7, shows that Turkana households with few assets in
} terms of social networks are less resilient at the time of shock. 
somewhat overlooked by the livelihoods framework. In tailoring the sustainable livelihood approach to how the Turkana people survive during crises, components of symbolic interaction theory and social exchange theory were incorporated. This enhanced the usefulness of the sustainable livelihood approach in guiding the identification of the pertinent process of livelihood sustainability in the Turkana region.

For instance, a close examination of household livelihood responses as conducted by Blumer (1969) and Schutz (1970), expands the sustainable livelihood analysis, showing that households normally define the situation and gives it a meaning before deciding on a particular livelihood strategy. The social exchange theory by Homans (1961) and Blau (1964) includes the concept of reciprocity in the analysis of livelihood strategies. The three theories and personal knowledge of the Turkana situation were used to formulate a framework for analyzing Turkana pastoralists' adaptation to the dryland situation with special response to drought and famine as in Figure 4. In the framework, drought is analyzed within the general vulnerability context so as to understand the inherent fragility of Turkana peoples' livelihoods which makes them less able to cope with stresses. Of great concern to this study is how Turkana people respond to crises by drawing on social networks that act as an insurance system. Therefore, the framework provides a lens through which the Turkana people's livelihood during drought and famine could be understood, and is a useful heuristic tool for guiding the research. The following chapter provides the research methods and the techniques used in the data analysis. 


\section{CHAPTER 3 RESEARCH METHODS}

\subsection{Introduction.}

This chapter presents the research methods used in this study, and provides an overview of research design (including data production and analysis). As suggested in the previous chapter, the livelihood approach was central to this research. It was designed to get a comprehensive overview of the vulnerability context in the study area, and explore the complex nature of Turkana pastoralists' livelihoods during the 2005-2006 drought and famine period. The approach provided the conceptual basis from which the overall research question was formulated and was also instrumental in guiding and informing the overall methodology and the actual questions asked. Analysis of Turkana people's livelihoods was done by applying concepts such as assets, perceptions, and social networks.

Such an investigation necessitated a period of fieldwork, ${ }^{47}$ principally involving going to rural villages in the Turkana District to talk to and document the voices and views of the Turkana people: men, women, and children who possed first hand experience of the crises. Following Strauss and Corbin (1990), Kanbur (2001), and White (2002), complementary qualitative and quantitative data were collected. I predominantly applied a qualitative $^{48}$ research strategy to explore perceptions and gain deeper insights of specific issues, and to address the institutional context of livelihoods and changing livelihood responses to growing difficulties at both the household and community level (Salkind 2003). A quantitative method was used as a means to document repetitive patterns of interest to the study, and to summarize assets and activities. The quantitative data were also intended to increase my understanding of the range of situations

\footnotetext{
${ }^{47}$ My thesis fieldwork was conducted in the period from early February 2007 to the end of July 2007.

48 This study supports Kane's (1995) argument that qualitative methods are participatory in nature and seek to understand the reality of the situation from the actors' points of view. In addition, a qualitative study implies an in-depth study that utilizes a variety of data collection techniques, which envisages the holistic nature of the data.
} 
and the degree of variations (or homogeneity) within and between the villages chosen. Pictures were taken to give an extra dimension to the written information and to make the thesis attractive.

Throughout the research, the household $(a w i)^{49}$ is used as the major unit of analysis and comparison, and not the smaller mother and children unit (ekol) which is often incorporated into a larger awi. Traditionally, Turkana pastoralists shared their daily meals in the awi (Wienpahl 1984). Although households (awis) may also form larger groups 'neighbourhood' (adakars), matters relating to food security are still decided at household level as it (the household) is the main production and consumption unit. 50

\subsection{Selection of the study area.}

As already discussed in chapter 1, I had selected the research area and topic before starting a PhD program at Victoria University in 2006. Having been a government officer in the Turkana District in 1999, I came to realize that the district is one of the most marginalized regions in Kenya, and has experienced serious food shortages since colonial days. I learnt that one of the major causes of famine in the region is drought, and it was my own conviction that more needed to be done to strengthen the resilience of the local people to drought and famine. I observed that this could be achieved through research of this nature.

A long spell of drought period from 2005-2006 which led to serious national food shortages in the Turkana District made this study possible. The Turkana District was reportedly the most affected district in Kenya by 2005-2006 drought and famine (UNICEF 2006).

\footnotetext{
49 For detailed description of the Turkana 'awi' and its role as a production and consumption unit, refer to the discussion in Chapters 4 and 5 .

50 For this reason therefore, much of the primary data used for this study has been collected from the household unit.
} 
However, it was not possible to generalize about the impact of drought and famine on local people's livelihoods across the Turkana District, because conditions and problems tend to be very location specific. This follows Zoomer's (1999) argument that there is need to consider structural components while analysing people's livelihoods. She argues that structural components such as geographical settings, whether rural or urban, and different agro-ecological zones such as mountainous regions, distance to markets, and demographic structure, influence the set of opportunities and outcomes of the actor. For instance, the impact of 20052006 drought and famine was not the same in all areas in the Turkana District, as some areas were worse affected than others. Based on this fact, I selected two contrasting villages (Morulem and Lokichar) in southern Turkana, of varying social environments. ${ }^{51}$ The two sites were not only reportedly hit hardest by 2005-2006 droughts and famine, but both also had a large number of famished pastoralists being fed by the Turkana Rehabilitation Project Management (TRPM). At the time of the survey, the feeding programme had been running for almost six months, the first consignment of famine relief food having reached the sites towards the beginning of September 2006.

Morulem is located approximately 180 kilometers south of Lodwar (district headquarters). Morulem experiences an average daytime temperature of 38 degrees Celsius with very limited rainfall for most of the year (Republic of Kenya 2002: 8). When it rains, it falls in torrents, washing away the planted seeds and much of the grass and therefore has very little pasture for animals. Consequently, Morulem is purely a pastoralist area. Residents have to walk long distances to access water in view of the low water table. Other infrastructures such as roads are in equally bad condition. For example, the road from Lokichar to Morulem, which is the only access road, is completely impassable when it rains (Republic of Kenya 1999).

\footnotetext{
51 See the location of these two study areas in Figure 1.
} 
The reasons for choosing Morulem as a study site are threefold: Firstly, it was very dry compared to other areas in Turkana. Secondly, its remoteness from any major population centre made it an ideal location for making observations on how 'pure' pastoralists adjust to drought and famine on their own presumably with little initial outside help. The inhabitants of Morulem are part of the Ngibelai territorial section of Turkana. It is a purely rural environment with a relatively homogenous community. Thirdly, Morulem has hardly any of the facilities Lokichar enjoys; it is more or less a wilderness. At the time of the study, there were four poorly stocked and almost broken-down shops and a primary school. Apart from the listed facilities, there is very little else that might be described as modern. The shops rarely carry more than maize meal, beans, and local meat. Famine relief recipients remained in their usual homes (Manyattas).

Lokichar is located approximately $70 \mathrm{~km}$ south of Lodwar town and about two and half hours from Morulem. Like Morulem, it also experiences high temperatures of about 38 degrees Celsius with very limited rainfall most of the year (Republic of Kenya 2002: 8). Lokichar is more influenced by Kenya government administration and ministries. It has a police post, six shops, mostly run by Somali people, and two government primary schools.

The site was chosen mainly for comparison purposes in the hope that data collected there would show differences from Morulem in adjustment to the 2005-2006 drought and famine. The section of Turkana around Lokichar, like their Ngibelai neighbours, belongs to the Ngisonyoka territorial section. They are also traditionally 'pure pastoralists'. However, the assumption in selecting the Ngisonyoka for the study was that, owing to their closeness to Lodwar town and to the economic changes occasioned by the introduction of Lodwar-Kitale highway in 1985, they have been exposed to modern life styles. Lokichar is a centre of a communication network linking the Turkana District with the wider society. It seems to 
posses all the trappings of an emerging urban centre. Lokichar was therefore seen as presenting a different socio-economic environment to influence adjustments to drought and famine.

In summary, the choice of the two sites, Morulem and Lokichar, was determined by the need to find affected Turkana households whose experience would be recorded to help answer the research objectives. Additional care was taken to include in the survey both rural and urban environments for purposes of comparison.

\subsection{Sampling of informants.}

Sampling can be defined as the process of selecting a representative set of cases from a much larger set (Ragin 1994). There were two kinds of data sources in this study which required sampling. These were the household surveys and key informant interviews. A random sampling method was used to select the respondents. The Turkana Rehabilitation Project Management (TRPM) kept registers of all the Turkana households (awis) at each of the sites. These were the registers used to prepare the sampling frame for the interviews.

Sampling households: Since there were large numbers of households at each site living roughly in loose clusters, a multi-stage sampling method was chosen as the best way of selecting the respondents ${ }^{52}$. The units of analysis were the household (awi). The households were listed as they appeared in the records held by the Turkana Rehabilitation Project Management and sampled. The purpose of this method was to avoid bias in the sample, and to steer me to households throughout the research sites. Households studied were randomly selected. Details are shown in Figure 5 below.

\footnotetext{
52 Bryman (2004) asserts that multi-stage sampling is preferably used whenever the aim is to interview a sample that is to be drawn from a widely dispersed population such as national population, or a large region, or even a large city.
} 
Figure 5: Total households in each village and sample size.

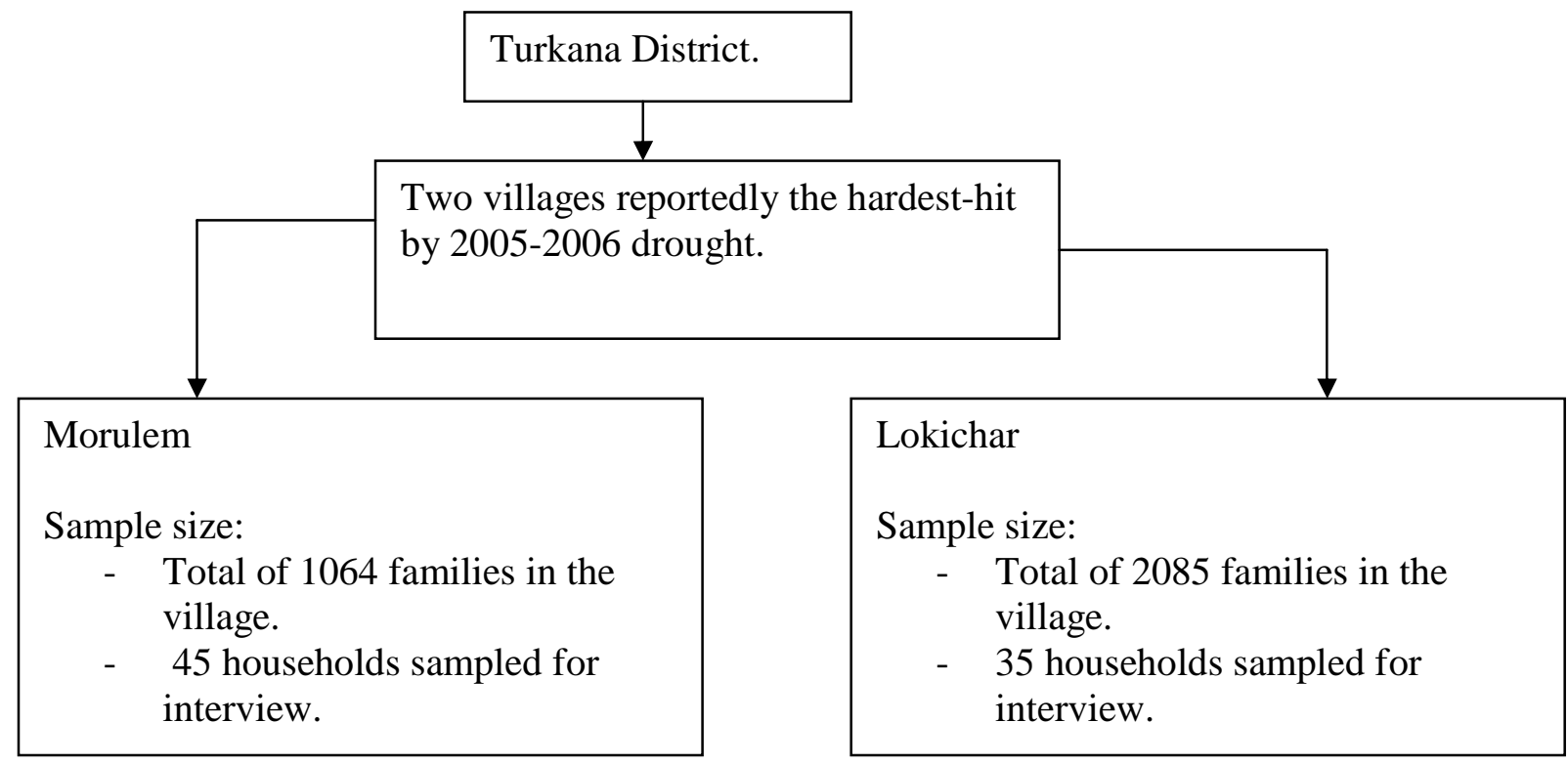

Source: Author 2007.

\section{Morulem}

There were approximately 1064 families. They were living at the site in six distinct clusters.

Sampling stage 1: The six clusters were given numbers 1-6. Two of the numbers were picked at random: numbers 2 and 5 .

Sampling stage 2: All the households in clusters 2 and 5 which had fallen into the sample were listed as they appeared in the registers held at the Turkana Rehabilitation Project office. Once the sample frame was ready, respondents were selected for the study (using a paper and basket method). I began by assigning numbers to all the households on the sample frame. The numbers were then written onto separate pieces of paper and folded. All the folded papers were thereafter put in a basket that was later shaken thoroughly. Numbers were then drawn from the basket, one after another, until the sample size was reached. A random sample of 45 households was picked at Morulem. 


\section{Lokichar}

There were approximately 2085 families. They occupied a fairly extensive area but there were ten distinct clusters. As already mentioned, they were living in their usual (Manyattas) homes. The sampling was done as follows:

Sampling stage 1: The ten clusters were given numbers 1-10. Two of the numbers were picked at random: numbers 3 and 7 .

Sampling stage 2: All the households in clusters 3 and 7 which had fallen into the sample were listed as they appeared in the registers at the office of Turkana rehabilitation Project. The sample procedure used at Morulem was repeated here. A random sample of 35 households was picked at Lokichar.

The total sample size for questionnaire interviews was therefore 80. It was originally designed that a sample of over 100 respondents would be picked for the interviews. However, for reasons which will be discussed below, the sample was made smaller for intensive interviewing and cross-checking of responses. The samples interviewed were considered representative of the pastoral community in the study sites.

In practice, however, due to the fact that Turkana pastoralists are normally mobile, I was prepared to repeat the sample process to select another household within the same sample area if a sample household had migrated, 53 but nevertheless, I found the main sample community to be intact. There were also other contingency measures in place. For example; if an entire sample community had moved out of the area, a new sample area was to be selected.

53 In such a case, efforts were to be made to follow the sample community that had migrated to their new destination, and continue interviewing them there. In cases where this was not possible, for example due to long distances being involved, a new sample community was to be selected. I did not experience any problem with my original samples. 
Sampling key informants: There was no sample frame prepared for the selection of key informants. During the reconnaissance survey, I established rapport with many villagers, and, through observation, informal meetings, interaction and discussion with various groups of people in market places and in other social places, i managed to identify eight key informants. Key informants are people perceived to have particular insight or opinions about the topic under study. They may be ordinary people and not necessarily the specialists, the better educated, those in power or the officials (Mikkelsen 2005). In my study, the main criteria for selecting the key informants were their ages, especially the old, (65 years and above), and those assumed to have extensive knowledge of the Turkana cultural practices related to drought and famine, both today and in the past, and lastly, their length of stay in the study site.

A total of eight key informants were identified from the villagers on the basis of the criteria as set above. Five were interviewees at Morulem and three at Lokichar. The ones interviewed were those willing to volunteer relevant information to my study. They were interviewed in-depth on the cultural history of the Turkana, and the traditional modes of adjustment to drought and famine.

\subsection{Data collection techniques and their limitations.}

The approach adapted in this study views research as a process of interaction between theory and methodology. According to Crosbie Walsh (2005: 93) "methodology is a means for generating data to be used in testing hypotheses which derives from theory where applicable, the testing of the hypotheses leads to recasting of theory and emergence of new theoretical paradigms". Similarly, Mikkelsen (2005) argues for a closer relationship between methodology and theory. According to her, advancing 
a set of hypotheses, which data generated by a given methodology cannot test, would be a futile exercise.

This study used a variety of data collection techniques and sources of information to collect both qualitative and quantitative data. I applied multiple strategies, or triangulation. Different methods were used, and different people were asked the same questions in different settings. This reduced the chances of ending up with biased interpretations.

Initially, I was meant to use participatory rural appraisal (PRA) exercises at selected research sites. While in the field, I realized that it was very difficult to organize Turkana pastoralists to come together because of their nomadic nature. Therefore, I decided to use four main sources with an understanding that data collected would help in answering the research questions. This complied with Mikkelsen's (1995: 223) argument that "methods should not become straitjackets" and it is the objectives that should guide one to choose the methods, and not the other way around. The main data sources drawn upon were: documentary search, observation and informal interviews, key informant interviews, household surveys, and case histories and mapping. These methods and their limitations are elaborated as below:

\subsubsection{Documentary data.}

Mikkelsen (1995: 74) writes "no matter what your research topic is there is almost always a wealth of information hidden in a variety of sources". For this thesis, published and unpublished research and reports on historical, socio-economic, cultural, political, ecological, national, and area-specific issues have been reviewed, and both used as background information, and to strengthen presentation of findings and analysis. The main source of secondary data was library and archival research. 
Library research was carried out at Nairobi University, Kenyatta University and Kenya National Library in Nairobi. Other resource centres visited included the Turkana District Information Centre, Turkana Department of Survey Office, Turkana Rehabilitation Project office, and the Ministry of Lands and Settlement Offices in Nairobi. Documents read in these libraries included books, journals, newsletters, newspapers, manuscripts, theses, and magazines. I studied accounts from historians such as Lamphear (1976) and other researchers such as Gulliver's (1951, 1955) work on the Turkana from the 1940's to 1950's. From these documentary reviews, I identified key themes that had been tackled by various previous researchers, and noted the existing gaps in knowledge. I was able to construct a proper context of my study in view of the knowledge gathered at this level.

I also conducted extensive study of the archival records at the Kenya National Archives in Nairobi. The colonial government had kept reports on social and economic life in the Turkana District up to the 1940s. These are now open to the public for reading. Various report papers and files relating to the vulnerability context in Turkana and the socio-economic history were studied. Of particular interest were records which pertained to drought and famine in the district and how their adverse effects were managed during colonial and pre-colonial days. Through these records, I realized that famine has been a persistent problem in the Turkana District for decades, and that the first fully recorded famine was in 1932. The government responded to it by providing money for famine relief.

Archival records had a number of limitations. Firstly, the records tended to blame the Turkana way and their way of life (nomadism) as the main cause of famine, and concluded that if they could abandon nomadism and settle down as cultivators, they would never again experience recurrent food shortages and famines. Secondly, the records said absolutely nothing on 
how the Turkana themselves managed the situation of drought and famine.

\subsubsection{Observation and Informal Interviews.}

The limitations of the archival records on the history of the Turkana adaptation to drought and famine made it necessary to talk to the Turkana themselves and learn from them. Therefore, much of the study time prior to the household surveys was taken up by visiting the selected sites for the purpose of observation and informal interviews. This was necessary to make myself known, conceptualize the problem on the ground, and consequently to plan for intensive formal interviews.

Due to the fact that areas around my research sites were operational areas namely areas of insecurity due to raids and counter attacks staged by their neighbours (Pokot cattle rustlers across the borders), it was found advisable to work in close collaboration with local leaders' in terms of movement and residence.

The local chiefs from the two sites (Morulem and Lokichar) accorded me all the necessary help. They personally took me around their respective areas of jurisdiction and introduced me to the locals and other influential people within those areas. When they could not travel with me, they made sure one of the clan elders would take me around. I visited quite a number of households. I was introduced to the people as a PhD student in Development Studies at Victoria University of Wellington, New Zealand, doing research on 2005-2006 drought and famine, and how the Turkana coped on their own. The villagers didn't have any difficulty in welcoming me. The Turkana nomads only have difficulties with neighbours who are perceived as interested in raiding their livestock. I was welcomed and asked for tobacco. 
Once I had found somewhere to live for my initial two weeks, I spent much of the study time with the villagers, talking to them and making observations. The Turkana men speak a little Kiswahili (Kenya's national language) and school children speak some English. This helped occasionally in communication. However, I identified two male Turkana research assistants, and friends who could speak both English and Kiswahili to help me in interpreting some of the words. During the course of data collection, I could intermittently engage a female interpreter when I planned to interview a female respondent. However, I made efforts to pick up a few words in the local language. This was relatively easy since the Turkana speak a version of my mother tongue (dholuo) and many words in the two languages (Ngaturkana and Dholuo) are mutually intelligible ${ }^{54}$. As long as esoteric matters were not the topic of conversation, it was therefore quite easy for me to get the general drift of a discussion in Ngaturkana.

This period of familiarization and observation was crucial as it was during this time that the study took shape. The issues to be investigated through future questionnaire interviews were selected from the experiences gained during this early period. Since I had only lived and worked in Turkana as a government officer and had never carried out research with nomads before, I had to learn what the most effective method of interviewing them was. I was therefore learning as I stayed and discussed various subjects with them.

Although observation and informal interviews were useful in introducing me to the pastoral life style, it also helped me to gain extensive background information on the drought and famine problem and helped sharpen the focus of my study. This method also had its limitations. Firstly, the respondents were not systematically selected. We just happened to live together and talk. Secondly, the issues discussed were never entirely controlled. A topic would come up and be discussed spontaneously and

\footnotetext{
${ }^{54}$ See appendix 4 for some of the pairs of words in Ngaturkana and dholuo.
} 
was discussed there and then. Therefore, data generated in this way left a lot of gaps in the subject of response to drought and famine. Thirdly, the data generated through observation and informal interviews was not enough to bring out completely, the Turkana people's cultural interpretation of drought and famine, and how they currently cope with such conditions on their own within their network ties. There was then a need for a more systematic data collection technique specifically designed to explore the adaptation phenomenon.

\subsubsection{Key Informant Interviews.}

To assemble systematic information on the history of drought and famine, cultural interpretation of drought and famine and modes of adaptation in the past and today, eight key informants were identified and interviewed in-depth. This investigation was conducted in informal semi-structured interviews with general topics and open-ended questions. Mikkelsen (2005) points out that with a semi-structured interview, everything is negotiable and the informant can criticise, correct, or point out that it is sensitive, or answer in any way they wish. During the data collection, the semistructured technique allowed me to follow my interests and ask follow-up questions in order to get a deeper understanding of local people's behavioural patterns during crises. Questions were asked according to a flexible checklist or guide (see Appendix 3). ${ }^{55}$ A framework for analyzing Turkana pastoralist's adaptation to a dryland situation with special response to drought (see Figure 4), and a framework for micro policy analysis of rural livelihoods (see Figure 3), were used as a guideline when establishing the checklist. 56

The interviews were expected to generate expert information about the two research sites based on the research objectives. Fourteen days of intensive

55 The livelihood configurations discussed in Chapter 2 were subsumed into the key informant and household interview schedules.

56 The two frameworks were also used in the form of a household questionnaire. 
interviews (nine days for Morulem and five for Lokichar) generated quite an amount of interesting information on the subject. I was able to capture qualitative information that enriched the survey and enabled me to clarify certain issues touched upon in the questionnaire, but which required to be elaborated on so as to reach plausible conclusions on the findings. My two research assistants assisted me in interpreting whatever I could not understand properly. I cross checked the data I collected by interviewing all my key informants on the same topics.

The challenge I experienced in the beginning with the key informant interviews was that, when I asked them questions, some would give me an answer that they assumed I wished to hear. However, I was fortunate to have trustworthy research assistants, who knew the respondents well and had many relatives in the study community. Sometimes, after an interview, my research assistants would tell me that the respondent was not telling the truth. After a while, I would take the opportunity to comment and confront the respondent with the answers he/she had given me. My response made them realize that I was in search of genuine answers hence the need to be truthful.

When an interview session was over (this is applicable to household interviews also), I would ask the respondent if he or she wanted to add something, and also ask for permission to come again in case I needed more information. This question gave the respondent an opportunity to discuss things they considered important for them to focus on.

One of the key informants, an old man (a mzee) of about 75 years old living at his Manyatta at Lokichar village, had a lot of cultural knowledge. I spent about two days with him discussing and recording information about drought and famine in Turkana and people's religious practices in response to these calamities. For the first time, I had the opportunity to visit a Turkana religious shrine (A Kipeyare or Amurunet) where, at the 
height of the drought, sacrifices were made to the high God $(a k u j)$ at the instruction of the regions high priest or diviner (Emuron).

\subsubsection{Household interview.}

Even though I refer to the Turkana people in previous chapters as 'rural people', the 'vulnerable people', the 'poor people', or men, women and children, I am fully aware of the danger of presenting people as a homogenous group. I chose the household interview method because I fully recognize that the informants are individual actors with different experiences, status, needs, and motives. I also acknowledged that within my research domain, it was important to be able to categorize individual people's experiences, behaviours, and values to be able to say something general about the specific group of people I was researching, and their livelihood. This conforms to conventional livelihoods literature where a household is usually regarded as the suitable social unit for livelihoods research (Mikkelsen 2005; Bryman 2004).

To be able to systematically select the interviewees (informants), I found it prudent to get the local definition of the term 'household'. Ellis' (2000: 31) recommends a clear definition of a household while studying livelihoods of rural people. He states "a household may represent a barrier to understanding interaction between individuals and group identities if unnecessarily narrow, unitary and static view of household, its composition, and the roles of its individual members are taken".

The concept of a 'household' is a fairly contested and complex term, and defining it may not be as straightforward as it seems. No matter which definition one decides to use, it may not be applicable to all societies and cultures. The specific forms and characteristics of households often depend on context, a combination of social and cultural norms and economic incentive (World Bank 2001). The way in which households are 
constituted changes in response to demographic and economic change, as well as changes in norms (World Bank 2001). According to Eriksen (1996), the most frequent definition of the household is relatives who live under the same roof, and regularly eat their main meals together. However, the character of 'live under the same roof' may not be very essential because the living arrangements vary throughout different communities. In some communities men and women do not share the same domicile. The household is sometimes composed of a nuclear family with details; husband, wife, and children, and is other times a compound family with details; husband, wives, and children.

For instance, households in Turkana are not as typical as in Eriksen's definition above. Since there are great seasonal variations and combinations concerning who shares food with whom in Turkana society, this definition may be too narrow to identifying a discrete unit on which a consistent analysis can be built. For instance, in Turkana society, the household members eat their main meals from the same pot but not together; women and girls eat separately from men and boys. 57 Secondly, polygamy is common and wives may either live close to each other or scattered. The husband may stay permanently at one of his wives' houses or can move around between them. It is also common for members of the nuclear family to follow grazing cattle and live in cattle camps while some move back and forth between their houses in the villages and the cattle camps. In the cattle camps, the units living together are not the same as in the village, and people who do not share the same house in the village can share food and sleep together in the camp.

A key informant, an old man aged 80 years from Morulem village, defined what, to us, a household stands for in Turkana society. His understanding of 'household' was shared by a number of respondents interviewed. They stated as follows:

57 Mother-children unit is what is refers to ekol. 
A household in the Turkana community is a single unit formed by a group of persons (family or closely related people) living in the same physical homestead when they do not live in the cattle camp, answerable to the same head, sharing the same granary and food from one pot, and money from the same purse (they may have different sources of income but they combine their income to share a common 'purse') (Household Interview $4^{\text {th }}$ February 2007, Morulem village; Household Interview 14th March 2007, Lokichar Village).

\subsection{Preparation for the interviews.}

Household interviews were the main source of both qualitative and quantitative 58 data used in answering my research questions. The head of each household was interviewed in-depth. Where possible, the rest of the members in the household participated to supplement information. In my study, a household was referred to as male headed when the husband, or the man who has inherited the woman, has regular contact with the wife/or widow and takes part in decision-making in the household, i.e. he lives in the same area, either together with another wife or in cattle camps, or temporarily away. A household is female headed if the woman does not have any, or only sporadic, contact with the husband or the man who has inherited her. 59

The timing of the household survey had a number of methodological justifications. First, the drought had lasted for nearly two years and its effects had been felt within the household and at an individual level. It was therefore the ideal time for the people to tell of their own experiences and how they had responded on their own to the 2005-2006 drought and famine, before any livelihood support reached them from outside the community. Secondly, I had already gained enough experience with

\footnotetext{
58 I will present the analysis of quantitative and qualitative data in Chapters 6 and 7.

$59 \mathrm{~A}$ woman whose husband is dead or displaced, or who is divorced and taken care of by another man is assumed to have been inherited.
} 
interviewing the Turkana pastoralists informally during a reconnaissance survey, and this had helped me to gain enough confidence to conduct more intensive interviews. Thirdly, documentary data, observation and informal interviews had made it possible to sharpen the focus of the study, and enabled me to redesign and update the original interview schedule.

During the household survey, I used a one page questionnaire (see appendix 1) for the bio-demographic data. It was useful to have this data in hand while I proceeded with the rest of the interview. The rest was a structured interview with some open-ended questions (see Appendix 2).

\subsection{Pre-testing of questionnaire.}

The first interview task was to pretest the questionnaire. The original interview schedule had been prepared in advance while still at Victoria University of Wellington, aided by the help of some guide points generated from 'Rural livelihoods and diversity in developing countries' (Ellis 2000), and 'measuring social capital: an integrated questionnaire' (Grootaert, Narayan, Jones, and Woolcock 2003).

The pretesting interview task was done on my second day at Morulem village. I visited one cluster of homesteads and randomly selected six households. The household heads of those six selected households were interviewed. It took six days to complete the interviews.

From the result of the pre-testing interviews, it became clear that it was very difficult for the nomads to honour appointments, and interviewing one household could take even more than two days. This made it necessary to arrange the interviews in such away that they could be conducted at different times of the day, depending on the availability of the respondents. Secondly, I realized that the questionnaire was rather too long. The interview was expected to take less than one hour per household, but it 
took between two and two and a half hours. Therefore, the questionnaire had to be shortened. Thirdly, I learnt that some questions were never answered at all by anybody, while at the same time; particular questions were popular with everybody. It was also noted that some questions were not relevant in answering my research question. The questionnaire was therefore streamlined by removing those questions which were ineffectual. At least twenty five key questions were identified that had generated useful data from all the six respondents during the pretesting of the questionnaire. These questions were used to design a new interview schedule. The questions were designed in a structured manner but still interviewees could pursue interesting answers. ${ }^{60} \mathrm{I}$ utilized the interview guide approach, making the interviews flexible, conversational and situational.

It is worth noting here that questions number 25 and 11 , under the household and key informant schedules respectively, were meant to elicit information about the community perception of wealth and poverty ${ }^{61}$ (see appendix 1 and 2). Since I could not bring the pastoralists together in a group to discuss their wealth statuses ${ }^{62}$, it became very difficult for me to ask how they differentiated or categorized themselves. All my respondents, however, volunteered information that was quite relevant to this study. Initially, I felt that asking each and every respondent directly about his/her wealth status and that of other members of the community was an impossible task. Thus I would move around the issue and ask why there were some families were popular and known by every one, while others were not. The answer to the question also depended on the household I was talking to. For example, some households answered the question

60 According to Salkind (2003), interviewees should be allowed to respond to interesting answers to enable a full exploration of the subject at hand.

61 The study adapts Chambers (1995) definition of poverty as lack of physical necessities, assets and income.

62 Wealth ranking is normally done through group discussions and assist in getting the sample. In this study, wealth ranking was not intended for getting the sample, so I got the information from each and every respondent. Though this was a unique method, the data acquired was sufficient in answering the question. 
directly and gave me the reasons why $\mathrm{X}$ was rich and $\mathrm{Y}$ was poor, while others could only talk about themselves.

Another challenge was lack of privacy when interviewing the household heads. This came about because the people were crowded within the clusters and many people were always around either just listening or occasionally joining in the interviews completely uninvited. For instance, when question 17 was asked (see Appendix 2) "were there any human losses you know of due to starvation?" There would be chorus answers "Yes, many etc". This came from even neighbours' who were passing by.

Yet to maintain the rapport which had been established between the interviewees and me, i could not stop them talking, as to do so would be to cut the flow of potentially useful information. My earlier stay with the Turkana nomads while working as a government officer in 1999, and during my reconnaissance survey, had taught me that Turkana people are good talkers when properly motivated, but become completely withdrawn at the slightest suspicion that you are unhappy with the way they conduct themselves. Similarly, I could not pull someone aside to interview privately. Such an action would be highly suspect and I would have risked being called anti-social or even an enemy (amoit) who wanted to do harm to the person pulled aside. I could have been isolated, and that would mean the end of my interviews with them. So, I proceeded cautiously. Sometimes I noticed that while interviewing a respondent, someone whom I had just interviewed a short while ago or on the previous day was sitting quietly close by and occasionally making gestures as questions were asked and attempts were being made by the respondents to answer them.

The sum total of the experiences gained during the pretesting phase was that, in order to minimize negative effects, I had to find new approaches to the interviews. Absence of privacy in particular seemed to contribute to the 
high proportion of uniform answers provided in the course of the six pretest interviews.

\subsection{Household Interview schedule and supplementary questions.}

To avoid repetition so that those who had already been interviewed did not unduely influence subsequent responses, I found it necessary to scatter the interviews over a much wider area. I also attempted to resolve this problem by reducing the sample size and by interviewing the few households selected, both intensively and extensively, to help cross-check the responses on the spot. More importantly, a large number of supplementary and probe questions were used. It was therefore critical to interview not more than one person per day. I took seventy days to complete the 45 interviews at Morulem and another fifty days for the 35 interviews at Lokichar.

Direct observation was also done alongside the interviews. Observation had a function of giving me a broader picture than what was obtained during interviews and helped in filling some gaps of information. I used my eyes as a data collection tool. I observed structures in the study areas such as family houses, homesteads, livestock sheds, boreholes, and family tasks in relation to livestock. This enabled me to confirm to some extent the socio-economic activities of the households, and to get a clearer picture of the local people's dependence on pastoralism as a livelihood source. But, I cannot say I practiced 'participant observation' in that I did not carry water and firewood or herd goats with the people. It took most of my energy to walk to all my sample households. Although walking was not my first choice as a means of transport (I could not afford a vehicle), it actually provided me with hundreds of observations and opportunities to be closer to the people. It also released me from the image of wealth and power that 
a vehicle could bring to a rural part of Kenya, and instead added the interactive element of begging for rides and favours. 63

The core questions centred on the vulnerability context and the social economic status of the study areas, the impact of the 2005-2006 droughts at both the household and community level, assets, and local people's livelihood strategies and capabilities. The questions also aimed at eliciting data on how the insurance systems of reciprocity and symbiosis worked during the 2005-2006 drought and famine period. Further information was sought on environmental perception, cultural practices associated with drought and famine, and the role of the high priest or diviner (Emuron) in rain making practices to avert droughts and famine. These questions finally helped to generate the data needed for the subsequent analysis of human response to drought and famine among the faminished Turkana nomads.

\subsection{Reliability of household interview data.}

As I proceed to analyze my data using survey sources, two main limitations emerged: First, the sample size was not big enough. However, as already noted above, it was necessary to have a small sample to interview in-depth rather than a large one which could not be handled profitably. Furthermore, this data limitation was compensated for by the fact that there were several other supplementary data sources to which I had access to check my findings.

The second limitation with the survey had to do with the interview environment. I got the impression that once people start depending on famine relief, their attitude towards life and the people around them

63 However, visitors are always perceived by many Turkana pastoralists as ones who have come to help and give, and their indigenous begging from each other is easily extended to visitors. I did not give away much at the beginning to avoid elevating expectations and increasing a crowd at my doorstep. My practice was to give tobacco to those who requested it, at the end of each interview. 
tended to change. They viewed themselves as helpless and had to relate to others in a way that would not jeopardize their chances of survival. I got the impression that the interviewees' responses to questions somehow become part and parcel of their response to drought and famine predicament. For instance, I became quite convinced, as I carefully looked at their response to questions about the impact of drought, that the people quite deliberately exaggerated their livestock losses to project a seriously gloomy reflection on their socio-economic status. My respondents, if not all, viewed this as an opportunity to determine the level of destitution for the purpose of removing the better off from the famine relief lists as if they stood to gain by exaggerating their livestock loses. For example, when the question was asked: "How many animals did you lose in the 2005-2006 droughts?" the answer would be: "I lost everything" (Household Interview $11^{\text {th }}$ February 2007, Morulem village). Nobody really wanted to volunteer information about existing livestock wealth. Projecting misery was erroneously thought of as a means of increasing the household chances of getting better treatment when food is distributed. They were all complaining of being cheated out of their rightful share of food which came either too little or too infrequently. This scenario forced me to continually explain to each and every household interviewed that I was simply a student carrying out research, the content of which will be analyzed for writing an academic thesis, and that it had nothing to do with the availability of relief food. The use of other data techniques also helped to verify the information acquired.

The question of numbers was really a big problem among the Turkana people. Responses to questions about numbers presented some difficulties because the Turkana nomads have a peculiar system of counting their livestock. For instance if a man was asked: 'How many goats did you have before the drought?". The answer would be: arei (meaning two). But when you sought to know where exactly the two goats used to forage, the answer was: one was at locality $\mathrm{Y}$ with my second wife and one was at locality $\mathrm{X}$ 
with my $3^{\text {rd }}$ wife. Obviously, it was going to be extremely strange that two goats belonging to one person should be kept singly at separate homesteads. Further questions were asked to elicit the actual figures. The man had 8 sheep and goats with the second wife and 15 sheep and goats with the third wife. From the first experience, I learnt that the Turkana nomads do not normally count their animals. They believe it is a taboo to do so, and may spell disaster. So, whenever they count, they would rather refer to groups instead of individual numbers. However, none of them seemed to mind if I counted the animals myself. ${ }^{64}$ The whole exercise of trying to ascertain the exact size of family herds before, and after the drought thus became painstakingly tedious. I had to cajole and prod to get any quantitative data from respondents.

\subsection{Case histories and mapping.}

I did not intend to use case histories or mapping as a source of qualitative data. Information emerged naturally from the responses to supplementary and probe questions during the survey interviews. Most of the data gathered through case histories were recorded in the form of field notes and maps. ${ }^{65}$ Therefore, mapping was only used to a limited extent of visualizing people's movements, and their interactions with relatives or other people outside the community during the 2005-2006 drought and famine.

Individuals interviewed described how they used to survive during the drought and famine. A number of them told of their journeys to Ethiopia in search of food or about having sent their sons or wives out to fetch it. Others retold their migration histories upcountry to other major towns in Kenya, such as Kitale and Eldoret, and back when famine relief food was

64 It is generally true that Turkana people do not count animals, but know them individually. My research assistants made attempts to count the animals in the grazing lands due to their geographical knowledge of the area. It was also easy to count the animals as they were led out in the morning and corralled at dusk.

${ }^{65}$ Some of the maps will be displayed in chapter 6 while presenting the research findings. 
brought in by the government. For instance, one respondent related how the family migrated from the Lokwanamur area down the vast central plains to Lokichar. When the family was faced with serious food shortages on the way, he was forced to prematurely marry out one of his daughters to a 'rich' herdsman in exchange for food. Two of their children remained behind with the newly married sister, as the custom requires in order to keep her company. The family now had enough food which lasted many days as they travelled south. At the time of the interview, the two children were still living with their sister at Lekudule, a few kilometres north of Kakuma town. The parents still visit them occasionally.

Yet another interviewee told of the story of his trek from the Sudan border, down across Turkana land and West Pokot to Kitale town, to look for employment. There were many such stories whose content analysis helped me to gain valuable insight into the adaptation phenomenon, and also enriched the amount of data available.

\subsection{Notes and data recording.}

In my study, I used two different recording techniques to collect the data:

Note taking: Note taking was the most frequently used method to record data. My notes included the names and ages of the informants and the dates and places of interviews. Notes were taken during the formal and informal interviews and elaborated later. A careful crosschecking of interpretations of what respondents said, or how they understood their own or other people's words, was ensured. After each interview session, I would sit down with my two research assistants, and review what we recorded and saw. In addition, I would revise my daily work and write down full notes at the end of each day. This included all the interviews I conducted or participated in during the day, those whom I interviewed, what I observed in relation to my study, and my comments on the 
interviews and/or interviewees. There are some cases when the method appeared time consuming, reduced my concentration with the respondent and surrounding, and when i could not probe promptly where necessary. In these cases, I had to supplement note taking and use an audio recorder.

Audio recording: According to Bryman (2004), recording of conversations and interviews is to all intents and purposes mandatory if the approaches used entail detailed attention to language, such as conversion analysis and discourse analysis.

This study used audio recording as a method, but it was employed cautiously so as not to affect the progress of my research. For example, after conducting one household interview where I used an audio recording, the respondent went outside and called one of my research assistants and asked him nervously in his mother tongue (Ngaturkana): "Are you sure he is just a student or will he take my answers to relief food officers in Lodwar, I told him every thing...." (Household Interview $8^{\text {th }}$ April 2007, Lokichar Village)

To avoid such a reaction, respondents were informed in advance of the use of an audio device, shown the gadget, and I requested permission to use it to record the interview. This device gave me an opportunity to record for many hours continuously, and to catch up with what I had missed during the interview session. One disadvantage with this type of recording was that it needed a continuous supply of electricity from batteries, and these were not readily available within my research sites, especially in Morulem village. Interviews were only recorded with a few of my key informants and household heads. 


\subsection{General reflections around the data.}

Logistics and time: The duration of the fieldwork was limited to five and a half months. The intention was to spend longer, but one week was lost at the beginning owing to the logistical difficulties of getting in and out of one of my study areas (Morulem). There was no regular public transport and because the roads were in such poor condition, it required a four wheel drive vehicle to get to the study area. My movements were then limited to whenever the lorries taking relief food to the research site (e.g. Morulem) were available.

Language: Although the national language of Kenya is Kiswahili, the Turkana people's version of Kiswahili was different from mine, and their spoken words were not readily understood by me. Also I realized that not all key informants and household heads had a good knowledge of Kiswahili. Therefore, I needed interpreters to act as research assistants. Getting a research assistant that had sufficient English skills was originally quite difficult, as the ones who did speak English often engaged in other activities, or had moved to Lodwar (districts headquarters) in search of jobs. However, the use of these interpreters made the interviews possible and the language differences were dealt with adequately.

Male perspective: The two research assistants employed were men. This reflected the fact that it is men who are most likely to travel outside the region, who make most decisions in Turkana society, and who frequently interact with outsiders regarding assistance, information, livestock exchange, and food sharing. According to informants, one of the reasons why Turkana women are excluded from decision making is that the men get their wives from 'outside' the clan. By being 'outsiders' and living among people who may look at them as an 'outsider', women's influence in decision making is limited. Informants also claimed that women's social networks are smaller than what is the case for the men. Men invest cattle 
in reciprocal claims and social networks, and thereby tie his family and clan with other families and clans. Due to these traditional beliefs, however, it became prudent to engage a female research assistant whenever I wanted to interview a female informant. This is because women respondents would be most reluctant to respond to my questions when I was accompanied by only the male interpreters.

Overall, due to these difficulties in talking to women as a male researcher, women were underrepresented in the research. Only 7 women were interviewed compared to 87 men. Therefore, I feel that the results and observations of this study may be male biased, as there is a possibility that the perceptions of the men who were interviewed might dominate responses. The results may have been different if more women were interviewed, for their social networks and views regarding household livelihood strategies may have been different from the men. It should also be noted that the respondents were adults and younger people, such as teenagers, were not included largely because they are not involved in household decision making and because they would not have had experience of previous times of hardship and famine in the same way that older people had.

Despite this possible bias towards men and adults, however, I believe that the interviews conducted were intensive and extensive enough to answer my research questions. The interviews with women did not reveal significantly different responses from the men and, in terms of understanding the decisions made by households in response to famine; it was the male (and adult) view that was critical because it is they who dominate decision making.

I was also positioned at my research sites as a Kenyan, educated and from a western country. This background seemed to have influenced the interviews in many positive ways, mainly by being close to my informants. 
Most people in the rural Turkana District had never travelled abroad, and they were curious about the western way of life. They had the notion of western people as a 'different kind of human being' who, because of their prosperity, never encountered problems of hunger, lack of education, and bad health. Therefore, they thought that I knew a lot of things since I was living in a western country. Some of the men would even talk to me about intimate issues regarding sexual problems such as family planning, condom use and HIV/aids, and would ask me for advice. Others would talk about their experiences and losses during cattle raids by Pokot neighbours. During the conversation, the informants would mention some details that they themselves did not consider as relevant to the interview.

Another feature of the small rural places where I did my fieldwork was that people tended to know each other. A few people would tell me horrible rumours concerning other villagers, but I decided not to let such talks affect my sense of judgment and my work. Most of all, I felt appreciated and welcomed in Morulem and Lokichar. Therefore, I did not feel lonely or a stranger. The discussions I had with the informants were an important process of learning about their views, perceptions, and attitudes regarding their livelihoods. In return, they also came to know me, and I became aware of the cultural prejudices I had held before undertaking the research.

\subsection{Data analysis.}

The study has mainly used qualitative analytic tools to organize, summarize, interpret and present research findings in relation to the study objectives. The analysis of the qualitative data was ongoing right from the field. I edited the work at different stages while out in the field during data collection. Editing each interview soon after it was conducted gave me a chance to get back to respondents to fill in missing information. After data collection, the field notes were first organized into categories and subjected 
to thorough analysis to eliminate any errors. This included rationalised selection of evidence after corroboration with other sources to ascertain authenticity and validity of information. I then edited them again for quality control purposes before developing a coding scheme. I coded the responses and assigned numbers to the categories. Thereafter, analysis was conducted within the context of the theoretical framework with the aim of searching for emerging patterns, themes, or consistency in ideas. The information was finally evaluated to determine its usefulness in answering the research questions. The facts and opinions heard from the informants are presented as well as author's own observations.

Quantitative statistics such as ages were also utilized to find out if there was any demonstrable difference in the impact of drought and famine in the two research localities (Morulem and Lokichar), and to generalize the study findings to the entire study population.

\subsection{Research ethics.}

My research fieldwork involved human subjects, and ethics approval permission was required by the Human Ethics Committee of Victoria University of Wellington in order to undertake research. An application for ethics approval with full details was submitted to the committee and the formal approval was received on $17^{\text {th }}$ December, 2006 (see appendix 6). It was after receiving the ethics approval that I preceded to Kenya for fieldwork.

Although my research topic was not sensitive in the Kenyan context, I was still of the opinion that some ethical issues and concerns could still be raised. It was therefore necessary to maintain a high ethical standard.

In rural villages in Kenya, getting a prior consent from participants for such kind of work is not altogether easy. Most villagers feel very uneasy, 
scared, or reluctant to give written consent. Villagers normally become very curious when asked for written consent. They don't have a clear understanding of written consent as it is not part of their everyday life. I didn't try to seek written consent because that may have discouraged them from participating. I therefore asked for a verbal consent from my respondents.

An information sheet explaining the purpose of my fieldwork was prepared in advance and sent to the respondents (See Appendix 8). For those who could not understand the contents of the form, my research assistants read and explained to them verbally in Ngaturkana. As stated above, the information sheet introduced me to the respondents as a PhD student in Development studies at Victoria University of Wellington, New Zealand, undertaking a research project leading to a thesis. I informed them that the project I was undertaking sought to inquire into the indigenous strategies employed by Turkana nomads within their respective social and economic backgrounds to cope with 2005-2006 drought and famine. They were requested to willingly share their insights on their practices, realities, and observations regarding their livelihoods in the face of drought and famine. Those not willing to participate were at liberty to withdraw any time without question.

In addition to the information sheet, I showed the respondents an introductory letter from my supervisor (see Appendix 7). The letter was also translated verbally into the local language (Ngaturkana). To develop their confidence during the interview, I continuously asked for permission whenever I wanted to take any photograph or use an audio recorder.

During and after the research, all data have been safely stored by me with reasonable security safeguards against loss, unauthorized access, use, modification or disclosure and other misuse. Only my supervisors and I have access to the information collected. That information will be kept by 
me for a period of two years to assist in data analysis and writing of the thesis. After two years duration, all the information will be destroyed and electronically wiped out. The confidentiality of the participants has been carefully protected. Specific personal information has not been used in the thesis.

\subsection{Chapter summary.}

In this chapter, an account has been given of the methodological approaches used in my study. It is apparent in the discussions that no single method could provide a holistic approach in understanding how the Turkana people adapt their livelihoods during drought and famine. Combinations of different methods were required, where each serves a different but complementary role within the overall research design. The research methods employed included: documentary review, observation and informal interview, key informant interview, household survey, and case histories and mapping.

I realized that the collection of information concerning drought and famine in rural Turkana District required a good level of trust between the researcher and the respondents. An informal discussion with villagers and local leaders during the reconnaissance period, prior to conducting formal interviews was used as a way of achieving this trust among villagers. Identifying research assistants who were resident in the area and already held in trust by village members was another way of overcoming this problem. Using different methods and asking different people the same questions was a means of ensuring reliability of the information collected. The use of open-ended questions was aimed at obtaining a deeper and clearer understanding of the livelihood responses of different groups, with different level of access and rights to socio-economic resources. A number of difficulties were encountered during the data collection stage. However, the data collected was comprehensive and sufficient to meet the research 
objectives. The chapter following is a critical discussion of the Turkana environment, its ecology, and the socio-economic and political resources. 


\section{CHAPTER 4 THE TURKANA REGION: HISTORY, CHARACTERISTICS, AND RESOURCES}

\subsection{Introduction.}

This chapter establishes the context of the study. The chapter consists of two sections. Section One explores the origin of the Turkana people before they settled in the Turkana District, and provides a general environmental and demographic background of the Turkana region. Specific information is given on the environmental context in which Turkana people make a living such as the agro-climatic zones, rainfall patterns, and demographic patterns. This is an important part of the discussion since Turkana pastoralists' livelihoods and their social relations configurations are affected to a large extent by the environment. It is argued here that the environment, in which Turkana households live, provides opportunities and limitations that influence their decision making.

Most ethnographic studies of nomadic people in East Africa emphasize the importance of environmental conditions and usually have an introductory chapter with a description (sometimes extensive) of the local and even regional environments (Asad 1970; Gulliver 1955). Gulliver (1955) also pointed out that any study of the Turkana people to a certain extent is an ecological study, in that their culture centres around the management and care of livestock, and must take advantage of all available resources. Gulliver states as follows:

In the Turkana district, there is such a notably harsh and difficult environment that its effect on social life is all-pervasive, inescapable both for the people themselves and for the observer of their lives and activities. For a proper understanding of any facet of Turkana socio-economic organization it is necessary to begin with an appreciation of the environmental limitations rigorously imposed on all social activities (Gulliver 1955: 16). 
Section Two provides an overview of the various socio-economic and political assets which overtime has influenced the development of different kinds of livelihood strategies in the Turkana District. 66 This follows Moser's (1998) argument that local people's vulnerability is closely related to asset ownership: the more assets people have, the less vulnerable they are and the greater the erosion of assets the greater the level of vulnerability. Watts (1983), Adams (1992) and Deveurex (1993) also point out that assets owned and productive diversity is strongly related with resilience and successful adaptation in Sub-Saharan Africa. In this section, two major issues are explored in relation to assets: access to assets as the key issue in the conceptualization of the livelihoods, and Turkana people's own capability of transforming the assets to improve their existing livelihood strategies. Here, livelihood is considered as holistic, including economic, and material and non-material aspects of well-being. Bebbington (1999) affirms as follows:

\begin{abstract}
A person's assets, such as land [cattle], are not merely means with which he or she makes a living; they are assets that give them the capability to be and to act. Assets should not be understood only as things that allow survival, adaptation and poverty alleviation; they are also the basis of agents' power to act and to reproduce, challenge or change the rules that govern the control, use and transformation of resources (1999: $3)$.
\end{abstract}

The information in which this chapter is built comes from an extensive review of several Turkana studies, as well as from discussions with key informants and household heads during my field study period.

\footnotetext{
66 As discussed in Chapter 2, it is the disorganization of the assets during crises that
} facilitate the search for various survival strategies by the Turkana people. 


\subsection{Brief historical background of Turkana people.}

The Lake Turkana basin has a long history of human occupation and is still a haven for archaeologists looking for evidence of early humanity. Trapped and fossilized in the silts of Lake Turkana are the remains of the earliest human ancestors - Australopithecus, Homo habilis, and Homo erectus. The following summary of Turkana history is brief; more lengthy descriptions and references may be found in Ehret (1971), Gulliver (1951), Lamphear (1976) and Ong'any (1981).

The critical question being asked here is: Who are the Turkana people? According to oral traditions the 'original' Turkana was the eastern vanguard of the 'Ateker,' groups of the eastern Nilotic linguistic family known as the central para-nilotes, which replaces the incorrect and misleading term 'Nilo-hamitic' (Lamphear 1976, 1992). Traditionally, tribal groups which share close linguistic ties with the Turkana are the Karamojong, Jie, Dodoth, Iteso, Ngangatom, and Toposa (Lamphear 1992) (see the location of these groups in figure 6). According to Lamphear (1992), these tribal groups were Turkana neighbours and inhabited the Korten-Magos hills in the present day Karamoja district of Uganda at the beginning of the $18^{\text {th }}$ century. During this time, they adopted a strong pastoral outlook and kept thoracic hump zebu cattle that permit long distance patterns of transhumance (Lamphear 1992). The massive migration of these groups to Korten-Magos hills led to serious ecological pressures, exacerbated by one or more serious droughts, and internecine feuds over pastoral resources (Lamphear 1992). The Ateker group broke into segments that were to form distinct linguistic groups such as the Karamajong, Dodos, and Toposa. Moving southwards from the KortenMagos hills down to the Apale River and to the northwest of the KotenMagos hills were elements of the Jie and the Turkana (Lamphear 1976). The Turkana later separated from their brethren, the Jie (now in Uganda), and expanded their territory in all directions, displacing the Toposa, the 
Dongiro (Nyangatom), and the Merille (referred to as Dassanech) in the north, the Dodoth (Dodos) and Karamajong in the west; the Pokot in the south and the Samburu in the southeast (Lamphear 1992) (see Figure 6). Displacement by the Turkana occurred over an extended period of time by exerting pressure on key opponents. In this milieu of change, some defeated groups were assimilated, while some were forced out, themselves exacting pressure on their neighbours and so on (Oba 1992).

Turkana traditions depict military activities during this period of expansion as small-scale raids and skirmishes rather than coordinated military campaigns (Gulliver 1955). They captured large numbers of animals including Boran Zebu cattle, and also many camels. Although they had acquired camels earlier from the raids in Loima Hills region, Lamphear (1988) reports that extensive camel husbandry by Turkana people began at this time. The final expansion reached south as far as Lake Baringo, with raiding parties marauding up the eastern shore of Lake Turkana, although the Turkana did not occupy this region. As discussed in Chapter One, this conquest of other tribes by the Turkana people was made possible by the fact that the Turkana were isolated from the rinderpest disaster of the 1880s, and were therefore in a comparatively stronger economic and military postion than their neighbours, whose livestock was decimated by the epidemic (Gulliver 1955).

The larger Nilotic grouping migrated southward from the Nile region and includes the Kenya Luo. Other paranilotic peoples also called plain Nilotes, include the 'Maasai' and the 'Kalenjin' culture groups which settled in and around the Rift Valley (Ehret 1974).

Linguists think that Eastern Cushitic languages (e.g. older roots of Somali, Boran, Rendile or Galla) were spoken in northwestern Kenya before the para-nilotes took over (Lynch and Robbins 1979; Soper 1985). It has been documented that in the $17^{\text {th }}$ and $18^{\text {th }}$ centuries, the Karamajong-Teso 
group rapidly expanded and migrated close to their present locations (Ehret 1974). Lamphear $(1976,1988)$ reports that the Turkana's major expansion to and 'conquest' of their current territory took place in the 1850s. The people's own origin myth refers to an eastward migration down from the Jie territory in Uganda, where relatives sought after an old woman who ventured to gather wild fruits and a lost bull (Lamphear 1988).

From the 1850s onwards, due to unfavourable climatic conditions in the Turkana District leading to variable fodder and water supply, poor security, and because of the unique requirements of each stock species, Turkana pastoralists developed a flexible social system and a pastoral system well augmented with agriculture, hunting, gathering, and fishing (Lamphear 1992).67 Turkana people also had competitive raiding relationships with the surrounding pastoralist tribes, except for a short period of cessation during British domination (Gulliver 1951). By the 1890s before the first arrival of the British military presence, Turkana people had gained control of virtually all territory which was ever to be regarded as Turkana. The encounters between Europeans and local Turkana were mostly hostile initially, and increased the Turkana's distrust of outsiders. Although the Turkana generally had no major political leaders, Lamphear (1992) documents how a few powerful diviners rose to war leadership in resistance against the British. 68 The diviners led a major uprising from 1916 against the colonial powers, but its suppression seriously disrupted the Turkana peoples' social security system (Lamphear 1976). 69

The Turkana District has remained remote since Kenya became independent as a nation in 1963. The development of this arid part of

67 This will be explored in chapter 5.

68 Diviners were men, and occasionally women, who exhibited supernatural powers of prophesy, and whose influenced embraced the entire Turkana society (Lamphear 1988)

69 See chapter 5 for detailed discussion of Turkana resistance against the British and its suppression. 
Kenya has not been a priority of the Kenya government until the decade of the 1980s (Republic of Kenya 1992). ${ }^{70}$ However, the paving of a road through Turkana to Sudan has accelerated changes, and the administrative centre Lodwar is now a bustling frontier town of over 20,000 people (Republic of Kenya 2002). A mix of 'modernizing' influences, both beneficial and detrimental, has diffused spatially along the road corridor: Kenyans from 'upcountry' coming north to operate businesses, the number of available goods, and public education have all been strong influences. Interestingly, most Turkana people still follow their traditional beliefs and customs. They could be seen keeping cattle, camels, donkeys, and goats, wearing traditional clothing, and inhabiting huts near the towns.

\subsection{General description of the Turkana District.}

As discussed in Chapter One, Turkana is an arid and desiccated area. It lies just north of the equator, within the Great Rift Valley, the world's most formidable geological fault, a great scar that runs north-south for 3000 kilometres through Eastern and Central Africa. It is one of the largest districts in Kenya and covers $77,000 \mathrm{~km}^{2}$ which is approximately 12 per cent of Kenya's land mass. This area includes $6,000 \mathrm{~km}^{2}$ occupied by Lake Turkana (Republic of Kenya 2002). It shares international boundaries with Uganda to the west, and Sudan and Ethiopia to the north (see Figure 1 and 6). The area is also bordered by highland regions occupied by other peoples. To the west, atop the escarpment in northeastern Uganda, live the Karamajong, Jie, and Dodos. In the mountains at the northern end of the escarpment are pockets of hunting and gathering people known as the $\mathrm{Ik}^{\mathrm{a}}$, who are Kuliak-speakers (Lamphear 1992). To the north across the mountainous frontiers of the Sudan and Ethiopia are Toposa and Nyangatom who speak languages akin to that of the Turkana, as well as Cushitic speaking Dassanetch. In the south are the Kalenjin speaking, and

\footnotetext{
70 See further explanation in chapter 5 .
} 
Pokot. East of the Pokot and in the areas beyond the southeastern tip of Lake Turkana, are the Maa speaking Sampur (currently called Samburu) who live in close pastoral association with the Cushitic speaking, camelrearing Rendile (Lamphear 1992).

Currently, Turkana District is divided into 17 administrative divisions, ${ }^{71}$ 58 locations, 158 sub-locations and 3 constituencies (Republic of Kenya 2002). During my field study period, the constituencies ${ }^{72}$ were Turkana North, which covers seven divisions (Lokitaung, Kaaling, Kibish, Kakuma, Lapur, Oropoi, and Lokichogio), Turkana Central which covers five divisions (Central, Kerio, Kalokol, Turkwel, and Loima), and Turkana South which covers five divisions (Lokichar, Lomelo, Lokorio, Katilu, and Kainuk).

The district is geographically isolated from the rest of Kenya by rough terrain. From the escarpment of the Rift Valley, Turkana appears a vast stretch of dry plain. The plains which form the main topography of the Turkana District are below 600 metres, making the area the lowest anywhere in the East African hinterland (Lamphear 1992). Informants noted that the plain is very important to the Turkana people, as they regard themselves as people of the plains who make use of the mountains unwillingly, and only by necessity. When a Turkana person is asked where he lives, he usually gives the name of the plain where he lived during the wet season. Therefore, Turkana people call the plains 'homeland' (akwap).

In the centre of Turkana are the plains, and around it to the south are isolated barren landscapes of extinct volcanic mountain ranges. In the north and northeastern part of the district, these ranges include: Lokwanamoru Range, Lorioneteom Range, Pelekech Hills, Mogilla Range, Loima and Songot, Moroto, Lotikipi and Puch Prasir Plateau. In the south:

\footnotetext{
${ }^{71}$ A division is the third largest administrative unit in Kenya.

72 Each Kenyan Member of Parliament represents an administrative area normally referred to as a constituency.
} 
Kamorok, Kailongkol, and Laiteruk mountain ranges can also be found. McCabe and Ellis (1987) measured the average elevation of the plains at 600 to 650 meters, and the altitude of the mountain ranges from 1500 to 1800 meters above sea level (Republic of Kenya 2002). The ranges are particularly important as key elements within the annual cycle of the Turkana pastoralists, especially as a dry season grazing area.

Figure 6: Map of Turkana showing the physical features, and the neighbouring peoples.

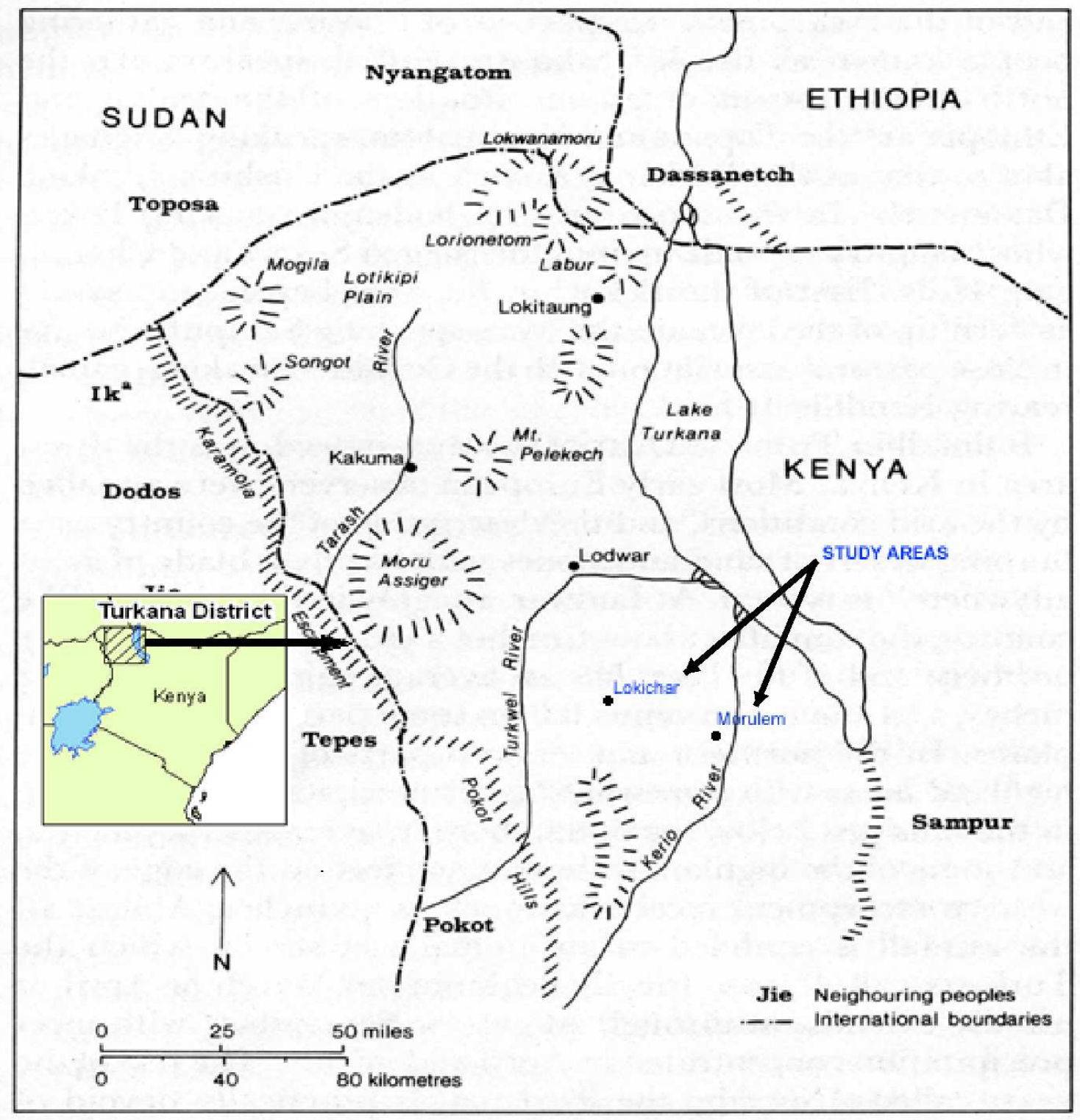

Source: Lamphear (1992:8). 
The Turkana know their environment intimately. Although there are no westernstyle signs to mark locations, each place, hill, and dry river bed has a name, and the names are widely known by the people who live in the area. According to informants, men have a broader geographical knowledge than women because they tend to have more experiences away from the camps, for instance, herding animals, and visiting distant friends to exchange livestock. However, men, women, and children are all very well oriented in their social environment.

\subsection{Ecological classification.}

According to the ecosystem adopted by the survey of Kenya (Pratt and Gwynne 1966; Republic of Kenya 1992), land in the Turkana District covers six agro-climatic zones (III-VIII) of which 'arid' and 'very arid' ecoclimatic zones VI and VII respectively, cover the major part of the district. These agro-climatic zones have been classified according to annual rainfall and evaporation patterns. Moisture indices are calculated not only from rainfall and evaporation, but also include measures of radiation, temperature, saturation deficit, and wind speed. According to this classification, an index of -60 is the minimum possible and is equivalent to no rainfall, or 'true desert'. Zone VII (moisture index -57 to -60 ) is not found in East Africa (Pratt and Gwynne 1977).

The arid zone V (moisture index of -42 to -51 ) is characterised by wooded and thorn-bushed grassland. The very Arid Zone VI (moisture index of -51 to -57 ) is dwarf shrub grassland with acacia trees mostly confined to water courses and depressions. Lava outcrops and gravel flats are common in many parts of Turkana. ${ }^{73}$ The east central region is nearly a desert; even the shoreline of Lake Turkana has little vegetation.

73 According to Pratt and Gwynne (1977: 66), goats may be the only domestic animal capable of utilizing some of the dry lava bush lands in Turkana 
Turkana is adjacent, and ecologically similar, to a stretch of 'droughtpulsed ecosystems' in southern Sudan, Ethiopia and Somalia, and is similar to the Sahel region bordering the Sahara desert and the West African savannas (Ellis 1984). Most of these areas are inhabited by subsistence pastoralists, who, like the Turkana, have a wide range of survival strategies for land which is too arid for crop growth.

\subsection{Temperature.}

The low-lying plains in Turkana are hot and dry, and temperatures are high, but fairly uniform throughout the year, with an average daily range of about 24 degrees to 38 degrees centigrade and are seldom lower even at night. Ground absorption and radiation can increase temperatures over lava flats to at least 67 degrees centigrade (Coe 1972). During the day, the extremely high temperatures are accompanied by strong easterly winds sweeping across the largely barren countryside, carrying large quantities of sand. ${ }^{74}$

\subsection{Rainfall.}

In the Turkana District, climate variability, caused by uncertain rainfall patterns, is one of the most unstable factors that affect pastoral production systems (Ellis 1994). Long-term data from various stations show that rainfall in Turkana is not only sparse, but is spatially and temporally erratic. Rain tends to fall intermittently, but it can occur any time. Ideally rain starts in March or April and usually extends on through August and September with most precipitation concentrated in April and

\footnotetext{
${ }^{74}$ Interestingly, during my fieldwork, I learnt that the Turkana people's perception of their harsh (hot) environment was different from my own perception. Most Turkana people have never travelled outside their district, and therefore, know no other environment for comparison. They do not consider it to be too hot because they do not know what it is like to live in a place with more moderate temperatures. Respondents explained that they respond to the hot temperature by attempting to accomplish most of their work and travel in the cooler parts of the morning and evening. They value shade trees, and build their house structures on stilts to make more shade for work or rest during the day.
} 
July. Precipitation is somewhat correlated with elevation, with higher amounts in the northern and western parts of the district, decreasing eastward to Lake Turkana. Government records show annual averages of 150millimeters to 300millimeters for central and southern Turkana. Mean annual rainfall is 159 millimetres in Lodwar, the district headquarters (EcoSystems Ltd 1985).

Rain often comes in sharp storms in Turkana, and because of minimal grass cover and baked soils, runoff can produce flash floods. Groundwater recharge may be helped by floods flowing to the eastern, drier parts of the district. Recharge is highest where the ground cover is sandy gravel and fractured rock.

The Turkana people describe the two major seasons as dry (akamu) and wet (akiporo). According to Gulliver (1955), these two terms, in keeping with realities, are used in an extremely elastic manner. More precisely, Akiporo refers to the times when the rains have been sufficient to produce new and fairly well-established vegetation. Akamu means no rain or sporadic rain that does not produce new growth (Gulliver 1955). 75 The ideal pattern is reflected in the names of Turkana months. At the beginning of the rainy season is Titima ('when Grass is growing'), followed by Eliel ('Spreading' - when homesteads move with their herds across the country to utilize the new grass), Lochoto ('Mud'), and Losuban ('The Time of Marriages'). The advent of the dry season is marked by Lopoo ('When Dry Berries are Gathered'), followed by Lorara ('When Leaves Fall'), Lomak ('When Trees are Bare'), and by sinister periods of Lolongo ('Hunger') and Lokwang ('The White Time' - when clouds of white dust envelop the land) (Lamphear 1992: 7-8). During the time I arrived in Turkana for my fieldwork, two weeks after strong rainstorms, several people told me that they were still 'waiting for the rains to come' to go visit their friends. When

75 Barrett (1988) argued that Turkana people also refer to the two seasons, akamu and akiporo, as atepunet and aceer respectively. 
I asked about the rains that had already come, they replied that those were not the real rains which bring grass. I had to concur with Gulliver when he reported that "Turkana say, with truth, that only about one year in four or five has a 'good wet season', with rainfall well above the average paucity" (Gulliver 1955: 23).

The predominant low mean annual rainfall, coupled with extremely high variability, indicates a drought - stressed ecosystem. Seasonal dry periods vary between six and nine months. Long-term data series suggests one to three year droughts have occurred, accumulating to approximately 12 times during the past 80 years, with an average of one drought every six to seven years (Turkana Drought Contigency Planning Unit 1992).

\subsection{Demographic considerations.}

The demographic structure of a given community is quite important in understanding livelihood strategies of that particular society. The effect of characteristics such as household size and composition on adaptive options at household disposal has been documented widely in literature (Adams 1992; Toulmin 1986). In this study, knowledge of population dynamics is essential to understanding Turkana human ecology. According to the 1999 population and housing census, the Turkana District had a population of 450,860 persons in 1999 . This population was projected to increase to 497,779 persons in 2002 and to 606,774 persons in 2008. Figure 7 provides the district population projections by sex. As can be noted from Figure 7, the population has been increasing dramatically, and this rapid growth rate is estimated at 3.3 per cent per year (Republic of Kenya 2002:17). In absolute terms, the population of the district is estimated to increase by about 22 per cent between 2002 and 2008 (Republic of Kenya 2002). The population density varies from 29 persons per $\mathrm{Km}^{2}$ to the northern part of the Turkana District to one person per $\mathrm{km}^{2}$ to the south frontier of the district (Republic of Kenya 2002). 
Figure 7 Population projections by sex in the Turkana District, 1999-2008.

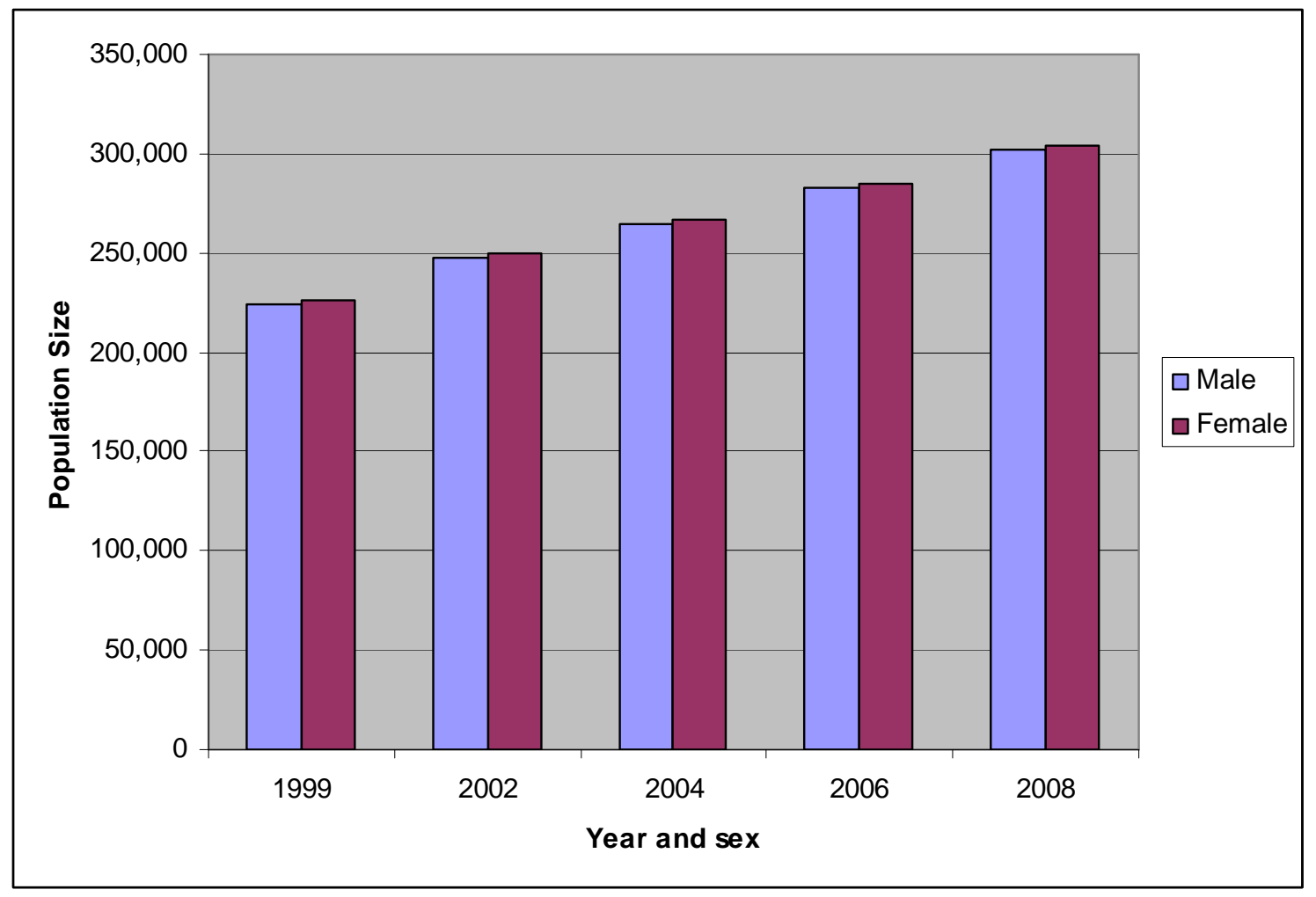

Source: Adapted from Republic of Kenya 2002:18.

The observation I would make here is that the population in Turkana is increasing fairly rapidly and is therefore exerting a lot of pressure on the available scarce facilities and resources such as food, water, pasture, vegetation, education, employment, and health. This is manifested by the persistent drought, famine, malnutrition, unemployment, poverty, and the inability of the district residents to access basic services such as health and education, as discussed below. Furthermore, high population has led to increased competition with pastoral neighbours for pasture and water, leading to violent armed attacks between Turkana and their neighbours the Pokot pastoralists (Daily Nation 15th May 2007: 13).

\subsection{Livelihood platform in the Turkana District.}

This section discusses the livelihood platform in the Turkana District as complement to the livelihood context in that region. The intention is to 
contribute to the understanding of the extent to which Turkana people sustain their livelihood based on locally available resources. A livelihood platform is taken in this thesis as based on the assets an actor has rights and access to. The assets could be natural, physical, human, financial, social, and political capital (Ellis 2000). These assets can be used to produce outputs (Ellis 2000). Asset access thus strongly influences households in their decision making when pursuing livelihood activities. Analysis in this thesis considers Kabeer's (2000b) argument that access to resources is determined by rules and norms, and these rules and norms give certain actors authority over other actors in determining the principle of distribution and exchange.

\subsubsection{Natural capital.}

Natural capital is the natural resource stocks, and environmental services from which resource flows and services useful for livelihoods are derived (DFID 1994; Scoones 1998; Ellis 2000). Natural capital is the basic source of livelihood in rural communities, such as the Turkana community. The natural 'capitals' I will deal with here are land, soil, water, and vegetation.

Grazing land: Grazing land is a critical asset for pastoralists. ${ }^{76}$ For instance, the carrying capacity of the land may affect the resilience of pastoral households by placing limits on options with respect to size, diversification and dispersal of their herds. In the Turkana District, the general nature of land tenure, as elsewhere among Kenyan pastoral communities, is that land is communally owned. Land rights are reserved to communities rather than to individuals, and land is an undivided part of the social system where rightful use is determined by affinity, common residence, social status or these in common (Ekwee Ethuro 1994; Gulliver 1955). Turkana people do not perceive land as a limited resource, as they

76 See chapter 7 for detailed exploration of the importance of grazing on livelihood sustainability in the Turkana District. It is pointed out that availability of land enables mobility from dry to wet season during drought conditions. 
normally get access to graze their animals. A preliminary conclusion from my observation during fieldwork is that land belongs to the community and not individuals. Several respondents from Morulem and Lokichar study villages confirmed the notion of free access to land and stated as follows:
All rural lands belong to the people and are held under customs. To date there is no problem with this system. There are no restrictions for what we can do with the land. It is well known that this land belongs to our community; however, access to land in some places bordering the Pokot tribe has been restricted only due to insecurity (Household Interview $7^{\text {th }}$ February 2007, Morulem village; Household Interview 10 $10^{\text {th }}$ May 2007, Lokichar Village).

Two important aspects of land tenure within the Turkana District are the system of Amaire and Ekwar 77 (Barrow 1990). The Turkana make optional use of the sparse vegetation by moving livestock between wet and dry season grazing, and by setting aside specific dry season grazing reserves called Amaire. The system of Ekwar mainly exists along riverine areas in central and some southern Turkana regions, where strips of riparian woodland are claimed by individual awis, based on usufruct rights to the trees held by those households and handed down by their ancestors (Barrow 1987, 1990, 1996; Lane and Swift 1989). This system is of particular importance during the dry season, when the riverine areas are the main producers of fodder for livestock and the collection of wild fruits. Although the system is still widely in use, a growing concern is the alienation of this land through government intervention and its allocation to development projects, such as irrigation schemes. However, generally, the system of Ekwar remains effective in conserving environmental resources in the Turkana District, where it is still applied (Barrow 1987, 1990).

77 Amaire means reserved grazing areas, while Ekwar means family owned areas of important trees (Barrow 1990) 
Soils: The soils in the Turkana District are highly variable. They are shallow and generally of light and medium texture as shown in Figure 8. There are either constraints of a chemical composition, or physical limitations such as rockiness, mantle, slope, and depth. They are subject to compaction and capping and are susceptible to erosion. Degradation exists along the base of Uganda, the lower portion of the basin east and northeast of Lokichar, one of my research sites. A small section at the middle of the Kerio valley is fairly suitable for subsistence agriculture (EcoSystems Ltd 1985). However, it is worth noting that these areas suitable for cultivation make up a very small part of the total land area of the district.

Figure 8 Soils in Turkana.

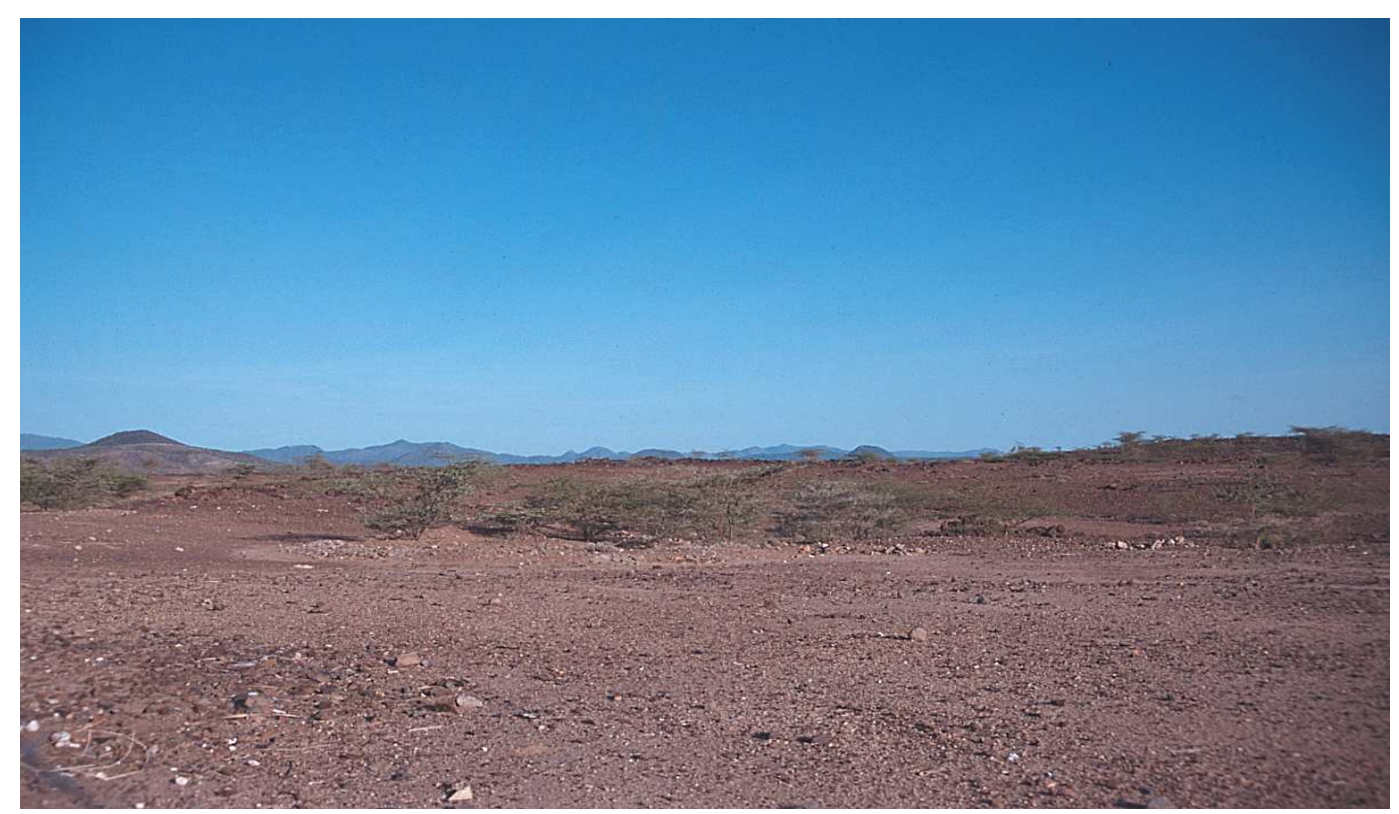

Source: Fieldwork 2007.

Water: Water is crucial to sustaining the Turkana pastoral livelihood. Water is predominantly used by their herds and for domestic purposes. The two main rivers in the Turkana District, the Turkwel and Kerio, which flow more or less continuously from April to September, receive the bulk of their water from the Kenya highlands, far south of the district (Gulliver 1955). Other rivers in Turkana include the Tarach, Kawalathe, Kosipir, 
and Suguta. According to Norconsult (1990), these rivers have water from three to ten months of the year. The seasonal Tarach River in the northwest empties into the Lake Lotikipi plain; otherwise 80 per cent of the district drains into Lake Turkana. Many other water courses flow only during the rains, which may be from a few hours to a few weeks per year. Immediately after a storm, they rage in flood, flow for a brief period, and then cease leaving pools of water and deposits of silt and debris (Gulliver 1955).

Figure 9 Turkana women looking for water.

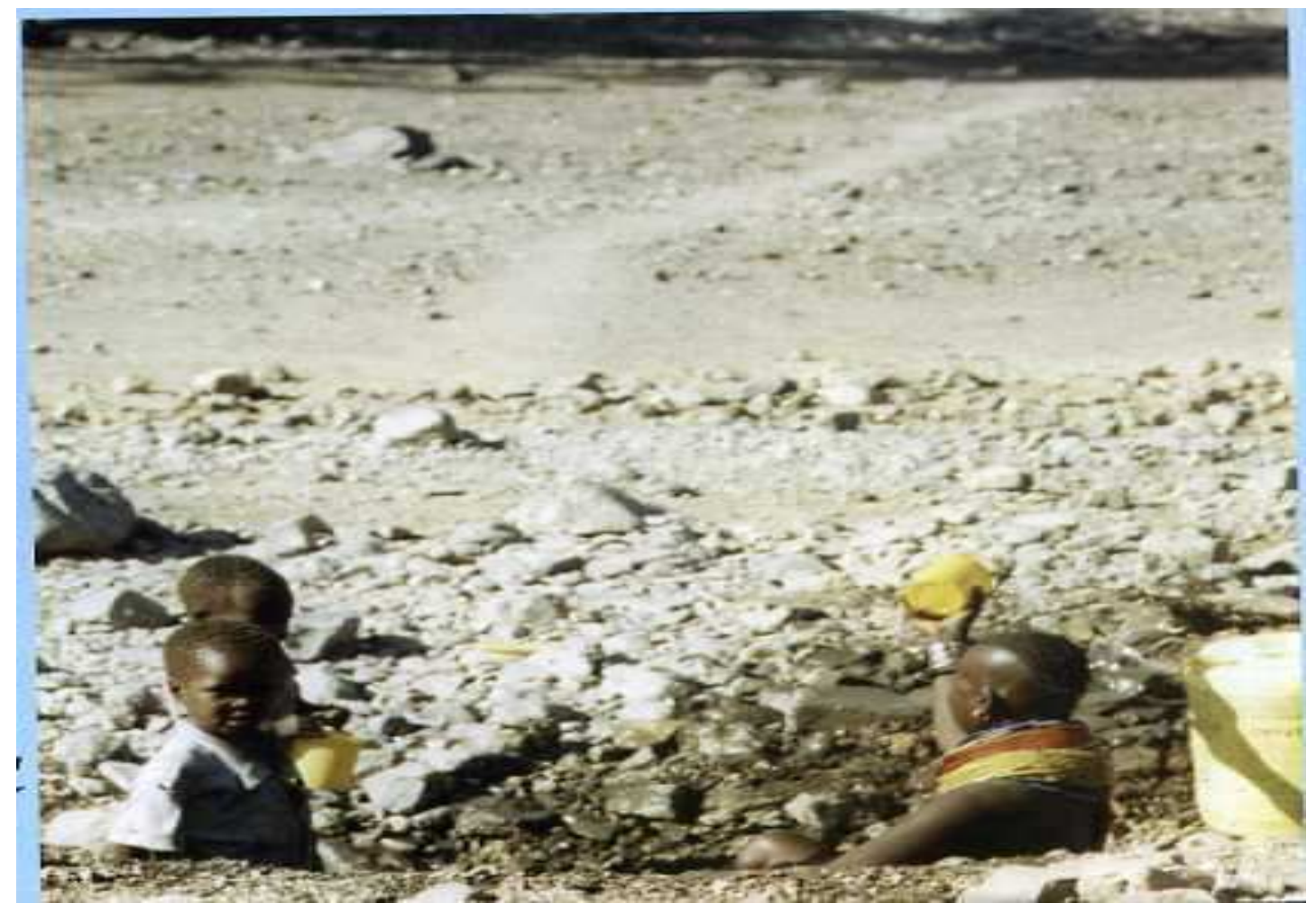

Source: UNDP 2000: 22.

Informants stated that clean drinking water is a limited resource in Turkana. This is not different with circumstances facing the Dinka pastoralists in southern Sudan. Operation Lifeline Sudan (2002) reported that safe water is probably the most critical issue in southern Sudan. Three quarters of the southern Sudanese people do not have access to safe water (Operation Lifeline Sudan (OLS) 2002). For the Turkana people, they 
collect their water from rivers, springs, rock pools, and waterholes which they dig in dry river beds. They explained that during extreme dry seasons, waterholes (akar) may to be dug up to 25meters below the ground, from which water is passed up in containers by human chains of sometimes up to 10 people. Water fetching in Turkana has traditionally been the female's responsibility (see figure 9). Males fetch water only for their animals. The groundwater is generally good from having been filtered through sandy aquifers, but it can become contaminated with animal dung around waterholes. Sometimes the groundwater is salty and brackish. People are often required to drink browncoloured water with high silt content.

Vegetation: Vegetation is also critical, and forms the foundation for the pastoral production system. According to Barrow (1996), vegetation provides important browsing for livestock, fruit and foods, medicines, as well as wood based products for pastoral people. Fundamentally, they are a vital safety net in dry and drought times (Barrow 1996).

In the Turkana District, vegetation distribution is determined mainly by water availability, but also by temperature and evaporation, topography, soils, and historical influences. A quarter of the district is devoid of trees and two thirds support only scattered trees (Norconsult 1990). Reliable sources of grass with high productivity are small in the area and widely scattered. Ellis and Dick (1986) point out that plant biomass is related to elevation except for riverine areas. The two main types of woody vegetation found in Turkana are riparian and non-riparian. They are acacia species.

Tree vegetation in Turkana mostly appears as riverine vegetation. Although the numbers of tree species are fewer than in a humid environment, they are well known and important to the Turkana people (Morgan 1971). Acacia tortillis ("umbrella thorn," Turkana "ewoi," or "etir" when young) is the most valuable tree. Both the Turkwel and the Kerio rivers have thick belts of riparian vegetation on either side, with deep-rooted acacia tortillis 
forming a canopy forest with little understory. The seed pods ("ngitit")78 are a prized feed for goats and the crushed seeds are food for humans. Moving away from the river, there is a sequence of thickets of cordia sinensis ('edome'), salvadora persica ('asekon' or 'toothbrush tree'), balanites species ('ebei', 'elemach'), Acacia seyal, and dichrostachys cinerea (Morgan (1971). In areas distant from the water courses, the species vary, but include acacia nubica ('epetet'), acacia mellifera, acacia reficiens ('eregae'), dobera glabra ('edapal'), boscia coriacea ('erdung'), commiphora africana ('ekadel'), and euphorbia cuneata. Near the lake and lower stretches of the rivers, hyphaena coriacea ('eengol' or 'doum palm') is dominant (Barrett 1996; Barrow 1988, 1996; Norconsult 1990; Soper 1985).

The wood, fruits, leaves, bark, and gums from these trees are used by the Turkana people in many ways. Fruits, seeds and leaves are foods for livestock and people. The temperature difference offered by shade (Perhaps 10-15 degrees F) is another high value. The wood is used for fuel and making charcoal ${ }^{79}$ [see figure 10 below], and for building homes, fences, furniture (traditional stools; chairs; and beds), and fashioning many traditional utensils, containers for milk and oil, and watering troughs. Wood is made into toothbrushes, walking sticks, spears, bows, arrows, and a type of club used against wild animals. Fibre is woven into rope, baskets, packing carriers for donkeys, and thatched mats used for bedding. Medicines, ornaments, dyes, and perfumes are some of the other uses of tree products (Barrow 1996).

In relation to vegetation resources, Scoones (1994) argues that in general, ecosystems in dry land areas do not follow equilibrium dynamics, but biomas production is highly spatial and temporarily variable. Therefore, in these so called non-equilibrium ecosystems, as in Turkana, pastoral

\footnotetext{
78 The Latin name or scientific name followed, in parentheses, by the Turkana name.

79 According to UNEP (2000) there is an enormous increase in charcoal burning in the Turkana District during drought period.
} 
production systems are designed to deal with high levels of spatial variability in resource production.

The environment of southern Turkana was surveyed in detail by the south Turkana Geographical Expedition (Baker and Lovenbury 1971; Caukwell 1971; Coe 1972; Hemming 1972; Morgan 1971, 1974). More recent environmental and mapping studies include the Turkana District Resources survey (Ecosystems 1td 1985), Ellis and Dick's Landsat analysis of Turkana vegetation (1986), Norconsults Environmental study of the Turkana District (1990), and Republic of Kenya (2002).

Figure 10: Charcoal for sale in Turkana.

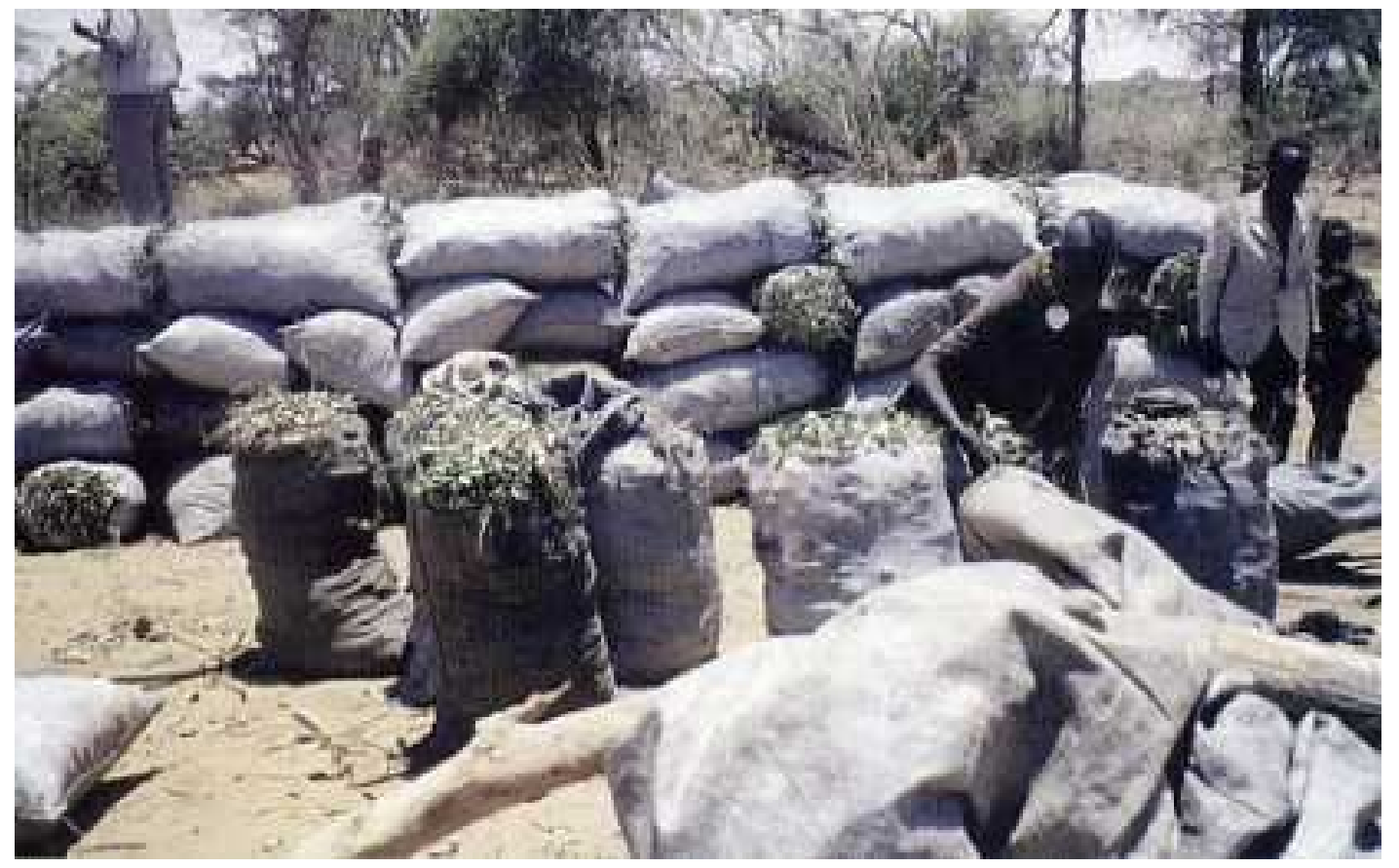

Source: UNDP 2000: 45.

\subsubsection{Physical capital.}

Physical assets are resources used in production of goods and services. Buildings, irrigation, canals, roads, tools, machines and so on are physical capital (Ellis 2000). Traditionally, the Turkana did not have much physical 
capital, and the material culture of the people has been simple (Gulliver 1955). Even today, Turkana people do not have many tools and utensils, and when moving from one cattle camp to the other, the girls and women carry the family's belongings on their heads. In this study, I identified two main categories of physical capital: private capital (houses) and public capital (infrastructure).

Houses: As mentioned, the sections and clans own the land, but houses and constructions on the land are privately owned. A house indicates that an individual or family has user rights of the land where it is located. Construction of houses is done by women while men are in the field taking care of the animals. Most Turkana men have more than one wife and it is common that each wife maintains a separate house.

Infrastructure: Roads and means of transportation are essential to diffusing knowledge and technology, which facilitate the development of communities (either rural or urban). In the Turkana District, the infrastructure is generally very poor. There is only one major road passing through Turkana to Sudan and when it rains this is impassable. In the interior parts of Turkana, most of the roads and bridges are either damaged or destroyed. There is no public transport system, and most people have only one option when travelling from one place to another: to walk. Some people have bicycles, but it can be hazardous to use them on bad roads. The problem of poor roads and public transportation has negatively affected the livelihoods of Turkana people, for example, it is hard to get supplies into rural areas, and this limits trade with other regions. The Turkana people have no tradition of using carts and animal power to transport commodities and goods, and rely on carrying everything themselves. There are some large trucks that bring food supplies to rural centres in Turkana during famine periods, and these trucks do take some passengers on top of their loads. 
Women are the most negatively affected by the bad roads and transport problems. Traditionally, men should not carry loads on their heads; therefore, women should commute by foot carrying loads on their heads. When there are emergencies during child delivery, owing to the lack of qualified midwives, women have to walk long distances to available health clinics. This is explored below.

\title{
4.8.3 Human capital.
}

Human capital refers to the labour available to the household: it includes education, skills, and health (Carney 1998). For demographic reasons, the human capital of households changes constantly. During my fieldwork, I learnt that a number of Turkana households have suffered serious losses of people in the immediate past, due to deaths caused by persistent drought, famine, disease, and war with their neighbouring tribes. When a family loses the breadwinner, their livelihood platform is seriously weakened.

One woman, a key informant from Morulem village, captured the impact of such loss brought about by drought and disease:

\begin{abstract}
Women, children and the old have been the most affected by drought because they wait at home for what has been brought by men. We have no health services. Young girls have problems producing children. Children have become vulnerable to various diseases because of malnutrition. Our people and animals have died (Key Informant Interview 3rd February 2007, Morulem village).
\end{abstract}

The vast majority of people in rural Turkana District have no access to health services and secondary education. The exception is in areas around Lodwar (district headquarter), and Lokichogio town near the border of 
Kenya and Sudan. There are shortfalls in human capital relating to education (including training), health, and skilled labour.

Education and Training: Education is one of the most important factors that determine the quality of human capital. The current education system in Kenya is basic school (eight grades), followed by secondary school (four grades), and then university (four years). In the Turkana District, there are a total of 161 primary schools and eight secondary schools (see Table 1). While analysing the enrolment situation in the Turkana District in 2002, out of the 115,989 children aged between five and 13 years who were of primary school age, only 37,483 (32) were enrolled in primary schools (see Table 1 and 2). Also noted is the dropout rate in primary schools, which stood at 62.9 per cent, and is higher than the enrolment rate of 33.9 per cent. During the same period (2002), the enrolment rate in secondary schools was 4.95 per cent against the dropout rate of 24.1 per cent (see Table 1). It was my observation that the low enrolment rate is because the existing service provision in the Turkana District does not take into account the nomadic nature of pastoralism. Mobile schools could solve this problem, but so far these have not been delivered in sufficient measure.

It could be reported further that given the high dropout rate at both the primary and secondary levels, it may be quite hard to find many formally qualified people amongst Turkana society. The government of Kenya has also pointed out that there is a great shortage of teachers in the Turkana District, and that the teacher pupil ratio is $1: 70$ and 1:40 for primary and secondary schools respectively (Republic of Kenya 2002). The few schools with classrooms are overcrowded since the rooms are too small. Consequently, most children learn under trees and sit on stones. My respondents informally explained that staff shortages in schools are exacerbated by the fact that Turkana is a hardship area, and that many teachers from other parts of Kenya are unwilling to take up a teaching 
position in that district. The climate is hot, and most teachers are not willing to lead a semi-nomadic life.

Table 1: Education status in the Turkana District.

\begin{tabular}{|c|c|}
\hline Total number of households & 80,921 \\
\hline \multicolumn{2}{|l|}{ Pre-Primary Schools } \\
\hline Number of pre-primary schools & 277 \\
\hline Enrolment in pre-primary schools & 27,102 \\
\hline Teacher/pupil ratio in pre-primary & $1: 74$ \\
\hline \multicolumn{2}{|l|}{ Primary Schools } \\
\hline Number of primary schools & 161 \\
\hline Number of boarding schools & 41 \\
\hline Primary school going age (6-13) & 115,989 \\
\hline $\begin{array}{l}\text { Number of enrolled pupils in } \\
\text { primary schools }\end{array}$ & 37,483 \\
\hline Enrolment rates in primary schools & $33.9 \%$ \\
\hline Dropout rates in primary schools & $62.9 \%$ \\
\hline $\begin{array}{l}\text { Teacher/pupil ratio in primary } \\
\text { schools }\end{array}$ & $1: 70$ \\
\hline Average years of school attendance & 5 \\
\hline \multicolumn{2}{|l|}{ Secondary Schools } \\
\hline Number of secondary schools & 8 \\
\hline Secondary school going age (14-17) & 50,097 \\
\hline $\begin{array}{l}\text { Enrolment rate in secondary } \\
\text { schools }\end{array}$ & 2,466 \\
\hline $\begin{array}{l}\text { Enrolment rate in secondary } \\
\text { schools }\end{array}$ & $4.95 \%$ \\
\hline Dropout rate in secondary schools & $24.1 \%$ \\
\hline $\begin{array}{l}\text { Teacher/Pupil ratio in secondary } \\
\text { schools }\end{array}$ & $1: 40$ \\
\hline \multicolumn{2}{|l|}{ Adult Literacy } \\
\hline $\begin{array}{l}\text { Number of adult education learning } \\
\text { centres }\end{array}$ & 163 \\
\hline $\begin{array}{l}\text { Enrolment in adult education } \\
\text { learning centres }\end{array}$ & 2,803 \\
\hline Average class attendance & 1,488 \\
\hline Number of adult teachers & 163 \\
\hline Teacher/Learners ratio & $1: 11$ \\
\hline
\end{tabular}

Source: Republic of Kenya 2002:10.

There is a high degree of illiteracy in the study areas. The education situation for girls is especially poor, as they rarely get the opportunity to study. Noted with interest was girls' low enrolment in both primary and 
secondary schools, as compared to boys'. I realized that this is related to cultural practices, as most informants argued that educating a girl is seen as "a waste of money", as they will move away from their family when they marry. A key informant (an old man from Morulem village) summarized the situation as follows:

They [girls] are visitors; they will get married and move with their husbands. It is better to spend money in education of boys than girls (Key Informant Interview $6^{\text {th }}$ February 2007, Morulem village).

A woman respondent (from Morulem village) added to this statement as follows:

\begin{abstract}
Some girls are sent to school, but in many cases parents do not see any benefits of investing money in a daughter's education when they will marry her to another family. A woman's voice cannot be heard, so when a father decides when his girls are to marry so he can get riches and cows, the mother keeps quiet, because traditionally mothers should not say anything (Key Informant Interview 15 $5^{\text {th }}$ February 2007, Morulem village).
\end{abstract}

These views about school enrolment in the Turkana District were summarised by one informant (an old man from Lokichar village). His opinion was shared by many people interviewed during the fieldwork. He stated as follows:

Some children are not sent to school because the family needs their labour; some cannot afford to pay the fees and uniforms; many have no access to schools; and others see it as misuse of resources to send children to school when there are very few employment opportunities for those who have education (Key Informant Interview $7^{\text {th }}$ May 2007, Lokichar Village). 
Health: The major diseases that have regularly been reported in the Turkana District are malaria, skin diseases, respiratory tract infections, and diarrhoea (Republic of Kenya 2002; UNICEF 2006). Malaria can be prevented by the use of bed nets, but not everybody has the financial means to acquire nets. These are similar to what Bonfiglioll and Watson (1992) found to be common diseases among poor people throughout the World. Therefore, the interpretation could be that most Turkana people are generally poor.

During my fieldwork, I learnt from a doctor stationed at Lodwar District hospital that one out of four children in the Turkana district is malnourished and undernourished. UNICEF has also tried to eradicate polio in many parts of the Turkana District through vaccination, but this has not been achieved in many parts of Turkana. Informants narrated how bad sanitation and hygiene contribute negatively to the health of the population. They claimed that only a few households have sanitary latrines. I observed that solid human waste is disposed in fields close to homesteads, and can make the area also susceptible to diseases. Animals are slaughtered near homesteads, and the remains are left for the flies and other parasites.

Despite the fact that Turkana people are exposed to various diseases, there are very limited health centres in rural Turkana, and a doctor/patient ratio is estimated at 1:75,000 (Republic of Kenya 2002: 10). This is made worse by the fact that in Kenya, healthcare planning is centralised. Drugs and medical supplies sent to rural health centres are made centrally in Nairobi (capital city) and don't always reflect the specific needs of the rural areas. The average distance to the nearest health facility in the Turkana District is 50 kilometres. Therefore, in cases where treatment is necessary, people have to travel long distances to hospital. As mentioned earlier, the infrastructure is very poor, and there is no reliable public transport system. The result is that many people who need assistance never reach 
the medical services and end up dead or disabled. Medical personnel at Lodwar District Hospital complained that people come too late to the hospital when they are sick, which makes it harder for doctors to treat the disease.

Children are especially vulnerable and susceptible to insect transmitted diseases; mainly they walk around naked and defecate in open places. Many children also die because they get treatment for malaria too late. Another problem for medical personnel is that people get treatment from the local doctors or magicians, and only go to the hospital when the local treatment fails. The kind of treatment offered by local doctors can often worsen the condition of the patient, and makes it difficult for the medical doctors to treat the illness. But Turkana people use indigenous medicines if what is received from the clinic fails or are perceived to be taking too long to work. They divide illness into those caused by God (Ngidekesiney ka $A k u j$ ) and those caused by witchcraft (Ngidekesiney ka ekapilan). According to informants, illness caused by God is part of the everyday natural world and considered manageable. Illness caused by witchcraft is treated locally using traditional herbs. It was also my observation that the introduction of cost sharing (fees) in public hospitals by the Kenyan government limits the entitlement of health services to many Turkana people, the majority of whom are poor, and that few clinics which are in the rural Turkana region are not effective as people can wait a whole day without receiving treatment. Therefore, poor health, nutrition, and medical services contribute to the perilous state of human capital in the Turkana District.

Labour: According to the 1999 population census, the figure for active labour is expected to rise from 264,242 in 2002 to 322,101 in 2008 (see Table 2). The dependency ratio is $100: 88$ implying that in every 100 people 
there are 88 dependents (Republic of Kenya 2002: 19) ${ }^{80}$. The high dependency retards the growth of the district economy as resources are diverted to consumption, and hence, there is less saving and investment. Furthermore, the majority of people in the district are engaged in pastoralism, fishing, and small business activities, whose returns have been greatly affected by unfavourable climatic conditions and lack of investment resources (Republic of Kenya 2002: 19). Therefore, there is need to create more employment opportunities for the labour force.

In my interactions with various Turkana people during fieldwork, I realized that household labour was organised in such a manner as to meet the demands of the pastoral economy. Polygamy was a common practice and a man can marry as many wives as he can pay bridewealth. One reason for having many wives is that the family will become large, and thereby provide labour for herding and protecting cattle. In most cases I investigated, the first wife encouraged her husband to marry a second wife when her workload became too much to manage. Women are married for both their productive and reproductive role; that is to say, for her labour, as well as for producing children. According to informants, in Turkana society, the ideal wife is one who can work hard.

While discussing the labour situation in the Turkana District, it is necessary to briefly discuss the gender division of labour as shown in appendix 5. The gender division of labour highlights the fact that both men and women play a critical role in the Turkana production system. This disputes the old stereotype that Turkana men tend to play a more important role than women. For example, by custom, herding of animals is done by male household members, but during my fieldwork, I realised that in practice, the task of herding and watering animals, both small and large

80 The concept of a dependency ratio is, however, relevant in societies such as the Turkana where both the elderly and children contribute actively to household livelihoods. 
stock, greatly depends on the availability of labour within the household and is shared between men and women (see Appendix 5).

Table 2: Population Projections for Selected Age Groups, 1999-2008, in the Turkana District.

\begin{tabular}{|c|c|c|c|c|c|c|c|c|c|c|}
\hline \multirow{2}{*}{$\begin{array}{l}\text { Age } \\
\text { Group }\end{array}$} & \multicolumn{2}{|c|}{1999} & \multicolumn{2}{|c|}{2002} & \multicolumn{2}{|c|}{2004} & \multicolumn{2}{|c|}{2006} & \multicolumn{2}{|c|}{2008} \\
\hline & M & $\mathbf{F}$ & $\mathbf{M}$ & $\mathbf{F}$ & $\mathbf{M}$ & $\mathbf{F}$ & $\mathbf{M}$ & $\mathbf{F}$ & $\mathbf{M}$ & $\mathbf{F}$ \\
\hline $6-13$ & 53,090 & 51,966 & 58,615 & 57,374 & 62,614 & 61,288 & 66,886 & 65,470 & 71,449 & 69,937 \\
\hline $14-17$ & 24,069 & 21,306 & 26,574 & 23,523 & 28,387 & 25,128 & 30,324 & 26,843 & 32,392 & 28,674 \\
\hline $15-25$ & 57,063 & 52,491 & 63,001 & 57,954 & 67,300 & 61,908 & 71,891 & 66,131 & 76,796 & 70,643 \\
\hline $15-64$ & 114,907 & 124,428 & 126,865 & 137,377 & 135,521 & 146,750 & 144,767 & 156,762 & 154,644 & 167,457 \\
\hline
\end{tabular}

Source: Republic of Kenya (2002:18).

While men have full control concerning grazing, sale, and slaughter, women control the products of livestock that are allocated to them. In addition to performing their roles of fetching water and wood, caring for the family, watering calves, carrying loads on their heads, gathering wild fruit, child nurturing, milking livestock, constructing houses, skinning and cutting meat, grinding millet, making fat and butter, making and repairing clothes, bedding materials, and pots, and garden work, women also play the crucial role of cultural reproduction in socializing children especially girls, and participating in rituals and cultural ceremonies (Gulliver 1951). However, in view of the numerous and taxing roles played by men and women, the performance of these roles becomes even more challenging in a drought situation when basic resources are scarce.

In pre-colonial Turkana society, young girls assisted by fetching water, cooking food, making clothes, beadwork, baby sitting, and herding of goats and sheep. Boys looked after young stock such as lambs and calves. They also hunted for squirrels, rats, and birds. Warriors have been involved in raids to acquire and protect pastures, water points, and homesteads from external aggression (Gulliver 1951). A review of the gender roles is quite important for this study because the adaptive strategies employed by Turkana pastoralists to cope with the 2005-2006 drought and famine, though based on social networks, were complemented by the gender 
specific knowledge and skills acquired over the years from living in the drought-stricken district. 81

\subsubsection{Financial capital.}

Financial capital consists of a stock of liquid financial resources such as money, savings and access to credit, and less liquid resources such as livestock, food stocks, and reciprocal claims (DFID 1994; Scoones 1998; Ellis 2000). Financial capital discussed in this study includes livestock, and reciprocal claims. Despite their high risks, these means of saving are preferred by Turkana people over banks, because they are not only a means of living, but also play a critical role in people's lives, including determining their status.

As pointed out by Galaty, Aronson, Salzman, and Chouinard (1981: 55) "one must remember that livestock, particularly cattle, are not merely a food resource; they are also capital, which is essential to all kinds of negotiations involving influence and alliance; they are not merely savings, they are the only form of investment available to tribal pastoralists". As Deng (2002: 52) explains, "For Dinka pastoralists' in southern Sudan, cattle are not only part of their life but they are the life". A recent study of African pastoralists also found that the number of livestock a household owns is usually the most significant asset determining its wealth (Catley 2000; FEWSnet 2004/5).

Livestock: With an estimated livestock population in the Turkana District of over 143,000 cattle, over 800,000 sheep, over 1,000,000 goats and over 30,000 donkeys, livestock are a key factor in the livelihood platform for the Turkana District. A careful study sponsored by the Kenyan Government showed that livestock income still contributes over 56.6 percent of the total household income in the Turkana District (Republic of Kenya 2002).

${ }^{81}$ This will form part of the discussion in Chapter 6. 
Traditionally, livestock ownership and numbers in Turkana reflect wealth and prestige, help redeem from damage, and are a sacrificial gift (Gulliver 1951). According to informants, their livelihoods are based on livestock. They stated as follows:

The Turkana know each individual animal. It's all they do. They don't build houses, they don't drive motorcars - they just have animals. Their life is animals (Household Interview 10 $10^{\text {th }}$ March 2007, Morulem village; Household Interview $6^{\text {th }}$ June 2007, Lokichar Village).

Turkana households also own livestock to provide meat, milk, blood, hides and skin, and other by-products. Cattle, camels and goats can be used as payment e.g. bridewealth and bloodwealth 82 (Gulliver 1951). Turkana people also constantly strive to increase the number of their livestock. When they attain certain numbers, and initiations, marriages and livestock exchanges may take place. Species composition is also manipulated to ensure that animals' diets and water requirements are met. The sex composition of the herd is manipulated to maintain a higher ratio of female to male animals and thus, a higher level of livestock productivity. Surplus males are traded in town markets to buy nonlivestock goods (e.g. tobacco, beads, rubber tyre sandals, sugar, maize meal etc).

It is important to note that Turkana women have no control over the livestock despite the fact that they are responsible for the care of small animals. In terms of access to livestock, women have access through their husbands, sons, and male relatives, but very limited access to their own. The rationale provided to explain why women have limited access to livestock was summarised in a discussion held with a female key informant, aged 60 years, from Morulem village. She stated as follows:

82 Bloodwealth means compensation paid when responsible for the death of another person. 
The livestock belong to men. They have to herd them to make sure they are not raided. Women can't herd because they can get raped and raided. Women also can't make decisions regarding the cattle. Culturally it is men's responsibility. If we buy cows, the men will take them to the cattle camp and we will never see them again. When our daughters get married, it is the father who has the power to keep the animals given as dowry. We do not like this as it is unfair, but there is little we can do as we have to please our people (Key Informant Interview $12^{\text {th }}$ march 2007 , Morulem village).

In the Turkana District, men are the ones who are in charge of livestock. They make the decisions concerning their animlas and control the financial capital. If a man wishes to divide his herds into several groups, he can do it without referring the matter to the women of the household. For women who spend most of their time around the homestead in the villages, it can be quite difficult to keep track of herd changes. Women interviewed explained that this scenario leaves them vulnerable to cheating if their husband dies and relatives take care of the cattle.

From what I gathered during fieldwork, if a woman becomes a widow, the family's livestock is passed down to her elder son. If she does not have a son, or he is too young to take this responsibility, a relative of the late husband will take care of the livestock. Sons in the family will take over when they grow up. This is how the rule in Turkana society operates, but informants explained that the male relatives do not always follow the rule. One widow informally interviewed stated that the man taking care of her deceased husband's livestock refused to give her any of the benefit, and moved and scattered the herds to camps far away, to hinder her from reaching them. Unfortunately, this had devastating consequences for her family during the 2005-2006 drought and famine, since she no longer had access to the family livestock especially cattle. Those widows who had access to family herds sent their children to cattle camps to drink milk in order to survive. 
The importance of livestock in the Turkana livelihood system cannot be underestimated, and, over the years, there has been considerable growth in the number of sheep and goat herds in the district. For instance, between 1948 and 2002 (see Table 3), the number of sheep and goats doubled. The impact of concentrating considerable stock numbers in a largely arid area is not difficult to imagine. The risks to the ecology are even more serious if we consider the fact that sheep and goats are said to be more destructive to the vegetation than the other animals.

Table 3: Livestock numbers in the Turkana District, 1948 and 2002.

\begin{tabular}{|l|l|l|l|l|}
\hline \multicolumn{2}{|l|}{} & 2002 & $\%$ Increase & \% Decrease \\
\hline Cattle and & 800,000 & $2,439,000$ & 204.9 & 88 \\
\hline $\begin{array}{l}\text { Sheep } \\
\text { goats }\end{array}$ & & 176,000 & - & \\
\hline Donkeys & 96,000 & 32,000 & - & 33.3 \\
\hline
\end{tabular}

Source: Republic of Kenya (2002:9-10) and (Gulliver 1951:7).

It is also interesting to consider that in spite of the remarkable increase in sheep and goats, Turkana pastoralism remains stagnant in the sense that the majority of the people are poor (Republic of Kenya 2002:8). Stock numbers have increased in absolute numbers but the size of the family herds have either remained static or declined. Assuming equal distribution of herds, each of the 80921 households in Turkana by 2002 would own an average of 2 cattle and 30 sheep and goats. This was not any better than the situation in 1948 when a careful study by the ethnographer, Phillip Gulliver found that an average household had 25-30 cattle and 101-150 sheep and goats (Gulliver 1951). A recent study by Niamir-Fuller and Turner (1999) found that the minimum number of livestock units ${ }^{83}$ below which a pastoral household is unable to resist drought cycles is 50 . When

${ }^{83}$ A livestock unit is being defined as 1 cow, 6 sheep or 6 goats (Niamir-Fuller and Turner 1999). 
this ideal number is compared with the actual size of herds, it becomes clear that most Turkana households are currently vulnerable to periodic droughts.

In the Turkana District, there are also very limited veterinary services and the imposition of quarantine has become the endemic reaction to the outbreak of livestock diseases. Indeed, the Turkana district has been under permanent and rigorous cattle quarantine since colonial days. According to Spencer (1983), the quarantine policy provided the colonial regime with a means to confiscate much of the land with the highest agricultural potential for the settlers. Informants lamented that:

For almost 43 years now since independence, the district has been under permanent quarantine because of the existence of contagious Bovine pleurapneumonia (CBPP). Lack of enough free veterinary services has also made it difficult for the Turkana people to reap the benefits of modern animal husbandry (Household Interview 19th May 2007, Morulem village; Household Interview 22nd June 2007, Lokichar Village).

This state of affairs not only restricts cattle sales but also encourages overstocking, and therefore overgrazing. Overstocking and overgrazing are serious ecological problems in the Turkana District at present (Republic of Kenya 2002).

Reciprocal claims: Reciprocal claims are considered as a saving process $^{84}$. In many senses, Turkana people see their livestock as belonging not only to individuals, but also to the extended family. In some cases, the number of livestock paid as bridewealth is often much larger than one man can pay, and the size and composition of bridewealth depends on the wealth of the bridegroom and that of his extended family. According to key

\footnotetext{
84 Reciprocity is covered in detail in Chapter 5 whilst discussing Turkana social
} organisation. 
informants, relatives, neighbours and friends (stock associates) will help and contribute an animal. Animals provided by others are not purely gifts, and those who give expect to get back at a later stage. The reciprocal claim can go from one generation to the next. Informants re-affirmed that the Turkana people traditionally regard the reciprocal system as part of risk management as it enables the community to establish social bonds of mutuality between affiliated parties.

For instance, a Turkana man pays livestock to get a wife, the wife gives him daughters who will be married for bridewealth, and this bridewealth can be invested in new wives and social networks through reciprocity. It follows that a family that has lost livestock, but has daughters of marriageable age, can quickly recover from losses as the girls get married, but also, sons will grow up and get married, which will lead to payment of bridewealth and reduction in the number of cattle. This scenario is best explained by Figure 11, which shows the financial investment of capital and savings from a male perspective. Boys are seen to reduce the number of cattle through payment of bridewealth, and daughters are seen to add to it. In this process, a 16 year old girl informally lamented that:

Girls do not have much say in this process. If she refuses to marry a certain man accepted by the father, her father may even kill her (Informal interview, Morulem village $20^{\text {th }}$ March 2007).

Informants also claimed that by dividing herds into several units, some as reciprocal claims and some taken care of by relatives, reduces the chance of losing everything if a disease erupts, or if a particular cattle camp gets raided. It is also a strategy for not letting the community know how many animals a person has. There is a general fear that knowing the exact number of livestock an individual has may spell disaster or bridewealth and claims will be adjusted accordingly. This is also the reason why it is impossible to get an accurate answer when asking Turkana men how many animals they own. They would either not tell, or they would 
underestimate the number, and informants pointed out that this question was like asking a western (white) man how much money he has in his bank account. 85

Figure 11: Investment of capital from a male perspective

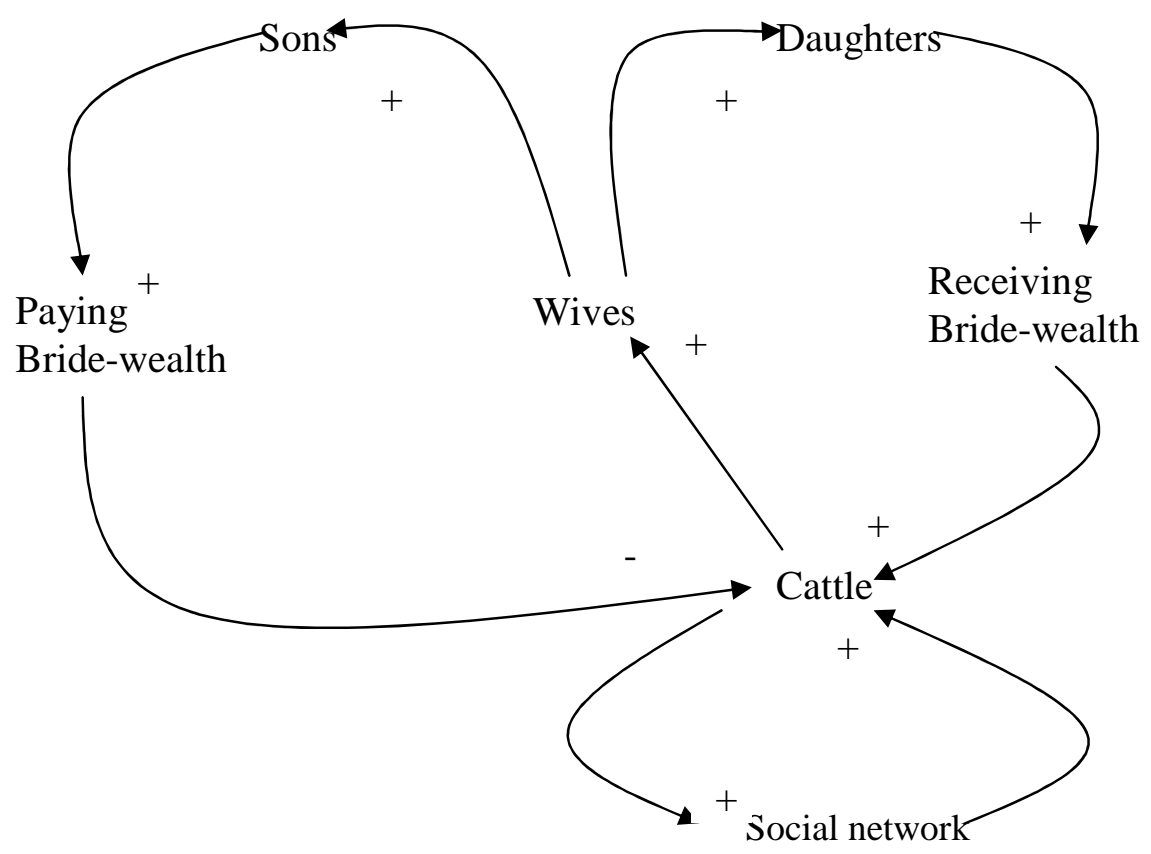

Source: Fieldwork (2007)

One key informant, a 65 year old man from Morulem village, summarised the general idea as to why Turkana do not want other people to know how many animals they own. He stated as follows:

I do not keep all my animals in the same herd. They are scattered because of security. Others should not know the number of your animals. If you keep all in the same herd, people can be jealous of you and even God can be jealous and infect the animals with diseases. Some animals you can lend to other people or relatives. These animals will be given back when you need help or have

\footnotetext{
85 As mentioned in the methodlogy section, it was due to this reason that we were to follow the informants to the grazing fields and physically count their herds. My research assistants knew the informants well, and where their herds used to graze.
} 
to pay bridewealth (Key Informant Interview $13^{\text {th }}$ February 2007, Morulem Village).

\subsubsection{Political capital.}

Political capital can be defined as the ability to use power in support of political or economic positions and to enhance livelihoods (Baumann and Sinha 2001). It is used to mediate access to the other five capitals by influencing the stream of entitlements available through policies, institutions and processes - either to gain access legitimately or illegitimately, to such entitlements, or to deny others access to them (Baumann and Sinha 2001). Turkana people use their political capital, at national and local levels, to influence the stream of entitlement in order to improve the socio-economic status of their region. I will summarise their political activities at both the national and local levels because they encompass the Turkana lifestyle.

As will be explored in Chapter 5, the Turkana people have been engaged in politics, in the form of resistance and small revolts, since time immemorial. These rebellions were protests against the imposition of new rules by colonial and post-independence regimes that subordinated the Turkana and rejected their preference to remain under traditional tribal rule (Oba 1992). In fact, from the colonial era to post-independent Kenya, the Turkana pastoralists were seen as having less to offer the state, especially resources for the export market, which meant they had less political influence either in or on government (Hendrickson, et al. 1998). The colonial regime also assumed that the Turkana people, like other pastoralists in Kenya, should have less political influence, because they were seen as unwilling to modernize, entertained an emotional attachment to their livestock, lacked rules and regulations to manage their resources, and were attached to a traditional way of life (Hendrickson, et al. 1998). Nevertheless, the British administration found it convenient to establish a system of indirect rule. A hierarchy of chiefs was granted considerable 
juridical powers and was made responsible for taxation and labour mobilisation (Lamphear 1976).

This political marginalization continued into the post-independence period. Turkana people are still denied a voice in decision making because they have little political representation at the national level. Although by territory alone the Turkana region is one of the largest districts in Kenya in terms of size, it has only three representatives in the Kenyan parliament. These representatives have a very limited voice in policy formulation in a country dominated and ruled since independence, by major tribes from agriculturally productive areas. Thus the Turkana people have been consistently marginalised throughout history, 86 and therefore have very little influence in the national arena.

In terms of gender, women have, in general, even less access to political capital. The three Turkana representatives in Kenyan parliament are all men. Women are also not allowed to address public gatherings, and even in cases referred to the council of men, a male relative of the offended woman must present her case for her. As women in general have less access to control over various assets, it becomes harder for them to achieve political capital through the accumulation of assets.

When it comes to political capital at the local level, the features of formal political leadership and hierarchy of offices among Turkana people is still debatable. One school of thought claims there is neither a formal system nor a hierarchy (Hogg 1986). Mair (1967), for example, claimed that if the Turkana have any government at all, then they have less than any other people in East Africa, and possibly anywhere in the world. The second school of thought argues that Turkana had a strong local political system.

\footnotetext{
86 A discussion of how Turkana people have been marginalised during the colonial and post-independence period will be the focus of discussion in chapter 5 .
} 
For instance, Apthorpe (1986) established the existence of an effective leadership system. He stated as follows:

There is an actual or a potential state within a state; not least with its own foreign relations and policy (indeed we have seen how Turkana and Karamajong 'chiefs' negotiated their own treaty of amity at the end of the 1970s without aid from either [the Kenya or Uganda] government) (Apthorpe 1986: 18).

I concur with Apthorpe's conclusion, because, during fieldwork, I realised that local chiefs, clan elders, and cultural leaders have political power to varying degrees. Traditionally, the Turkana political system functioned through lineages, with each descent group being an autonomous unit. Spear-masters, witchdoctors and rainmakers have traditionally been able to influence society through their capacity to heal bewitched people, chase demons away, predict the future, foresee crises, and unite the people, and they would be consulted before people went into battles. Lamphear (1992: 31) emphasizes that "the [Great] Diviners were the ones who directed the Turkana warriors as to how it should raid. The elders merely prayed for the success of the warriors. Therefore, if warriors disobeyed the instructions for the raid, it was the diviner they disobeyed, rather than the elders". Informants claimed that despite the fact that the traditionally divine people have lost some of their power due to the influence of Christianity, given the fact that some Turkana people have become Christians, a reasonable number still seek help and advice from traditional healers and doctors.

I also gathered that local (ordinary) Turkana people achieve political capital through accumulation of financial assets, mainly cattle, and social networks. When the social network is large, a person or a group will seek support from relatives and friends, and stand strong in relation to other 
groups. ${ }^{87}$ The poor have in general few assets from which political capital can be drawn.

\subsubsection{Social capital.}

As already described in Chapter One, social capital is one of the social resources upon which people draw when pursuing different livelihood strategies that require coordinated actions (DFID 1994; Scoones 1998; Ellis 2000). Social capital mediates resource flows that are often critical to household livelihood, consumption, health, and status. In Turkana, social capital is important for sustainability of livelihoods, and is the focus of this study. The most critical social activities that influence local people's livelihoods in the Turkana District are family affairs and friendship. ${ }^{8}$

Family affairs: In the context of Turkana society, family affairs mean arranging marriages and divorces and managing widowhood.

Marriage: According to key informants, marriage in Turkana society is a social institution which not only connects a couple, but also extends beyond the nuclear family to encompass the clan. Marriage is a passage into manhood and womanhood; it legitimizes children, and expands peoples' social networks. Turkana people can only marry inside or outside of their section membership, but must marry outside their clan. The main reason for the prohibition of marriage between clan members, as told by informants, is that clan members are considered brothers and sisters concerning reciprocal obligations and rights, and incest is, therefore unacceptable. Other reasons include the desire to avoid problems within

\footnotetext{
87 See Chapter 6 for a thorough discussion of the importance of social networks during the 2005-2006 drought and famine crises.

${ }^{88}$ By friendships, I mean the relationship between families, clans, territorial sections, agesets, and stock associates. Friendships are bonded through exchange and reciprocity. This will be the core of discussion in Chapters 5 and 6 .
} 
the same clan, and to avoid giving birth to ill offspring. ${ }^{89}$ The last reason is to bring more labour in from outside the clan. The mediums that connect the members of the marriage institution are the bridewealth. Turkana pastoralists refer to bridewealth as 'stock of marriage' or 'ngebarin Akortar' (Gulliver 1951). According to informants, marriages are not considered to be permanent and official until a ceremonial ox is slaughtered and livestock are handed over. In practice, the couple may not live together before all the bridewealth is transferred (see Figure 12). Affinal kin (in-law) relationships are especially valued by the Turkana, and the selection of a bride is made with this consideration in mind.

Informants emphasised that if indebtedness is allowed to linger, a sense of both obligation and this trust required to keep the in-law relationship vital may be placed at risk. The bride-wealth is widely distributed among patrilineal and matrilineal ${ }^{90}$ lineages to establish and strengthen kinship between affinals, as well as to establish bonds of marital status between the bride and bridegroom; and the legitimacy of the children conceived in and born out of the union (Gulliver 1951). Among Turkana, children born out of wedlock, in an arrangement in which the bridewealth has not been paid, are not recognised as 'heirs' in the patrilineal home (Gulliver 1951). It is also interesting to note that bridewealth in Turkana is among the highest recorded for pastoral people in East Africa. Gulliver (1951) found that the bride price ranged from 30-50 cattle, 15-50 camels and 85-100 goats. These figures have changed slightly in the recent past. A recent study by McCabe (2002) established that a typical bride-wealth includes 10-30 cattle, 10-30 camels and 1-200 small stock.

89 Turkana people believe that marriage between members of the same clan leads to production of mentally handicapped or paralysed children.

90 These are the lines of descent traced through the paternal and maternal sides of the family respectively. 
Figure 12: A dispute over bride-wealth before a wedding.

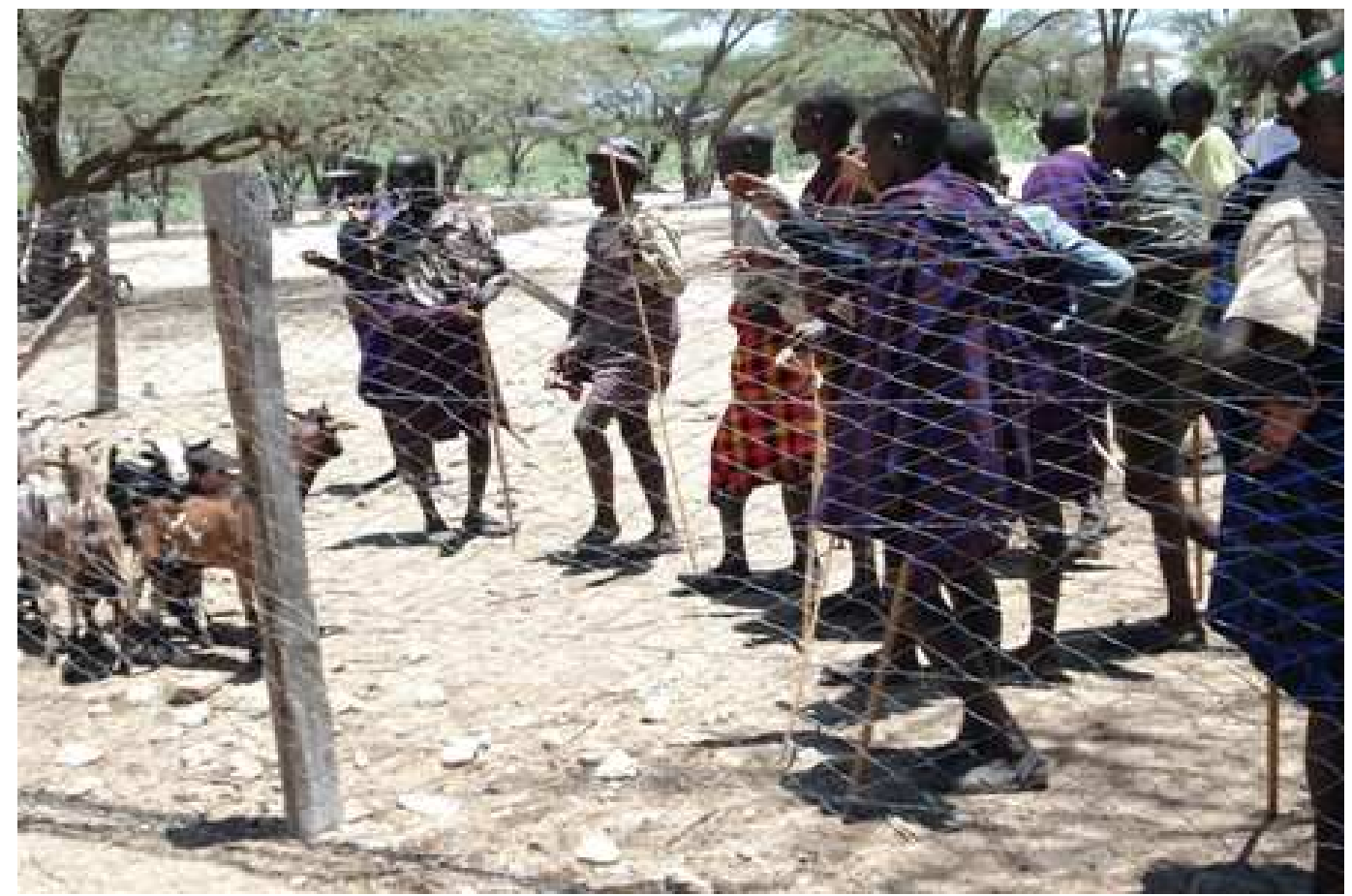

Source: Fieldwork 2007.

Clan elders are consulted at times of marriage, as they are intricately involved in negotiations about the bridewealth animals. A man is a member of his father's clan for life, whereas a woman joins her husband's clan at the time of marriage (see Figure 13 for married women). ${ }^{91}$ According to informants, even though a woman leaves her own lineage for that of her husband, her kin maintains an interest in her affairs and come to her aid according to need throughout her marital life, especially when a food crisis looms. As already discussed, when a man marries a woman, a social relationship based on a series of obligations, claims, and the transfer of cattle, camels and goats will develop between the two families.

\footnotetext{
91 Informants pointed out that in Turkana, youths are not considered adults until they marry. A girl (apese) becomes a woman or wife (aberu) about the age of 20, but a boy (idia) traditionally does not marry and become a man (ekile) until about the age of 30 .
} 
Figure 13: Married Turkana women. ${ }^{92}$

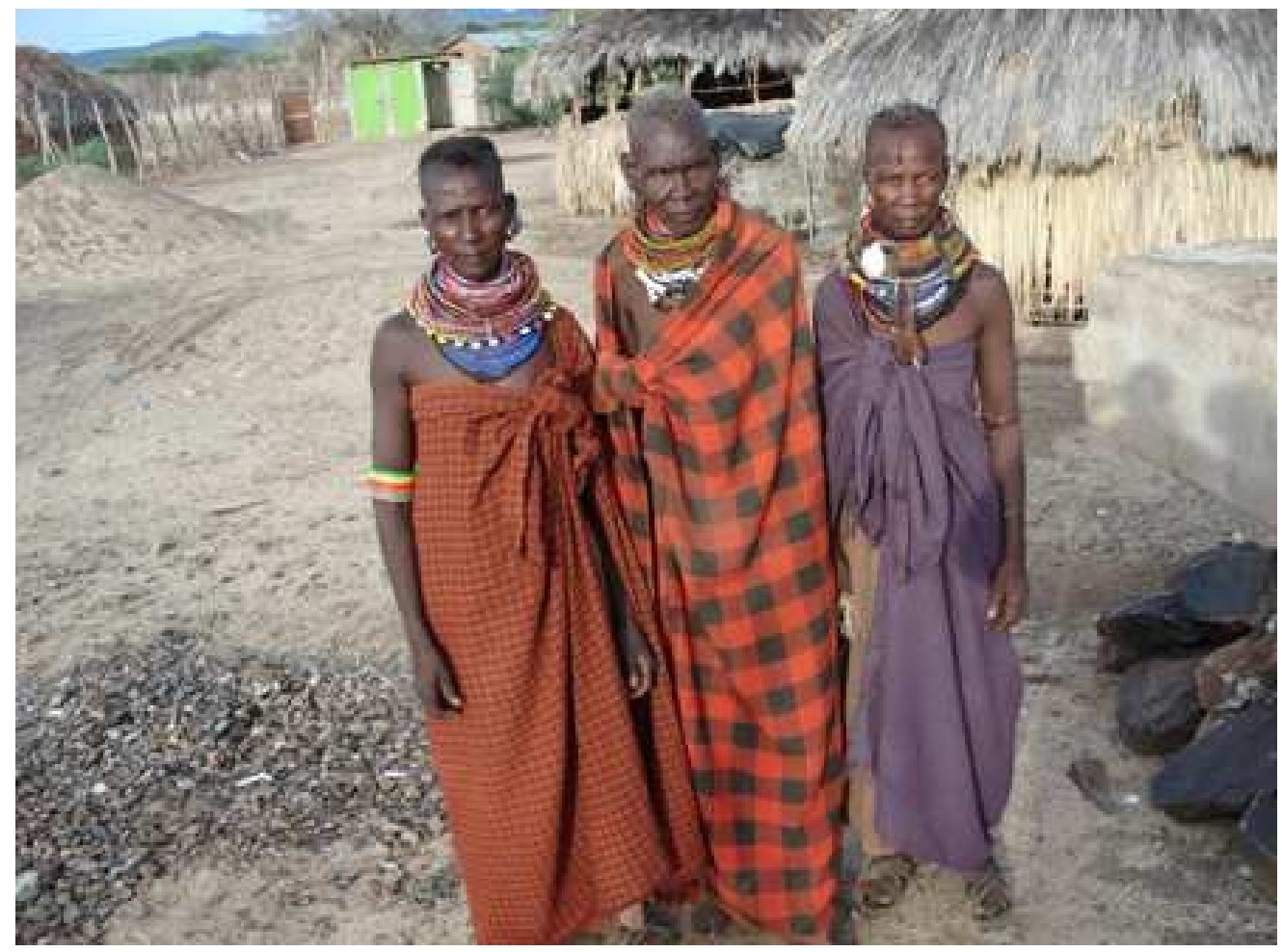

Source: Fieldwork 2007.

Polygamy: This is a very common practice among the Turkana community. During the fieldwork, I noted a different meaning for the term 'co-wives' from what I expected. The following story explains how Turkana people sometimes conceptualise the word co-wife in a different way. During my visit to a family of three co-wives, the eldest wife told me that the husband of X [her co-wife] had arrived. I commented "he is your husband also!" She replied "no he is my husband's younger brother". I then asked, "But why you do you call her co-wife?" "Yes she is, but she is not the wife of my husband". I asked again, "But why do you call her co-wife?" She answered, "Because, the wealth [the cattle] is one [shared]". I therefore learnt that in Turkana society, the term co-wife can sometimes be used to denote the wives of brothers if they pool their wealth and share the same kitchen.

\footnotetext{
92 Note the Ostrich egg beading on the pinafores, and the quantity of beads worn. These are meant only for married Turkana women. These are old women who have earned the highest respect label of akimat.
} 
Apart from the explanation above, the term co-wives in Turkana society also refers to two or more women married to one man. Co-wives are not necessarily living in the same compound or house. The first wife (not necessarily the eldest) is called 'the mother of the house' and she has control over other wives if they both live in the same compound. The husband delegates some authority. As already discussed, one reason for having many wives is that the family will become large, and thereby provide needed labour for herding and protecting the cattle. A point worth mentioning here is that Ellis (2000: 78) argues that large rural households tend to be poorer, in per capita income, than smaller households, although no direction of causality can be inferred from this finding. The opposite seems to be the case amongst Turkana society, where a large household is a symbol of wealth and insurance at times of food crises. The Turkana case therefore concurs with what Toulmin (1986) and Adams (1992) found in Mali that large households are relatively wealthy and resilient and have the ability to avert or cope with crisis through labour substitution and livelihood diversification. A recent study by Nikola (2006) also established that better-off pastoral households tend to be larger than poorer households.

Widowhood: According to informants, in the case of the death of a wife, the husband marries another woman to continue the tasks of the dead. This usually involves caring for him and his children. If a woman becomes a widow, a male relative of her late husband will inherit her. For this marriage she is not paid a bride-wealth. The man, who marries the widow, will take on the reproductive role, and take care of the livestock owned by the deceased. Even though he takes on the reproductive role, the children he produces together with the widow will not belong to him, but to the late husband. Turkana people do not only value social relations with their living relatives and friends, but also with those who have died. 
Informants argued that when a widow remarries out of the clan of her late husband, an equivalent of the value of her bridewealth is refunded to the family of the diseased husband. Furthermore, if she gives birth before she remarries or pays the first instalment of the bridewealth, the child belongs to the deceased husband's family because she or he is considered 'born in his bridewealth'.

Turkana people believe that their spirit will live on through their names, and it is important that each man gets children who can pass the name on. According to my informants, every Turkana fears dying without a son to continue his name and revitalize his influence in this world. From the time a boy is born, he is prepared for his role; and from the time he comes of age to the time he enters the grave, the main concern is that he himself begets children to do for him what he has done for those before him. This is also the reason why a family must marry wives to the sons who have died before the age of marriage. Sons will be married according to the order in which they were born. The eldest son will get married first, and when the family have gathered enough livestock, the next son will follow. If the first son dies before he gets married, the second son will marry a wife for the dead brother. These marriages are sometimes called 'ghost marriages', but are highly regarded by Turkana people.

Divorce: In the Turkana community, disputes between couples are resolved within the family. If the consultation fails to achieve positive results, then the issue is taken before a traditional council of men. The resolutions of the council of men are final, and rarely do the parties in dispute reject them. ${ }^{93}$ According to informants, divorces among the Turkana people are rare. The respondents claimed that one reason for this is the complexity of returning bridewealth. All the cattle have to be traced back, even from relatives who received a share of the bridewealth, a process which can be very complicated given that cattle may have also

93 Turkana people rarely take their family cases to the Kenyan courts. 
been invested in new marriages. When a divorce occurs, the children belong to the father and his family. This is also the case when a man dies. The process of returning the cattle and giving up children hinders widows from getting remarried. Therefore, the clansmen are very keen on the continuation of marriage.

\subsection{4: Chapter summary.}

This chapter began with a brief discussion of the origin of the Turkana people to show that they were pastoralists even before moving to their present location. A detailed background description of the Turkana District as the general study area was then provided. It includes indepth information on the ecology of the Turkana region, and emphasis was put on social-economic resources. It is noted that the environment plays a significant role in the lives of the Turkana people as it impacts either negatively or positively on their survival strategies.

As explored in this chapter, the Turkana District is a region particularly suitable for the study of how pastoralists survive in harsh environments. Turkana people live in an ecological zone that is arid. Much of the district is also characterised by low-lying plains with scattered elevated features. This provides a range of vegetation types, which are exploited between wet and dry seasons by Turkana pastoralists. Tree vegetation mostly appears as riverine vegetation and acacia tortillis is the most valuable tree found along the banks of the Turkwel and Kerio rivers (the two main rivers in the Turkana District). Rainfall is unpredictable, the soils are poor, and water is scarce.

The Turkana people also tend to be both geographically and politically marginalized. The people live in remote places and are often disadvantageously excluded from political processes and associated development efforts. I argue here that, even though the Kenya government 
has made visible efforts to develop the Turkana District by introducing certain resources such as schools, health centres, and access to markets and infrastructure, they remain limited in scope. Therefore, Chapter 5 seeks out why maintenance and intensification of resource use has been limited in the study area. This is through analysis of factors of vulnerability in the Turkana District. 


\section{CHAPTER 5 THE VULNERABILITY CONTEXT IN THE TURKANA DISTRICT}

\subsection{Introduction.}

As pointed out in the theoretical framework in Chapters 1,2 and 4, the predicament in which Turkana people find themselves during famine crisis is as a result of accumulated impacts of various internal and external factors that substantially weaken their asset base. Therefore, it is argued in this chapter that to properly understand how Turkana people respond to food crises, it is imperative to appreciate that given the hostile nature of the Turkana environment as discussed in Chapter 4, there are many factors other than drought that are responsible for food shortages. For instance, a closer look at the history of famines in Turkana over the past century shows that climate change or drought are not solely responsible for recurrent famines, and have not lead to the decreasing resilience of the Turkana pastoral system (Dyson-Hudson 1972). As Lamphear (1972) has noted:

To study a nomadic society such as the Turkana, it is imperative to deal with a wide range of variables. Apart from environmental factors such as the annual deviations from ideal rainfall and grazing distribution, other factors, such as the presence of animal diseases and encroachment by hostile neighbours, can affect and further complicate Turkana livelihood strategies (Lamphear 1992: 13, emphasis added).

Oba (1992), on the other hand, has strongly indicated that for a proper understanding of all the factors that impact negatively on the livelihood of the Turkana people, an analysis should be made of the historical past. This thesis concurs that it may not be possible to adequately understand the nature of the contemporary livelihood responses in the Turkana District without knowledge (however imperfect) of what has gone before. The historical discussion also provides an opportunity to understand the emergence and relevance of different adaptive strategies as used by local 
people overtime. It is argued here that an 'actor'94 portfolio of activities depends not only on the assets and the opportunities available as per the discussion in Chapter 4, but also embedded in the historical socio-cultural repertoire of the actor. Recent studies shed light on the concepts of livelihood 'trajectories', 'styles',95 and 'pathways' which emphasize the consideration of the historical socio-cultural repertoire of the actor(s) in the framework of a livelihood approach (De Haan and Zoomers 2005).

The chapter is divided into two main sections. The first section documents and summarises the literature on factors which assert pressure on the Turkana livelihood system. As pointed out in Chapter 2, this section specifically focuses on the drought impacts, and the historical factors. 96 The historical analysis deals mainly with two distinct phases: the colonial, and the post-independence phases. The argument advanced to consider the colonial period is that the stage for food shortages within the Turkana region was set many decades ago. Oba (1992) contends that the root cause of the food insecurity problems among the Turkana people of today can be traced to the disruptive and inimical policies of both the colonial and postindependent governments. He argues that where policies have been applied, they have tended to be against the interest of the Turkana people. Lamphear (1992) emphasizes that the negative policies towards the Turkana people started with the colonial regime. A Turkana diviner called Lokorijam had a prophetic dream in 1875 about colonial infiltration. He is quoted: "I have seen a great vulture, coming from the sky, and scooping up the land of the Turkana in its talons" (Lamphear 1992: 48). Lamphear (1992: 48) further points out that "it is evident that a colonizing power who

\footnotetext{
94 Actor is a concept devised by Norman Long. See Long's book Development Sociology: Actor Perspectives (2001). According to de Haan and Zoomers (2005), actors of a particular style have similar dispositions and face similar life opportunities, expectations of others, resulting in a livelihood typical of their group.

${ }_{95}$ Nooteboom (2003) emphasises that style represents behaviour that reflects both longterm practices and institutions on one hand and individual strategic choices on the other hand.

96 There are many other factors which impact negatively on the livelihoods of Turkana people. Gulliver (1951) reported animal diseases and raids from neighbouring tribes but in this study limits itself to drought and history of negative policy environment.
} 
would wish to bring civilization [to the Turkana] will be obliged to fight them, to repress them or destroy them". For instance, the British colonial administration, in their attempts to pacify the Turkana at the beginning of the $20^{\text {th }}$ century, caused profound disruption. The Turkana lost a lot in terms of people and livestock. Abuse of commonly held pastoral resources was also experienced during this period. The British administration imposed their authority by drawing ethnic and national boundaries, and created grazing blocks that restricted cattle movements. Thus, pastoralism was subordinated as a primitive mode of production and efforts were made to discourage it. These policies seriously weakened and disrupted the Turkana peoples' indigenous production system, contributed to their economic and political marginalisation, and left them more vulnerable to periodic droughts and famine.

During the post-independence period, the Kenyan government seems to have perpetuated the colonial relic, as it was keen to change the Turkana, rather than the circumstances that surrounded them. They promoted sedentary livestock production which was at variance with indigenous livelihood practices. In particular, I will briefly review the historical process through which the Turkana area was integrated into the present state formation, and analyse more closely the impact this process had on local level survival strategies.

Section Two is a detailed discussion of the customary livelihood responses of the Turkana people, as well as cultural modes of existence developed to weather the effects of food crises, 97 with a special focus on the role of social capital.98 The need to consider customary livelihood responses

\footnotetext{
${ }^{97}$ In Chapter 6, I will make a thorough assessment to determine how effective some of these indigenous livelihood strategies still are at present times, and with what frequency and intensity they were implemented during the 2005-2006 drought and famine period. 98 The focus of the study is on social capital eventhough the Turkana people were also involved in various economic activities for survival, which are not focus of discussion in this thesis. These activities included agriculture, hunting, gathering, fishing, and other small scale activities (Gulliver 1951, 1955).
} 
stems from arguments raised by historians. Soja (1968) and Kjekshus (1977) both argue that during the pre-colinial times, East African pastoral economies had developed a well-tuned balance between humans and nature. They described pre-colonial East Africa as a 'sea' of pastoralism surrounded by a few islands of settled agricultural communities. They argued that many of the nomadic communities such as the Turkana were wealthy, and had indigenous ways to cope with impending food crises within their social networks. Van Zwanenberg and King support this line of thought and posit that in the pre-colonial period, pastoralists were the dominant force in East Africa (Van Zwanenberg and King 1975). These arguments are contrary to what is being experienced today where Turkana pastoralists are highly susceptible to famine. Therefore, contemporary change in their level of vulnerability also calls for an evaluation of their customary livelihood activities. This enables us to have a fully critical overview. If in the past Turkana people used to survive food crises on their own, why should they not sustain their livelihood in the contemporary times? It is believed that this discussion will enable us to understand how the Turkana people's attempt to adapt to the changing circumstances can be supported.

Therefore, this chapter makes interpretation and analysis of the data in the rest of the thesis more meaningful. This knowledge may enable us to gain satisfactory insight into the challenges facing Turkana people in attempting to secure a reliable and sustained livelihood, and how their livelihood responses can best be strengthened. It also becomes easier to draw comparisons with how the Turkana pastoral production system functioned during the 2005-2006 'drought stress' threat period. This will be part of the discussion in Chapters 6 and 7. Results from the key informant interviews and household interviews form the backbone of this chapter. This is complemented by local level information gathered from other sources such as informal interviews, observation, and case histories, as well as from a review of several Turkana studies. 


\subsection{Factors asserting pressure on the Turkana livelihood system.}

\subsubsection{Drought and famine occurrence.}

Periodically, the Turkana livelihood system has experienced a lot of pressure leading to widespread food shortages. 99 Swift (1985) and the Turkana Drought Contingency Unit (1992) extensively traced famine and rainfall patterns in Turkana, and reported that, on average, a district-wide disaster involving human starvation occurs once every 10 years. Although memories of food shortages may not be accurate, Table 4 indicates an increasing vulnerability and frequency of famine occurrences (Swift 1985; the Turkana Drought Contingency Unit 1992). A discussion with key informants in the surveyed villages (Morulem and Lokichar) in Turkana revealed that food shortages in Turkana were predominantly the result of drought. The respondents' comments concurred with an earlier model designed by Songreah engineers. As part of their consultancy to examine the Turkwel Gorge Multipurpose project and downstream effects in Kenya, Songreah engineers developed a model to explain "Factors influencing migration to and from settlements" in Turkana (Norconsult 1990: 87). They found that the major push factor is drought. I find the model helpful for this study, and have reproduced it here in Figure 14.

Therefore, while analysing occurrences of food shortages in the Turkana District, it is worth noting that the local people name the famine periods as they experience or perceive them. Each prolonged famine period has a specific name. 100 Table 4 indicates the years in which famine has occurred since the early 1920s, and includes the Turkana name given to each period and local people's perception. Respondents stressed that the famine years listed in Table 4 represent acute cases only since those were the ones they could remember. As shown in Table 4, it is clear that throughout

\footnotetext{
99 Refer to the discussion in Chapter 1.

${ }^{100}$ It has not been possible to locate data containing information about the exact names, dates, and types of stress which occurred by the time the Turkana people occupied their present location, estimated to be around the 1850s. Most of the data shows the period from the colonial era (see Table 4).
} 
the history of the Turkana, drought occurrences have in most cases been followed by famines.

Table 4: Major historical droughts and famines, names and descriptions among the Turkana.

\begin{tabular}{|c|c|c|}
\hline Year & $\begin{array}{l}\text { Local (Turkana) } \\
\text { name }\end{array}$ & Local perceptions \\
\hline 1925 & Ekwakoit & Bad hunger. \\
\hline 1930 & Abrikae & Drought and bad hunger. \\
\hline 1942 & Lolewo & Bad animal disease. \\
\hline 1943 & Ekuwan loyang & Drought and famine. \\
\hline 1947 & Ataa nachoke & Animal disease and famine. \\
\hline 1949 & Ngilowi & Animal disease. \\
\hline 1952 & Lotira & Animal disease, drought and famine. \\
\hline $\begin{array}{l}1953- \\
1954\end{array}$ & Lokulit & Bad years, famine continued. \\
\hline 1960 & Namotor & $\begin{array}{l}\text { Drought and famine. All people were } \\
\text { starving. }\end{array}$ \\
\hline 1966 & Etop & Serious but short drought. \\
\hline 1971 & Lolewo & Cholera epidemic, many deaths. \\
\hline $\begin{array}{l}1979- \\
1981\end{array}$ & $\begin{array}{l}\text { Loukoi (CCPP), } \\
\text { Lopiar, } \\
\text { Atanayanaye }\end{array}$ & $\begin{array}{l}\text { Animal disease (CCPP, anthrax), } \\
\text { security problems, famine. }\end{array}$ \\
\hline 1984 & Kilejok, Kidirik & Minimal rain, animal raiding. \\
\hline $\begin{array}{l}1990- \\
1992\end{array}$ & Lopiar & $\begin{array}{l}\text { Skins everywhere, many livestock } \\
\text { deaths. }\end{array}$ \\
\hline 1997 & Etop & Serious but short drought. \\
\hline $\begin{array}{l}2005- \\
2006\end{array}$ & Kumando & $\begin{array}{l}\text { Drought and bad hunger. Drought } \\
\text { which terminated everything. }\end{array}$ \\
\hline
\end{tabular}

Source: Swift (1985); Turkana Drought Contingency Unit (1992); and Field data (2007). 


\subsubsection{Phases of drought and effects in Turkana.}

It is now arguable that drought conditions in the Turkana area are becoming the norm while non-drought years are the exception (Levile and Crosskey 2006). But, in order to understand drought impacts in Turkana, one fundamental question needs to be answered: "How are Turkana pastoralist livelihoods affected by drought?” According to Swift (1985) and the Turkana Drought Contingency Unit (1992), drought conditions in Turkana have had serious implications in the past. The impact has mainly been on the herders' economy and their social lives. Both Figures 14 and 15 provide an overview of the socio-economic implications of drought related stress in the Turkana District. Some of these drought related events will be analysed in chapters 6 and 7 .

According to Swift (1985), Norconsult (1990), Turkana Drought Contingency Unit (1992), and field respondents, the most direct effect of a shortage in rainfall on Turkana pastoralists' livelihoods is the drying up of water sources and declining forage resources for livestock, as shown in both Figures 14 and 15. Livestock, which are the most important asset for Turkana pastoralists, are directly dependent on access to forage and water resources. Therefore, when forage supply is depleted, nutritional condition of livestock deteriorates, affecting their health, for example, their fertility and live weights. As seen in Figures 14 and 15, animal death rates increase, and, due to this, there are many skins on the market, and prices fall. Pastoral households increasingly try to sell or barter part of their animals, but market prices decline rapidly as there are few buyers. Cereals are not easily available since, in case of the nation-wide drought, the farm sector is affected by low production whereby cereal prices escalate, especially in the absence of price control. Alternative sources such as hunting and gathering, sale of firewood, and alternative income through casual employment could be sought. Movements become uneven, and households may break up to reduce the demand for food, though this may 
also lead to conflict with other herders. As shown in Figure 14, those herders who end up in settlements could either look for employment to support the pastoral system, or try to accumulate livestock, and, when enough stock is accumulated and the conditions are good, return to a pastoral system, or essentially stay as destitute or dependents around settlements.

Figure 14: Factors influencing migration to and from settlements in Turkana.

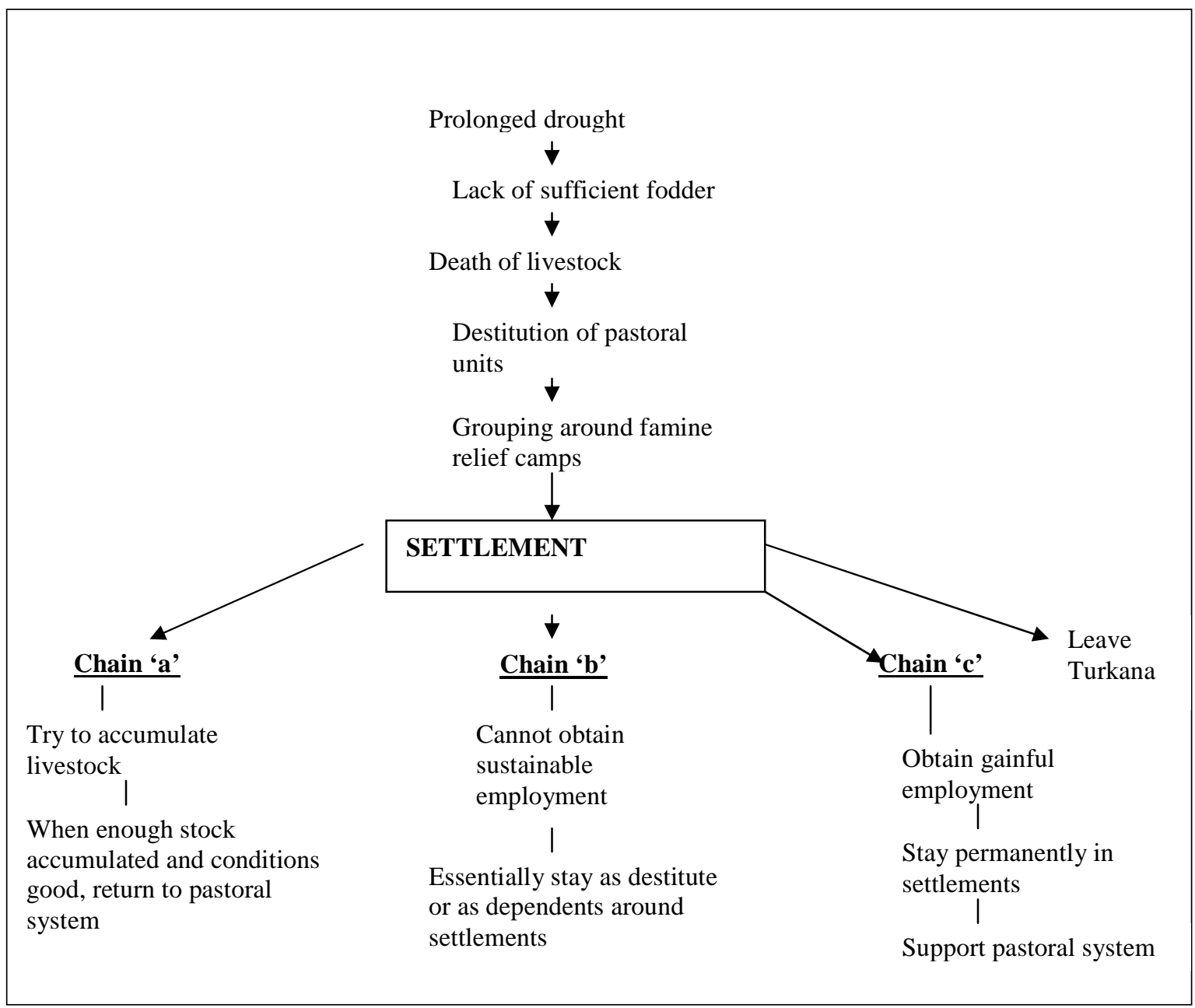

Source: Norconsult 1990:6.

Figure 15 further shows that during drought periods, changes in the distribution of wealth become notable. The rich, with many assets, are in a fortunate and better position, and may even exploit the situation for their benefit, as they can acquire more assets (e.g. livestock) at relatively low 
prices. The poor become poorer, as they need to sell whatever they have in order to purchase cereals (Swift 1985; Turkana Drought Contingency Unit (1992). Toulmin (1986) observes that several case studies about the impact of drought on pastoral communities in Sub-Saharan Africa show a similar pattern to that of the Turkana, shown in Figures 14 and 15.

Figure 15: Events in the build up to drought related stress in Turkana.

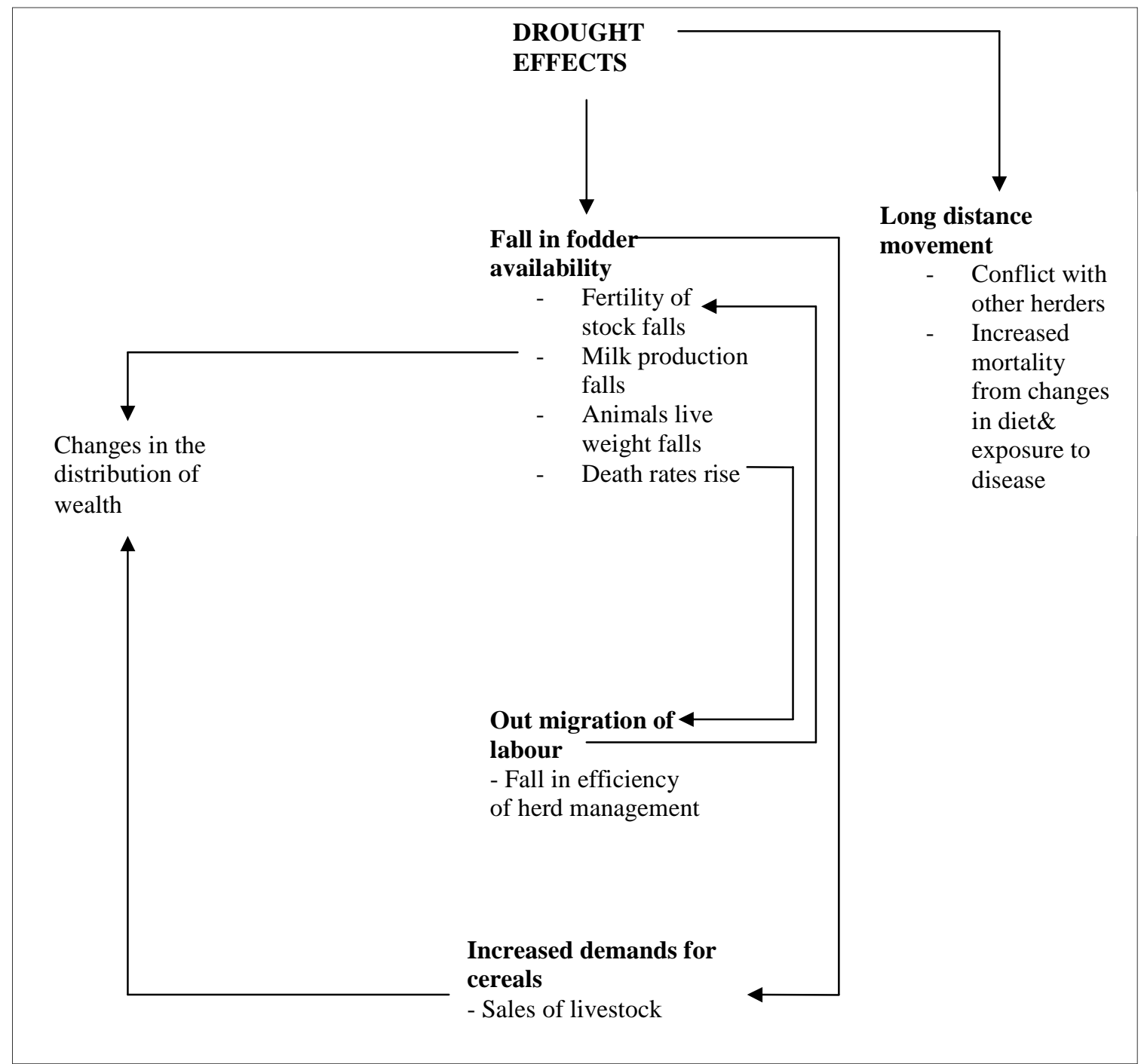

Source: Swift (1985) and Turkana Drought Contingency Unit (1992). 


\subsubsection{History of Negative Policy Environment.}

\subsubsection{The Colonial period.}

Between 1885 and 1963, Kenya was under the 'protection' of the British administration. Morgan (1973) argues that for easier management, the British administration divided Kenya into three distinct regions: the highly developed White Highlands; a less developed naturelands which was a pool of cheap labour; and the frontier/pastoral zones that were out of bounds. The British were mainly interested in the 'White Highlands'. ${ }^{101}$. According to Morgan (1973), the prime interest of the British in the 'white Highlands' was derived from a desire for transformation and intensification of crop production for export. The pastoral areas in Kenya were then seen by the British administration as areas where they could not develop reliable sources of strategic raw materials with which to supply their home industries. This was compounded by the distance of pastoral territories from the administrative centre of the colonial powers. The pastoral areas were closed off and one needed a permit to travel there. Barber (1968) pointed out that the colonial government priority in pastoral areas was order rather than development. Left on their own, pastoralists suffered from negligence and lack of attention. They witnessed very little interaction with the other communities in Kenya, and development within their areas was only focused on preserving security and the culture of the community (Republic of Kenya 1992).

\subsection{The era of Engolekume ${ }^{102}, 1888-1963$.}

Von Hohnel (1894) and Lamphear (1992) explained that Count Samuel Teleki Von Szek, a Transylvania aristocrat, whose expedition reached Turkana in June of 1888, was among the first brutal Europeans to travel to Turkana. He had a very low opinion of Africans and boasted openly of

101 'White highlands' were areas with fertile soil and favourable climatic conditions for agricultural production.

${ }_{102}$ This refers to the period of colonial administration in the Turkana District 
shooting 300 "niggers" during his expedition. "I do not like the blackman", he wrote, "I regard him as one big monkey"103 (Lamphear 1992: 53). He was accompanied by an Austrian naval lieutenant, Ritter Ludwig von Hohnel, who served as the expedition's geographer and recorder. They were followed by a succession of explorers: Fredrick Jackson, a British man in 1889; Donaldson Smith an American in 1895; Arthur H. Neumann a Briton in 1895; and Vittorio Bottego, an Italian, Henry Cavendish, a British adventurer, and Hugh Cholmondeley, a British hunter in 1897. Lamphear (1976) expressed that these Europeans were also followed by a series of mostly prejudiced and sometimes violent explorers and hunters. It could be noted that despite these explorers visiting Turkana, key decisions which would have profound effects on the future of Turkana were still being made in faroff places as the British administration was based within the Kenya highlands (Lamphear 1992). Barber (1968) claims that Turkana was a marginal area in every way. The harsh environment and sparse population offered few attractions to the colonial government. Turkana was not considered to be strategically important, and it showed no evidence of economic potential to justify the cost of subjecting it to regular administration. As a result, little if any attention was given to the Turkana pastoralists, their environment or their social promotion

Hendrickson, et al. (1998) argue that the isolation of the Turkana people was generally because of the colonial government's mistrust of their lifestyle. The colonial government had a notion that Turkana pastoralists were politically unreliable and difficult to control, and therefore a threat to security. Furthermore, the Turkana people were perceived as primitive, violent, and hostile towards change, and they lacked loyalty because of crossborder movements (Hendrickson, et al. 1998). But Markasis (1993: 193) argues to the contrary that the use of negative terms such as "warlike" and "violent" was a way of creating an enemy image and using it as

103 This testimony portrays the negative attitude the first Europeans had against Turkana people. 
an ideological justification for counter aggression. I learned during fieldwork that some of these perceptions of the Turkana community have persisted to date, sometimes contributing to hostile reactions towards the current Kenyan government.

\subsection{The period of apetaret ${ }^{104}, 1901-1924$.}

Generally, the period 1901-1924 is known as apetaret (the dispersals'). It is within this period that the British engaged in their last major raid on the Turkana people (Erukudi 1985). ${ }^{105}$ The war led to noticeable movements of various Turkana groups to other areas outside their territory, and the majority were welcomed by their neighbours the Samburu, Borana, Rendille, Karamajong, and Ngijiye as new immigrants, or accepted either as workers or associates for mutual benefit. It is worth noting here that the brutal military action taken against the Turkana during this period was instigated by two major factors: Firstly, there were inaccurate and exaggerated accounts of the circumstances in Turkana by early European fortune hunters. For instance, Von Hohnel (1894) had illustrated an etching depicting three Turkana warriors flying in the air supposedly to attack him. It could be argued that these illustrations were meant to overdramatize the Turkana people as warlike and fierce people, and to frighten and encourage the British to prepare before launching any attack on the Turkana, since this sketchy information led to the shooting of any male Turkana found holding a spear or walking stick. During my working experience and fieldwork in Turkana in 1999 and 2007 respectively, I learnt that the spear and walking stick are part of the normal attire for Turkana men. Lamphear (1992) also argues that the trooping dance (akinyiak), which is often done while raising the walking stick held in one hand, is a traditional activity and part of the welcome gesture, which does not actually mean flying in the air to fight somebody.

104 This is the period of dispersals in the Turkana District.

105 However, Lamphear (1992) reports that there were a number of isolated conflicts, between the British and the Turkana in the period of 1897 and 1899. 
Secondly, Lamphear (1992) emphasizes the perceived need by the British to conquer the Turkana people and confine them within the Turkana region for the sake of peace and order, and to save neighbouring communities from being swallowed up. But as discussed, the conquest had nothing to do with peace but had a lot to do with protecting British interests. Collins (1961) and Lamphear (1992) remark that, contrary to the British idea of protecting Turkana neighbours, the conquest was actually aimed at disrupting the evolving relationship between the Turkana and Ethiopians which threatened British economic and political interests in East Africa. For instance, by the 19 th $^{\text {ch }}$ century, King Menelik II of Ethiopia was expanding his realm of influence into the region south and west of the country. The Ethiopians were laying claims to the Turkana area and obtaining ivory from the Turkana people by bartering firearms with them, which the Turkana used with intense ferocity to raid other tribes and fight the colonial power. This expansion made the British apprehensive about the Ethiopian motives, and they decided to expand their influence to the Turkana region. Thus, the British expansion was aimed at counteracting the Ethiopian expansion (Barber 1968). There was also concern that the Turkana threat was forcing other groups southward, thereby posing a serious challenge to settlers in the white highlands (Muller 1989).

According to Lamphear (1976), the peak of the British invasion was experienced in the period 1911-1918. During this time, the British mounted a series of serious military expeditions to break Turkana resistance and to seize firearms. Despite being poorly armed, and rather than being subdued, the Turkana responded with valour by escalating raids on other tribes and the King's African Rifles (KAR) ${ }^{106}$ (Lamphear 1976; Barber 1968). This plunged the region into one of the most protracted and costly wars of primary resistance in Africa (Barber 1968; Lamphear 1976). The Turkana evolved an effective system for the universal

\footnotetext{
${ }^{106}$ Apart from British soldiers, many of the king's African rifles were members of other Kenyan tribes.
} 
mobilisation of young men into well-drilled corporate units. This made it possible for them to resist for over ten years the imposition of colonial hegemony over them (Lamphear 1976). By 1918, after many thousands of cattle and small stock had been confiscated by the British, the Turkana heroic struggle to keep their independence was dealt a mortal blow. Thus the British succeeded in pacifying Turkana resistance in 1918 (Lamphear 1976; Muller 1989).

During this era of primary resistance, the Turkana suffered heavy losses in men and property, and there was a complete disruption of their economy leaving many households impoverished (Lamphear 1976; Barber 1968; Muller 1989). Lamphear (1992) describes the experiences as traumatic and devastating. The Turkana were fired at from sight, and, on more than one occasion, they referred to themselves as wild animals hunted through the bush by the colonial government. Lamphear (1976) maintained that the imperial wars and punitive expeditions also destroyed the existing institutional relationships with neighbouring ethnic groups, making the basis for inter-ethnic relations insecure. Thus, the social security system of reciprocal assistance was completely disrupted. It also undermined the group's political unity, as different sections were identified with opposing belligerent parties (Lamphear 1976). Many of their livestock were captured and carried away by colonial troops. While it may be difficult to know how many people were killed or died from starvation and diseases arising from the livestock confiscation, historical records show, for instance, that between 1916 and 1918, an estimated quarter million livestock were confiscated from the Turkana, and many more were slaughtered by the various British expeditions and garrisons for their rations. The reduction of Turkana herds was carried out far more systematically and extensively than any which had occurred before. By the end of 1918, the northern sections had lost nearly all their cattle, and as late as 1933, many Turkana herds had still not been rebuilt to their former size (Barber 1968; Lamphear 1976; Muller 1989). 
Further reports during the same period expressed the fear that the district was faced with the problems of rapidly increasing human population and declining livestock numbers. Diseases and raids by the colonial troops were blamed for the depletion of the herds (Lamphear 1976). Livestock diseases such as rinderpest and pleuropneumonia, which were unknown in the past, became a permanent scourge to the animal population during this period. On this, Van Zwanenberg and King comment:

Red water, East Coast fever, rinderpest,
pleuropneumonia and tsetse fly have been major
scourges of the animal population of most of the
pastoral communities in the nineteenth century. There
is some evidence which suggests that these diseases
have become common only fairly recently to East
Africa, as a result of greater mobility and the opening of
the country by explorers. Redwater and East Coast
fever, for instance both tick borne diseases, are said to
have been imported through South Africa and
Madagascar around 1870 s. Rinderpest is a virus which
seems to have been introduced in Africa through
Northern part of East Africa around 1840s, and
pleuropneumonia, also a virus infected African cattle
from South Africa at about the same time" (Van
Zwanenberg and King 1975: 85).

By the mid 1920s, officers on the spot voiced concern that large captures had led to cases of human-induced starvation and hoped that the colonial policy towards the Turkana would be reversed to avert a future economic crisis (Turkana Political Records: Miscelleneous: 1921-1945 File No. TURK/17, DC/TURK 1/1).

During the British rule in the Tukana District, administrative and police posts were established in Lodwar ${ }^{107}$ and centres near the Ethiopian and Sudan border. Taxes were collected, and the king's African rifles helped to collect tax. The British administration first collected hut tax in the Turkana region in 1905. As will be explored below, the establishment of

107 This centre later became the district headquarters after Kenya became independent in 1963. 
the British administration in Turkana had an important consequence on land use and the socio-economic wellbeing of the Turkana people. However, Gulliver (1951) pointed out that most Turkana people were not greatly influenced by British administration.

\subsection{Imperialism and land-use system.}

The colonial policy in relation to land use is of particular interest to this study, as the issue constitutes the major underlying causes for changes in livelihood strategies in Turkana during the colonial era. As discussed above, prior to the colonial rule, the relationships between the Turkana and their neighbours in Kenya, Uganda, Sudan, and Ethiopia were characterized by open borders, that is, there were no land boundaries separating the areas where the various communities lived or grazed their livestock herds. The Turkana had access to grazing lands in Baringo, the land of the Marakwet, the Njemps, the Pokot, the Samburu, Karamajong and Ngijiye in Uganda, Topos in Sudan, Merille, Dodos, and Dongiro in Ethiopia (Lamphear 1992). The situation drastically changed when the British colonial rule was enforced in the Turkana area.

Following the pacification in 1918, the British disarmed the Turkana people, making them vulnerable to raids from their neighbouring tribes (Oba 1992). The British ratified the borders with Ethiopia, and embarked on policies which had profound ramifications for Turkana pastoralism. One policy prohibited Turkana from crossing international borders. They created a no-man's land along the international frontiers. The idea was to make important pasture and water resources, which Turkana depended upon during drought years, legally inaccessible (Oba 1992). Lamphear (1976) reports that violators of these restrictions were punished by an instant fine of 20 percent of the total number of livestock found trespassing. 
As explored in Chapter 1, fixed borders are alien to the pastoral mode of land use. The borders hinder free movement of pastoralists and livestock, and access to grazing land and water sources which are important during drought conditions (Spencer 1983). Therefore, the establishment of borders prohibited their movements between the wet season grazing within Turkana territory, and the dry season grazing movements, which took them across international borders (Oba 1992). Traditionally, the Turkana and other groups each maintained concessions over grazing and water rights, expecting reciprocal access when conditions were reversed. This important fact, though well-known, was ignored by the British administration (Turkana Development Annual Report 1938). Instead, the administration assumed the responsibility of arranging with those neighbouring countries also under British administration (Sudan and Uganda), but not including Ethiopia, for the Turkana to be allowed to use grazing and water resources across international borders. The colonial administration also denied the Dassenetch pastoralists in Ethiopia access to their traditional grazing grounds in Kenya. The Ethiopians countered by refusing Turkana access to Ethiopian territory (Oba 1992).

Notwithstanding their ultimate submission, the Turkana were alarmed by the attitude of the British administration. They viewed the British action as aimed at punishing them, while ignoring their rights to grazing grounds outside their territory. It was their conviction that the border administration and security structures were merely used to reinforce control over them, and to affect their mode of nomadism, which results from ecological demands necessitating mobility to balance ecological heterogeneity (Oba 1992).

Generally, these artificial boundaries imposed by the British to control human and capital livestock movements caused serious ecological problems in the Turkana region. Following the droughts of the 1930s and '40s, environmental degradation became a contentious issue in the whole 
of northern West Kenya. The colonial government then introduced controlled grazing schemes culminating in the first ten-year development plan (1946-1955) aimed at rehabilitating rangelands (Dietz 1987a; MigotAdhola and Little 1981).

Grazing schemes: Introduced grazing schemes were expected to alleviate environmental degradation (Turkana Development Annual Report 1943). According to the British, the reasons for the establishment of the grazing schemes were twofold: Firstly, to facilitate proper utilization of resources which were underutilised, and secondly, to push the Turkana away from the inter-tribal boundary to ensure they were safe (Turkana Development Annual Report 1943). The idea of grazing schemes was vehemently opposed by the Turkana people. According to Oba (1992), the grazing schemes failed because it had ignored three important factors of Turkana rangelands: Firstly, rainfall regimes are highly erratic and vary both in space and time; thus, one good year is usually followed by a series of bad ones, occasioning opening up of all grazing resources. Secondly, some grazing areas depended on by Turkana during periods of drought lie outside the district. Thirdly, the traditional wet and dry season grazing areas are deliberately set aside for use when needed most, and access to these resources is essential for the survival of the Turkana pastoral economy. The schemes failed to incorporate these traditional seasonal movements, superimposing measures which could not work. Oba (1992) argues further that since Turkana people are pastoralists, grazing control is unlikely to succeed. The low and unreliable rainfall in Turkana dictates that any form of grazing system must be extremely flexible and must be built on the traditional Turkana grazing movements, taking into consideration the need to cooperate with neighbouring countries of Uganda, Sudan and Ethiopia.

In addition to border restrictions and movement control, and the grazing schemes, the colonial government also imposed on the Turkana people 
market taxes, destocking campaigns, and quarantine. Initially, vigorous quarantine regulation was meant to restrict the spread of animal diseases, but instead, it provided a means to confiscate much of the land with the highest agricultural potential to settlers (Spencer 1983). Taxation also made border trade difficult and less profitable. By the 19th Century, most Turkana groups had adopted transhumance, a settled form of pastoralism through which only animals are moved in search of pasture and waters while the families settle 'permanently' in given locations (Ocan 1992).

\subsection{Famine amelioration measures.}

Food insecurity was a common feature in the Turkana region, even during the pre-colonial period. The earliest famine documented occurred in 1925 (Swift 1985; Turkana Drought Contingency Unit 1992). As already discussed, earlier cases of famine were generally as a result of drought, diseases, and raids from the neighbouring communities. But, during the colonial period, the drought risks were compounded by the colonial administration policies in relation to land, as discussed above. The colonial period was more disruptive in working towards alleviating famine in the Turkana area. As an early short-term response to food shortages, the British administration imported maize-meal to be sold to famished Turkana people at a subsidized price. This took place as early as 1932 (Hogg 1982). During very severe famine conditions, the colonial government would resort to providing free maize meal to the old people and the children. Other measures included providing food-for-work, and sending the most desperate paupers to permanent famine relief camps which were set at Furguson's Gulf on Lake Rudolf (now Lake Turkana), and Lodwar (Turkana Development Annual Report 1948, 1949). By 1937, the colonial government designed a long-term measure to food problems in the area by aggressively promoting fishing at Ferguson's Gulf as the best alternative to famine relief. In the period 1937 to 1942, about 26 destitute families on average were maintained at Ferguson's Gulf on the basis of 
fishing (Turkana Development Annual Report 1936, 1938, 1939, 1942). But the fishing project later failed because the fish supplies varied as the level of the lake fluctuated (Turkana District Annual Report 1948). But as will be discussed below, the project was later revived through the assistance of the Norwegian government after Kenya became independent.

In summary, looking at the history of the Turkana people during the colonial regime, it is understood that food security could not be achieved in the Turkana area through the Britishtype rule of force from above, which ignored the indigenous social-economic and political institutions, and goals of the local people. The major lesson learnt here is that sustainable livelihood in Turkana could only be achieved with the people, not for the people.

\subsubsection{Post-independence period.}

\subsection{Introduction.}

At independence in 1963, the Kenyan government realised the chronic nature of food insecurity and underdevelopment in pastoral areas. A holistic development plan and strategies were formulated for pastoral areas recognising the potential of livestock products for export and consumption (Republic of Kenya 1992). These measures saw some greater attention being focused on pastoral districts. However, these measures were still limited in terms of their capacity to meet the needs of the pastoral population since they were based on the acceptance of a neoMalthusian understanding of the situation. This meant that policies to encourage pastoral production were only to be directed towards sedentary livestock production, a system not suited to climate and ecological conditions in pastoral areas (Brown 1963; Dames 1964). The measures also meant changing the pastoralists themselves, rather than the circumstances that surround their existence. 


\subsubsection{Inappropriate government policies for pastoral areas.}

The impact of government policies on pastoralists in Kenya has been widely documented (Republic of Kenya 1992, 2002). Some of these measures designed to remedy the problems of food shortages and underdevelopment in pastoral areas included: the Special Rural Development Project and the Kenya Livestock Development Project. These projects are briefly discussed below:

Special Rural Development Project (SRDP): This was undertaken in five pastoral districts with the objective of testing regional planning and project implementation. These pilot projects had minimal success as local community participation was very low, and there was no inbuilt machinery for sustainability of completed projects (Republic of Kenya 1992).

Kenya Livestock Development Project (KLDP) 1969-1981: Further attempts to develop livestock industry in pastoral areas were made through the Kenya Livestock Development Project (KLDP). This was a government designed project aimed at helping pastoralists from destroying their fragile land. The project was a replication of a range management model developed in America and Australia for their drylands. The model was tried in Africa for the first time in the 1960s and '70s. The project proposed a beef stratification policy where the rangelands in the north of Kenya were managed as grazing blocks. Boreholes and dams were developed to provide water for the animals. The plan was that the grazing blocks would produce immature stock that would be fattened in the southern drylands that were wetter. The southern rangelands in Narok and Kajiado districts were organised into group ranches to buy and fatten the immature stock. To achieve that, the national livestock marketing division was strengthened to purchase the immature stock, and the Kenya Meat Commission was to be the final destination for the product (Republic of Kenya 1992). 
The project failed due to lack of sustainability. The local people were not involved in the initiation and implementation of the project. The planners thought that they could modernize the economy from above simply by introducing modern production technology and encouraging economic differentiation (Omosa 2003). The project definition of pastoral development was that of settlements based service delivery, implying that the pastoralists were to pay for the growing demand of beef in Kenya. This ignored the fact that these were people with very specific needs for frequent movements. The Kenya Livestock Development Project intervention saw an increase in health and education services and vaccination of livestock. With these free services, the local people got used to government provision of their needs, slowing down their practice of pastoralism (Omosa 2003; Republic of Kenya 1992). It should be noted that the project was meant for all the pastoral areas, but ignored the Turkana District completely (Livingstone 1986). This was despite the fact that, up to 1979, almost 90 percent of Turkana people were engaged in pastoralism, whereas only less than 7 percent relied on fishing, and only a little over 2 per cent on cultivation (Ochieng-Aketch 1993).

In summary, despite the integral role played by the above programs in improving the lives of pastoral groups in Kenya and, in particular, Turkana region, sustainable livelihood in pastoral areas in Kenya still remains elusive. Events in the 1990s and into the present have resulted in the pastoral areas making little contribution to the national development and food shortages is still a big threat. These negative events which have impacted negatively on the pastoral livelihoods includes: withdrawal of government from the provision of basic needs and services, for example, the introduction of cost sharing in education, health, water supply, and veterinary service; conflict spillover from the collapse of government in Somalia; the 1991-1992 and 2005-2006 droughts, and famines; and more recently, the tribal tension resulting from the 2007 Kenyan presidential election fiasco. 


\subsection{Food security measures in Turkana.}

Kenya experienced a severe famine in 1960 and 1965 as a result of drought, and the Turkana District was identified as the worst affected. Following this famine, the newly formed independent Kenya government, 108 with the support from various international development agencies, was eager to introduce new, supposedly more reliable sources of livelihood for the Turkana people (Turkana Development Annual Report 1966). The measures were based on the argument that only onefifth of the district's population could base their subsistence on livestock, whereas the remainder should be absorbed into settled activities (Brown 1963; Dames 1964). The establishment of a small-scale fisheries industry at the Ferguson Gulf on Lake Turkana (as early as 1937, fishing at Lake Turkana was proposed as the best alternative to famine relief), resettlement on small-scale irrigation schemes along the Turkwel, Kerio, Ewaso Nyiro, and Tana rivers, and restocking were considered as the only viable solutions, to the food insecurity problem in Turkana (Dames 1964; Hogg 1986). For the purpose of this study, these projects are reviewed below:

Restocking: This was seen by the Kenya government as an alternative to fishing and small-scale irrigation schemes, where each destitute family would be given animals to enable them to resume the traditional nomadic life (Turkana Development Annual Report 1963). Various relief agencies assisted the government and undertook restocking programmes (Hogg 1980), which, however, failed to increase food security in Turkana. Since the viability of individual Turkana households depends on managing multiple species - cattle, goats, sheep, camels and donkeys, restocking with small stock alone was inadequate. Lacking the other necessary species, families restocked with smallstock simply consumed or sold their small-stock when they became hungry. Thus restocked families still remained vulnerable to food insecurity (Oba 1992).

108 Kenya became independent from the British in 1963. 
Similar problems hampered other development projects, and by early 1970s, it became clear that, in terms of preventing famine, the strategies of specialized alternative economies in the Turkana District had failed.

Small-scale irrigation schemes: In 1966, the Kenyan government started a new project to develop small-scale irrigation schemes along the Turkwel, Kerio, Ewaso Nyiro, and Tana rivers. Irrigation trials were not a new thing in Turkana. It started in 1942 along the Oromo river delta, an area traditionally farmed by the Dassenech group. Some were earlier started in and around Lodwar with little success (Gulliver 1951). Despite huge financial investment by the Kenyan government in the new project which began in 1966, it was a total fiasco since the schemes could generate neither food sufficiency nor food security. Crop yields were highly variable from scheme to scheme and from year to year, and were generally below expectations (Oba 1990).

Fisheries industry: The Kalokol Fishermen's Cooperative Society and an ice-making and cold storage plant and accessories which had been set up on the western shore of Lake Turkana in 1924 were revived in 1980 through funding from the Norwegian government. However, this project failed because it appeared to have ignored the inherent instability of such marginal ecosystems. In the planning phase, the lake's fish stocks were assumed to be relatively constant in terms of abundance, density, and location; so that sufficient quantities would be available for a large-scale market-oriented scheme involving about 20,000 people (Watson 1985). This security was merely assumed, as there was no comprehensive data on fish stocks, production costs, markets or other key factors. The planners of the fish intervention were also misled into believing that large quantities were constantly available, and that the limiting factor was production technology (Oba 1992). 
Following the failure of the above cited programs, the Kenyan government had to move fast and design ways of sustaining the livelihoods of the Turkana people whenever famine looms. This strategy has been the provision of famine relief food. Unfortunately, the new strategy appears to undermine the local people's own indigenous livelihood techniques rather than enhancing them. However, a long-term solution to food crisis in the Turkana District may be found in a better understanding of the Turkana pastoralists' indigenous capacity to adapt their livelihoods. Gulliver (1951, 1955) pointed out that Turkana people, as other pastoralists in Africa have demonstrated in the past (before the colonial administration) what they could do with apparently very limited opportunities for diversifying their sources of income within their socio-economic and cultural background. This is the focus of discussion below.

\subsubsection{Customary response to famine.}

\subsubsection{Introduction.}

Due to the lack of systematically documented information, it is not very easy to trace the Turkana people's livelihood strategies prior to the colonial period. However, a study by Gulliver (1951) found that Turkana people, like other pastoralists in Sub-Saharan Africa, experienced food shortages during the pre-colonial period. This argument is supported by Lamphear (1992) who emphasised that it would be incorrect to conclude that life in Turkana was without problems prior to the colonial era. As discussed above, Gulliver $(1951 ; 1955)$ maintained that, because of the highly vulnerable resource base and reccurrence of famine, local people adapted by developing a series of socio-economic and cultural activities.

This section focuses primarily on the social activities. Overlying social structures of nomadic Turkana life based on qualitative data is discussed. An attempt is made to understand the effect of nomadic lifestyle - the 
influence of irregularly - and sometimes frequently changing social and environmental conditions.

For instance, the Turkana people evolved social structures aimed at wellbalanced resource utilisation and equitable distribution of resources. Some of the social institutions considered here are the family, kinship, age-set organisation, neighbourhood (adakar), territorial divisions (ekitela), and stock associateship (lopae). There were also judicial institutions that regulated conduct, provided guidelines and resolved conflicts arising out of resource utilisation. These issues are discussed with the aim of demonstrating that, although Turkana pastoralists lived in a hostile environment, they had means and ways of surviving when disaster struck.

\subsubsection{Social organization. 109}

The Turkana people had flexible social organisational structures which enabled them to respond to unpredictable ecological variables (Gulliver 1955; Lamphear 1992). According to my respondents, the majority of the Turkana population still live a nomadic livelihood and function within these same traditional institutions. Therefore, the social organization of the Turkana, as presented in this study, is not merely a social heritage that has evolved and had been sustained over centuries of adaptation to the environment; it is also about the Turkana today. Moreover, their social organizational structures are presented as institutions that enable them to facilitate the organization of subsistence production activities. The major social institutions of the traditional nomadic Turkana are (with the local term listed in the singular) as follows:

1) The family (household) unit (awi) and satellite camps (abor)

2) Clans (emachar)

109 Detailed discussion continues in Chapter 6, where an analysis is provided of how social relations enabled the Turkana people to survive the 2005-2006 drought and famine. 
3) The 'neighbourhood' or 'traditional grazing association' (adakar)

4) Livestock association and bond-friendships (lopae)

5) Territorial sections (or 'subsections') (ekitela)

6) Generation sets or 'alternations' (Gulliver 1951; Soper 1985)

Awi: The Turkana people refer to a household by the general word awi110 (see Figure 16). Gulliver (1955) further describes a Turkana awi as a 'nuclear family' which is an independent, corporate kin group, specifically identified by its ownership and use of herds of domestic livestock. An awi is composed of a man, his wife, their children, and, quite often, a number of dependants who may include widows or related unmarried men and women.

The head of the awi performs a supervisory role. He supervises herding activities such as watering animals and the castration of male animals. He also assesses the status of pastures before a homestead can be relocated. He also has to authorise the slaughter of an animal for a ritual or gifted as part of bridewealth or compensation for injury or offence committed by a member of the household or stock associates (Gulliver 1955). McCabe (1983) also emphasized how the lack of hierarchy in Turkana social organization allows for each individual (herder) household head to quickly respond to social or ecological change, according to the needs of his family and animals.

The family has two homesteads (awi); one in the mountains called the grazing homesteads (awi nepoli), where young boys and men graze animals; and the other 'a browse homestead' (awi neengos), occupied by the head of the family, wives and children (Gulliver 1955). If shelters are built by accompanying women, the satellite camps are termed awi. If the young male herders are not accompanied by women and do not bother to

110 According to informants, the most basic economic unit, a woman and her children, and the 'day hut' she has built, is called an ekol, which is normally integrated in the awi. 
build shelters, the satellite camps are termed abor (Dyson-Hudson and McCabe 1981). During the rains, a family usually comes together in it's ere, or wet season pasture area, when dietary needs of stock can be met in a small locality. Gulliver (1951), Dyson-Hudson and McCabe (1981), and McCabe (1983) outlined that nomadic families, such as the Turkana, may move from five to fifteen times a year.

Figure 16: Turkana homestead. Note the cattle kraal in the centre.

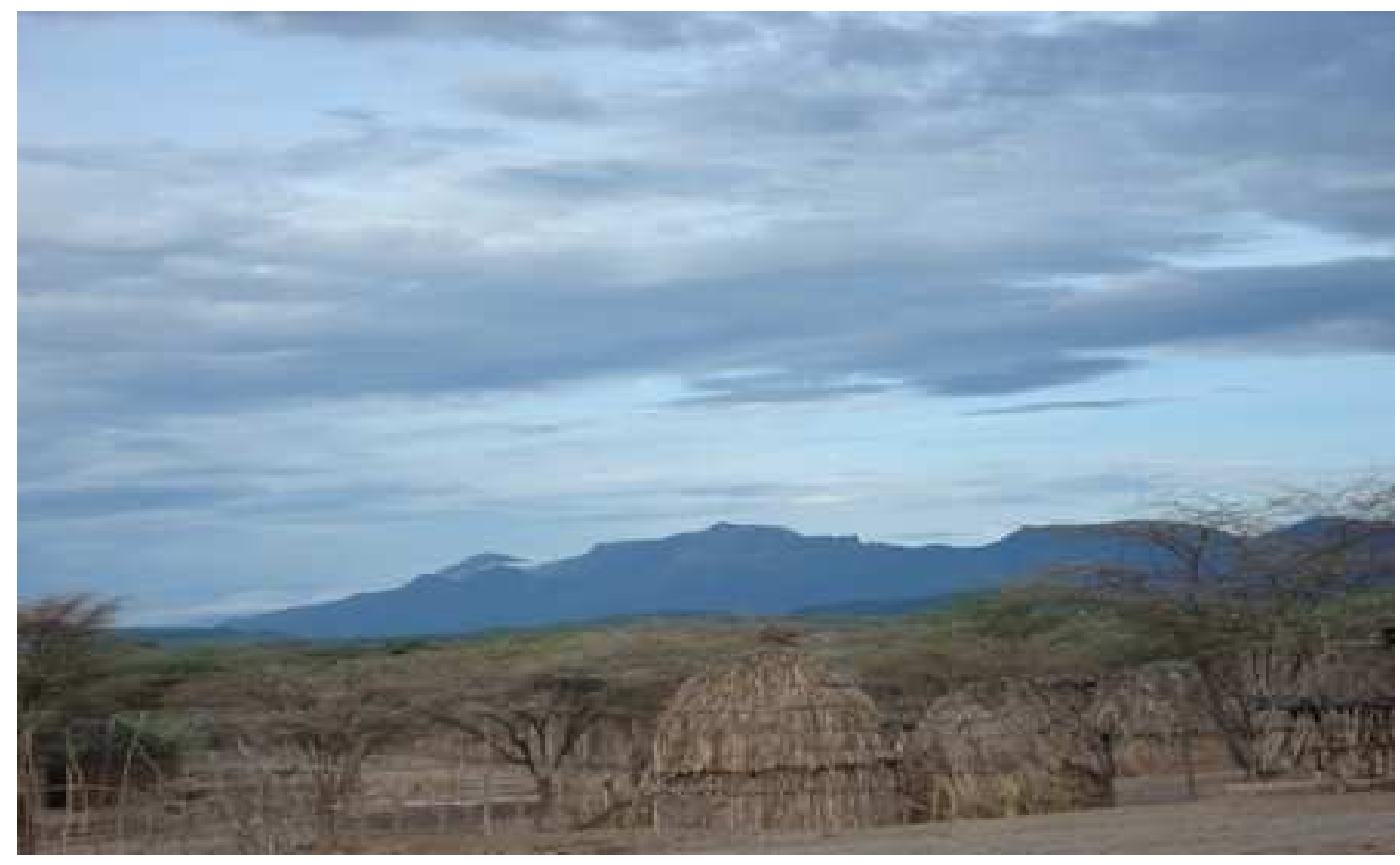

Source: Fieldwork 2007.

Clanship (emachar): At birth, a child becomes a member of his or her father's clan. Male children retain the membership of their father's clan for life, while female children, in marriage, take up membership of the household's clan. There are 28 exogamous clans among the Turkana people (Gulliver 1951). Clans act as units of cooperation in case of compensation for injury or offence committed by a member of the clan. Clan members collectively pay for the offence in the form of stock (Gulliver 1951). Informants added that when death of the head of the household occurs, clan members oversee proper distribution of property and livestock among household members. 
A clan's identity is expressed by slight variations in clothing, custom, and livestock brands (Barret 1988; Gulliver 1951). The livestock brands are used to identify and claim animals if they have strayed away, been stolen or even to eat in times of dire need. When stock changes hands, the brands are left untouched, so that in every clan there are livestock with other clans' brands (Soper 1985).

Neighbourhood (Adakar: The Turkana word for neighbourhood is adakar. It is derived from Adak, meaning to graze or browse, also translated as 'traditional grazing association'. According to Gulliver (1955), neighbourhood refers to a distinct group of homesteads or common areas of grazing. It is a loose grouping of awis of friends and relatives, which may move together to follow new pastures. According to informants, there may be three or four homesteads strategically grouped at central points, such as in a valley or along a main water course. These grazing associations, or neighbourhoods, are often a temporary expression of more permanent ties between relatives, in-laws, and friends. Adakars vary in size from a few to several hundred-member households and are headed by strong personalities assisted by a council of men.111 Adakar can be led jointly by both a general and Emuron (seer), whereby the general unites their group of awis (households) for military strength, and the Emuron guides and blesses the combat activities of the general (Gulliver 1955). Gulliver (1951) identified two categories of neighbourhoods among the Turkana. These are primary and secondary neighbourhoods. Primary neighbourhoods are small groups of homesteads in a given geographical locality such as on a plain. The homestead may number up to three households which are located about 500m apart. A secondary neighbourhood may be comprised of up to two or three primary

\footnotetext{
111 The council of men is often referred to as the 'Tree of Men' (ekitoingikiliok), the location where it usually conducts their meetings. Members of Adakar, who may number from 1020 heads of families, meet daily under the 'tree of men', after their daily management chores (Akabwai 1992).
} 
neighbourhoods in an area of about $10 \mathrm{~km}^{2}$. The homesteads are geographically close to each other and use the same water points and pastures or grazing areas (Gulliver 1955).

Neighbourhoods provide some security from possible raids by bandits or neighbouring tribes. Neighbourhoods also play a regulatory role governing access to water, pasture, and general natural resource use by all members in a given geographical area. For example, during a prolonged drought, members from primary and secondary neighbourhoods may use the same pastures and water points. Apart from sharing resources, homesteads share corporate responsibility for maintaining water holes (Gulliver 1951).

Informants pointed out that neighbourhoods act as a corporate system whereby members share food such as meat, milk, and grain in adverse ecological conditions. For example, heads of households would slaughter animals in turn and share meat with all members of the neighbourhood. Neighbourhoods also perform social roles or functions. Converging points in a neighbourhood such as water pools become centres for the dissemination of information on the state of pastures, timing of feasts, raiding plans or a place to barter goats, skins for grain or iron ware (Gulliver 1951).

A neighbourhood is not a permanent social institution. It breaks up often and units would regroup in response to environmental changes. Changes in climatic conditions such as the change from wet to dry season pastoral conditions result in the movement of homesteads and hence the disintegration of neighbourhoods. Gulliver (1951) reported that the composition and locations of neighbourhoods fluctuates widely from year to year; my observation during fieldwork is that when the risk of raids or food crises is greater, an adakar grows, is more cohesive, and moves as a unit. 
Stock-associates and Bond-friendships ${ }^{112}$ (Lopae): Stock-associateship has been a practice among the Turkana people since pre-colonial times, and were not formed strictly within Turkana borders. These configurations are a major institution of collaboration among individual Turkana herders. It includes relatives and special friends whose relationships are built or strengthened by mutual assistance or the gift exchange of stock animals. One may seek stock in time of need and give stock when others are in need (Gulliver 1955). According to informants, when stock is depleted by epidemics or failures of pastures or drought, a person with insufficient stock to warrant a separate camp of his own would put his stock together with other stock associates to minimize the risk of disease or loss from raiding. Therefore, stock associateship is the core of social relations among the Turkana people whereby one may attend feasts and get food and shelter in the home of a stock associate. Each man's circle of stock associates is a different network, both socially and geographically, and provides him with a type of support structure and mutual insurance. Gulliver (1951: 104-105) estimated that each herder has about 30 stockassociates. The exchange of animals involves much begging (Ngulip) and argument, which the Turkana enjoy.

Gulliver (1955) identified two categories of stock associateship among the Turkana. The first category involves close agnates (Ngitungakan-my people), such as in-laws. In this category, reciprocal rights would involve gifts of cattle and the relationships are intense, reliable, and persist for a long time. The second category of stock associateship involves acquaintances or strangers (Ngikolomata). Reciprocal gifts would involve goats or sheep. The relationship diminishes with time and eventually dies (Gulliver 1955).

\footnotetext{
${ }^{112}$ In this study the terms 'special friend' and 'bond-friend' are used interchangeably. The term means those whom you demand animal, food, or gift during hardships (crises), and you also have an obligation to give, when they are in hardships. In other words they are exchange relationships.
} 
As discussed previously, the Turkana people have no corporate institutions to administer justice, and according to Gulliver (1955), they do not perceive crimes to be committed against 'society' but by one individual against another. Because most disputes involve livestock (e.g. theft), each person's stock associates are his support structure in adjudication for a major offence. Compensation for injury or settling disputes is also payable in stock. In compensation, the offender has to seek the assistance of his stock associates. Interestingly, many respondents stated that the most common method of dealing with minor conflicts and stresses is to simply move away ${ }^{113}$ (Gulliver 1955).

A lopae is a special bond-friend (or 'best friend'), and someone in this relationship has a right to demand an animal in time of need, and an obligation to give into his bond-friend's need. In the pre-colonial period, bond-friendships were not restricted to Turkana borders (Gulliver 1955).

Reciprocity was displayed over time if the friendship was to continue. In a year of poor rainfall or local disease outbreak, Turkana must seek alternate pastures or restock their herds, and for this, they go to their lopae for help and support. A woman may have her own lopae, and share her husbands or husband's with another woman (Gulliver 1955).

Territorial sections (ekitela) among the Turkana: The Turkana people are divided into two groups or sections, namely: Ngimoni (little) and Ngikuro (waterfalls). Each of these sections is sub-divided into various territorial sections and divisions. A territorial section may cover 50-100 miles and may comprise of an approximate population of 10-20,000 persons (Gulliver 1951). Each Turkana person is a member of one of 19 territorial sections, spatially vague areas without well-defined boundaries or any concept of exclusive grazing or watering rights (Lamphear 1992).

113 For detailed discussion, see Chapter 6. 
Territoriality is highly transitory and randomly formed. Individuals move out of the territory in accord with nomadic patterns (Gulliver 1955). According to Gulliver (1951), territorial sections are formed after habits and socio-economic activities established that are peculiar to each locality. Informants mentioned that the Ngithonyoka Turkana in the southwest of the Suguta river, draw their territorial name derived ngut (greed) and inyo (grass). It means that they are always greedy for better grass in the suguta valley, and are eager to dislodge other sections of the Turkana from the area. The territorial name of the Ngimazuk Turkana have their territorial name ('mazuk') derived from trade. The Ngimazuk Turkana were among the first sections of the Turkana to contact Swahili and Arab traders in the region.

Gulliver (1951) and Lamphear (1992) identify a number of territorial sections and their locality (see Figure 17). Among the Ngimoni (little) Turkana there are, among others, the following territorial sections: Ngiepakuno (cutters of ekunoit) trees are located in the north of Lodwar, and the Muruassigger hills; Ngissiger (dressed up people) are in the vicinity of Lodwar, Peleketch Mountains, and Kaliow range; Ngibocheros (paupers) inhabit the area around the shores of the Lake Turkana. The Ngijie (the fighters) are in the northwest Turkana; the Ngkwatella Turkana inhabit Gatome valley, the Lorienatom mountains, and Logitippi swamp; Ngimazuk (dealing with early traders) inhabit the northwest Turkana District; Ngatunyo (lions) are in the Central Turkana; and Nyangangatank (yellow calves) in northwest Turkanaland. Among the Ngicuro Turkana are the following territorial sections: Ngilukomomg (oxen with sweeping horns); Ngiwoyakwara (the long spears) in northwest Turkana; Ngamaloik (the deviners) at Murerissand Turkwel river; Ngbelai (the broken fighting sticks); and Ngebotook (paupers) who inhabit the south west of Kolosia. 
Figure 17: Territorial sections in Turkana by 1900.

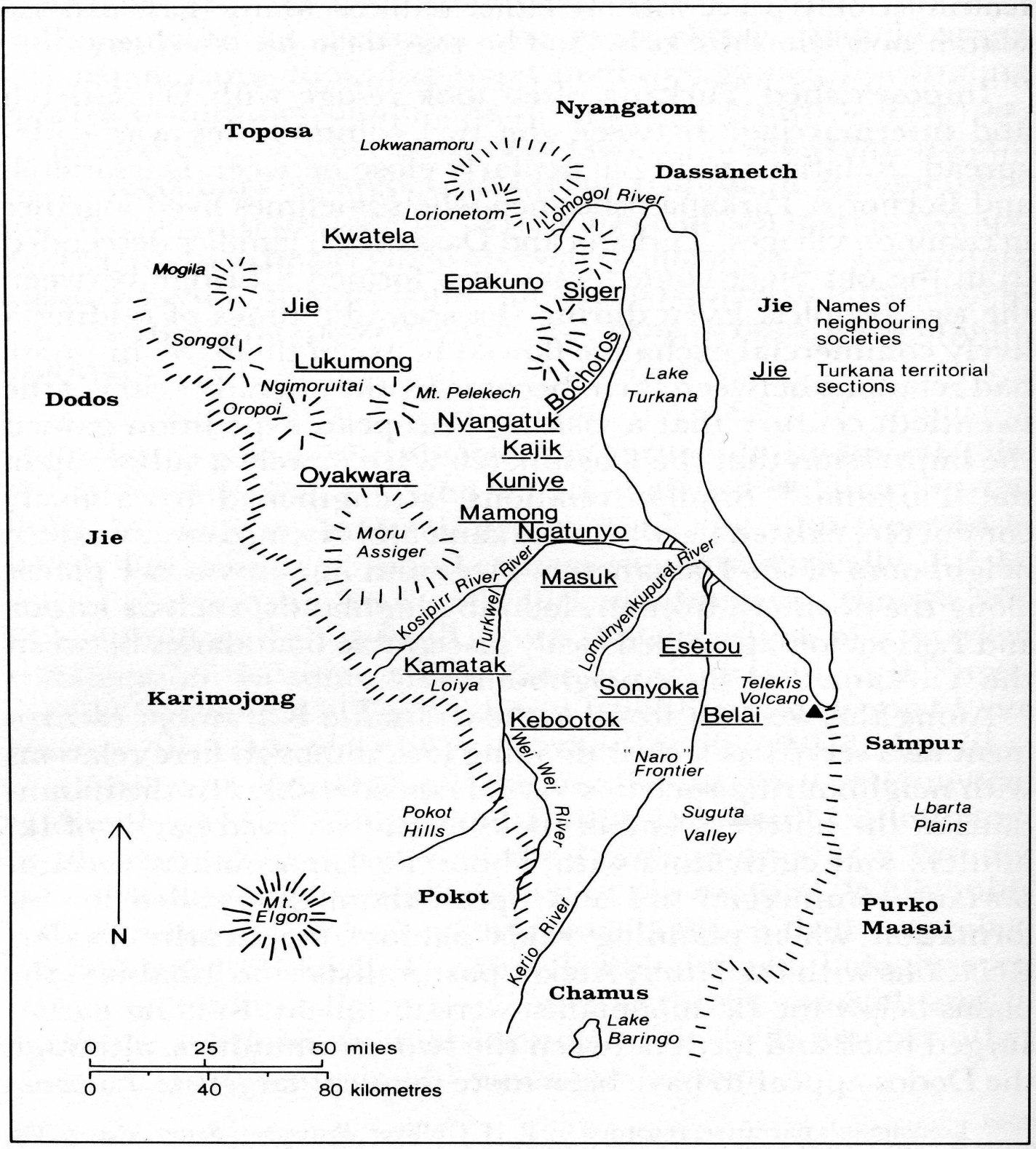

Source: Lamphear (1992:42).

Territorial sections give its members social identity; those who belong to the same territorial section have similar social activities and a sense of protection. Members of the territorial section would be identified by the way they brand domestic animals, body decoration and socio-economic activities that are common to them. Territorial sections define limits of ownership or accessibility of members to pastures, water, and salt licks. In 
principle, territorial members have inalienable rights to pastoral resources, but there are internal mechanisms that control movements of stock and people to various grazing areas within the group (Gulliver 1951). Informants noted that elders have the customary right to determine patterns of movement to safeguard scarce grass and water from being exhausted particularly in the dry season. There are, for example, grass reserves on mountains and hill tops that would not be used until the dry season period.

Informants clarified that territorial units bar or exclude non members from their grazing zones. But only under exceptional circumstances would outsiders be allowed into a territorial section. Outsiders have to seek permission from the group and perform certain customary rituals. They have to kill a bullock and provide tobacco for the elders of the section into which admission is sought. After careful vetting they would be allowed into a territorial section and hence access to pastoral resources. It is also worth noting that, although territorial sections do not fight each other, but together they feel animosity toward competitive neighbouring enemy tribes (Gulliver 1951).

Age-set organization: There are two generation sets in the Turkana precolonial society, namely stone (imuru) and leopards (eriait) which alternate generations in each family (called age-set by Gulliver (1951) and alternations by Soper (1985). Generation-sets function as groups only during initiation or other ceremonies and raids (Gulliver 1951; 1955).

Entry into the age-set is determined at birth, and every male child become a member of the opposite age set of the father. For example, if the father is initiated into the stone age-set, the male child will be initiated to the leopard set. Female children are not initiated into age-sets although immediately after marriage they take up the age-set of their husbands (Gulliver 1951). 
Each age-set has distinct characteristics. Those belonging to stone agesets wear hats with black ostrich feathers, while those belonging to leopard age sets adorn themselves in white ostrich feathers, silver bracelets, and leopard skins. They also sing different war songs and sit separately during rituals and feasts (Gulliver 1951).

Informants claimed that at a tender age, both members of stone and leopard age-sets are called epithe or 'child in arms'. It means that they are unable to wield spears and protect society from external aggression. Initiation takes place between 16-20 years when those who belong to a specific epithet move into the next social category known as warriors (ngabana). Initiation takes place after four years, and the core of the initiation ceremony is the spearing of a male animal (ox, camel, he-goat or ram) by each initiate. This is followed by a purification ritual and a feast of the slain animals by initiates and members of the senior age sets. By getting married and building a homestead, a ngabana becomes ngiliok (a full-fledged warrior). He slaughters a bull in front of witnesses, and this constitutes right of admission for a married man to enter the ngiliok class. From ngiliok, there are no further rights of passage. One becomes gathika (senior member) by age ${ }^{114}$ (Gulliver 1951).

One of the major functions of age-sets according to respondents is raiding to acquire territory, pasture, water supply, and animals, and to protect these from external aggression. Warriors are always ready to fight and defend homesteads, herds, pastures, and water points. Age-set systems built on the basis of military activities for raiding to acquire stock and pasture and kill enemies. The elder men from clans and generation-sets are also asked to say traditional prayers at these events (Gulliver 1951).

114 Informants told me that any male born child automatically becomes epithe at birth. They become ngabana 16-20 years, and move in to the next social category called ngiliok when they are 20-24 years. One automatically becomes a gathika after the age of 30 years. 
Respondents explained that members of the senior age sets are believed to possess mystic powers and are therefore deemed to be close to the high god $(a k u j)$. In the case of prolonged drought, the senior members intercede to bring rain and prevent the stock from dying. This is done through elaborate rituals. Senior age set members also perform an arbitration role between warring clans or individuals. Conflict normally arises over the use of pastures and water holes. A senior age-set member interposes his body between the warring functions as a way of mediating a dispute. This can have consequences, occasionally including death, if the expected protocols are not adhered to by the warring parties. Age-set members assist each other in times of need. For example, when a member of a respective age-set is getting married, they give gifts of animals for bride wealth (Gulliver 1951).

Informants expressed the belief that these traditional social institutions facilitate mobility. I would argue that the age-set organizations act as an integrative mechanism in Turkana society.

\subsubsection{Legality in the traditional Turkana society.}

From what I gathered in the field, Turkana people have legal or moral mechanisms that guide the management of pastoral resources. The legal system also corrects defiant behaviour and forms the basis upon which disputes that arise over resource use can be settled. The Turkana precolonial legal system categorized laws or moral guidelines relating to preservation of the environment, accessibility of pastoral resources, and resolution of conflicts arising over resource use and disposal of property and inheritance. Laws that relate to, for example, the preservation of the environment ensures that certain trees and animals that have intrinsic value to the community are protected. Trees, such as hypaene and balanites are preferred for building with because they are termite resistant (Soper 1985). Informants claimed that customary laws prevented aimless 
cutting of these species of trees for any purpose other than building homesteads. Birds such as open hill, stork, marabou, and horn hill crow played an important role in the removal of ticks from animals and were therefore not supposed to be killed. Ecological conservation was engrained in religious beliefs and aimed at protecting areas regarded as sacred by the Turkana people. These include places of worship near rivers or water points. They also include areas where diviners reside such as sacred mountains or hills (Loima). Informants stressed that because of their religious beliefs, the Turkana people maintain restrictions over resource use in such places.

There were also legal mechanisms regulating access to pastoral resources. Firstly, one has to belong to the territorial section that claims exclusive rights, or this group has to be asked for entry. Secondly, as regards water, if a man digs or clears a waterhole (aker), under Turkana customary laws, he assumes ownership. Others have to seek permission before using such waterholes. But informants argued that water from natural springs or ponds (kanamat), such as Lorititio on the Loima Mountains, was used on the basis of first come first served, because rights of ownership were vested in individuals or groups (Gulliver 1951).

Informants mentioned that, in the dry season, pasture and water are scarce. Disputes often arise over access to pastures, salt licks, and watering points. Fighting over scarce pastoral resources between individuals or clans can sometimes lead to injury or death of some of those who were involved. If serious consequences result, the Turkana have elaborate mechanisms of legal redress. Where disputes lead to death, the offender, if caught at the first instance, would be killed, usually by a member or group of men from the community of the slain member. If the person responsible escapes, the case would be taken up by the stock group of the victim and presented to the council of elders (or tree of men). 
The stock group assists in paying for the offence as already discussed (Gulliver 1951; 1955).

\subsubsection{Religious practice among the Turkana.}

In the pre-colonial period, the Turkana people had a religious system based on the conception that the high God (akuj) was the provider of domestic stock, pasture, and water, and that his intermediary was the diviner (emuron) (Gulliver 1951). They also believed that the high God had a large homestead with vast numbers of stock feeding on evergreen pastures. The Turkana people believed that, if they led a virtuous life, the high God would bless them with domestic stock and abundant grass, drive away diseases and multiply and fatten their domestic stock (Gulliver 1951).

Respondents remarked that the most renowned diviners in pre-colonial Turkana society were the Ekerua of the Loima Mountains in western Turkana, and the Lokorio of Atatepes. They were famous for rain making ability. The diviners would also foretell the future by looking at the entrails of slaughtered goats or by throwing sandals. The diviners would throw sandals in the air and could be able to foretell the future by looking at the way the sandals fell on the ground. For example, a diviner would predict the outcome of animal diseases, and possible raids from neighbouring tribes and recommend what actions should be taken. In case of possible raids, he would advise the people to move to secure areas or grounds, and in the case of animal diseases or severe drought, the diviner recommended appropriate sacrifices of domestic stock (Lamphear 1976; Muller 1989).

Divination was an important social institution in pre-colonial Turkana society. The office was not necessarily hereditary, as any person could be called by the high God to be a diviner. Once called on, the person would mysteriously disappear from the community and reappear after a 
considerable period of time. He would be able to predict, with some degree of accuracy, the occurrence of possible future events (Gulliver 1951). Informants confirmed that diviners became wealthy individuals and were influential in military and non military matters. After every successful raid, they received stock from raiders. They also charged a fee in the form of goats and sheep for the treatment of sick people. The Turkana people also evolved various cultural institutions to govern resource conflicts that arose.

\subsubsection{Chapter summary.}

This chapter has considered some of the salient aspects of the historical institutional and policy environment concerning the livelihood of the Turkana people. The discussion has helped us to gain a satisfactory insight into the related challenges in their attempts to secure a reliable and sustainable livelihood. An attempt has been made to trace the history of famine in the Turkana District, and it is suggested that the area has experienced recurrent food shortages based on a number of factors at both micro and macro levels. During these periods, although drought appeared to have been the major determinant of food shortages, other problems such as history of negative policy environment, animal diseases, as well as the raids from neighbouring tribes were contributory factors. Various attempts have been made by the Kenyan government during the colonial and post-independence periods to exercise a strong level of control over pastoralists in Kenya, in particular, the Turkana. These inimical policies were totally at variance with the Turkana peoples' own understanding of how their livelihoods could be sustained, and have had a predominantly disruptive overall impact in terms of food security.

During the colonial period, the aim was to pacify Turkana pastoralists and to ensure peace and order. This tendency had several implications. It tended to present the Turkana as an unreliable people prone to violence 
and, hence, to propagate depastoralisation. This was an elite outsider's view of pastoralism as a primordial mode of production which should be discouraged. However, it is shown that the colonial period was marked by the increasing occurrence of food shortages. This seems to suggest that, aside from the effects of natural factors, there were other factors which had direct influence on the food situation. Of particular importance were negative policies in relation to land. The period witnessed the drawing of political boundaries and creation of block grazing schemes. Borders were fixed, and access to key resources was curtailed with little regard to seasonal variation and the needs of the people for pasture. The policy also placed the integral Turkana tribal land area under more than one political entity, which conflicted with indigenous resource use strategies. This meant that within the new fixed tribal boundaries, the environment was placed under more severe pressure. These measures greatly affected the transhumant patterns already mastered by the Turkana pastoralists from their long experience with ecological hardships. The border restriction also destroyed the lubricating social rubric traditionally obtained through trade and intermarriages with the neighbouring tribes.

During the post-independence period, a number of changes have occurred that have influenced the food situation and coping strategies in pastoral areas in general, and in Turkana in particular. The most profound of these are fishing, irrigation schemes, and restocking. Attention has grown in stages, realising a number of achievements. But from the evidence adduced, fishing and irrigated agriculture have not been successful and have failed as a viable means of solving the food crisis in Turkana. Restocking, as a means of reinstating destitute back into pastoral life, has also failed. The failure of the projects seems to suggest that the traditional technologies have been replaced with largely unsuitable adaptations from those operating in the high potential agricultural areas. Those few technologies that have been introduced in pastoral projects have either not worked satisfactorily or have only done so at prohibitive and hence 
unsustainable costs. The Turkana local economies gradually become almost totally dependent on continuing international aid during this period.

However, despite the disruptive nature of various factors on the Turkana livelihood system, it has been recognised that social institutions as a foundation of social capital, have traditionally acted as a fundamental livelihood strategy. For example, territoriality and neighbourhoods were units of identification in a given geographical space and enabled social forces such as ethnic groups to establish inter-unit relations in the utilization of resources. The organizational structure of splitting the family unit into grazing homesteads and browse homesteads was ecologically innovative, as it utilized the widely dispersed vegetation inorder to meet the dietary needs of livestock (Gulliver 1951). Labour organization within the family was geared towards the sustenance of the pastoral economy. The head of the household performed a supervisory role of herding, branding, and watering animals. Women performed the task of milking and watering young animals, while young girls assisted in fetching water, cooking, and herding goats and sheep. Young boys herded young stock, such as calves and lambs. Stock associateship enabled individuals to widely disperse livestock among affinals inorder to prepare against instant decimation of livestock by ecological disasters such as epidemics and drought. It also enabled individuals to establish social bonds and reciprocal relations between contracting parties. Legality in Turkana society guided individuals in the utilization of the pastoral resources such as water, salt licks, and grass. It enabled them to contain deviant behaviour and to resolve conflict. The same social institutions such as kinship and rangeland territoriality were the basis of organizing sustenance in producing activities such as pastoralism. They were also the basis of identity and legitimization of the Turkana social and economic quests. 
It is hoped that the historical vignette in this chapter provides a baseline against which contemporary adaptive behaviour can be assessed. A number of lessons were learnt which could be used in undertaking future projects in Turkana. Firstly, successful technologies for use in the pastoral areas in Kenya, and Turkana in particular, must be those that demonstrate the capacity to yield tangible results, while remaining simple enough to be grasped and adopted by the local communities. Secondly, projects should be designed in a way which takes into account such physical factors as unreliable and erratic rainfall, scarcity of basic resources like water, fragile ecosystems, and poor or unsuitable infrastructure. Thirdly, there is need for research to adapt to specific areas and needs, and recognition and utilisation of local knowledge and technologies in application of technological solutions to the development of sustainable livelihood in the Turkana District. From the discussion above, it is clear that there have been few attempts to base modern livelihood policies on customary ways of doing things. There could be many difficulties in doing this, but the failure of alternative policies suggests at least that this option should be tried. This thesis suggests the need to descend to the local level and analyse the famine situation in Turkana from the point of view of the local people; men, women and children, who have first hand experience. This will be explored in Chapters 6 and 7 with a focus on the 2005-2006 drought and famine. 


\section{CHAPTER 6 THE 2005-2006 DROUGHT IMPACTS, PERCEPTION AND RESPONSE}

\section{1: Introduction.}

The previous five chapters outlined the wider context of this research and the methodology used during the fieldwork. This chapter presents the analysis of field research undertaken in the two study villages (Morulem and Lokichar) in the Turkana District. The chapter takes a closer look at the challenges, opportunities and constraints Turkana people faced during the 2005-2006 drought and famine, and how they constructed their livelihoods on the basis of their social relations.

The chapter consists of two sections. Each section deals with an element of the framework discussed in Chapter 2 (see Figure 4). The first section focuses on the quantitative dimensions of Turkana households' livelihoods. It gives an overview of the impact of the 2005-2006 droughts and famine in the study area so as to enable us to appreciate the difficult economic conditions Turkana people went through: conditions which they were forced to grapple with on their own before they received any livelihood support from the Kenya government and external donors. This will be followed by an analysis of Turkana people's environmental perception and an interpretation of their economic predicament.

Section two then turns to what can be considered the crux of the thesis behavioural patterns which emerged in the process of adjustment to stem the negative effects of the 2005-2006 drought and famine. This section takes a more qualitative approach, focusing on richer and deeper interview data. It looks at issues surrounding change, aiming to better understand Turkana responses to drought. As discussed in Chapter 4, Turkana people are generally known as opportunists taking advantage of various options for subsistence, which again is an adaptation to the risks of their 
environment. But, this study focuses only on types of special relations ${ }^{115}$ that provided livelihood security that was necessary to persist with during the 2005-2006 drought and famine. It is argued here that social networks may promote a form of resilient social security that allows Turkana people to implement their livelihood strategies to good affect in the moderately productive arid environment they inhabit. In cases of emergency or crises, Turkana households with good social relations can get both financial and moral support. 116

\section{2: Effects of the 2005-2006 droughts.}

Following the discussion in Chapters 1, 4, and 5, the Turkana District has experienced a long history of drought conditions leading to famine and, to a large extent, poverty (Swift 1985; Turkana Drought Contingency Unit 1992). Generally, poverty research has also revealed characteristics which are widely shared among poor people and their families. There is a consensus that, poverty is caused by a variety of socio-economic, political and environmental factors, and poverty has fundamentally to do with deprivation (Chambers 1995; Hettne 2002). Ellis (2000) argue that, the most fundamental of these characteristics may be lack of assets, meaning lack of ownership or access to land, other productive assets, skills, education, and wealth. It is on the basis of this argument that it is necessary to analyze the impact of the 2005-2006 droughts on the Turkana people's livelihood, and the extent to which this impact has increased their vulnerability.

Although the available climatic data held in Kenyan government offices suggests that the period 2005-2006 did not represent a particularly severe

\footnotetext{
115 This study will not endeavour to look at the structure of various categories, formation or genealogy of relationships, but specifically analyse and discuss more general types of social networks activated during 2005-2006 drought and famine, which enabled the local people to survive the crisis.

116 As stated in chapter 3 (methodology), this analysis considers social relations as a mediator.
} 
drought as compared to the 1979-1980 droughts (Republic of Kenya 2006), the Turkana people interviewed regard its effects as having been harsh. 91 percent of the pastoralists interviewed stated that the 2005-2006 droughts were the worst they remembered, and though this may be partially explained by the fact that it was the most recent, it does indicate that its impact was great. To get a clear picture of how the local people were affected during this period, all the respondents were asked to name the problems they faced during that period.

While the responses revealed specific problems, it became obvious that the 2005-2006 drought was a period of general social malaise and unrest in the area. Apart from lack of food, which was experienced by all the respondents, respondents also mentioned lack of water, loss of livestock (see Figure 18), loss of human lives and conflict over resources. Due to the fact that respondents mentioned a myriad of problems, it may be true that there could be other ways of determining the impact of 2005-2006 droughts, but in this study, "livestock losses" and "human losses" were used as the measuring tool. ${ }^{117}$

\subsection{1: Livestock losses in the household.}

While analysing the livestock losses during the 2005-2006 droughts, it was necessary to take into account the number and size of herds prior to the drought, as it was vital for comparison purposes (see Appendices 9 and 10). As discussed in Chapter 1, the traditional strategy of pastoralists is to build up the numbers of livestock in good years in anticipation of the losses which will occur during drought. A herder will attempt to enter the period of drought with enough animals to enable him to provide for subsistence needs during the crisis despite animal deaths.

117 The information about "livestock losses" and "human losses" was acquired primarily from household heads. 
Figure 18: Livestock losses.

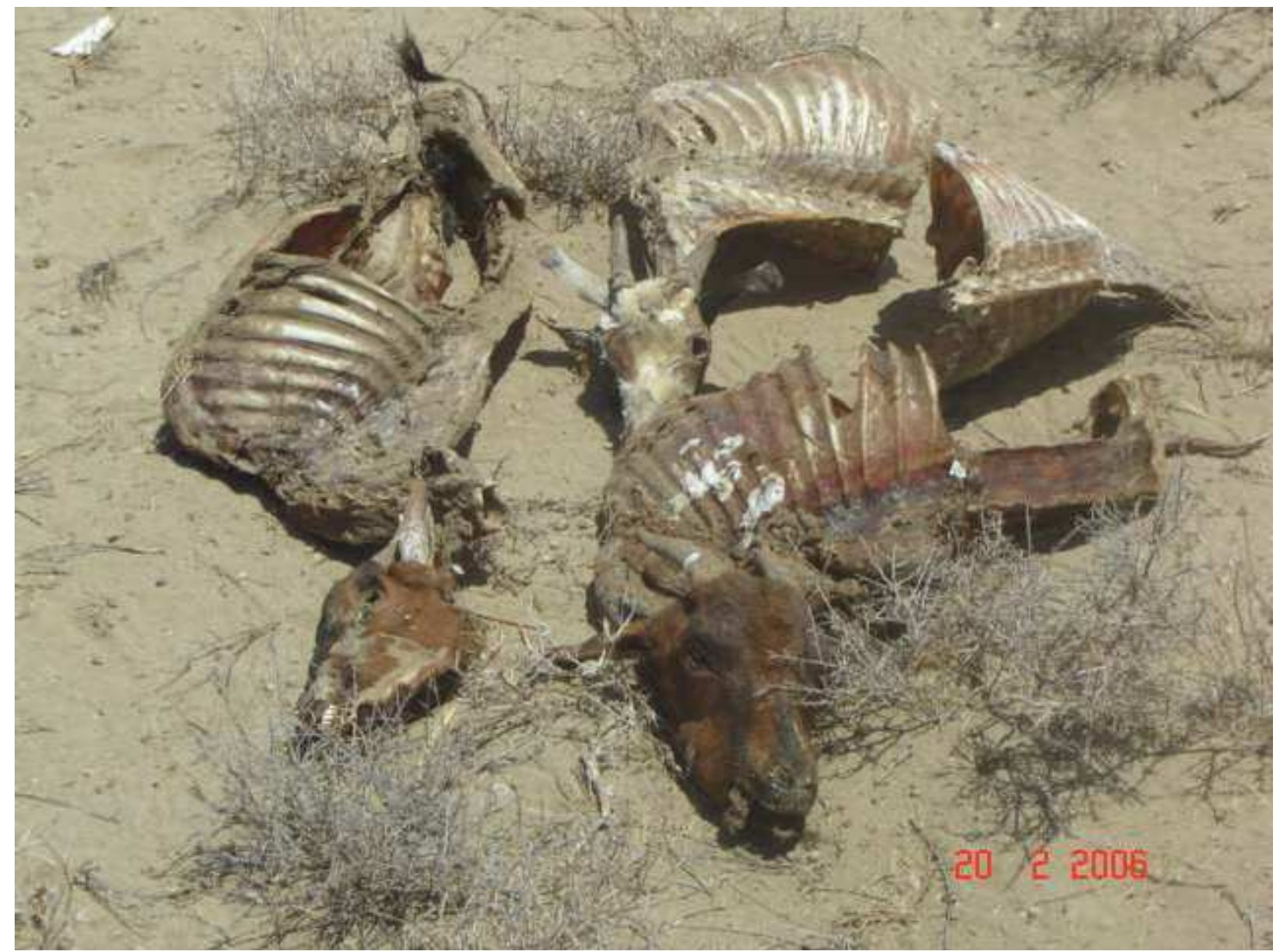

Source: Republic of Kenya 2006: 9.

For the Turkana case, computation of the data reveals that before the 2005-2006 droughts, each of the 80 households studied owned an average of nine cattle, 11 sheep and goats, two camels and two donkeys (see Table 5). ${ }^{118}$ According to the discussion in Chapter 4, these numbers were still below the minimum livestock units that pastoral households require to resist drought cycles. ${ }^{119}$ This may partially explain why the Turkana people were more vulnerable. Household heads explained that they had less stock prior to the 2005-2006 droughts and famine because the drought condition under study occurred just before they were sufficiently recovered from the 2000 drought. Respondents stressed that there was

\footnotetext{
118 Average numbers of livestock per household during the pre and post-drought period were arrived at by dividing the total number of each species by the total number of families interviewed.

119 Niamir-Fuller and Turner (1999) found that the minimum number of livestock units below which a pastoral household is unable to resist drought cycles is 50 .
} 
also foot and mouth disease which affected the cattle during 2004 leading to loss of some livestock.

Table 5: Pre-drought livestock numbers.

\begin{tabular}{|l|l|l|l|l|}
\hline \multicolumn{2}{|c|}{ Cattle } & $\begin{array}{l}\text { Goats and } \\
\text { sheep }\end{array}$ & Camels & Donkeys \\
\hline $\begin{array}{l}\text { Total No. of } \\
\text { livestock }\end{array}$ & 742 & 869 & 154 & 156 \\
\hline $\begin{array}{l}\text { No. of } \\
\text { livestock per } \\
\text { household }\end{array}$ & 9.3 & 10.9 & 1.9 & 2 \\
\hline
\end{tabular}

Source: Fieldwork data 2007.

Further explanation from respondents is that the number of sheep and goats taken together were very low per family because just before the 2005-2006 drought, the number of goats had been drastically reduced by an outbreak of contagious Caprine Pleuroneumonia (CCPP).

Table 6: Post-Drought livestock numbers.

\begin{tabular}{|l|l|l|l|l|}
\hline \multicolumn{2}{|c|}{ Cattle } & $\begin{array}{l}\text { Goats and } \\
\text { sheep }\end{array}$ & Camels & Donkeys \\
\hline $\begin{array}{l}\text { Total no. of } \\
\text { livestock }\end{array}$ & 343 & 377 & 152 & 53 \\
\hline $\begin{array}{l}\text { No. of } \\
\text { livestock per } \\
\text { household }\end{array}$ & 4.3 & 4.7 & 1.9 & 0.7 \\
\hline
\end{tabular}

Source: Fieldwork data 2007.

As shown in Table 6, after the 2005-2006 drought, each family surveyed had an average of 4.3 cattle, 4.7 sheep and goats, 1.9 camels, and 0.7 donkies each (see Table 6). These figures suggest that 53.8 percent of the pre-drought family cattle, 56.9 per cent of the sheep and goats, 0 percent of the camels and 65 per cent of the donkeys died (see Table 7). Respondents explained that this loss had a major impact on their livelihood since they depend solely on livestock for meat, milk, blood, hides and skin, other by-products, and for payment of bridewealth and bloodwealth. 
The greatest deficit was in the number of cattle, sheep and goats. Respondents pointed out that the loss in goats and sheep seriously worsened their situation, since goats and sheep are the most important source of food in a period of drought when the milk production of cows decreases. This is because goats are primarily browsers and thus expected to survive during dry conditions. It also seems logical to rely on browsing animals for economic use, as the rangeland is often covered by bushes and trees. Furthermore, the great loss in goats and sheep may be interpreted to mean that the dry conditions were more difficult than what was reported in government documents.

Table 7: Livestock survival/Death rates

\begin{tabular}{|l|l|l|l|l|}
\hline \multicolumn{2}{|c|}{ Cattle } & $\begin{array}{l}\text { Goats and } \\
\text { sheep }\end{array}$ & Camels & Donkeys \\
\hline $\begin{array}{l}\text { Pre-drought } \\
\text { herds per family }\end{array}$ & 9.3 & 10.9 & 1.9 & 2 \\
\hline $\begin{array}{l}\text { Post-drought } \\
\text { herds per family }\end{array}$ & 4.3 & 4.7 & 1.9 & 0.7 \\
\hline $\begin{array}{l}\text { livestock death } \\
\text { per household }\end{array}$ & 5 & 6.2 & 0 & 1.3 \\
\hline Survival rate (\%) & 46.2 & 43.1 & 100 & 35 \\
\hline Death rate (\%) & 53.8 & 56.9 & 0 & 65 \\
\hline
\end{tabular}

Source: Fieldwork 2007

Note:

- Livestock survival rate per household is post-drought family herds expressed as a percentage of pre-drought family herds.

It is clear that there was a very low survival rate. As depicted in Table 7, only 46.2 percent of cattle, 43.1 percent of goats and sheep, and 35 percent of donkeys survived.120 All camels, however, survived. Most respondents explained that this was a great loss, considering the fact that they had very few livestock following the impact of the 2000 drought and famine. The data also show that 100 percent of camels survived, and

120 The point to be kept in mind here is that the herd sizes described in Table 7 are nevertheless far below those regarded as necessary for a sustainable livelihood. 
informants explained that camels, unlike other animals, were able to survive for a long period of time without water. Respondents were in agreement that, had the drought conditions continued to the year 2007, the situation would have become much more serious. They maintained that even with the favourable conditions which began in January 2007, it was still very difficult for Turkana households to rebuild their herds and fulfil their subsistence needs thereupon. This, indeed, was the case, and at the time of the survey (February 2007 - July 2007), the livelihood situation was still very unstable.

As discussed in the methodology chapter, it is important to note that the difficulty in obtaining accurate and reliable information about livestock numbers in Turkana is legendary, and some care should therefore be taken of the numbers shown as some respondents seemed to have been in the habit of exaggerating losses from the drought in the hope of receiving larger and more frequent relief rations. ${ }^{121}$ Secondly, the Turkana nomads never count their stock, and some thought they may be cursed if they uttered the correct number. One informant stated: "to count stock would be to challenge fate" (Key Informant Interview, Morulem Village $9^{\text {th }}$ February 2007). It was as a result of a gentle and careful probing that any figures were obtained at all. They should be interpreted with equal caution. However, these figures give a clear idea as to the magnitude of the 20052006 droughts.

One important point needs to be noted concerning cattle loss during 20052006 droughts. In the case of the Turkana, as in similar disaster situations the world over, an extraordinary contradiction (Dirks 1980: 2123) emerges in which wealth can be seen in juxtaposition to human misery. The drought had varied degrees of stress down to the household

\footnotetext{
121 As explained in the methodology Chapter 3, it was simply this behaviour that had me continually explaining to respondents that I am a research student, whose work would be analyzed for writing an academic thesis.
} 
level. Some households were struck more severely than others ${ }^{122}$. Apart from the varied responses to the survey questions which recorded both 'total' loss and some 'loss', a visitor to Lokichar village would have wondered why it had been found necessary to feed many in the Ngisonyoka territorial section on famine relief food. ${ }^{123}$ Between $7 \mathrm{am}$ and $9 \mathrm{pm}$ daily, it was baffling to find a herd of anything up to a hundred healthy cattle roaming along the Kitale - Lodwar road and in the countryside, as if this was one of the best years in the history of Turkana pastoralism. Since the contradictions were so obvious, all the three key informants and 35 household heads from Lokichar village were asked who owned these herds - those seen in the countryside along the road from Lokichar to Lodwar (the district headquarters). They gave varied answers which generated three different explanations.

The first explanation from the respondents was the argument that those stock belonged to the destitute who moved in search of famine relief food. They said that the stock which had survived the drought had been brought together by the owners who formed small corporate groups. As the owners moved to look for famine relief food, the livestock was left in the hands of a few specialized herders to whom payments in the form of relief food is sent from time to time.

The second claim was that this stock belonged to pastoralists who had been only mildly affected by the drought. The respondents argued that these were pastoralists who had been lucky to occupy hilly pastures during the drought and used them selfishly at the exclusion of others. They did not find it necessary to move in search of famine relief foods and continued to live in the countryside even at the time of the study.

\footnotetext{
122 This will be the core of the discussion in Chapter 7 while comparing the two study areas (Lokichar and Morulem village).

${ }^{123}$ Most respondents from Lokichar village are from the Ngisonyoka territorial section.
} 
On the defence of pastures during periods of prolonged droughts, Philip Gulliver writes:

\begin{abstract}
Some years ago when rainfall had been unusually poor for two years consecutively, dry-season grasslands on Pelekec Mountain failed before the dry season ended, and most cattle had to be moved. Some went west to parts of Muruapolon, some north-west to Thungut, Mogila and the Dodoth Escarpment, and some north, to Lokwanamur. In most cases men were able to go to areas where they had bond-friends or kinsmen. One group, however, attempted to move en block to Naitamajong. Following early brawling, a serious fight occurred, and some serious injuries were incurred on both sides. The "invaders" retired, split up and separately found entrance elsewhere. Naitamajong, the nearest mountain to stricken Pelekec, had suffered almost equally badly, and the men there were genuinely afraid of the grave consequences if more stock came to graze there" (Gulliver 1955: 35).
\end{abstract}

From the historical observation above, it could be possible that some Turkana people had access to better pastures than their less fortunate colleagues and, thus, saved quite a large portion of their pre-drought family herds. However, one needs more substantive evidence before making an authoritative conclusion on this claim about selfish defence of pastures as a survival strategy. The literature on pastoralism excludes mention of the role of vigorous physical defence of pasture leading to violence.

The more vocal third claim was that the stock one saw in the countryside around Lokichar belonged to the rich salaried, those who are firmly integrated into the modern sector of the economy and thus use their salaries and various forms of non-pastoral sources of income to accumulate livestock. This claim supports Henriksen's findings that the rich livestock owners in the Turkana District are the teachers, politicians, businessmen, and civil servants who rely marginally on their herds for subsistence (Henriksen 1974). Those who like class analysis of drought 
and famine could, in this respect, view the phenomenon among the Turkana as a class famine where the poor suffer while the rich remain largely unscathed. ${ }^{124}$

\subsection{2: Human losses in household.}

If we adopt our earlier definition of famine borrowed from Devereux (1993) as severe food shortage which results in raising a community's death rate then one method of determining the magnitude of drought and famine is to use recorded deaths as a measurement tool. In the questionnaires, the 80 household heads were asked to name all the members of the household (if any) who died from hunger or famine during the 2005-2006 drought, or related diseases such as cholera. The sex, age, and status in the family of the dead were recorded in each case (see appendix 2).

Table 8: Mortality in the surveyed households. ${ }^{125}$

\begin{tabular}{|l|l|l|}
\hline & Households interviewed & Percentages (\%) \\
\hline $\begin{array}{l}\text { Total number of } \\
\text { households recording } \\
\text { death }\end{array}$ & 37 & 46 \\
\hline $\begin{array}{l}\text { Total number of } \\
\text { households recording } \\
\text { no death }\end{array}$ & 43 & 54 \\
\hline
\end{tabular}

Source: Fieldwork 2007.

As shown in Table 8, of the 80 families surveyed, 37 of them (46\%) recorded at least one death claimed to have been caused by starvation or famine-related diseases during the 2005-2006 drought. The total number of deaths recorded (for both Lokichar and Morulem residents) was 95, which gave an average of 1.19 deaths per family (see Table 8 and 17).

124 See the analysis in Chapter 7 , but, as will be discussed in chapter 8 , future studies will need to focus on this aspect.

125 In this table, the mortality is calculated for all the 80 households surveyed. The eight key informants were not included. 
Crude computation of the data gives a mortality rate of 19.83 deaths per 100 of the population. ${ }^{126}$ Although these are mere estimates made from the statistics, they would appear to portray quite a high death rate caused by the 2005-2006 drought and famine effects. However, the death statistics ought to be read against the background that:

i) Even in the absence of drought and famine, the infant mortality rate in the Turkana District was projected to be 220 deaths per 1000 live births by 2007 (Republic of Kenya 2002: 9). These are the children who die before attaining the age of 2 years.

ii) Deaths from natural sources were projected to be 50.3 per 1000 by 2007 (Republic of Kenya 2002: 9).

Therefore, considering the normal mortality rate of 220 deaths per 1000 live births, and deaths due to natural causes of 50.3 per 1000 , one could then deduce that further human losses at the rate of 198.3 deaths per 1000 due to the 2005-2006 droughts could have had a devastating impact on Turkana people. In most cases, the parents and relatives of the famine victims provided what seemed to be valid diagnostic explanations as to the cause of deaths: starvation. Thus, starvation significantly increased the community's death rate. Essentially, this is what Devereux (1993) defines as famine. However, it is interesting to understand local people's perceptions of their situation and circumstances surrounding the occurrence of the 2005-2006 drought and famine.

\section{3: Perception and contemporary cultural interpretation of drought incidences.}

Having noted the impact of 2005-2006 droughts on Turkana peoples' livelihoods, the interviewees were further asked about their perceptions of their livelihood in terms of any problems they had and any changes or trends occurring over recent years, and also what forces and factors have

\footnotetext{
126 According to the data, a typical Turkana household size is six persons.
} 
been influencing such changes. This is what Pennings and Smidts (2000, 2003) refer to as risk perception; the local people's own interpretation of the likelihood of being exposed to the content of risk. It is argued here that a critical assessment of local people's perceptions and attitudes tell us much more about the relevance of the adaptive strategies brought into play. The crucial question asked was: What is the Turkana people's interpretation of drought and famine? Secondly, how would their interpretation of the situation determine their choice of adjustments to drought and famine?127 These were sometimes difficult issues to talk about, but still, informants were willing to do so. The symbolic interaction theory which this study adopted to analyze the adjustment phenomenon among the Turkana people states that such adjustments are made through cultural filters of taboos, values, personality, etc. This approach therefore develops psychological tests which use verbal responses to predetermined questions as a basis for analysis. The local people's cognitive map of reality, their cultural values and individual personalities were all taken as crucial factors determining their choices of adjustments for drought and famine in this case.

The informants interviewed initially recognised the fact that they live in a hostile environment where famine is prevalent. Apart from drought, other factors were also mentioned as the major cause of famine in the Turkana district. ${ }^{128}$ When informants were asked to list specifically the contemporary interpretation of the frequency and severity of drought conditions today, they offered three broad but complementary explanations. The explanations are cultural as well as historical. As seen in figure 19, they all suggest the fact that Turkana people are aware of the socio-economic changes which have swept through the community in the last century.

127 This was a supplementary question meant to elicit more information.

${ }^{128}$ Refer to the discussion in Chapter 5. 
Figure 19: Interpretation of the causes of drought Problems

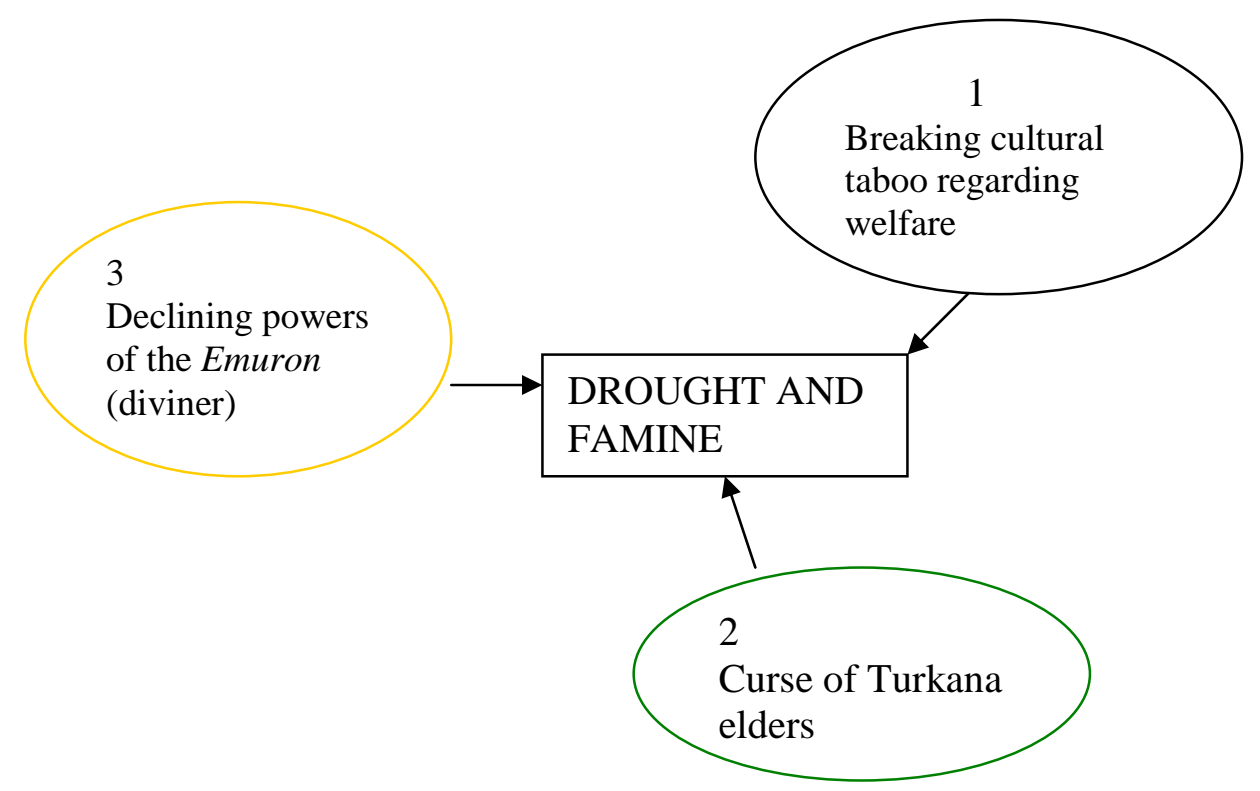

Source: Fieldwork 2007

The first explanation is that Turkana people broke an important cultural taboo regarding welfare. They declared tribal war on their 'elder brother' the Ngijie of Uganda. Informants stated as follows:

Tradition handed down to us from our ancestors told us that we never (and do not) fight or kill a Ngijie. It is a taboo. All our roots are found there. Stock marks are to be found there. But now they fight. No one knows who started the feud, but it is now bloody war fought with guns. It is stocks that have been bought with tears and blood of our kin that have brought a curse on us. It has burnt all our stock wealth (Household Interview 12 April 2007, Morulem village; Household Interview $18^{\text {th }}$ June 2007, Lokichar Village).

The key informants believe strongly that it is the curse from their elder brother Ngijiye that accounts for the recurrent scourges. They think these calamities are not due to purely climatic changes. Informants stressed that there are good pastures all along the Turkana borders, but that they cannot use them due to warfare and poor relations, even with their own kin the Ngijiye. To illustrate their claim, the informants pointed out that after any bloody encounters with the Ngijie resulting in the death of a 
Turkana, the Ngijie would always return home (Uganda), kill a bull and perform a "mock" burial ceremony as though the dead Turkana were a Ngijie. The significance of this in their religious practices is that they look on the Turkana not as an 'enemy' but as "kinsmen" who must be buried according to custom. The Turkana, on the other hand, do not observe a corresponding burial ceremony when they kill a Ngijie in such bloody encounters. The informants believe that this phenomenon has had cultural effects of transferring 'blood guilt' on to the Turkana: an evil spell which has caused their doom. Informants thought that in order to be prosperous again, the Turkana must make peace with the Ngijie and plead with them to lift the curse. Informants maintained as follows:

We have to live in peace with the Ngijie if we are to survive as a people. It is only when there is peace that we can regain our economic prosperity of the past (Household Interview 10 th July 2007, Morulem village; Household Interview 30th June 2007, Lokichar Village).

The second explanation by informants is that the recurrent drought and famine predicament has been caused by a curse of Turkana elders due to intergenerational conflict in the community. They told a long story which cannot be retold here in full. I shall summarize its basics. It sounds partly factual and partly myth; but as myths are part of a culture they are therefore cultural data subject to analysis and interpretation.

The traditional rule by elders (gerontocracy) (Spencer 1965) had the unchallenged powers of moderating cattle raids so as to make them a kind of sport rather than war. Thus raids and counter raids had to be blessed and sanctioned by elders. About four generations ago the elders refused to bless or sanction an anticipated raid because the people to be raided lived in a distant land, and to elders, it was a risky experience. The warriors, however, defied the orders of the elders not to undertake the raid. The elders tried to restrain them, but the warriors rebuked them and told them to return home. The elders felt insulted and cursed themselves, and the 
rebellious warriors and their generation-set. The curse was that they would live at war with their neighbours and their neighbours would not allow them to gain access to better watered pastures in their northern and western borders. Many Turkana herders would be killed in their attempts to force their way into these pasturelands.

According to informants, the elders said that the land has to be cleansed of that curse if the Turkana people were to regain their lost economic prosperity. Elders suggested that this could be done by organising a community-wide ceremony, where the generation set representing the rebellious warriors would collectively present offerings in the form of livestock to the elders representing the offended generation set. The latter would then be asked to lift the curse, for it would be in the interest of all including themselves. By the time of the study, no cleansing ceremony had been organised, which could explain to some extent the regular occurrence of drought and famine in the Turkana District.

Lastly, the respondents attached some blame for their problems on the declining powers of the Emuron (Diviner). Since this study was concerned with drought (absence of rain), it sought to inquire into the present status of the rain maker. In the past, the most reputed Emurons were also the rainmakers (Gulliver 1951). ${ }^{129}$ The Emuron akuj (chief priest) possessed the mystic powers of healing, communicating with God (akuj), and inducing rain. These were the power bases of men like Ekerua of the Loima Mountains in western Turkana and Lokorio of Atatepes, which enabled them to wield a tremendous amount of religious and political influence that transcended community borders (Lamphear 1976). ${ }^{130}$

Responses from key informants and survey interviews on the role of Emuron (rain-maker) seemed to suggest that Emuron's mystical powers are

\footnotetext{
129 Refer to the discussion in Chapter 5.
}

130 See the discussion in Chapter 4. 
on the decline. The respondents viewed themselves as a people without a strong spiritual leader, unlike their grandfathers whose spiritual leaders, like Lukeria, spearheaded the occupation of the land and the acquisition of the camel. They lamented that the "whiteman" destroyed the spiritual foundation of their society by hunting down and killing powerful Emurons and then introducing new religious practices. Thus, the office of the Emuron had since lost its customary mystic aura that made it so formidable in pre-literate times. Informants pointed out that the office of the Emuron remains legendary, but are currently of little practical use. Many people today, especially the youth and the educated, do not take Emurons seriously in their deliberations. The educated, for instance, campaign against the Emurons, calling them desperate opportunists interested only in making money out of dying trade.

There was, however, some evidence that in times of crisis, the Emuron is still consulted by those who still believe in his mystic powers. The Emuron also still claims to be able to predict the coming crises and advises on measures to avert them. Prayers and sacrifices to Akuj (God) are still made on Emurons' instructions. I learnt during fieldwork that the dilemma currently facing the Turkana people is that in the majority of the cases, Emurons prayers are never answered.

At Lokichar, approximately 30 percent of the surveyed interviewees stated that they had been alerted of the coming of the 2005-2006 drought and famine by an Emuron by the name Akiyobok Nkwatella. The majority of the respondents (70 percent) said, however, that they did not hear of the warning from Akiyobok. At Morulem, 100 percent of the surveyed interviewees stated that they were not alerted of the coming of the 20052006 drought and famine. I realised during the field study that there was no Emuron among the Ngibelai territorial section, ${ }^{131}$ a fact which may

131 Most of the Morulem villagers belong to the Ngibelai territorial section while, Lokichar villagers belong to the Ngisonyoka territorial section (see discussion in Chapters 3 and 4). 
partly help to explain why not many people heard of his warning and religious advice. The few who heard of the warning went through the religious rituals individually, like painting oneself with mud or performing community rites, to induce rain and avert the crisis. It was, however, in vain.

At Lokichar village, a key informant, an old man (a mzee) nearly 75 years old, led me to a religious shrine they called Akipeyare or Amuronet in the mountains where prayers had been conducted and sacrifices made to God (Akuj) when the local people heard of Akiyobok's warning and instructions. Two camels had been slaughtered and offered as sacrifices, and heaps of their bones were still at the site at the time of the visit.

This particular prayer function was led by the eldest man in the village at the time, Lomoria Kilitar, aged approximately 80 years. Lomoria died towards the end of 2006, and drought struck when he went out of his home area to look for food. Like Lomoria, the Emuron Akiyobok also died during the 2005-2006 drought. To the people, their deaths meant that the mystic powers of the Emuron had seriously declined. It was a bad omen to the people.

When further inquiries were made to hear from the people why they thought prayers were ineffectual today, the key informants at both Morulem and Lokichar villages stated as follows:

One reason which makes these ceremonies fail to be effective today is because of the change of things from true mediation and submission to God to the situation of hypocrisy. These days, people who come to the ceremonies are motivated more by the desire to eat the sacrifice rather than serious prayer, hence the slaughter of camels instead of goats. But still, people go home hungry and say they did not eat enough. So it is not prayer, it is feasting. It is all hypocrisy. And the Gods refuse to be fooled as the people do not humble 
themselves before them. Moreover, after the prayers, many people return to their Manyattas and commit various sins, for example, wife beating, which angers the Gods. That discipline that would make prayers effective is no longer forthcoming (Key informant Interview 17th February 2007, Morulem Village; Key Informant Interview $2^{\text {nd }}$ May 2007, Lokichar Village).

\section{4: Identity crisis.}

Due to the serious impact of the 2005-2006 drought and famine as discussed above, Turkana people saw themselves as having lost control over their destiny. They see a society caught in a crisis as it drifts into a gloomy future. Even their religious and cultural practices for averting droughts and famine have become increasingly obsolete due to the declining powers of their spiritual leaders (Emuron). They were caught up in a serious identity crisis. A key informant from Morulem village put their predicament into the following poetic words:

We are not Turkana

PAUSE

We-A-R-E not Turkana

The people you see here receiving famine relief food are not Turkana

The Turkana are up in the mountains attending to their stock

Those who are here are destitute...MAA-SKINI

People have lost their Turkana identity

To be Turkana means:

To own livestock,

To be well fed in milk, meat and blood,

To have wife and children who bathe in milk and ghee,

To be held in high regard as manager of livestock,

Today we are not men, we are animals.

We are now being fed by government, and we diarrhoea, and our children develop over-grown bellies.

WE ARE NOT TURKANA (Key Informant Interview $6^{\text {th }}$ February 2007, Morulem Village).

I found this portrait of the changing Turkana pastoral life important to this study because it kept recurring in subsequent 
interviews. It represented a consensus view about the economic problems facing the local people. The Turkana despise relief food and strongly feel that they could do better if they could have a strong network maintained through exchange of animals. For instance, weeks later, at Lokichar village, another key informant projected the same image of a changing pastoral life using slightly different words. He said as follows:
A Turkana has three legs.
Two human legs and the third is social - his livestock.
The third leg is the most important in human relations.
Remove his livestock and he is a cripple
Without livestock, you cannot mix freely with other colleagues and peers.
You cannot ask for food and be given with a clean heart.
You cannot entertain friends and relatives
YOU ARE NOTHING (Key Informant Interview 4th May 2007, Lokichar Village).

One would conclude that the magnitude of the 2005-2006 drought and famine seemed to have had serious psychological effects on the Turkana people. The heavy livestock and human loses were emotionally disturbing. The psychological stress became more intense due to starvation and loss of human life, particularly children. What distressed the people most gravely was the fact that over the years, they have witnessed a systematic erosion of pastoral values, ideology, and lifestyle.

\section{5: Response to the 2005-2006 droughts.}

\subsection{1: Introduction.}

As discussed in section one of this chapter, the economic disaster which the Turkana people faced as a result of the 2005-2006 drought and famine made it imperative for them to seek out ways of topping up their 
household food reserves. This they did through a number of adjustment mechanisms whose analysis is the subject of this section of the thesis. Of great importance to this study are the types of social networks that enabled the Turkana people to weather the effects of the 2005-2006 drought and famine. The analysis is based primarily on the interpretation of the questionnaire interview responses.

All over the world, social networks link various tribes and people togather. Peasants and pastoralists practice livestock-grain, trade and exchange connections in many parts of the world, especially in Sub-Saharan Africa (Nikola 2006). Traders may act as middlemen, or the people may barter directly, thus personalizing the exchange. Gift exchanges are also part of the glue of social networking in many cultures and induce an expectation of reciprocity (Johnson and Bond 1974).

In cattle keeping societies, livestock association and bride-wealth exchange are common. Goldschmidt $(1969,1976)$ observed that among the Sebei pastoralists in Uganda (called Sabaot in Kenya), close reading of a man's animals is a record of the major social interaction of his life. Among the Pokot, Turkana's neighbours and 'enemies' to the south (see Figure 18), the tilia gift exchange starts at the age-set initiation, establishing a lifelong link between a young man and an influential elder who continue to exchange animals (Scheneider 1957).

In the Turkana District, intra-regional exchanges of livestock, food, and gifts have flourished since time immemorial, basically in times of local drought, disease or raids. Informants explained that in the past, when crisis looms, one could go to his associates to beg for animals or food or to share pastures. Informants affirmed that it is custom for the Turkana people to constantly "beg" (akilip) ${ }^{132}$ or ask for things from each other, and

132 "Begging" (akilip - to beg, ask, or plead) does not usually have a negative connotation in Turkana, and is a normal part of social interaction. 
asking for assistance is not only a way of getting livelihood support during crisis, but also to initiate friendship ${ }^{133}$ which they could depend on in the future. They outlined that although true 'loans' of stock are not common, if one friend is in a time of hardship, he may 'borrow' a goat to slaughter and then the next year he will repay with another goat.

Gulliver $(1951,1955)$ also points out that, in the past, each individual Turkana herder had a network of associates who served as a type of insurance policy. Gulliver estimated that an average herder had about 30 associates, but did not estimate the average number of bond-friends, giving only one example of a man who had three (Gulliver 1951: 104-105). It is these kinds of human relationships, and their impacts on Turkana livelihood strategies during the 2005-2006 drought and famine that form the centre of the discussion in this section.

\subsection{2: Trade ties and symbiosis.}

During the 2005-2006 drought and famine, previous ties with the traders and businessmen in the district, and symbiotic relations with the Merille of Ethiopia were revitalized and exploited to the full as survival strategies adopted by the famished pastoralists. The respondents said that without these two allies (the traders and Merille); it would have been much more difficult for them to cope with the hardships.

Many famished Turkana households went across river Omo into Ethiopia either to trade or beg food from affines. Those who went to trade used skins, ornaments or cash to buy food. They bought sorghum, and maize meal.

133 According to Porter (1987) and Lemarchand (1990), friendships and the lively discussions about animal gift and food exchanges bring enjoyment and satisfaction to the Turkana and are examples of a type of "economy affection" found in many non-market economies. 
The practice in Turkana has been for the household heads to send their sons or wives to look for food. However, in one instance during the 20052006 drought and famine, there was mass emigration of faminished Turkana pastoralists who wanted to settle temporarily in Merilleland to take advantage of a better food situation across the border. The Ethiopian government was reportedly airlifting food from Addis Ababa into her border with Kenya twice a week. Informants reported that Kenya's security at the Numurupus ${ }^{134}$ border post refused to allow such mass emigration for reasons which the respondents were unaware of. Movement in small groups for the purpose of trade was, however, permitted. And through this would be seen that the Ethiopian government, by default rather than design, helped to feed the drought and famine stricken Turkana pastoralists.

It is also worth noting that symbiotic relationships have existed between the Turkana and the Merille for as long as the two pastoral communities have existed as neighbours. We have seen in Chapter One how the Turkana used to cope with drought and famine in the past by exploiting these kinds of relations for survival. The Turkana traded with the Merille and sometimes settled among them during such periods of hardship. The data reveal that such symbiotic relationships still exit between the two communities (Turkana and Merille) and were useful during the 2005-2006 drought and famine.

Respondents also outlined that there was increased dependence on the Somali (oria) traders who travelled with their merchandise in large trucks to the countryside and bartered them for goats, hides and skins. Similarly, the pastoralists forged greater ties with the various market and rural centres where they sold their hides, and skins to traders for cash. The cash income was then used for procuring essential commodities from the local commercial stores. From these transactions, the Turkana people were

${ }^{134}$ Numurupus is a town at the border of Kenya and Ethiopia. 
able to maintain a fairly steady supply of maize meal, salt, tobacco, and other essential commodities. According to respondents, the peak period of this business was between May 2005 and January 2006. After that period, informants explained how things became much more difficult, since there were now no more hides or skins to sell as most of the stock had long since perished. Moreover, the people had run out of the cash previously earned from the trade in skins.

\subsection{3: Splitting herds and families.}

In pastoral communities, the practice of splitting herds and families is a dominant feature of life. This is done in relation to spatial and temporal variability of the rangeland vegetation. Turkana people believe that splitting herds conserve and safeguard range resources from being degraded and overgrazed in an irreversible way. During the 2005-2006 droughts, local people had an elaborated herd splitting strategy, and herds and flocks were split in base camps and satellite camps. ${ }^{135}$ Milking and young animals were tended as base herds closer to the village by young girls and boys. Immature flocks before the age of puberty were tended by older boys at a relatively far distance from the settlement, and less productive but strong herds were sent as satellite herds to remote areas and managed by adults.

It should be noted that base camp and satellite herd sizes are dynamic, and are determined by factors such as availability of feed, water, and labour. For instance, due to the lack of enough water and pasture around the villages during the 2005-2006 droughts, I observed a shift of part of the base camp herd to a satellite herd leading to an increase in satellite herd size. The reverse started to happen by February 2007 when the rainy season had begun, and the condition of pasture improved. I would argue

135 The satellite camps and base camps were made by group of families (households). Base camps are those next to the village and satellite camps are those far off from the village. 
here that such movements could be harnessed in future as an early indicator of emerging intensity of drought crisis for timely drought contingency planning and intervention in the Turkana District.

However, the kind of splitting families which emerged with the 2005-2006 drought and famine among the famished Turkana pastoralists was entirely new. It was done specifically to prevent depletion of existing household food resources. The data were particularly rich in cases of children who had been sent off either to kinsmen, friends, or school as a survival mechanism for sloughing off population from the pastoral sector. One respondent from Morulem village stated as follows:

Before the drought I had 15 cattle, 60 sheep and goats, and seven donkeys. After the drought, I remained only with six cattle, 25 goats and sheep and three donkeys. Therefore my second wife and her four children went to Lodwar town to look for work. She works for a Kikuyu 136 trader there. I stay here at Morulem village with my first wife. She has five children in all; one is with us here and four we sent to school. Unless the family is split, it would be difficult for us to survive (Household Interview 2nd July 2007, Morulem Village).

As stated above, the unique way of splitting family during the 2005-2006 droughts and famine, which was of particular interest for this study, is the practice of sending off children to school due to lack of pastoral duties and the shortage of food. The school was popular at such times because in nearly all the primary schools in the district, the children were fed by the government or missionaries. The school enrolment rises during the drought and probably decreases in more prosperous times. For instance, the total school enrolment (primary and secondary) in the District was projected to rise to 39,949 in 2006 from 27,411 in 2002 (Republic of Kenya 2002). Respondents explained that 2004 was a prosperous year, while in 2005 and 2006, the drought had stretched the pastoral economy to its

${ }^{136}$ Kikuyu is one of the major tribes in Kenya. 
limits. In 2006, the 10 public primary schools in the Turkana District were full and had nearly three times their authorised capacity (Republic of Kenya 2006).

We could demonstrate this by examining the enrolment trend at Lokichar primary school137 during the 2005-2006 drought periods. The annual statistical returns obtained from the head teacher showed that the school's enrolment for standards ${ }^{138}$ one to five ${ }^{139}$ rose from 58 pupils in 2004 to 142 in October 2005. This was a large increase of approximately 145 per cent. Table 9 illustrates the trend and shows that the school enrolment in 2005 was more than twice that of 2004. This, however, reflected the general trend in the whole of Turkana District during the same period. It was observed that during the 2005-2006 drought periods, the Kenya Government was providing free food to those pupils attending schools, and this could have facilitated high enrolment.

Table 9: Lokichar school enrolment by sex, during $2004-2005$.

\begin{tabular}{|l|l|l|l|l|l|l|l|l|l|l|}
\hline \multirow{2}{*}{} & \multicolumn{2}{|c|}{ Class 1 } & \multicolumn{2}{c|}{ Class 2 } & \multicolumn{2}{c|}{ Class 3 } & \multicolumn{2}{c|}{ Class 4 } & \multicolumn{2}{c|}{ Class 5 } \\
\cline { 2 - 10 } & Boys & girls & Boys & girls & Boys & girls & Boys & girls & Boys & girls \\
\hline 2004 & 18 & 11 & 15 & 4 & 4 & 6 & 0 & 0 & 0 & 0 \\
\hline 2005 & 53 & 25 & 28 & 9 & 14 & 5 & 4 & 1 & 3 & 0 \\
\hline
\end{tabular}

Source: Fieldwork 2007.

Table 9 shows that although there was an increase in the number of students seeking enrolment during the 2004-2006 droughts, the number of boys was slightly higher than that of girls. This could also be explained by the fact that there were limited herding activities for boys due to losses of livestock whch resulted from drought conditions.

\footnotetext{
137 Lokichar primary school is located within Lokichar village (my research site).

138 'Standard' in a Kenyan context refers to the year of study

139 Data was taken for standard one to five only, as this was deemed to offer enough (required) information for my study.
} 
It was also noted that the lower classes, particularly class 1, attracted more pupils than any of the other classes. Lokichar primary school was, in 2005, forced to run two streams of class 1 due to this sharp rise in enrolment.

The rush for learning places at Lokichar primary school in order to ease the consumption strain on household resources could further be depicted in table 10 and figure 20.140

Table 10: Total enrolment per year of study at Lokichar primary school.

\begin{tabular}{|l|l|l|}
\hline Year of study & $\mathbf{2 0 0 4}$ & $\mathbf{2 0 0 5}$ \\
\hline 1 & 29 & 78 \\
\hline 2 & 19 & 37 \\
\hline 3 & 10 & 19 \\
\hline 4 & 0 & 5 \\
\hline 5 & 0 & 3 \\
\hline
\end{tabular}

Source: Fieldwork 2007.

Table 10 and figure 20 further illustrates that Turkana children do not further their education to the higher classes, and that enrolment continues to diminish from class 1 to class 5 . It is also observed that the enrolment was simply sporadic in response to drought crisis, after which the children leave school and go back home to undertake pastoral duties.

140 It may be noted from this discussion that my respondents sent most of their children to school during the drought period. This analysis may have a bearing on the impact of drought on the respondents. It indicates that the effect may have been very harsh on them. 


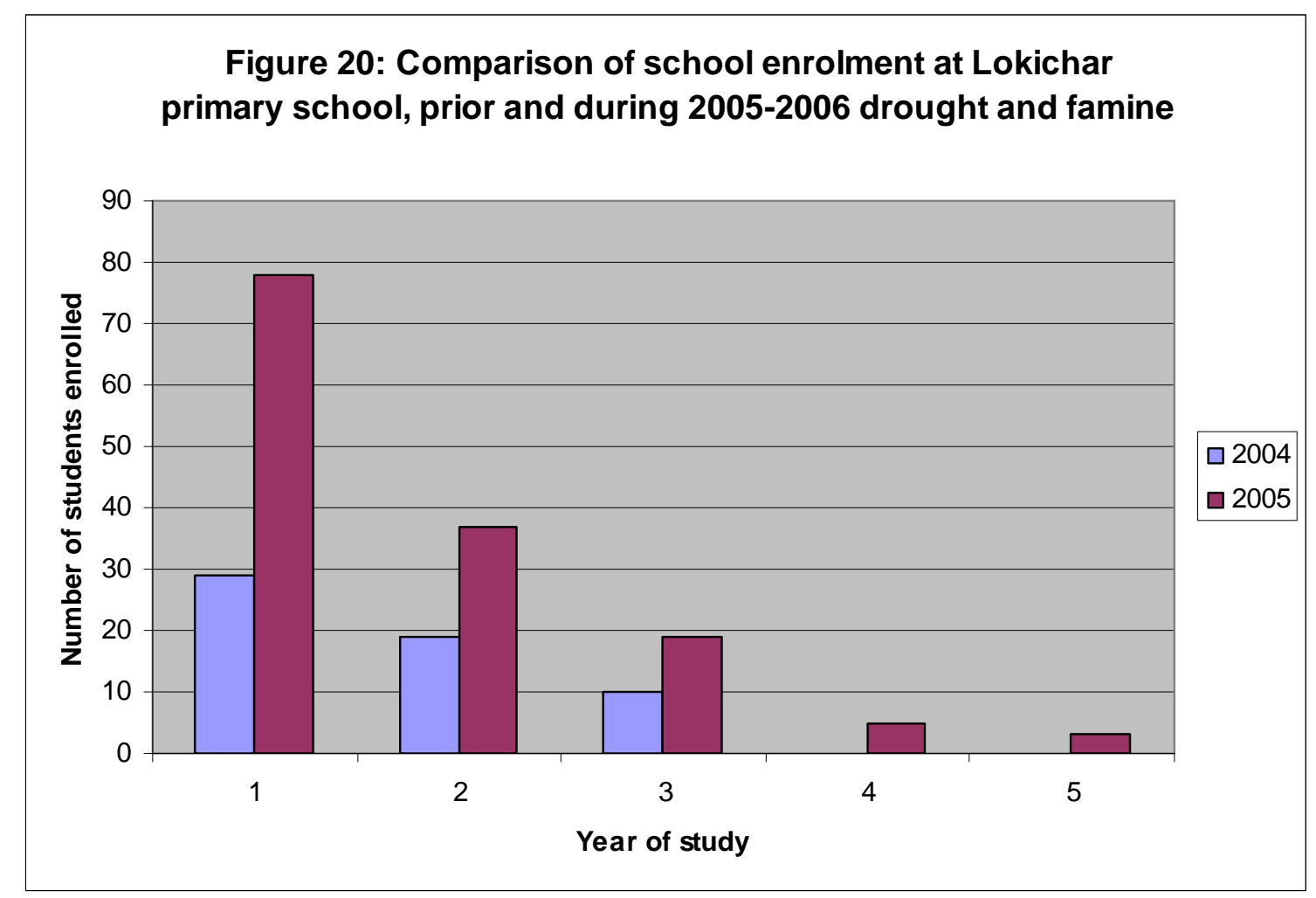

Source: Fieldwork 2007.

Therefore, it could be summarised that, to a large extent, schools played a critical role as a survival strategy during the 2005-2006 drought and famine.

\subsection{4: Pooling resources.}

There was evidence which suggested that during and after the 2005-2006 drought and famine, herders joined together in corporate groups and pooled their surviving stock in order to exploit economies of scale. The respondents said that once the livestock had been so pooled, they were left in the hands of a few selected men or families in the pasturelands as the rest moved in search of food. Migrants had similarly left their families and livestock with kinsmen and neighbours or friends as they went out in search of employment and other income generating activities. 
The respondents went on to explain that this mechanism of pooling resources during and after drought or loss of livestock from catastrophes is customary. Historically, the able bodied but dispossessed pastoralists' would leave behind whatever had remained of their stock and "disappear" into distant lands to settle and work there temporarily. Most of them would emigrate to Merilleland in Ethiopia. Written evidence exists to this effect (Turkana Political Records. Miscellaneous: 1971-1943 File No. TURK/59, DC/TURK 3/1).

The dispossessed would live among the Merille for as long as the economic hardships lasted, which would be upto two years. When more prosperous times returned, they would collect their 'pay' and gifts in livestock and return to Turkanaland to re-enter the mainstream of pastoral life. This was quite similar to what other nomads such as the Gabra and the Maasai do in response to drought and famine. ${ }^{141}$

According to respondents, those who left during the 2005-2006 drought and famine would receive their share of the built up livestock from the pooling system when they return.

A study by Laughlin and Brady (1978) illustrates how, when ecological or political stress increases for a population, the initial response is for its people to pull together, set aside hostilities and grievances, and pool resources. After a peak of cooperation, if the stress continues in the extreme, concern for family and, ultimately, concern for oneself overtakes concern for group survival. Group cohesion therefore weakens and can even fall apart. The idea does not exactly fit the Turkana: although their condition during the 2005-2006 drought and famine was full of stress, their social structure reflected more independence and flexible small units

141 See discussion in Chapter 1 
than group solidarity. ${ }^{142}$ However, as discussed below, friendly cooperation did take place among kin, neighbours, and friends. I argue, however, that perhaps the stresses did not reach the extreme peak that leads to a downward curve, following the Laughlin and Brady model.

\subsection{5: Reciprocity and exchange.}

In Turkana society, there is a difference between 'asking' (akilip) for an animal and 'exchanging' (akilokony) an animal. When a man 'asks' for an animal, "he simply asks for it". For example, he might say, "my children are hungry and I need a milking cow". In such cases, "you do not tell the man you will give him something later". To exchange (akilokony), one goes to a man who is known to have a surplus of the wanted or needed animals; if both parties are willing, an exchange is made. "Exchanging is like buying something" and both parties are mutual beneficiaries. Akilokony is a way to increase or diversify the herds.

The concept of reciprocity is an important and often overlooked aspect of Turkana survival, but it is an essential aspect of their ability to survive their environment. To fully appreciate reciprocity in Turkana society, one must abandon western notions of the concept. Although westerners may value the concept, they do not practice it to the extent that the Turkana do during a crisis. The western/agrarian ideal of saving seems contradictory to the practice of reciprocity in the Turkana District. Reciprocity is an intimate part of the social fabric of nomadic Turkana culture. It is altruistic behaviour and its benefits outweigh the costs. In Turkana, the cost, or risk, of not reciprocating is social ostracism. Generally, the act of reciprocity is uniformly adhered to in Turkana culture, and a herd owner can be confident that a gift (cost) today will probably yield a greater needed gift-in-return (benefit) at some point in the future. In effect, the more one

\footnotetext{
142 This was a mere observation, as it is beyond the scope of this study to analyze the Turkana social structure.
} 
gives, the more (social) security one can accumulate for the future. Informants stated as follows:

People who do not reciprocate are not good. How can people survive if they do not reciprocate to those who gave to them when they were faced with a problem? When you go to someone's awi and they give you food when you don't have any, you need to reciprocate when you do have some. Those who don't reciprocate are like wild animals. Next time you will not even talk to them (Household Interview $5^{\text {th }}$ July 2007, Morulem Village; Household Interview 10 th June 2007, Lokicahr Village).

This Turkana behaviour of reciprocity is quite similar to what has been observed among other communities in Sub-Saharan Africa. For instance, Mauss (1967) pointed out that in a number of civilisations, exchanges and contracts take place in the form of presents; in theory these are voluntary, but in reality they are given and reciprocated obligatorily.

On reciprocity, a number of gifts were exchanged during the 2005-2006 drought and famine. Respondents pointed out that Turkana society is organised around the allocation of resources through gifts: gifts are mostly distributed within the family and kin group and among friends and individuals when each other is in need and must be acknowledged for it. They mentioned that gift exchange are very common during crises, but also help in making and nurturing social ties. 84 respondents (approximately 95 percent) interviewed said that during the 2005-2006 drought and famine, they exchanged some gifts with their friends and relatives through the traditional hospitality system. The major categories are shown in Table 11. Similarly, they indicated that they could not remember having given away much due to the depletion of their household resources. Moreover, respondents reiterated that the mass wandering and dispersals (see Figure 23) due to the 2005-2006 droughts tended to bring friends and relatives together, making immediate contact and exchange of gifts feasible. 
Table 11: Gifts exchanged by Turkana households during the 2005-2006 drought and famine.

\begin{tabular}{|l|}
\hline Gifts exchanged \\
\hline 1. Animals (Goats and sheep, cow, donkey, camel) \\
2. Food (slaughtered animal upon the friends visit, or other prepared \\
food, sorghum, and maize-meal) \\
3. Containers (for water, milk, oil) and tools e.g. shovel and spear \\
4. Tobacco and maize-meal \\
5. Jewellery \\
6. Money
\end{tabular}

Source: Fieldwork 2007.

By far the most common gifts exchanged between friends and relatives were goats, donkeys, food, and tobacco (mentioned by 90 per cent of all the respondents) ${ }^{143} .56$ per cent of Morulem residents gave their bond friends and relatives goats and donkeys. Lokichar residents gave their bond friends and relatives gifts more typical of a 'town' i.e. what can be purchased from the shops being food (62 per cent of respondents), jewellery (56 per cent of respondents) and tobacco (100 pe cent of respondents). However, 75 per cent of Lokichar respondents received, and 25 per cent gave goats and sheep and donkeys, which indicates that animals still hold reasonably a high value among the Turkana during times of crises. But all the 88 respondents pointed out that reciprocity involving the exchange of livestock gifts was not very popular during severe drought conditions. This is because it works best in building up the herds after a drought rather than as a source of subsistence during drought. I observed that the exchange of livestock had begun among kinsmen, affines, and trusted bond friends on a noticeable scale following heavy rains in January 2007, and that this was in anticipation for a return to full-scale pastoral life.

${ }^{143}$ This took place when the drought condition had just begun. 
When the respondents were asked to confirm or deny Henriksen's (1974) findings that the cessation of reciprocity forces poor Turkana to fall off the exchange network, respondents noted that with respect to the 2005-2006 drought and famine, there was no such thing as "falling off", for the majority of people were almost equally hard hit. Turkana culture prohibits asking for help from a neighbour, kinsman or friend who is himself a victim of disaster; you console him or her, you do not beg from him. To do so is viewed culturally as anti-social and insulting. ${ }^{144}$

Therefore, analysis of the mode of reciprocity and exchange during the 2005-2006 drought and famine brought to the foreground the following observations:

i) In history, Turkana pastoralists have traditionally operated with a minimal involvement in the monetary economy. The preferred means of acquiring food has been through trade or begging rather than direct purchase, thus avoiding the use of money. However, during the fieldwork, I learnt that 20 percent of the respondents (47 percent of those in Lokichar village) indicated that money was one of the gifts to their bondfriends. I argue here that this is an indicator of the increasing gradual incorporation of the Turkana people into the Kenyan national economy. If this trend continues, as in other parts of the World, exchanges among pastoralists may become more and more depersonalised.

ii) Gift exchanges in Turkana during crises are voluntary and between two individuals. The exchanges do oscillate: in several cases, my respondents replied they were "still waiting for the rains" to go to visit and beg from or exchange gifts with their friends. Because of long distances between friends and a scattered population in Turkana, exchanges are not as frequent as other communities with denser populations. Animals are also larger gifts during crises than a plate of food passed to friendly neighbours.

\footnotetext{
144 The fact that respondents could not request gifts from their close friends and relatives who were equally affected by drought and famine could explain why they made contacts with friends and relatives from other places as shown in Table 12, and Figure 23.
} 
iii) Gift exchanges in Turkana during crises are mostly asymmetrical and reciprocal, but leaders and rich people are expected to give more to others. Some leaders (e.g. local chiefs and clan elders) informally told me that many more people beg from them during crises (and they give) than the few they consider to be their true bond friends. It is possible that more people consider wealthy Turkana to be their friends than vice versa. These relations could be considered asymmetrical.

Therefore, given the prominence of exchange relationships among the respondents during the 2005-2006 drought periods, it became prudent to locate the various friends the respondents depended on.

\section{6: Geographical dispersal of bond-friends of all the respondents.}

As discussed in the previous chapters, the Turkana posses an intimate knowledge of their physical environment, for their survival has depended on skilful management and movement. They also have very detailed social maps (mental maps) of geographical areas through which they have travelled on foot. All topographical features (e.g. hills, rocky outcrops, and stream beds, plain) and areas have place names. The Turkana adults

posses this knowledge, as they spend most of their lives herding nomadically. Dyson Hudson (1982) documented that the Turkana people have accurate ways of communicating information about space.

From the case histories compiled during the survey interviews, Turkana special friends live in a wide geographical area, and these special friends are sought during hardship. For instance, during the 2005-2006 drought and famine, there were mass movements in search of special friends. These migrations were determined by the individual's environmental perception, and most important, the existence of friends, kinsmen or affines at the receiving end. Those who so migrated said that it was not 
just a plunge into the unknown wilderness. They knew where they were going and they believed before setting off that they would find friends to welcome and give them hospitality.

For instance, one respondent told a story of how he walked from the Kenya-Sudan border to Kitale town (located in the southern part of Turkana District) in search of employment. But it took him nearly one month to reach Kitale town because the journey was made in stages. He walked to Kakuma, then to Lodwar, later to Katilu, and finally through West Pokot to Kitale. At these named stopping places, he stayed a couple of days with a friend, a kinsman or affine before proceeding further. The respondent had hoped to settle at Kipsongo, a Turkana slum in Kitale town. ${ }^{145}$ However, the respondent didn't get to his relative at Kipsongo slum. He was arrested by Kenyan police, accused of loitering, and jailed for three weeks. Upon his release in January 2007, ${ }^{146}$ he returned to Lokichar village with the aim of returning to full-scale pastoralism.

It is important to note that though many immigrants knew where their friends were, the interviews also revealed that on certain instances, the migrants merely exploited fictive kinship ties to find a place to stay while looking for a job or waiting to move to the next stopping place. For instance, one of the respondents who walked to Kitale said as follows:

I used to hear that a distant cousin had settled in Kitale with his family after the drought and famine of 2000. I had hoped to trace him and ask for his help in getting a job (Household Interview 14th May 2007, Lokichar Village).

\footnotetext{
145 According to respondents, Kipsongo slum is estimated to have approximately 3000 poor Turkana who over the years have been driven out of Turkanaland when they lost their livestock due to drought raids or epidemics. I gathered that those who moved to Kipsongo slum engaged themselves in all sorts of odd jobs. A number of them settled down and took to basket making, rope making, and various types of what Hjort Ander (1979: 13) termed "ten per cent trade".

${ }^{146}$ Lokichar village in southern Turkana received heavy rains from January, 2007.
} 
Another respondent narrated how he walked down the Lokikipi plains to Kakuma through Lokitaung and Kakuselei down to Lokichar village. This respondent appeared to have experienced a more difficult time than many of the migrants, for he was trekking with the whole family. The household ran out of food before reaching Kakuma at a place called Lekudule. He was then forced to prematurely marry out his eldest daughter (or was it pawning?) to a rich man in exchange for food. ${ }^{147}$ Two other younger sisters remained behind with the newly married daughter as the rest of the family continued south subsisting on bride wealth. ${ }^{148}$

Therefore, the data reveal that networking behaviour increases during drought and famine. For example, the range of bond-friends for each of those interviewed was from 0 to 33 people. Only four of the 88 respondents replied that they had no bond friend. These four were key informants who claimed that their animals had died, and they were too old to walk long distances to visit others and make friendships. Each of the 84 respondents was quite specific when I asked "where do your special friends or bondfriends live?" 149 A total of 64 places were named and some of these places are listed on table 12 .

Because many of these places were rural and remote, we can assume that many of these bond-friends are still mobile pastoralists. Although the majority of the bond-friends are in a cluster surrounding Morulem region, they still show a wider geographical dispersal. Most of the friends generally live in Ngibelai, Ngisonyoka, and Ngisetou territorial sections in southern Turkana, with a few in the northern Turkana towns of Kitale, and other locations in Kenya such as Maralal.

\footnotetext{
${ }^{147}$ It is worth noting that this particular herder used bride wealth to sustain his livelihood during these hard times.

148 By the time of interview, the man's two young daughters were still staying with their married elder sister

149 This supplementary question was asked to elicit more information required for data analysis. The question was never recorded in the formal interview schedule.
} 
Table 12: Location of exchange friends of 84 sample respondents of Lokichar and Morulem village.

\begin{tabular}{|lll|}
\hline Baragoi & Katilu & Morulem \\
Eldoret & Kitale & Nachar \\
Elelea & Kochodin & Nadikam \\
Golgol & Kolong & Nakorinya \\
Kaaling & Korinyang & Nakosawan \\
Kailongkoi & Lochebu & Nakwakal \\
Kakitoe & Lochwakala & Napeitom \\
Kakulit & Lodwar & Naraman \\
Kakumol & Lokichar & Naroo \\
Kakurio & Lokichoggio & Natir \\
Kakwachune & Lokitaung & Nawinkipur \\
Kalokol & Lokori & Ngichwae \\
Kalagmata & Lokwamosing & Suguta \\
Kalinyenyang & Lokwawa & Tambach \\
Karomerilim & Lokwii & \\
Kaleso & Loling & \\
Kamende & Lomomug & \\
Kamuge & Lomuritae & \\
Kanaudo & Lomunyenakwan & \\
Kangotit & Loriu & \\
Kapenguria & Lotien & \\
Kapsowar & Lotuba & \\
Karasagol & Loyangalani & \\
Kasimanang & Maralal & \\
Kitilia & Molo & \\
Source: Fieldwor 2007. & \\
\hline
\end{tabular}

Source: Fieldwork 2007.

As illustrated by the three networks of Morulem residents in Figure 21 (bond-friends locations for three Morulem residents), the respondents commonly have bond-friends in alternate directions, for example, from Kaling to the north, Riget to the east, and Kitale (outside Turkana) to the south. This dispersal is consistent with the pattern earlier observed by Gulliver in north Turkana (Gulliver 1951).

It was also observed that men were favoured for bond-friends because the head of the household has the ultimate authority to decide who to visit, 
when to give, sell or slaughter an animal.150 Married women basically shared bond friends with their husbands. Those unmarried could share with their parents. There were cases where women developed friendships by giving beads, cooked food or grain, traditional containers for milk and fat, or other items from the household. I also observed that in cases of hardship, a young male would request a gift from his father and give to the parents of his adolescent girlfriend who are not part of his father's bondfriends. But this did not form part of the bride-wealth. This concurs with what Wienpahl discovered when he pointed out that among the southern Turkana, a male friend of an adolescent girl may 'give' her an animal, and "there is no connotation of sexual relationships between female and male friends or "best friends" Wienpahl (1984: 213). ${ }^{151}$

\footnotetext{
150 As discussed in chapter 5, traditionally, Turkana women hold usufruct rights, but not legal ownership of properties (assets).

151 The male-female adolescent (non-kin) interaction I observed often involved some amount of shyness or flirting. However, this was not a topic of my study, so the observations were indirect rather than focused.
} 


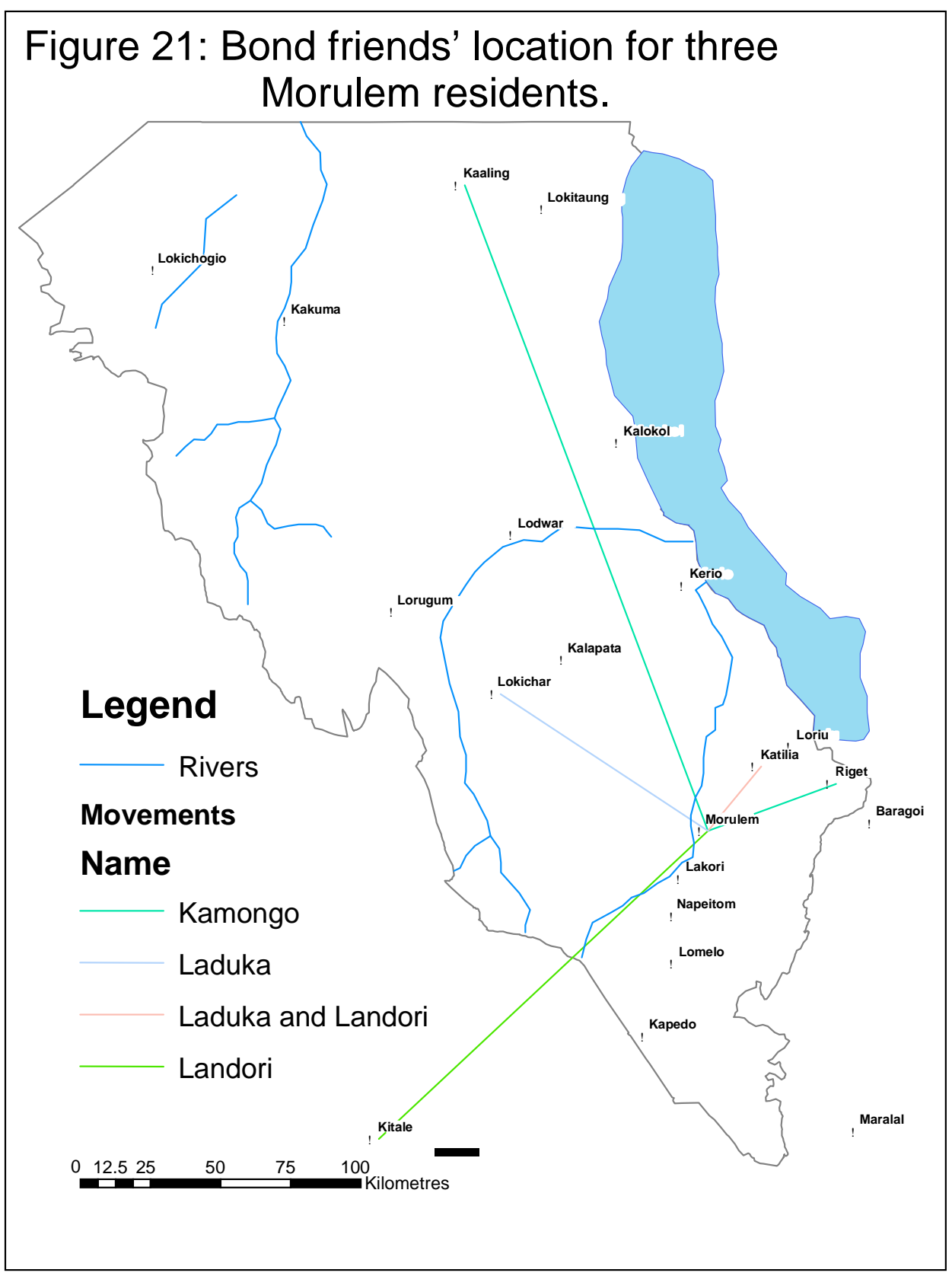

Source: Fieldwork 2007.

\section{7: Taxonomy of Turkana social ties during crises.}

As mentioned earlier, it was beyond the scope of this study to discuss the formation, or how various relationships were formed during the 2005-2006 droughts. A few comments however, are necessary. This study mapped for a practical analysis of livelihood resilience in Turkana, only social relations 
that emerged during the 2005-2006 drought and famine to provide access to productive resources, coping mechanisms and livelihood opportunities.

Studies by Woolcock (1998) and Cross, and Mngadi (1998) have much relevance to the type of human relationships observed in Turkana during the 2005-2006 droughts. Woolcock (1998) refers to human relationships that exist within a community as integrated ties, and linking ties, which refers to those between different communities. Cross and Mngadi (1998), also identified two distinct types of networks which rural people rely upon for aid during a crisis: bound networks which includes relations with close relatives that begin at birth and are connected by obligations based on kinship roles, and achieved networks which includes a person's or household's list of personal contacts that are gained through experience and not inheritance.

My study integrates the ideas of Woolcock (1998), and Cross and Mngadi (1998) with my own field data and formulates a Turkana social network taxonomy observed during the 2005-2006 droughts. This is presented here in Table 13.

Table 13: Turkana social network tie taxonomy during crises.

\begin{tabular}{|l|l|l|}
\hline & Integrated & Linking \\
\hline Bound & - Extended family & $-\begin{array}{l}\text { Clan (emachar) links } \\
\text { outside the village }\end{array}$ \\
& $-\begin{array}{l}\text { Immediate } \\
\text { family }(\text { awi }) .\end{array}$ & - Migrated family members. \\
\hline Achieved & $-\begin{array}{l}\text { Stock } \\
\text { associates/bond }\end{array}$ & - Migrated friends/others \\
& $-\begin{array}{l}\text { Other friends } \\
\text { e.g. traders etc. }\end{array}$ & \\
& & \\
\hline
\end{tabular}

Source: Fieldwork 2007.

The observation in Table 13 concurs with Gulliver's (1951) earlier finding which grouped Turkana social relationships into five categories: kin, 
affines, friends, neighbours, and passers-by (including those well-known or even unknown). ${ }^{152}$ It was noted that the Turkana people diversified their relationships during the 2005-2006 drought and famine. Apart from the immediate family and clan members, relationships were also formed with the local schools to ease pressure on the existing food resources. The literature in Chapter 1 reveals that, in the past, several types of social relationships used to be exploited for survival in times of economic hardship. They were kinsmen, affines within the pastoral communities themselves, reciprocal partnerships, symbiotic relationships with neighbouring agricultural or pastoral communities, and finally, relationships with outsiders such as traders, state officials, missionaries, employers, and the sedentary population. These were the types of relationships observed during the study period (see Table 13), and formed the core of analysis.

\section{8: Chapter summary.}

This chapter has presented the findings of interviews with key informants and household heads. It has focused on the impact of the 2005-2006 drought and famine and the behavioural patterns which emerged in the process of adjustment to stem the negative effects of the 2005-2006 drought and famine. It reveals that the Turkana pastoral economy has become highly vulnerable to droughts and famine. During the 2005-2006 drought periods, the Turkana lost many of their livestock and many people were rendered destitute. The people saw themselves as caught up in a crisis.

There is evidence that the 2005-2006 drought and famine led to deaths from starvation, judging from the high death rates during that period. The evidence available also indicates that the famished Turkana had applied various ways of weathering the food crises. Thus, they did not simply wait

\footnotetext{
${ }^{152}$ See discussion in chapter 4.
} 
passively, but ventured out creatively to find ways and means of survival through their social networks.

A fundamental question in this chapter is: Does social network influence one's success during drought and famine in Turkana? The answer is yes. One's network is part of a risk strategy which provides a person with both physical and psychological security. It promotes a form of social stability that allows the Turkana to implement their pastoral strategies to good effect in the arid environment they occupy, in order to bridge environmentally stressful periods of time. For instance, during the 20052006 drought, the famished Turkana pastoralists sought out allies as a way of coping with the stress. The various livelihood strategies which sprung up during this period, for example trade ties and symbiosis, splitting herds and families, pooling resources, and reciprocity and exchange, were all as a result of networking with bond-friends, local relatives, and friends. It is observed that if one is hungry, a person can go to a member of his or her network or relative and ask for a gift in terms of food or animals. People can also take management risks such as moving into unfamiliar areas knowing that he or she will always have the support of friends. The study agrees with an earlier observation by Wienpahl (1984) that "redistribution through exchanges contracts the Turkana norms of individual autonomy and thus lends a cohesive force to an otherwise atomistic society Wienpahl (1984: 237).

Social networks among Turkana pastoralists are also links to the past, present, and potentially future friendly relations. It has been observed that these links are very strong during drought and famine, and that they seem to be based on mutual need and caring. During the 2005-2006 droughts, social networks were chosen as a type of investment and risk dispersal over a wide geographical area. This evidence supports the hypothesis that drought and famine stimulate the search for potential allies. 
Therefore, this analysis highlights the following: Firstly, that Turkana people apply a perceptual filter to the crisis before choosing any strategy. The decisions regarding pastoral strategies are based on their past experience and cultural interpretation of the crisis. Secondly, livelihood strategies during crises draw on social networks that act as an insurance system. The next chapter critically compares the impact of the 2005-2006 drought and famine on the two study villages, in order to analyze the social and economic resources that determine the range and scope of adaptive responses. 


\section{CHAPTER 7 FACTORS THAT IMPINGE ON ADAPTABILITY IN THE TURKANA DISTRICT}

\subsection{Introduction.}

The previous chapter described livelihoods in the two study villages by focusing on the impact of the 2005-2006 drought and famine, local people's perception and awareness of the situation, and subsequent indigenous responses through their social networks. It was pointed out that the ultimate purpose in cultivating relationships is to gain access to economic opportunities that enable Turkana pastoralists suffering from food shortages to obtain additional food supplies to top up their household food reserves. Some of these responses are explicitly recognised in the livelihood framework, while others are less obvious, yet still relate to the Turkana people's livelihood situation.

In this chapter, it is argued that responses to drought and famine as discussed in Chapter 6 do not take place in a vacuum. Turkana people respond to such situations in complex and creative ways based on the resources accessible to them. For instance, issues relating to the ability of households with different resource endowment to undertake the activities, and the types of resources required are quite important in understanding a community's livelihood response. Swift (1989), Chambers (1989), Moser (1998), Siegel and Alwang (1999) and Ellis (2000) have presented arguments that closely link vulnerability to asset ownership and generally suggest that, if a person's livelihood platform is weak, his or her livelihood strategies are limited, and the outcome may be poverty. On the other hand, a person with a strong livelihood platform has many strings to play, and may be able to secure his or her livelihood, even in crisis. Therefore, a critical analysis of some of the socio-economic resources that impede Turkana people's adaptability would help to deepen our understanding of their situation and enlighten us on what can be done to strengthen their adaptability. 
In the methodology chapter, it was explained that to understand all the resources which impinge on adaptability in the Turkana District, it was necessary to assume that Turkana households, as with other pastoral households in Sub-Saharan Africa, are not homogenous. Therefore, the sample population was categorized into rural and urban. Two study villages, Morulem and Lokichar, which were rural and urban respectively, were identified and used as research sites.

This chapter is divided into two parts. The first part will analyse if there existed any differences in the impact of the 2005-2006 droughts and famine on the sample population at Morulem and Lokichar villages taken separately. As mentioned in Chapter 6, the impact of drought will be measured in terms of 'livestock losses' and changes in post drought wealth statuses of households in the two localities, while the impact of famine will be analysed in terms of 'human losses'. ${ }^{153}$ On the basis of the results, we will then proceed to the second part of the chapter and discuss the factors which impinge on adaptability.

\subsection{Impact of 2005-2006 droughts on Morulem and Lokichar residents.}

\subsubsection{Livestock losses at Morulem and Lokichar Villages.}

As stated above, for us to find out if there were any differences in the two study villages in terms of livestock losses, the size of each family's herds prior and after drought was calculated. Then, the difference between each family's herds prior to, and after drought was also calculated to enable us get the percentage death rate. This is shown in table 14 below ${ }^{154}$.

\footnotetext{
153 As already mentioned in chapter 6, it is true there could be other ways of determining the impact of drought scientifically, but in this study 'livestock losses' were used as a measuring tool.

154 See appendix 9 for the full data.
} 
According to Table 14, the two studied villages experienced no significant loss in camels during the 2005-2006 droughts. But Morulem village appears to have been hit by drought harder than Lokichar village. This is demonstrated by the fact that in Morulem, livestock losses per household were 58, 62.5, and 73.7 percent for cattle, sheep and goats, and donkeys respectively, while each household in Lokichar experienced 47.8, 50, and 57 percentage loss for cattle, sheep and goats, and donkeys respectively. Therefore, it could be summarised that the impact of the 2005-2006 drought was different in the two studied villages with Morulem households suffering more in terms of livestock loss than Lokichar households. 
Table 14: Livestock losses per household for Morulem and Lokichar residents

\begin{tabular}{|c|c|c|c|c|c|c|c|c|c|c|c|c|c|c|c|c|}
\hline & \multicolumn{4}{|c|}{ Cattle } & \multicolumn{4}{|c|}{$\begin{array}{l}\text { Sheep } \\
\text { and goats }\end{array}$} & \multicolumn{4}{|c|}{ Camels } & \multicolumn{4}{|c|}{ Donkeys } \\
\hline Herds & D1 & D2 & D3 & D4 (\%) & D1 & D2 & D3 & D4 (\%) & D1 & D2 & D3 & D4 (\%) & D1 & D2 & D3 & D4 (\%) \\
\hline Morulem & 9.4 & 3.9 & 5.5 & 58.5 & 10.4 & 3.9 & 6.5 & 62.5 & 1.5 & 1.5 & 0 & 0 & 1.9 & 0.5 & 1.4 & 73.7 \\
\hline Lokichar & 9.2 & 4.8 & 4.4 & 47.8 & 11.4 & 5.7 & 5.7 & 50 & 2.4 & 2.4 & 0 & 0 & 2.1 & 0.9 & 1.2 & 57 \\
\hline
\end{tabular}

Source: Fieldwork 2007

Note

- Family (household) herds were calculated by dividing the total number of herds in each research site, by the total number of households in the same research site.

- D1 indicates size of pre-drought family herds

- D2 indicates size of post-drought family herds

- D3 indicates total livestock loss per household (family)

- D4 indicates percentage livestock death rate per family = D3 expressed as a percentage of D1 
To appreciate the analysis in Table 14, the information was translated in the form of a histogram as shown in Figure 22.

Figure 22: Percentage loss in livestock per household, at Morulem and Lokichar villages.

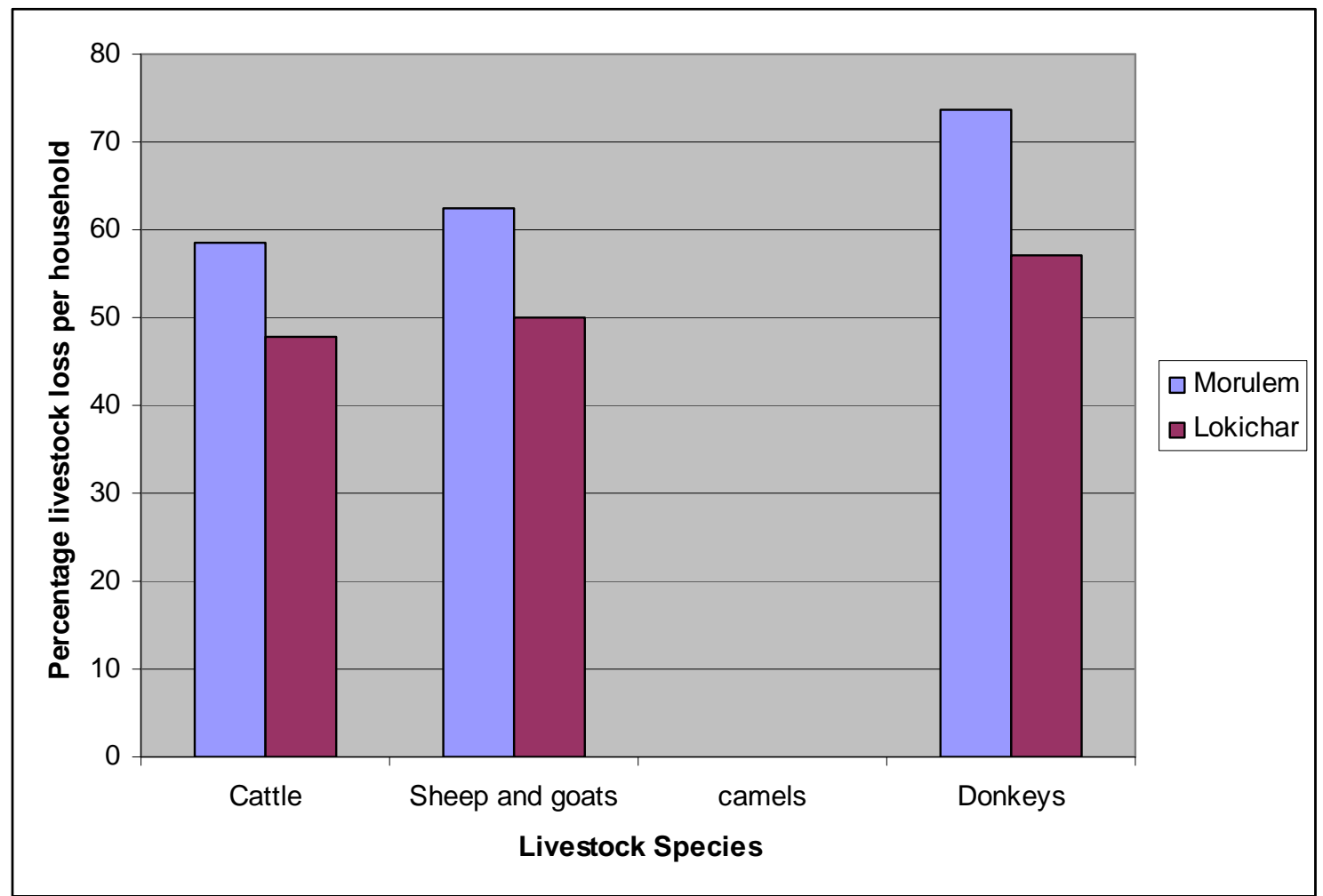

Source: Fieldwork 2007.

To help improve the precision of our conclusion concerning the impact of the 2005-2006 droughts on the people of Morulem and Lokichar, a further comparison was done of the wealth status of the respondents prior to and following drought conditions. It is believed that the 2005-2006 droughts brought about changes in the distribution of wealth and access to income among those affected in the Turkana District. This analysis follows Nikola's (2006) findings that droughts tend to have a stratifying effect within communities, the weaker members becoming further impoverished while the rich are able to minimize their losses and may even increase assets in time of crisis. In this study, it is pointed out that since the two study villages, Morulem and Lokichar, were rural and urban respectively, 
there is a possibility of differing capacities of households to protect themselves and their assets in times of crises.

\subsubsection{Changes in the distribution of wealth.}

As discussed in previous chapters, the need to analyze the wealth statuses of the respondents stems from a common consensus in risks, poverty and rural development literature (Chambers 1989; Ellis 2000), which suggests that poor households are more susceptible to risks and less resilient than are non-poor households because they have fewer resources at their disposal. Davies (1993) also points out that wealthier households can benefit when poorer members of the community are faced with a crisis and have to sell their assets at depressed prices.

Therefore, in this study, it was also necessary to categorize the respondents according to their wealth status so as to identify which village had a large number of respondents who were able or not able to cope with the 2005-2006 droughts. ${ }^{155}$ Since the questions concerning people's perceptions of wealth are of a highly subjective nature, Ellis (2000) suggests participatory methods as the best way to capture the multiple aspects of poverty by facilitating the poor themselves to identify the factors that militate against the improvement in their circumstances. ${ }^{156}$ Economists, on the other hand, have traditionally based their work on objective approaches. The lack of adequate income to command basic necessities is the most widely known aspect of poverty. For instance, in many developing countries such as Kenya, the most commonly adopted poverty line is the one prescribed by the World Bank, which has been

\footnotetext{
155 As already discussed, the aim of this categorization was to demonstrate the difference in the impact of the 2005-2006 droughts on the sample population in the two studied villages.

156 Wealth ranking is normally done through participatory rural appraisal using group discussions, but as discussed in the methodology chapter, it was impossible to bring the pastoralists together for group discussions. Therefore, the information was obtained from household heads and key informants through a semi-structured interview.
} 
estimating global income poverty figures based on sample surveys of households since 1990 (Ellis 2000; Shanmugaratnam 2002). But, as discussed in Chapter Four, poverty goes beyond the lack of income, and in a situation like the one in rural Turkana where the banking system has collapsed and only a few people if any have salaries, objective measurements of income are not particularly helpful. According to Turkana people, the number of livestock owned is the main determinant of wealth.

For example, when respondents in Morulem and Lokichar were individually asked how they defined their situation in terms of wealth, 157 one key informant from Morulem village, a woman, described the wealth status in terms of access to food. More interesting however, was the community leaders, perception of wealth and poverty. For example, the local chief and some clan elders informally mentioned the number of wives a person has as a key determinant of wealth. A fundamental question that arises here is, does this imply that women cannot become wealthy in Turkana society?158

The majority of respondents mentioned the number of livestock owned as the main criteria for describing an individual or family's social position and wealth. It is possible to analyze this further: when Turkana people answered that livestock is the variable which determines if an actor is wealthy or poor, they may not only mean the number of livestock, but also what this implies. As discussed in Chapter 4, a family who has a large number of livestock may invest some in social capital. Wives will provide children, and daughters will again lead to more cattle because they are married to other families and will bring bridewealth to their relatives. As analyzed in Chapter 6, investment in social networking is a strategy which

157 This was a supplementary question and was not directly included in the interview schedule.

158 Data collected was deficient in analyzing this aspect, but it could be interesting for future studies to document the relationship between wealth and sex in Turkana society in order to establish the position of women. 
makes the family safer in view of crises, and it is a way to scatter the cattle in order to spread risk when there is drought in particular places, diseases occur or cattle camps are raided. A large number of livestock then implies a large family and social network, which again implies a high social position in the community. The family will also stand strong in opposition to others, and can build up political capital and power.159 Therefore, this study adopted the majority of responses, and categorizes the respondents in various wealth groups according to the number of livestock owned.

Respondents reported that drought affects Turkana herd-owners differently depending on their level of livestock wealth. The number of cattle, goats and sheep, and camels were mentioned as a good indicator of the wealth status in the Turkana community. Donkeys were not considered to constitute the wealth status of households. ${ }^{160}$ It was to the interest of this study to document why camels were considered as a determinant of wealth, but not donkeys. It was observed that due to the changing ecology and feed availability, camels are capable of lasting a longer period without water during the dry season. Respondents also believe that camel's milk is slightly more nutritious than cow's milk, as they lactate for a long period of time (estimated to be between 13-18 months), are milked twice a day, and because the milk is easily digestible and can be used to feed babies. ${ }^{161}$

Therefore, while in the field, it became necessary to initially get data on what constitutes wealth under normal circumstances when there is no drought and famine crisis. This was meant to be used as control data for comparison purposes when analyzing the situation in the two study villages during the 2005-2006 droughts. On the basis of the data collected,

159 The question of political capital and power was a mere observation during my interaction with the local administrators and clan elders. It was not part of the analysis. 160 Informants explained that donkeys are never exchanged during crises and neither are they used as bridewealth. Some respondents' referred to donkeys as beasts of burden.

161 I observed that since camels are browsers, it is logical to rely on browsing animals, as they make economic use of the rangeland which is often covered by bushes and trees. 
it was clear that respondents were in agreement that, under normal circumstances when there is no crisis, they use four categories to rank households on the basis of the number of herds owned. As shown in table 15 , these are; the better off, middle, poor, and the very poor. According to respondents, the better off are those owning 50-100 cattle, 80-150 sheep and goats, and 10-20 camels; the middle class own $\geq 7<50$ cattle, $\geq 50<80$ sheep and goats, and $\geq 5<10$ camels; the poor own $\geq 1<7$ cattle, $\geq 15<50$ sheep and goats, and $\geq 1<5$ camels; while the very poor own 0 cattle, $0-14$ sheep and goats, and no camels. These different wealth categories observed are quite close to what Levine and Crosskey (2006) found in three locations (Lokitoung, Kaaling and Lapur) in the northern division of the Turkana District

Table 15 Wealth categories under normal circumstances in the Turkana District.

\begin{tabular}{|l|l|l|l|l|}
\hline & Better off & Middle & Poor & Very poor \\
\hline Cattle & $50-100$ & $\geq 7<50$ & $\geq 1<7$ & 0 \\
\hline $\begin{array}{l}\text { Sheep and } \\
\text { goats }\end{array}$ & $80-150$ & $\geq 50<80$ & $\geq 15<50$ & $0-14$ \\
\hline Camels & $10-20$ & $\geq 5<10$ & $\geq 1<5$ & 0 \\
\hline
\end{tabular}

Source: Fieldwork 2007.

Having obtained the control data in Table 15, I then documented the number of livestock owned by each respondent both prior to and after the 2005-2006 droughts. Since the numbers of livestock owned by each household varied from one village to another as shown in appendies 2 and 3 , it was assumed that the number of households in each wealth category could also vary. 
Therefore, by analyzing the herd size of each respondent prior to and after the drought and then comparing it with the control data, it was possible to categorize each and every respondent into various wealth groups. This also made it possible to compare the change in wealth statuses of Morulem and Lokichar respondents prior to and after the 2005-2006 droughts (see Table 16).

On closer inspection of Table 16, one would argue that the herd size of each household in the studied villages, prior to and after the drought was still far below what is regarded by them as necessary for a sustainable livelihood. This implies that the respondents were actually not able to derive a sustainable living. ${ }^{162}$

Further analysis of the economic strata or 'wealth groups' in the two studied villages shows that both prior to, and following the 2005-2006 drought, about only 6 percent of the households in Lokichar village had the required number of camels for the 'better off' category, and a very negligible proportion of households owned the required cattle and camels for the middle category. A critical look at Table 16 also shows that the households owning cattle in the middle category reduced from 62 and 57 percent prior to drought, to 24 and 31 percent after drought for Morulem and Lokichar respectively. After the drought, decreases were also seen in the number of households owning sheep and goats in the 'middle' category.

Most notable in Table 16 is the increase in the number of the 'poor' and 'very poor' in the two villages after the 2005-2006 drought. For example, the households owning cattle in the 'poor' category increased from 38 and 31 percent prior to drought, to 56 and 43 percent after drought for Morulem and Lokichar respectively. Those owning sheep and goats in the

162 As explained earlier, the respondents had mentioned that the 2005-2006 droughts and famine started before they could recover from the impact of the 2000 drought condition. 
'poor' category though reduced from 24 and 20 percent prior to drought, to 4 and 6 percent after drought, for Morulem and Lokichar respectively, the decrease led to an increase in the number of households in the 'very poor' category. This means that those households who were in the 'poor' category before drought, moved to the very poor category after drought.

Therefore, it could be pointed out that these results indicate that the impact of the 2005-2006 droughts was associated with locality, and that Morulem might have suffered more than Lokichar. This is shown by the fact that, firstly, after the 2005-2006 drought, there were still few (approximately 6 percent) Lokichar households owning the acceptable quantity of camels for the 'better off' category, while Morulem had none. Secondly, a large number of households in the 'very poor' category were from Morulem village after the drought conditions. It is the destitute which formed the largest proportion in Morulem village after the 2005-2006 drought condition. 
Table16 Pre- and post-drought wealth statuses of Morulem and Lokichar residents.

\begin{tabular}{|c|c|c|c|c|c|c|}
\hline \multirow{2}{*}{\begin{tabular}{|l|} 
Better off \\
\end{tabular}} & \multicolumn{2}{|l|}{ Cattle } & \multicolumn{2}{|l|}{$\begin{array}{c}\text { Sheep and } \\
\text { Goats }\end{array}$} & \multicolumn{2}{|c|}{ Camels } \\
\hline & Pre-drought & $\begin{array}{l}\text { Post-drought } \\
\geq 50-100\end{array}$ & Pre-drought & $\begin{array}{l}\text { Post-drought } \\
\geq 80-150\end{array}$ & Pre-drought & $\begin{array}{l}\text { Post-drought } \\
\geq 10-20\end{array}$ \\
\hline \multicolumn{7}{|l|}{ Number of households: } \\
\hline Morulem & $0(0 \%)$ & $0(0 \%)$ & $0(0 \%)$ & $0(0 \%)$ & $0(0 \%)$ & $0(0 \%)$ \\
\hline Lokichar & $0(0 \%)$ & $0(0 \%)$ & $0(0 \%)$ & $0(0 \%)$ & $2(6 \%)$ & $2(6 \%)$ \\
\hline Middle & & $\geq 7<50$ & & $\geq 50<80$ & & $\geq 5<10$ \\
\hline \multicolumn{7}{|l|}{ Number of households: } \\
\hline Morulem & $28(62 \%)$ & $11(24 \%)$ & $1(2 \%)$ & $0(0 \%)$ & $7(2 \%)$ & $7(16 \%)$ \\
\hline Lokichar & $20(57 \%)$ & $11(31 \%)$ & $2(6 \%)$ & $0(0 \%)$ & $5(14 \%)$ & $5(14 \%)$ \\
\hline Poor & & $\geq 1<7$ & & $\geq 15<50$ & & $\geq 1<5$ \\
\hline \multicolumn{7}{|l|}{ Number of households: } \\
\hline Morulem & $17(38 \%)$ & $25(56 \%)$ & $11(24 \%)$ & $4(9 \%)$ & $17(38 \%)$ & $17(38 \%)$ \\
\hline Lokichar & $11(31 \%)$ & $15(43 \%)$ & $7(20 \%)$ & $6(17 \%)$ & $18(51 \%)$ & $18(51 \%)$ \\
\hline Very poor & & 0 & & $0-14$ & & 0 \\
\hline \multicolumn{7}{|l|}{ Number of households: } \\
\hline Morulem & $0(0 \%)$ & $9(20 \%)$ & $33(73 \%)$ & $41(91 \%)$ & $21(47 \%)$ & $21(47 \%)$ \\
\hline Lokichar & $4(11 \%)$ & $9(26 \%)$ & $26(74 \%)$ & $29(83 \%)$ & $10(29 \%)$ & $10(29 \%)$ \\
\hline
\end{tabular}

Source: Fieldwork 2007. 
Notes:

- Households in each category were expressed as a percentage of the total number of households interviewed in each research site.

\section{3: Impact of $2005-2006$ famine on Morulem and Lokichar residents.}

\subsection{1: Human deaths in the households of Morulem and Lokichar} villages.

Having shown the impact of the 2005-2006 drought on the households from the two study villages, our next step is to find out the impact of famine at the two localities. As discussed in Chapter 6,163 this analysis is done by understanding the death rates in the two study villages. Table 17 shows the distribution of deaths per household for the two sites.

Table 17 Human losses in the household at Morulem and Lokichar.

\begin{tabular}{|l|l|l|l|}
\cline { 2 - 3 } \multicolumn{1}{c|}{} & Lokichar village & Morulem village & \multicolumn{1}{|l}{} \\
\hline $\begin{array}{l}\text { Deaths per } \\
\text { household }\end{array}$ & Households & Households & $\begin{array}{l}\text { Total } \\
\text { number of } \\
\text { households }\end{array}$ \\
\hline 0 & recording death & recording death & 43 \\
\hline 1 & 28 & 15 & 9 \\
\hline 2 & 4 & 5 & 12 \\
\hline 3 & 2 & 10 & 6 \\
\hline 4 & 1 & 5 & 6 \\
\hline 5 & 0 & 6 & 4 \\
\hline
\end{tabular}

Source: Fieldwork 2007.

Computation of the distribution of the deaths in Table 17 indicates that there were a total of 95 deaths at both Morulem and Lokichar. 84 of them (88.4 percent) occurred at Morulem as compared to 11 (11.6 percent) for Lokichar. In addition, most of the households at Morulem who recorded

163 We refer to Devereux' (1993) definition of famine as discussed in Chapter 1. 
deaths lost between 1-5 members each as compared to 1-3 for the corresponding Lokichar households. Therefore, it could be pointed out here that the deaths at Lokichar village were comparatively few.

Morulem village had 30 (approximately 67 percent) of households suffering death as compared to 7 (approximately 20 percent) of households for Lokichar village. And on average, Morulem lost 1.87 persons per household while the average for Lokichar was as low as 0.31 persons per family. Therefore, it could be summarised that Morulem village was struck much more severely by famine than Lokichar village.

\subsection{Impediments to adaptability during 2005-2006 droughts.}

The findings discussed above were important for our analysis, for they show that while the impact of the 2005-2006 droughts had a greater effect in terms of 'livestock losses' at Morulem than Lokichar, famine was also more severe at Morulem than Lokichar. It now remains for us to discuss the causal variables. There was a probe question which all the respondents had been asked and whose answer was meant to show the factors that impinge on adaptability in Turkana. Each and every respondent interviewed was asked to explain why he or she thinks they suffered more severely than his or her neighbour. The respondents provided the answer in an attempt to explain the differences:

Firstly, in an attempt to answer this question, respondents were asked to voluntarily list their sources of food prior to and during the 2005-2006 drought and famine. The information was collated in terms of the two study villages, as shown in Table 18. Differences between the Ngibelai and Ngisonyoka were indeed remarkable. ${ }^{164}$ While both the Ngibelai and Ngisonyoka relied on social networks and relief food, the impact of the

164 As has been discussed in the previous chapters, Lokichar residents are from the Ngisonyoka territorial section, while Morulem residents are from Ngibelai territorial section. 
environment became quite marked. Apart from relying on social networks, the Ngibelai heavily depended on wild fruits, nuts and berries, as major sources of food during the 2005-2006 drought and famine periods, while the Ngisonyoka included rice and fish in their list as well many other openings.

The assortment of wild fruits, nuts and berries, named by all the 45 Ngibelai interviewees included Dobera glabra (edapal), and Balanites species (ebei $\left.{ }^{165}\right)$. Edapal was the most dominant in the diet and was still part of the diet at the time of the study. Edapal is a semi-poisonous wild fruit which is gathered in bags, brought home and processed by women for consumption. It is boiled and pounded several times to remove the poison. The recovered and processed beans are then cooked and eaten. I learnt that the edapal beans were mixed with maize and cooked together. Collection of wild fruits became more important to the Ngibelai too when there was no other alternative. Therefore, it is possible to argue that the Ngibelai heavily dependant on poisonous wild fruits, nuts, and berries as a result of severe drought of the 2005-2006, may have contributed to the high death rates recorded. It is true, however, that a conclusive statement on this cannot be made without a laboratory test of their food value. But, even in the absence of such tests, the food value of poisonous wild fruits, nuts and berries, cannot match that of livestock products such as milk, blood, and meat to which Turkana pastoralists are accustomed and which was in low supply during the period studied.

165 The Latin name is first, followed in parentheses, by the Turkana name. See Soper (1985) and Barrow (1996) for detailed analysis of various vegetation types in the Turkana District. 
Table 18 Sources of food or cash for the respondents.

\begin{tabular}{|c|c|c|c|c|}
\hline & $\begin{array}{l}\text { All the } \\
\text { time }\end{array}$ & $\begin{array}{l}\text { Early } \\
\text { dry } \\
\text { season }\end{array}$ & $\begin{array}{l}\text { Late } \\
\text { dry } \\
\text { season } \\
(2005- \\
2006)\end{array}$ & $\begin{array}{l}\text { Only } \\
\text { during } \\
\text { severe } \\
\text { drought } \\
(2005- \\
2006) \\
\end{array}$ \\
\hline \multicolumn{5}{|l|}{ MORULEM } \\
\hline Basketry & $\mathrm{X}$ & & & \\
\hline Burning charcoal and selling fuel wood & $\mathrm{X}$ & & & \\
\hline Bleeding animals & $\mathrm{X}$ & & & \\
\hline Bride wealth & $\mathrm{X}$ & & & \\
\hline Begging & $\mathrm{X}$ & & & \\
\hline Selling livestock & & $\mathrm{X}$ & & \\
\hline Slaughtering animals & & $\mathrm{X}$ & & \\
\hline Feeding on dead animals & & & $\mathrm{X}$ & \\
\hline $\begin{array}{l}\text { Depending on gift exchange of food and } \\
\text { animals from kinsmen and friends }\end{array}$ & & & & $\mathrm{X}$ \\
\hline Splitting herd and family & & & & $\mathrm{X}$ \\
\hline Pooling resources & & & & $\mathrm{X}$ \\
\hline Reducing consumption & & & & $\mathrm{X}$ \\
\hline $\begin{array}{l}\text { Migrating to urban centres to look for } \\
\text { wage employment }\end{array}$ & & & & $\mathrm{X}$ \\
\hline Gathering wild fruits and berries & & & & $\mathrm{X}$ \\
\hline Relying on food aid & & & & $\mathrm{X}$ \\
\hline \multicolumn{5}{|l|}{ LOKICHAR } \\
\hline Basketry & $\mathrm{X}$ & & & \\
\hline Burning charcoal and selling fuel wood & $\mathrm{X}$ & & & \\
\hline Bleeding animals & $\mathrm{X}$ & & & \\
\hline Bride wealth & $\mathrm{X}$ & & & \\
\hline Begging & $\mathrm{X}$ & & & \\
\hline Selling livestock & & $\mathrm{X}$ & & \\
\hline Slaughtering animals & & $\mathrm{X}$ & & \\
\hline Feeding on dead animals & & & $\mathrm{X}$ & \\
\hline $\begin{array}{l}\text { Depending on gift exchange of food and } \\
\text { animals from kinsmen and friends }\end{array}$ & & & & $\mathrm{X}$ \\
\hline Splitting herd and family & & & & $\mathrm{X}$ \\
\hline Poolling resources & & & & $\mathrm{X}$ \\
\hline Reducing consumption & & & & $\mathrm{X}$ \\
\hline $\begin{array}{l}\text { Migrating to urban centres to look for } \\
\text { wage employment }\end{array}$ & & & & $\mathrm{X}$ \\
\hline $\begin{array}{l}\text { Buying food (e.g. milk, maize flour, rice, } \\
\text { fish) from (oria) Somali. }\end{array}$ & & & & $\mathrm{X}$ \\
\hline $\begin{array}{l}\text { Working for others as paid labour locally } \\
\text { at Lokichar market }\end{array}$ & & & & $\mathrm{X}$ \\
\hline $\begin{array}{l}\text { Trade ties and symbiosis with the Merille } \\
\text { of Ethiopia }\end{array}$ & & & & $\mathrm{X}$ \\
\hline Relying on food aid & & & & $\mathrm{X}$ \\
\hline
\end{tabular}

Source: Fieldwork 2007. 
Notes:

I) The food sources were arranged in terms of those relied on at all times, early dry seasons, late dry seasons, and during severe drought conditions.

ii) The Ngibelai and Ngisonyoka appeared to have relied heavily on their social networks during the 2005-2006 drought and famine.

Secondly, Morulem is isolated and far removed from any major population concentration centre such as towns or markets. In other words, it is remote, with a poorly developed social and economic infrastructure. The pastoralists, who live around Lokichar are, on the other hand, blessed in having a more favourable environment. They live near Lokichar market and are accessible to Lodwar town. ${ }^{166}$ These are areas of diversified economies as opposed to almost pure pastoral economy of the Morulem ecosystem. Therefore, the Ngisonyoka were more exposed to the modern sector of the economy than the Ngibelai, and were better placed to pursue many ends to top up their domestic food reserves. For instance, one respondent at Lokichar village narrated how his family survived, and from a content analysis of his story, one may see a people responding to a much more socially and economically dynamic environment. One key informant from Lokichar village, an old man aged 68 years, captured the views of many respondents interviewed at Lokichar village. The key informant stated as follows:

I engaged in small scale business at Lokichar market. I survived on (posho) maize meal bought from oria (Somali) traders in exchange for skins. My wife also bought grain using skins and some of her ornaments. At the end of 2006, Catholic priests at Lokichar parish were giving rice and cooking fat to those ready to do manual labour at their church. I then took up the job at the Catholic Church. I had five children and they all

\footnotetext{
166 As already mentioned in previous chapters, Lodwar town is the Turkana District. Headquarters.
} 
survived (Key Informant Interview 13 th February 2007, Lokichar Village).

The argument advanced here is that this wide range of opportunities at Lokichar locality saved the people. Therefore, diversification ${ }^{167}$ acted as a safety valve in this case. It signalled efforts by the Ngisonyoka to actively manage vulnerability to the 2005-2006 drought and famine. This finding is supported by studies suggesting that it is the maintenance and continuous adaptation of a highly diverse portfolio of activities that is a distinguishing feature of rural survival strategies in contemporary poor countries 168 (Haggblade, Hazell, and Brown 1989; Reardon 1997; Von Braun and Pandya-Lorch 1991). However, the nature of diversification for livelihood depends on the context in which it takes place. For instance, in the case of Turkana pastoralists, it is worth noting that the Ngisonyoka involvement in so many survival strategies may also have been a sign of distress, for there is risk of misinterpretation of diversification for a thriving economy and robust community and household livelihoods.

Thirdly, respondents explained that the inter-tribal feuds between the Ngibelai territorial section and their neighbours the Pokot tribe precluded symbiotic interaction. Consequently, the only symbiotic interaction during the 2005-2006 drought and famine under study was between the Turkana and the Merille of Ethiopia through the Namuruputh gateway. Yet, ironically, the Turkana share a much closer border with the Pokot than they do with the Merille. Thus, on account of their living close to the Pokot, the Ngibelai became greater victims of the forays from across the Pokot border than the Ngisonyoka. In this regard, we can argue that the Ngibelai environment is hostile and militates against adaptability.

\footnotetext{
167 In this study, livelihood diversification refers to the process by which the households studied constructed a diverse portfolio of activities and social support capabilities in their struggle for survival and in order to improve their standard of living.

168 According to World Bank World Development Report (2006), Kenya is among the poor countries (World Bank 2006).
} 


\subsection{Chapter summary}

The major focus in this chapter was to find any differences between the two study villages in terms of their resources, and any reasons for these differences. The study found differences in many aspects of livelihoods and raised a number of other issues that are common to most households in the study villages.

In a general sense, two important facts came out concerning our understanding of adaptability in the Turkana District. First, drought per se does not cause famine (human deaths from starvation); other social and economic factors must come into play to determine the ultimate outcome. In this case, these factors include friendly neighbours and well developed infrastructure. Secondly, in those circumstances where drought leads to famine, those in rural areas in the Turkana District are less resistant to the devastations of drought and famine than those living near the urban centres. Those living near urban centres are found to depend on a diverse portfolio of activities and income sources among which trade and casual employment, alongside other opportunities, contributes to family wellbeing. Engagement in a diverse portfolio of activities also means nurturing the social networks of kin and community that enable such diversity to be secured and sustained. Thus, livelihood diversity in this case has both economic and social dimensions. All these findings have implication both for theory and policy, as will be discussed in Chapter 8 . 


\section{CHAPTER 8: SUMMARY AND CONCLUSIONS}

\subsection{Introduction.}

The aim of the study was to find out how Turkana pastoralists in north western Kenya coped with drought and famine in 2005-2006, inorder to identify appropriate sustainable adaptive strategies. In particular, the study has sought to understand the indigenous models of adaptation in the absence of outside food aid, particularly famine relief food. The argument was advanced that sustainable adaptability can be built only if we take the existing local livelihood response as the starting point, and allow Turkana people to take the leading role. Therefore, Turkana people were asked what they do to mitigate the effects of drought and famine, and what they perceive as the factors which impinge on their adaptability.

The study was motivated by my own observation of the continual suffering Turkana people experience due to a long history of drought and famine in the Turkana District. Apart from drought, other factors identified in the literature as the cause of food insecurity were human and livestock diseases, raids from neighbouring tribes, and the colonial policy of marginalisation. It was learnt that during these crises, Turkana people were able to develop various indigenous livelihood strategies within their social and economic backgrounds to avert the catastrophe. These livelihood strategies were based on platforms of assets that families, households or individuals have access to. This information formed the basis upon which adaptive behaviour during the 2005-2006 droughts and famine could be assessed.

\subsection{Theoretical implications.}

Livelihoods in pastoral areas are normally complex and diverse, and this makes it difficult to capture the dynamics of livelihoods or adaptive 
strategies in one approach. How pastoralists' perceive food needs, how they interact with sociological processes taking place within and beyond their households, and the diverse ways in which they interpret these experiences may be viewed as determinants of how they cope with various perturbations, for example, drought and one of its consequences, famine.

For instance, given the limited period of study, capturing the dynamics of Turkana households' livelihood strategies during the 2005-2006 drought and famine and, at the same time, avoiding the dangers of simplistic overviews was no easy task. This called for a combination of different approaches, as discussed in Chapter Two. The core theory used in the study was the sustainable livelihood approach with a particular focus on a comprehensive and holistic understanding of issues at both the micro and macro level. The approach also focused on the household and its assets as a unit of social organisation. It implies that, following Sen (1981), what Turkana people actually have, for instance their strengths and capabilities, is more important to consider than looking at their needs or what they don't have. The scope of the sustainable livelihood approach was improved by the application of the symbolic interaction theory developed by Mean (1964), Blumer(1969) and Schutz (1970). Symbolic interaction theory views adjustment behaviour as being influenced by taboos and perceptions, as was the case in Turkana. Social exchange theory, as discussed by Homans (1961) and Blau (1964), broadened the sustainable livelihood approach, and helped to deepen our theoretical understanding of the dynamics of reciprocity and symbiosis as an insurance mechanism among Turkana pastoralists.

The purpose of combining the three approaches is that they have a rationale for focusing on issues affecting Turkana people, and they aim to strengthen the claims of the most vulnerable. The use of the three approaches has also helped in counteracting the limitations of each approach and allowed for consideration of various factors and processes 
that either constrain or enhance Turkana people's ability to sustain their livelihoods during crises.

From these theoretical formulations, a 'pastoral adjustments model' was constructed, and the various adjustment choices deriving from the literature review were fitted to it. Subsequently, two hypotheses were formulated to guide the study and to be tested at the data analysis stage.

It was hypothesized that drought and famine stimulate the search for potential allies in the effort to weather the negative effects of food shortages. This first hypothesis was linked with a second one which stated that the social and economic resources accessible to the famished Turkana pastoralists would determine the range and scope of adaptation responses. All these two hypotheses were discussed intensively at the stage of data analysis in Chapters 6 and 7 respectively.

\subsection{Methodological aspects.}

The study was carried out for six months of fieldwork in two villages (Morulem and Lokichar) in the Turkana District. This was an exploratory study, and a combination of qualitative and quantitative methods was used. The major source of data was primary, with most of the information coming from indepth interviews with key informants and household heads. These were supplemented by secondary sources such as documentary materials in the form of records kept by the colonial government in the National Archives in Kenya pertaining to drought and famine in the Turkana region. A total of eight key informants and 80 household heads were covered by the research.

With regard to the survey method, a number of methodological problems were encountered which called for a more cautious manner in the way in which questions were put and answers recorded. For instance, there was 
the puzzling problem with numbers. This had to do with the way the Turkana count their livestock and the possibility of exaggerating losses ostensibly to gain sympathy from the interviewer. To counter this and improve the reliability of the data, it was necessary to reduce the original size of the sample population, limit the number of questions, and finally, to use a large number of probe questions as a cross check mechanism. I also continuously explained to the respondents that I was just a student carrying out research, the content of which will be analyzed for writing an academic thesis, and that it had nothing to do with availability of relief food. My research assistants were also able to go to the nearby grazing lands when necessary to physically count the animals.

\subsection{Summary of the findings.}

The testing of the first hypothesis revealed that Turkana pastoralists sought help from quite a large number of 'allies' during the 2005-2006 drought and famine periods. Access to social capital made it easier for the local people to access other types of capital. Therefore, social capital has been traditionally and remains very important for Turkana society. For instance, the evidence suggests that, as a consequence of the 2005-2006 droughts, Turkana people were compelled by sheer necessity for survival to maintain trade ties with entrepreneurs and traders in the district and symbiotic relations with pastoral neighbours, principally the Merille of Ethiopia. Secondly, families were split, and as a survival strategy, children were made to take refuge with friends, kinsmen, and affines as the domestic food reserves dwindled. The evidence further indicated that in the family splitting mechanism for weathering the drought and famine effects, the school emerged as perhaps the most dependable ally. The sharp rise of primary school enrolment in the study area as well as in the district as a whole, was probably because of increasingly large numbers of hungry children who were sent to school principally to feed rather than to be educated, as the case should otherwise be under normal circumstances. It 
is argued that it appears that the 2005-2006 drought and famine must have stimulated the Turkana District primary school enrolments to increase.

Thirdly, out-migration became yet another mode of adaptation. During the sojourn, the migrants exploited friendship, kinship, and affinal ties to get food and shelter. Fourthly, Turkana pastoralists used reciprocity as an insurance mechanism to counter the devastations of the drought and famine, then and in the future. More significantly, the drought victims formed small corporate groups of cohorts, pooled their surviving livestock and left them in the care of a few among them as the rest dispersed to Ethiopia and other towns in Kenya such as Kitale in search of alternative means of livelihood. This pooling of resources had an added advantage, for it enabled the herders to exploit economies of scale. It would hasten the future return to the mainstream of pastoral life.

Regarding the second hypothesis, the data showed that adaptability is a function of the physical, social, and economic environment. Our test showed significant differences in levels of wealth, and livestock and human deaths at the two localities, thus being indicative of variations in adaptability. For instance, the people of Morulem village, because they inhabited a hostile environment, suffered more severely than the people of Lokichar, whose environment is more favourable to adaptability. It is that a hostile environment impedes adaptability and contributes to human vulnerability to the devastations of drought and famine.

\subsection{Conclusion.}

The findings of this study have important implications both for theory and policy towards nomadic pastoralism in general, and Turkana in particular. 
The sustainable livelihood model has been of much use to this study as it helped to formulate testable hypotheses which guided the study. But, academically, the study shows that an improved sustainable livelihood model is a viable theoretical framework for the study and analysis of adaptation among pastoralists. In applying the sustainable livelihood approach to this study, an issue became apparent. This is a suggestion for, rather than a criticism of, the framework. It might help to modify the framework to be used more effectively in analysing pastoralists' livelihoods. It has been observed that Turkana pastoralists apply a perceptual filter to the crisis before choosing any strategy, and the decisions regarding pastoral strategies during crises are based on their past experience and cultural interpretation of the crisis. However, the existing livelihoods framework does not draw attention to this factor. As such, it is suggested that this be explicitly recognised in the framework through the addition of a separate component (broadly entitled 'definitions and perceptions' as shown in Figure 4). This category may include how pastoralists define and perceive their situation in light of the crises affecting them. It may also include their attitudes towards the crises. Therefore, the framework has been designed specifically for the study of effects of drought and famine and local peoples' responses in the Turkana District, Kenya. But it should also be useful for more general studies of livelihood adaptation in response to food crises.

The findings have also helped to improve our theoretical understanding of adaptability for they have revealed that the Turkana pastoralists', like other pastoralists' elsewhere in sub-Saharan Africa, possess a repertoire of adaptive mechanisms which they call into action in times of economic hardship. They are not passive recipients of famine relief food from outside the district. They actively manipulate their social environment to maximize gain, which helps them to weather the negative effects of drought and famine. Thus, the findings of this study help to enrich the literature on pastoralists' social responses to drought and famine. They are particularly 
useful findings, for until now, we had not had detailed data on how the Turkana manage problems of such magnitude through their indigenous social activities.

The findings further suggest that drought per se does not necessarily lead to famine: death from starvation and hunger related diseases. Other intervening variables like the socio-economic environment are crucial. Those who inhabit hostile environments suffer, while those who live in better resource endowed environments generally survive.

Lastly, what is going on in the two villages under study is an indication of what might become a wider process in the whole of the Turkana District. I suggest that changes in development policies relevant to this area could lead to a sustainable adaptive strategy. Therefore, I conclude by recommending some policy changes.

\subsection{Policy implications.}

A number of policy implications could be derived from the findings of this study to help improve the pastoralists' local capacities for managing future droughts and famine. Some of the issues which need particular attention by the policy makers are highlighted.

This study has shown that Turkana people have faced drought and famine by resorting to a range of livelihood strategies which both draw upon traditional social networks and practices but which also exploit new opportunities in links with the modern outside world. Their responses are complex, dynamic and pragmatic.

In terms of appropriate policy responses, it is important to recognise the realities of daily life in the region and the way people span both traditional practices and new linkages. Policies should not be built upon the view 
that Turkana people are passive and helpless in the face of hardship but have considerable ability to adapt and respond.

On one hand, policies should recognise the importance of the traditional livestock economy and the way its ability to respond to crisis has been undermined by previous policies (such as the limiting of movement) as well as land degradation and population and livestock pressure. Having seen the importance of long standing customary social networks, policies might address the need to revive such linkages, either through measures to help end the conflict with the neighbouring Pokot or through allowing a greater degree of movement of people and stock across borders. Measures to help with rehabilitation of grazing grounds or water supplies could also assist.

On the other hand, measures should recognise the way Turkana people can use new opportunities in the interaction with the outside world. We have seen how during times of famine, households effectively used strategies such as sending children away to school or migrating temporarily for work in other regions. These could be enhanced through measures that build upon these interactions. Improvement of infrastructure is especially desirable. There is need for substantial investment in key infrastructure such as roads, trekking routes, and markets. Markets enable sales and exchange of livestock during drought and famine. However, Turkana people's ability to participate in the market depends on their physical capacity, education and skills. For instance, health and nutrition are integral aspects of the physical human capital which strongly influences the capacity of individuals to earn an income. Income earning opportunities and productivity also depend on their education and skills. This is why the promotion of market participation in the Turkana district has to be coupled with public programs and spending on health, education and social welfare which help to maintain and augment human capital in both its physical and intangible manifestations. 
The fact that those Turkana pastoralists who have ready access to nonpastoral economic opportunities seem to manage drought and famine better than those who remain isolated in the countryside means that there is also an urgent need to encourage Turkana people to diversify their pastoral economy. This should help the pastoralists to have viable alternatives to pastoral products when their livestock die from droughts. This is why the pastoralists, who lived near Lokichar market engaged in manual jobs to earn an income and traded with the Somali people in exchange for food, hence surviving the devastating effects of the 20052006 drought and famine. Turkana pastoralists who lived at Morulem village, a distant rural area in the pasturelands, suffered most severely since they could not diversify their activities. This implies that when pastoralists are left at the mercy of the vagaries of nature operating precarious subsistence economies like pastoralism, they become easy victims of climatic changes.

Apart from diversifying the pastoral economy, policy-makers should pursue development policies aimed at penetrating the rural areas in the Turkana District where the majority of pastoralists live. For now, there is a tendency to concentrate development efforts in a few selected urban centres while leaving the rural areas with a poorly developed infrastructure. Services should be taken to the people where they live. Schools in the Turkana District should also be enhanced and, if possible be provided with boarding facilities and free food to entice Turkana people to register and learn.

It is also important to emphasize here that drought and famine are national problems in Kenya and should be the subject of more serious thinking and cause of action than has traditionally been the case. In order to reduce the cost of drought and famine, there would be a need for Kenya to seriously consider setting up a 'Drought and Famine Monitoring Research Institute'. This is precisely because, in many instances, the 
nation is usually caught unaware of approaching droughts and famine, thus inflating costs and creating far more difficulty in controlling the situation than could otherwise be the case with the establishment of such a research institute. 


\section{Bibliography}

Acharya, M. (1997). Non-Governmental Organizations-Led Development Strategy in Nepal. In K. Bhatachan and M. Chaitanya (Eds.), Development Practice in Nepal (pp. 69-99). Kathmandu: Central Department of Sociology and Anthropology.

Adams, A. (1992). Seasonal Food Insecurity in the Sahel: Nutritional, Social and Economic Risk among Bambara Agriculturalists in Malawi. PhD Thesis, London School of Hygiene and Tropical Medicine, University of London.

Adams, A. (1993). 'Food Insecurity in Mali: Exploring the Role of the Moral Economy',. IDS Bulletin, 24(4), 41-51.

Adger, W. N. (2000). Institutional Adaptation to Environmental Risk under the Transition in Vietnam. Annals of the Association of American Geographers, 90(90738-90758).

Adger, W. N., and Kelly, P. M. (1999). Social Vulnerability to Climate Change and the Architecture of Entitlements. Mitigation and Adaptation Strategies for Global Change, 4, 253-266.

Agarwal, B. (1991). 'Social Security and the Family: Coping with Seasonality and Calamity in India. In E. Ahmed, J. Dreze, J. Hills and A. Sen (Eds.), Social Security in Developing Countries (pp. 171-244). Oxford: Clarendon Press.

Akabwai, D. (1992). Extension and Livestock Development: Experience from among the Turkana Pastoralists of Kenya: Institute of Development Studies, University of Nairobi, Kenya.

Apthorpe, R. (1986). Food Aid and a Stock Aid: Rehabilitation in a Drought Affected Area with a Large Nomadic Population, with Special Reference to the Relationship between Emergency and Development Assistance. Case Study of Turkana Kenya. Hague, Holland.

Aronson, D. (1980). Must Nomads Settle, Some Notes toward Policy on the Future of Pastoralism. In P. Salzman (Ed.), When Nomads Settle (Vol. 173-184): New York. Praeger.

Asad, T. (1970). The Kababish Arabs: Power, Authority and Consent in a Nomadic Tribe. London: Hurst.

Ashley, C., and Carney, D. (1999). Sustainable Livelihoods. Lessons from Early Experience. London: Department of International Development.

Babiker, M. (2007). Resource Alienation, Militarisation and Development. Adaptability, Identity and Conflict among the Hawaweer in Norhern Sudan. In B. Derman, R. Odegaard and E. Sjaastad (Eds.), Citizenship, Identity and Conflicts over Land and Water in Contemporary Africa (pp. 13-14). Londres: James Currey. 
Baker, M. J., and Lovenbury, H. T. (1971). The South Turkana Expedition Scientific Papers Vii. The 1969 Season Survey. Geographical Journal, 137(3), 349-360.

Barber, J. (1968). Imperial Frontier: A Study of Relations between the British and the Pastoral Tribes of North East Uganda. Nairobi: East African Publishing House.

Barret, A. (1988). English - Turkana Dictionary. Nairobi: Macmillan Publishers.

Barrett, A. J. (1996). Turkana and Their Trees. Their Medical and Ecological Value. Nairobi: The Catholic University of Eastern Africa.

Barrow, E. (1987). "Results and Findings from a Survey on 'Ekwar' Carried out from November. 1986 to July 1987". Lodwar: Turkana District Forestry Department.

Barrow, E. (1988). Trees and Pastoralists: The Case of the Pokot and the Turkana Social Forestry Network ODI Network Paper: 6b.

Barrow, E. (1990). Usufruct Rights to Trees: The Role of 'Ekwar' in Dryland Central Turkana Human ecology, 3.

Barrow, E. (1996). The Drylands of Africa, Local Participation in Tree Management. Nairobi: Initiative Publishers.

Barton, D., J. Morton, and C. Hendy (2001). Drought Contigency Planning for Pastoral Livelihoods, Natural Resource Institute (Vol. 15): University of Greenwich.

Baumann, P., and Sinha, P. (2001). Linking Development and Democratic Processes in India: Political Capital and Sustainable Livelihood Analysis. Natural Resource Perspectives Retrieved October 23, 2006, from www.odi.org.uk/nrp/68.pdf

Baxter, P., and Hogg, R. (1990). Property, Poverty and People: Changing Rights in Property and Problems of Pastoral Development. Oxford: Blackwell Publishers.

Bebbington, A. (1999). Capitals and Capacities: A Framework for Peasant Viability, Rural Livelihood and Poverty. World Development, 27, 2021-2045.

Bigsten, A. (1996). The Circular Migration of Smallholders in Kenya. Journal of African Economies, 5(1), 1-20.

Blaikie, P., Cannon, T., Davis, I., and Wisner, B. (1994). At Risk-Natural Hazards, Peoples Vulnerability and Disasters. London: Routledge.

Blau, P. (1964). Exchange and Power in Social Life. New York: J. Wiley.

Blumer, H. (1969). Symbolic Interactionism Perspective and Method. Englewood Cliff, New York: Prentice Hall.

Bonfiglioll, A., and Watson, E. (1992). Pastoralists at a Crossroads. Survival and Development Issues in African Pastoralism. Nairobi: NOPA. 
Bonte, P. (1975). Pasteures Et Nomads: I Exemple De La Mauritanie, in Secheresse Et Famine Du La Sahel. In Casciarri, B. 2002. Local Trends and Perceptions of Processes of Commodisation in Central Sudan: The Responses of Ahamda Pastoral System to State Pressures and Capitalist Dynamics. Nomadic Peoples, 6(2), 32-50.

Bovin, M., and Manger, L. (1990). Adaptive Strategies in African Drylands. In Casciarri, B. 2002. Local Trends and Perceptions of Processes of Commodisation in Central Sudan: The Responses of Ahamda Pastoral System to State Pressures and Capitalist Dynamics. Nomadic peoples, 6(2), 32-50.

Brown, L. (1963). The Development of Semi-Arid Areas of Kenya. Nairobi: Ministry of Agriculture, Animal Husbandry and Water Resources

Bryman, A. (2004). Social Research Methods. Oxford: Oxford University Press.

Bush, J. (1995). The Role of Food Aid in Drought: Oxfam's North Turkana (Kenya) Drought Relief Program, 1992-1994. Disasters, 19(3), 247-259.

Cahn, M. (2002). Sustainable Livelihoods Approach: A Concept and a Practice Devnet Conference 2002- Contesting Development: Pathways to Better Practice, Massey University. Retrieved May 21, 2006, from http://www.devnet.org.nz/conf2002/papers/Cahn Miranda.pdf

Campbell, D. J. (1984). Response to Drought among Farmers and Herders in South Kajiado District, Kenya. Human Ecology, 12, 35-64.

Carney, D. (1998). Sustainable Livelihoods: What Contributions Can We Make? London: Department of International Development.

Catley, A. (2000). Notes on Pastoral Livelihoods in Africa. Rwa International/Vetwork Uk (2000). Pastoral Livelihoods Programme Appraisal Mission. Final Report for the Department for International Development (Dfid). London: UK.

Caukwell, R. A. (1971). "The South Turkana Expedition Scientific Papers Vi. Field Survey in South Turkana". Geographical Journal, 137(2), 157-165.

Cernea, M. (1985). Preface. In M. Cernea (Ed.), Putting People First. Sociological Variables on Rural Development (pp. xi-xvii). New York: Oxford University Press.

Chambers, R. (1983). Rural Development: Putting the Last First.: Harlow: Longman Scientific and Technical, Essex.

Chambers, R. (1987). Sustainable Rural Livelihoods: A Strategy for People, Environment and Development. IDS Commissioned Study 8.

Chambers, R. (1989). Vulnerability, Coping and Policy. IDS Bulletin, 20(2), 1-7. 
Chambers, R. (1995). Poverty and Livelihoods: Whose Reality Counts? Brighton: Institute of Development Studies.

Coe, M. (1972). The Southern Turkana Expedition Scientific Papers Ix. Ecological Studies of the Small Mammals of South Turkana. Geographical Journal, 138(3), 316-338.

Collier, P. (1998). Social Capital and Poverty. Washington, DC: World Bank.

Collins, R. O. (1961). The Turkana Patrol, 1918. Uganda Journal, 25, 17-33.

Coppock, D. L. (1994). The Borana Plateau of Southern Ethiopia. Synthesis of Pastoral Research, Development, and Change, 1980-1991. Systems Study (Vol. 5). Addis Ababa: ILCA.

Corbett, J. (1988). Famine and Household Coping Strategies. World Development, 16(9), 1099-1112.

Cornwall, A., and Scoones, I. (1993). "Exploiting Diversity and Difference in Food Systems under Stress". In J. Pottier (Ed.), African Food Systems under Stress. Issues, Perspectives and Methodologies (pp. 67-95). Brighton: Desktop Display.

Crosbie, W. (2005). The Essential Reseach Skills. Suva, Fiji: Amokura Publications.

Cross, C., and Mngadi, T. (1998). Poverty at Ground Zero: Social Capital and Economic Shocks in Rural Kwazulu-Natal. Washington, DC: IFPRI (International Food Policy Research).

Dahl, G., and Hjort, A. (1976). Having Herds : Pastoral Herd Growth and Household Economy: Stockholm : Department. of Social Anthropology, University of Stockholm.

Daily Nation (5th June 2006). Drought in Northern Kenya Gets Worse

Daily Nation (15th May 2007). Violent Attacks among Pastoral Communities in Northern Kenya,

Dames, T. (1964). Reconnaissance of the Agricultural Potential of the Turkana District. Rome: FAO

Danny de Vries, P., Leslie, W., and McCabe, J. (2006). Livestock Acquisitions Dynamics in Nomadic Pastoralist Herd Demography: A Case Study among Ngisonyoka Herders of South Turkana, Kenya. Human Ecology, 34(1), 1-24.

Dasgupta, P. (2000). Economic Progress and the Idea of Social Capital. Social Capital: A Multifaceted Perspective. Washington, DC: The World Bank.

Davern, M. (1997). Social Networks and Economic Sociology: A Proposed Research Agenda for a More Complete Social Science. The American Journal of Economics and Sociology, 56(3), 287-302. 
Davies, S. (1993). Are Coping Strategies a Cop Out? IDS Bulletin, 24, 60-72.

Davies, S. (1996). Adaptable Livelihoods. Coping with Food Insecurity in the Malian Sahel. New York: Macmillan Press limited.

De Haan, L., and Zoomers, A. (2005). Exploring the Frontier of Livelihoods Research. Development and Change, 36(1), 27-49.

De Waal, A. (1989). Famine That Kills. Darfur, Sudan, 1984-1985. Oxford: Claredon Press.

De Waal, A. (1994). Dangerous Precedents? Famine Relief in Somalia 1991-1993. In J. Macrea and A. Zwi (Eds.), War and Hunger: Rethinking International Responses to Complex Emergencies (pp. 139-159). London:: Save the Children UK.

De Waal, A. (1997). Famine Crimes: Politics and the Disaster of Relief Industry in Africa. Oxford and Bloomington: African Rights and James Currey.

Deng, L. B. (2002). Confronting the War: A Comparative Study of Household Assets Management in Southern Sudan. IDS Discussion Paper 381, Brighton: Institute of Development Studies.

Dershem, L., and Gzirishvili, D. (1998). Informal Social Support Networks and Household Vulnerability: Empirical Findings from Georgia. World Development, 26(10), 18271838 .

Devereux, S. (1993). Theories of Famine. Harvester Wheatsheaf: Hemel Hempstead.

Devereux, S. (2001). Livelihood Insecurity and Social Protection: A Re-Emerging Issue in Rural Development. Development Policy Issue, 19(4), 507-519.

Devereux, S., and Naeraa, T. (1996). Drought and Survival in Rural Namibia. Journal of South African Studies, 22, 421-440.

DFID (1994). Sustainable Livelihoods Guidance Sheets Retrieved June 01 2006, from http//www.livelihoods.org/info/info guidancesheets.html

DFID (2001). Sustainable Livelihoods Guidance Sheets: Retrieved May 12, 2006, from http:/www.livelihoods.org/info/info_guidancesheets.html

DFID (2004). Sustainable Livelihoods Guidance Sheets. London: Department of international development.

Dietz, A. J. (1987a). The State, the Market and the Decline of Pastoralism; Challenging Some Myths, with Evidence from West Pokot. In J. Markakis (Ed.), Conflict and Decline in Africa (pp. 19). Oxford: Macmillan Press. 
Dietz, A. J., and Salih, M. A. M. (1997). Pastoral Development in Eastern Africa: Policy Review, Options and Alternatives. Amsterdam/Hague: University of Amsterdam: Institute of Social studies.

Dietz, T. (1987b). Pastoralism in Dire Straits. Survival Strategies and External Interventions in a Semi-Arid Region at Kenya Uganda Border: West Pokot, 19001986. Nederlanse Geografische Studies 49.

Dirks, R. (1980). Social Responses During Severe Food Shortages and Famine. Current Anthropology, 21(1), 21-43.

Dyson-Hudson, N. (1966). Karamajong Politics: Oxford: Clarendon Press.

Dyson-Hudson, N. (1972). The Study of Nomads. In I. William and Neville Dyson-Hudson (Eds.), Perspectives in Nomadism (pp. 2-29): Leiden: E.J. Briel.

Dyson-Hudson, N. (1984). Adaptive Resource Use Strategies of African Pastoralists. In F. DiCastri, F. W. Baker and M. Hadley (Eds.), Ecology and Practice (pp. 1). Dublin: Tycooly.

Dyson-Hudson, N., and McCabe, J. T. (1981). Preliminary Report to Norad on South Turkana Herd Movements and Water Supplies. Nairobi, Kenya.

Dyson-Hudson, N., and McCabe, J. T. (1985). South Turkana Nomadism: Coping with an Unpredictably Varying Environment. Ethnography Series Fl 17-001: New Haven.

Dyson-Hudson, R. (1982). Toward a General Theory of Pastoralism and Social Stratification. Nomadic people, 7, 1-8.

EcoSystems Ltd (1985). Turkana District Resources Survey, 1982-1984: Main Report. Turkana Rehabilitation Project (Development Support Unit). Nairobi: Ministry of Energy and Rural Development.

Ehret, C. (1971). Southern Nilotic History: Linguistic Approaches to the Study of the Past. Evanson: NorthWestern University Press.

Ehret, C. (1974). Cushites and the Highland and Plain Nilotes to A.D. 1800. In A. Zimani (Ed.), A Survey of East African History. Nairobi: Longman, Kenya.

Ekwee Ethuro, D. (1994, September 15). An Overview of Land Tenure and Land Law in Pastoral Areas Paper presented at the Third Annual Kenya Pastoralist Forum Meeting on Land Tenure and Land Law in Pastoral Areas of Kenya, Nairobi, .

Ellis, F. (1998). Household Strategies and Rural Livelihood Diversification. Development Studies, 35(1), 1-38.

Ellis, F. (2000). Rural Livelihoods and Diversity in Developing Countries. New York: Oxford University Press. 
Ellis, F. (2003). Human Vulnerability and Food Insecurity in Southern Africa. London: Overseas Development Group.

Ellis, J. (1994). Climate Variability and Complex Ecosystem Dynamics: Implications for Pastoral Development. In I. Scoones (Ed.), Living with Uncertainity: New Directions in Pastoral Development (pp. 37-57). London: Intermediate Technology Publications.

Ellis, J., Gavin, K., McCabe, J. T., and Swift, D. M. (1987). Pastoralism and Drought in Turkana District, Kenya: A Report to Norad. Belevue, Co: Development Systems Consultants Inc.

Ellis, J. E. (1984). Aspects of Energyin Pastoral Ecosystems: Wood Use by the South Turkana. In C. Barnes, J. Ensminger and P. O'Keefe. (Eds.), Wood, Energy, and Households, Perspectives on Rural Kenya: Beijer Institute and Scandinavian Institute of African Studies.

Ellis, J. E., and Dick, O. (1986). The Vegetation of Turkana District: A Landsat Analysis. Nairobi, Kenya.

Eriksen, S. (1996). Social Anthropology: Universitetsforlaget, Oslo.

Erukudi, C. E. (1985). Akisitamunet. Catholic Diocese Communications. Kisumu: Kenya.

Evans-Pritchard, E. (1940). The Nuer. A Description of the Modes of Livelihood and Political Institutions of a Nilotic People. Oxford: Oxford University Press.

Fedders, A., and Salvadori, C. (1977). Turkana Pastoral Craftsmen. Nairobi: Transafrica.

FEWSnet (2004/5). Famine Early Warning System. National Livelihood Profile. Retrieved August 13, 2007, from http//www.fews.net/livelihoods/files/td/national.pdf

Flood, G. (1976). Nomadism and Its Future. The Afar. London: IAA.

Fratkin, E. (1991). Surviving Drought and Development. Arial Pastoralists of Northern Kenya. Boulder: Westview Press.

Fratklin, E. (2001). East African Pastoralism in Transition: Maasai, Boran, and Rendile Cases. African Studies Review, 44(3), 1-25.

Freeman, H., Ellis, F., and Allison, E. (2004 ). Livelihoods and Rural Poverty Reduction in Kenya. Development Policy Review, 22(2), 147-171.

Galaty, J., Aronson, D., Salzman, P., and Chouinard, A. (1981, August 5). The Future of Pastoral Peoples. Paper presented at the Nairobi, Kenya. International Development Research Centre.

Glantz, M. H. (1987). Drought and Hunger in Africa; Denying Famine a Future. Cambridge: Cambridge University Press. 
Goldschmidt, W. (1969). Kambuya's Cattle. The Lgacy of an African Herdsman. Berkeley: University of California.

Goldschmidt, W. (1976). Culture and Behaviour of the Sebei. A Study in Continuity and Adaptation. Barkeley: University of California Press.

Gore, A. (1994). Earth in the Balance: Forging a New Common Purpose London: Earthscan Publications Ltd.

Grootaert, C., Narayan, D., Jones, V., and Woolcock, M. (2003). Measuring Social Capital. An Integrated Questionnaire. Paper No. 18 Ed. World Bank Retrieved August 10, 2006, from http://poverty.worldbank.org/files/11998_WP18-Web.pdf

Grown, C. A., and Sebstad, J. (1989). Introduction: Toward a Wider Perspective on Women's Employment. World Development, 17(7), 937-952.

Gudrum, D., and Ander Hjort (1976). Having Herds: Pastoral Growth and Household Economy: Stockholm.

Gulliver, P. H. (1951). A Preliminary Survey of the Turkana. A Report Compliled for the Government of Kenya. University of Cape Town: Communication from the School of African Studies, New Series No. 26.

Gulliver, P. H. (1955). The Family Herds : A Study of Two Pastoral Tribes in East Africa, the Jie and Turkana. London: Routledge and Kegan Paul Ltd.

Haagsma, B., and Hardeman, J. (1998). Pastoral Development in East Africa: Facts and Findings. Zeist Netherlands: I/C Consultants.

Haggblade, S., Hazell, P., and Brown, J. (1989). Farm-Nonfarm Linkages in Rural SubSaharan Africa. World Development, 17(8), 1173-1201.

Halpern, D. D. S. (2005). Social Capital. Cambridge, Polity Press.

Hemming, C. F. (1972). The South Turkana Expedition Scientific Papers Viii. The Ecology of South Turkana: A Reconnaissance Classification. Geographical Journal, 138(1), $15-40$.

Hendrickson, D., Armon, J., and Mearns, R. (1998). The Changing Nature of Conflict and Famine Vulnerability: The Case of Livestock Raiding in Turkana, Kenya. Disasters, 22(3), 185-199.

Henriksen, G. (1974). "Economic Growth and Ecological Balance: Problems of Development in Turkana", Occassional Paper No. 11, Universitet Bergen.

Hettne, B. (2002). Poverty and Conflict: The Methodology of a Complex Relationship. Paper presented at the Demcratisation and Conflict management in East Africa, Goteborg, February 28th - March 3rd, 2002., 
Hjort, A. (1979). Savanna Town - Rural Ties and Urban Opportunities in Northern Kenya. Stockholm Studies in Social Anthropology.

Hoffman, S., and Oliver-Smith, A. (2002). Catastrophe and Culture: The Anthropology of Disaster: Santa Fe, NM : School of American Research Press ; Oxford : J. Currey.

Hogg, R. (1980). Pastoralism and Impoverishment: The Case of Isiolo Boran of Northern Kenya. Disaters, 4(3), 299-310.

Hogg, R. (1982). Destitution and Development: The Turkana of North West Kenya. Disaters, 7(2), 156-156.

Hogg, R. (1986). 'the New Pastoralism: Poverty and Dependency in Northern Kenya'. Africa, 56(3), 319-333.

Hogg, R. (1987). Development in Kenya: Drought, Desertification and Food Scarcity. African Affairs, 86(342), 47-58.

Homans, G. (1961). Social Behaviour: Its Elementary Forms. New York: Harcourt: Brace and World.

Hussein, K., and Nelson, J. (1998). Sustainable Livelihoods and Livelihood Diversification. Brighton: IDS working paper: 69.

International Institute for Sustainable Development (IISD) (2003). Conceptual Framework Prepared by the Task Force on Climate Change, Vulnrable Communities and Adaptation: International Institute for Sustainable Development, Canada.

Jacobs, A. (1965). The Traditional Political Organization of Pastoral Maasai. PhD Thesis, Oxford University.

Jacoby, H., and Skoufias, E. (1998). Testing Theories of Consumption Behaviour Using Information on Aggregate Shocks. American Journal of Agricultural Economics, $80(1), 1-14$.

Johnson, A., and Bond, G. C. (1974). Kinship, Friendship, and Exchange in Two Communities: A Comparative Analysis of Norms and Behaviour. Journal of Anthropology Research, 30(1), 55-68.

Johnson, B. R. (1999). Social Networks and Exchange. In M. A. Little and P. W. Leslie (Eds.), Turkana Herders of the Dry Savannah: Ecology and Behavioral Response of Nomads to an Uncertain Environment (pp. 89-108): Oxford University Press.

Johnson, C. A. (1997). Rules, Norms and the Pursuit of Sustainable Livelihoods. Brighton: IDS working paper: 25 . 
Kabeer, N. (2000b). Resources, Agency, Achievements: Reflections on the Measurements of Women's Empowerment. In S. Ravazi (Ed.), Gendered Poverty and Well-Being (pp. 2 ): Blackwell Publishers Ltd.

Kanbur, R. (2001). Qualitative and Quantitative Poverty Appraisal: Complementaries, Tensions and the Way Forward. Ithaca, NY: Department of Applied Economics and Management, Cornell University.

Kandiyoti, D. (1998). Rural Livelihoods and Social Networks in Uzbekistan: Perspectives from Andijan. Central Asian Survey, 17(4), 561-578.

Kane, E. (1995). Seeing for Yourself: Research Handbook for Girls Education in Africa. Washington D.C: World Bank.

Kjekshus, H. (1977). Ecology Control and Economic Development in East African History: The Case of Tanganyika, 185-1950. London: Heinemann.

Kluckson, J. (1962). The Konso Economy of South Ethiopia. In P. Buhaman and G. Dalton (Eds.), Markets in Africa (pp. 409-428): NorthWestern University Press.

Korten, D. C. (1995). When Corporations Rule the World. London: Earthscan Publications Ltd.

Kroeber, A. (1948). Anthropology. New York: Harcourt, Bruce and Company.

Lamphear, J. (1976). Aspects of Turkana Leadership During the Era of Primary Resistance. Journal of African History, 17(2), 225-243.

Lamphear, J. (1982, November 6). The Territorial Expansion of the Turkana: Belligerent Aggrandisement or Peaceful Interactions? Paper presented at the African Studies Association Annual Meeting, Washington, DC.

Lamphear, J. (1988). The People of the Grey Bull: The Origin and Expansion of the Turkana. Journal of African History, 29(1), 27-39.

Lamphear, J. (1992). The Scattering Time. Turkana Responses to Colonial Rule. Clarendon: Oxford.

Lamprey, H., and Yusuf, H. (1981). Pastoralism and Desert Encroachment in Northern Kenya. Ambio, 10(2), 131-134.

Lane, C. (1996). Pastures Lost. Barabaig Economy, Resource Tenure, and the Alienation of Their Land in Tanzania: Nairobi Initiative Publishers.

Lane, C. R., and Swift, J. S. (1989, December 1-3 ). East African Pastoralism: Common Land, Common Problems', Drylands Programme. Paper presented at the The Pastoral Land Tenure Workshop Arusha Tanzania. 
Laughlin, C., and Brady, I. (1978). Extinction and Survival in Human Populations. New York: Columbia University Press.

Le Houerou, H. (1980). The Rangelands of the Sahel. Range Management, 33(1), 41-46.

Leach, M., and Mearns, R. (1996). The Lie of the Land: Challenging Received Wisdom on the African Environment. London: James curry.

Lemarchand, R. (1990). "African Peasantries, Reciprocity, and the Market - the Economy of Affection Reconsidered.". Cahiers D'Etudes Africaines 29(1), 33-67.

Levile, S., and Crosskey, A. (2006). Can Pastoralism Be Brought Back to Life? Towards a Safety Net and a Way Forward for North East Turkana. Nairobi, Kenya.

Lewis, I. (1961). A Pastoral Democracy: A Study of Pastoralism and Politics among the Northern Somali of the Horn of Africa: Oxford University Press.

Little, P. (1984). 'Land and Pastrolists.". Cultural Quarterly, 46-47.

Little, P., Mahmood, H., and Coppock, D. L. (2001). When Desert Flood: Risk Management and Climatic Processes among East African Pastoralists. Climate Research, 19, 149-159.

Long, N. (2001). Development Sociology. Actor Perspectives: Routledge, London.

Long, N. (2002). An Actor-Oriented Approach to Development Intervention. Backgroung Paper Prepared for Apo Meeting. Retrieved June 30, 2006, from http//apotokyo.org/icd/papers/selected_papers/Dr.Norman_Long.doc

Lynch, B., and Robbins, H. (1979). Cushites and Nilotic Prehistory: New Archeological Evidence from North-Western Kenya. Journal of African History, 20, 319-328.

Mair, L. (1967). Primitive Government: Harmondsworth.

Markasis, J. (1993). Conflict and the Decline of Pastoralism in the Horn of Africa. London: Macmillan.

Mauss, M. (1967). The Gift: Forms and Functions of Exchange in Archaic Societies. New York: Norton.

Mbithi, P., and Wisner, B. (1972). Drought and Famine in Kenya. Magnitude and Attempted Solutions. Nairobi: Institute of Development Studies, University of Nairobi.

McCabe, J. T. (1983). 'Land Use among the Pastoral Turkana'. Rural Africana, 15(16), 109126. 
McCabe, J. T. (1990). Success and Failure. The Breakdown of Traditional Drought Coping Institutions among the Pastoral Turkana of Kenya. Journal of African and Asian Studies, 25(3-4), 146-160.

McCabe, J. T. (2002). Impact of and Response to Drought among Turkana Pastoralists. In A. Oliver-Smith and S. Hoffman (Eds.), Culture and Catastrophe (pp. 213-236). Santa Fe: School of American Research Press.

McCabe, J. T., and Ellis, J. E. (1987). "Beating the Odds in Arid Africa". Natural History, $1,33-34$.

Mean, G. H. (1964). Mind, Self and Society. Chicago University: University of Chicago Press.

Migot-Adhola, S. E., and Little, P. D. (1981, August 4-8 ). Evolution of Policy Towards the Development of Pastoral Areas in Kenya. Paper presented at the Conference held in Nairobi, Kenya.

Mikkelsen, B. (1995). Methods for Development Work and Research: A Guide for Practitioners. New Delhi: Sage.

Mikkelsen, B. (2005). Methods for Development Work and Research. New Delhi, India: Sage Publications Ltd.

Morgan, W. T. W. (1971). The South Turkana Expedition Scientific Papers. Land Units of the Lokori Area. Geographical Journal, 137(1), 14-28.

Morgan, W. T. W. (1973). Geographies for Advanced Study. London: Longman Group Limited

Morgan, W. T. W. (1974). The South Turkana Expedition Scientific Papers X. Sorghum Gadens in South Turkana: Cultivation among a Nomadic Pastoral People. Geographical Journal, 140(1), 80-93.

Moser, C. (1998). The Asset Vulnerability Framework: Reassessing Urban Poverty Reduction Strategies. World Development, 26(1), 1-19.

Muller, H. K. (1989). Changing Generations: Dynamics of Generation and Age-Sets in South Eastern Sudan (Toposa) and Northwestern Kenya (Turkana). Spektrum Berliner Reihezu Gesellschaff, Wirtschaff and Politik in Entwicklungsladern. Saarbrucken, Fort Laudendale: Band 17 Verlag Breitenbach Puplishers.

Muriuki, G. (1974). A History of the Kikuyu 1500-1900. London: Oxford University Press.

Niamir-Fuller, M., and Turner, M. D. (1999). A Review of Recent Literature on Pastoralism and Transhumance in Africa. In M. Niamir-Fuller (Ed.), Managing Mobility in African Rangelands (pp. 11-13): Beijer International Institute of Ecological economics. 
Nikola, R. (2006). Policies and Strategies to Address the Vulnerability of Pastoralists in Sub-Saharan Africa. Retrieved March 18 2008, from http://www.fao.org/ag/pplpi.html

Nooteboom, G. (2003). A Matter of Style: Social Security and Livelihoods in Upland East Java. Amsterdam: Rozenberg.

Norconsult, R. (1990). Environmental Study of Turkana District. Lodwar, Kenya.

O'Leary, M. F. (1990). Drought and Change Amongst Northern Kenya Nomadic Pastoralists: The Palsson: The Scandinavian Institute of African Studies.

Oakley, P. (1991). Projects with People: The Practice of Participation in Rural Development: Geneva: International Labour Office.

Oba, G. (1990). "Culture and Extension: Friend or Foe? The Case of Kenya's Arid and Semi Arid Lands (Asal)." Keynote Address to the First National Agroforestry Extension Training Workshop Aberdares Country Club, Nyeri, Kenya.

Oba, G. (1992). Ecological Factors in Landuse Conflicts, Land Administration and Food Insecurity in Turkana. Pastoral Development Network Papers No. 33a. London: Overseas Development Institute.

Oba, G. (2001). The Importance of Pastoralists' Indegenous Coping Strategies for Planning Drought Management in the Arid Zone of Kenya. Nomadic People, 5(89), 89-119.

Ocan, C. M. (1992). Pastoral Crisis in Northeastern Uganda: The Changing Significance of Raids. Working Paper No. 2. Kampala: CBR Publishers.

Ochieng-Aketch, S. (1993). Land Use and Land Tenure Systems in the Arid and Semi-Arid Lands (Asal) of Kenya. Report Prepared for the Asal Team of the World Bank's Resident Mission in East Africa. Nairobi, Kenya.

Ochieng, W. (1985). A History of Kenya. Nairobi: Macmillan Publishers, Kenya.

Omosa, E. (2003). Natural Resource Based Conflicts and Pastoral Livelihoods: The Impact of Water Resource Based Conflicts on Pastoralism, Wajir District. University of Nairobi, Institute of Development Studies.

Ongany, M. (1981). Bibliography on Turkana. University of Nairobi: Institute of Development Studies.

Operation Lifeline Sudan (OLS) (2002). Operation Lifeline Sudan Southern Sector Annual Report . Nairobi, Kenya.

Pennings, J. M. E., and Smidts, A. (2000). 'Assessing the Construct Validity of Risk Attitude'. Management Science, 46(10), 1337-1342. 
Pennings, J. M. E., and Smidts, A. (2003). 'the Shape of Utility Functions and Organizational Behaviour'. Management Science, 49(9), 1251-1263.

Porter, P. W. (1987). "Wholes and Fragments: Reflections on the Economy of Affection, Capitalism, and the Human Cost of Development". Geografiska Annaler, 68B(1$14)$.

Pottier, J. (1993). African Systems under Stress. Issues, Perspectives and Methodologies.Unpublished manuscript, Brighton, Desktop Display, .

Pratt, D. J., and Gwynne, M. D. (1966). A Classification of East African Rangeland with an Appendix on Terminology. Journal of Applied Ecology, 3(36), 382.

Pratt, D. J., and Gwynne, M. D. (1977). Rangeland Management and Ecology in East Africa. London: Hodder and Stoughton.

Putnam, R. D. (1993). Making Democracy Work: Civic Traditions in Modern Italy. Princeton, N.J: Princeton University press.

Ragin, C. (1994). Constructive Social Research. Sociology for a New Century: Pine Forge Press, California.

Rahmato, D. (1991). Famine and Survival Strategies, Sweden, Uppsala.

Reardon, T. (1997). Using Evidence of Household Income Diversification to Inform Study of the Rural Nonfarm Labour Market in Africa World Development, 25(5), 735-747.

Reardon, T., and Vosti, S. A. (1995). Links between Rural Poverty and the Environments in Developing Countries: Asset Categories and Investment Poverty. World Development, 23(9), 1495-1506.

Republic of Kenya (1992). Development Policy for the Arid and Semi-Arid Lands (Asal). Nairobi: Government Printer, Kenya.

Republic of Kenya (1999). National Population Census: Report Prepared by Ministry of Planning and National Development. Nairobi: Government printer, Kenya.

Republic of Kenya (2002). Turkana District Development Plan 2002-2008: Effective Management for Sustainable Economic Growth and Poverty Reduction. Nairobi: Government Printer, Kenya.

Republic of Kenya (2006). Arid Lands Resource Management Project - Turkana District. Consolidated Progress Report 2003/4 -2005/6. Nairobi: Government Printer, Kenya.

Robinson, P. (1980, June 15-17 ). Disaster Responses among the Gabbra of Northern Kenya. An Historical Perspective. Paper presented at the National Museum of Kenya, Nairobi,. 
Robinson, P. (1985). Gabra Nomadic Pastoralism in Nineteenth and Twentieth Century Northern Kenya: Strategies for Survival in a Marginal Environment. Phd Dissertation. NorthWestern University, Evanston, IL.

Salkind, N. J. (2003). Exploring Research, 5th Edition. New Jersey: Prentice Hall.

Salzman, P. (1981). Afterward: On Some General Theoretical Issues. In J. G. Galaty and P. Salzman (Eds.), Change and Development in Nomadic and Pastoral Societies (pp. 158): Leiden: E.J. Brill.

Schafer, J. (2002). Supporting Livelihoods in Situations of Chronic Conflict and Political Instability. Overview of Conceptual Issues: Overseas Development Institute Working paper: 183.

Scheneider, H. (1957). The Subsistence Role of Cattle among the Pokot of East Africa. American Anthropologist, 59(2), 278-300.

Schumacher, E. F. (1997). Small Is Beautiful. New York: Harper and Row.

Schutz, A. (1970). Phenomenology and Social Relations; Selected Writings. Edited and with an Introduction by Helmut R.Wagner. Chicago: University of Chicago Press.

Scoones, I. (1994). The Economic Value of Livestock in the Communal Areas of Southern Zimbabwe Unpublished Manuscript: Annals of the Association of American Geographers.

Scoones, I. (1998). Sustainable Rural Livelihoods: A Framework for Analysis. Bringhton: IDS working paper: 72.

Sen, A. K. (1981). Poverty and Famines: An Essay on Enitlements and Deprivation. . Oxford: Clarendon press.

Sen, A. K. (1985). Commodities and Capabilities. Amsterdam: North Holland.

Shanmugaratnam, N. (2002). From Emergency Relief to Local Development and Civil Society Building. Dryland Group Report No. 18. Dryland Coordination Group. Retrieved May 21, 2006, from http://www.drylands-group.org/Articles/300.html

Siegel, P., and Alwang, D. J. (1999). An Asset-Based Approach to Social Risk Management: A Conceptual Framework and Social Protection Washington DC.: World Bank Discussion Paper No. 9926.

Sinclair, J., and Ham, L. (2000). Household Adaptive Strategies: Shaping Livelihood Security in the Western Himalaya. Canadian Journal of Development Studies, 21(1), 89-112.

Sobania, N. (1992). 'Feasts, Famines and Friends: Nineteenth Century Exchange and Ethnicity in the Eastern Lake Turkana Region'. Boulder: Westview Press. 
Soja, E. (1968). The Geography of Modernization in Kenya-a Spatial Analysis of Social Change, Economic and Political Change. Syracuse Geographical Series No. 2.

Soper, R. C. (1985). Social - Cultural Profile of Turkana District: Institute of African Studies, University of Nairobi, Kenya.

Spear, T., and Waller, R. (1993). Being Maasai : Ethnicity and Identity in East Africa. London: James Currey.

Spencer, I. (1983). Pastoralism and Colonial Policy in Kenya, 1895-1929. In R. Rotberg (Ed.), Imperialism, Colonialism and Hunger: East and Central Africa (pp. 4). Lexington: Lexington Books.

Spencer, P. (1965). The Samburu: A Study of Gerontocracy in a Nomadic Tribe: Berkeley: University of California Press.

Spencer, P. (1973). Nomads in Alliance. Symbiosis and Growth among the Rendile and Samburu of Kenya: London: Oxford University Press.

Strauss, A., and Corbin, J. (1990). Basics of Qualitative Research: Grounded Theory, Procedures and Techniques: SAGE Publications.

Stryker, S. (1973). Fundamental Principles of Social Interaction: John Wiley and Sons.

Sutter, J. (1982). Commercial Strategies, Drought and Monetary Pressure: Wo'daa'be Nomads of Tanout Arrondissement Niger. Nomadic peoples 11, 26-60.

Swift, J. (1985). Planning against Drought and Famine in Turkana, Northern Kenya. Oxfam and Turkana Rehabilitation Project Report. Nairobi: Government Printer, Kenya.

Swift, J. (1989). Why Are Rural People Vulnerable to Famine? IDS Bulletin, 20(2), 8-15.

Toulmin, C. (1986). "Access to Food, Dry Season Strategies and Household Size Amongst the Bambara of Central Mali". IDS Bulletin, 17(3), 58-66.

Turkana Development Annual Report (1936). Turkana District Annual Report. Nairobi: Kenya National Archive.

Turkana Development Annual Report (1938). Turkana District Annual Report. Nairobi: Kenya National Archives.

Turkana Development Annual Report (1939). Turkana District Annual Report. Nairobi: Kenya National Archive.

Turkana Development Annual Report (1942). Turkana District Annual Report Nairobi: Kenya National Archive. 
Turkana Development Annual Report (1943). Turkana District Annual Report. Nairobi: Kenya National Archives.

Turkana Development Annual Report (1948). Turkana District Annual Report Nairobi: Kenya National Archive.

Turkana Development Annual Report (1949). Turkana District Annual Report Nairobi: Kenya National Archive.

Turkana Development Annual Report (1963). Turkana District Annual Report. Nairobi: Kenya National Archive.

Turkana Development Annual Report (1966). Turkana District Annual Report, 1928-1961. Nairobi: Kenya National Archives.

Turkana Drought Contigency Planning Unit (1992). District Drought Manual. Lodwar: Government Printer, Kenya.

Turkana Political Records. Miscellaneous: 1971-1943 (File No. TURK/59, DC/TURK 3/1). Nairobi: Kenya National Archive.

Turkana Political Records: Miscelleneous: 1921-1945 (File No. TURK/17, DC/TURK 1/1). Nairobi: Kenya National Archive.

Umar, A. (1994). Symposium for Sustainable Development of North Eastern Kenya: Pastoralists Forum. Nairobi: Crescent of Hope.

UNDP (2000). Report on the Status of Drought Preparedness and Mitigation in SubSaharan Africa. United Nations (Volume 1). New York: Office of Combat Desertification and Drought, United Nations Development Programme (UNDP).

UNEP (2000). Devastating Drought in Kenya: Environmental Impacts and Responses. Nairobi: UNEP.

UNICEF (2006). As Drought Lingers, Kenya's Nomadic Turkana Tribes Are among the Worst Affected. Retrieved May 1, 2006, from http://www.unicef.org/infobycountry/kenya 31798.html

UNSO (1999). Drought Preparedness and Mitigation in Sub-Saharan Africa. New York: United Nations Office to Combat Desertification and Drought.

Van Zwanenberg, R., and King, A. (1975). An Economic History of Kenya and Uganda, 1800-1970. London: MacMillan.

Von Braun, J., and Pandya-Lorch, R. (1991). Income Sources of Malnourished People in Rural Areas: Micro-Level Information and Policy Implications. Washington DC: International Food Policy Research Institute. 
Von Hohnel, L. (1894). Discovery of Lakes Rudof and Stefanie: A Narative of Count Teleki's Exploring and Hunting Expeditition in Eastern Equatorial Africa in 1887 and 1888. Volume 2: London, Frank Class.

Walker, T. S., and Jodha, N. S. (1986). How Small Farm Households Adopt to Risk. In P. Hazzal (Ed.), Crop Insurance for Agriculture Development (pp. 17-34). Baltimore: Hopkins

Watson, C. (1985). Lake Turkana Fisheries Development Project, the Royal Norwegian Ministry of Development Cooperation, Evaluation Report 5.85, Oslo

Watts, M. (1983). Silent Violence: Food, Famine and the Peasantry in Northern Nigeria. Berkeley, California: University of California Press.

Wawire, V. (2003). Gender and the Socio-Economic Impacts of Drought on the Residents of Turkana District in Kenya Retrieved July 25, 2008, from http://www.ossrea.net/girr/no21/no21.htm

Werner, C. (1998). Household Networks and the Security of Mutual Indebtedness in Rural Kasakstan. Central Asian Survey, 17(4), 597-612.

White, G. (1974). Natural Hazards: Local, National and Global (Eds). New York: Oxford University Press.

White, H. (2002). 'Combining Qualitative and Quantitative Approaches in Poverty Analysis'. World Development, 30(3), 511-522.

Wienpahl, J. (1984). Livestock Production and Social Organization among the Turkana. Phd Desertation. University of Arizona, Tucson.

William, T., and Znanieki, F. (1974). The Polish Peasant in Europe and America. New York: Octagon Books.

Wisner, B. (1977). The Human Ecology of Drought in Eastern Kenya. Phd Thesis. Clerk University, Massachusettes.

Woolcock, M. (1998). "Social Capital and Economic Development: Towards a Theoretical Synthesis and Policy Framework". Theory and Society, 27, 151-208.

World Bank (1995). Staff Appraisal Report; Republic of Kenya; Arid Lands Resource Management Project. Nairobi: World Bank Report NO. 13692.

World Bank (2001). Engedering Development through Gender Equality in Rights, Resources, and Voice; World Bank Policy Research Report. Oxford University Press.

World Bank (2006). World Bank Development Report 2006: Equity and Development. New York: Oxford University Press. 
World Commission on Environment and Development (WCED) (1987). Our Common Future. Oxford: Oxford University Press.

Zoomers, A. (1999). Linking Livelihood Strategies to Development Experiences Form Bolivian Andes: Amsterdam, Royal Tropical Institute/Centre for Latin American Research. 


\section{Appendices}

\section{Appendix 1: Household Profile}

1. Household head

Name

Sex

$\mathrm{M} / \mathrm{F}$

Age

Clan Territorial section

2. Family size and composition (wives only)

Name of wife

Age

No of children

1 .

2 .

3.

.....

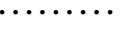

......

3. Family size (siblings only) by wives

Wife 1

$\begin{array}{ll}\text { Name of child } & \text { Sex } \\ 1 \ldots \ldots \ldots \ldots \ldots \ldots & \mathrm{M} / \mathrm{F} \\ 2 \ldots \ldots \ldots \ldots \ldots & \mathrm{M} / \mathrm{F} \\ 3 \ldots \ldots \ldots \ldots \ldots & \mathrm{M} / \mathrm{F}\end{array}$

Age

No of children

Wife 2

Name of child

$1 \ldots \ldots \ldots \ldots . . . .$.

Sex

$2 \ldots \ldots \ldots \ldots \ldots$

$\mathrm{M} / \mathrm{F}$

3.

$\mathrm{M} / \mathrm{F}$

Wife 3

$\mathrm{M} / \mathrm{F}$

Name of child

Sex

1 ................

$\mathrm{M} / \mathrm{F}$

2.

$\mathrm{M} / \mathrm{F}$

3

$\mathrm{M} / \mathrm{F}$

4. Close relatives in the household (man's side)

$\begin{array}{ll}\text { Name } & \text { Sex } \\ 1 \ldots \ldots \ldots \ldots \ldots \ldots \ldots \ldots \ldots \ldots \ldots \ldots \ldots \ldots \ldots \ldots \ldots \ldots \ldots & \mathrm{M} / \mathrm{F} \\ 2 \ldots \ldots \ldots \ldots \ldots & \mathrm{M} / \mathrm{F}\end{array}$

5. Close relatives in the household (wife's side)

Wife 1

$\begin{array}{ll}\text { Name } & \text { Sex } \\ 1 \ldots \ldots \ldots \ldots \ldots \ldots \ldots \ldots . . \ldots & \mathrm{M} / \mathrm{F} \\ 2 \ldots \ldots \ldots \ldots \ldots \ldots \ldots \ldots & \mathrm{M} / \mathrm{F}\end{array}$

6. Close relatives in the household (wife's side)

Wife 2

$\begin{array}{ll}\text { Name } & \text { Sex } \\ 1 \ldots \ldots \ldots \ldots \ldots \ldots \ldots \ldots & \mathrm{M} / \mathrm{F} \\ 2 \ldots \ldots \ldots \ldots \ldots \ldots \ldots \ldots & \mathrm{M} / \mathrm{F}\end{array}$

7. Close relatives in the household (wife's side)

Wife 3

$\begin{array}{lc}\text { Name } & \text { Sex } \\ 1 \ldots \ldots \ldots \ldots \ldots \ldots \ldots \ldots \ldots \ldots \ldots \ldots \ldots \ldots \ldots \ldots & \mathrm{M} / \mathrm{F} \\ 2 \ldots \ldots \ldots \ldots \ldots \ldots \ldots & \mathrm{M} / \mathrm{F}\end{array}$




\section{Appendix 2: Household Schedule}

1. Key issues related to assets

Prompts:

- What are your households' main assets?

- How 2005-2006 droughts did affect your assets? Explain

- How important are the assets during drought situations?

2. People with whom reciprocal exchange relationships are maintained

$\begin{array}{lccll}\text { Name } & \text { Age } & \text { Economic status } & \text { location } & \text { intimacy } \\ 1 \ldots \ldots \ldots \ldots & \ldots \ldots & \ldots \ldots & \ldots \ldots & \ldots \ldots \\ 2 \ldots \ldots \ldots \ldots & \ldots \ldots & \ldots \ldots & \ldots \ldots & \ldots \ldots \\ 3 \ldots \ldots \ldots \ldots & \ldots \ldots & \ldots \ldots & \ldots \ldots & \ldots \ldots\end{array}$

3. Livestock wealth kept away with the bond friends

Name of the bond friend stock kept with him

since when?

1

2.

3.

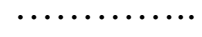

n...........

(n...........

.............

4. Livestock kept by the respondent for his bond-friends

Name of the bond friend

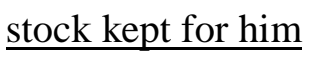

since when?

1

2 .

3.
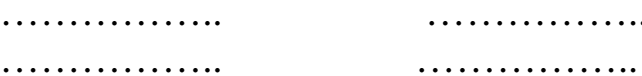

5. Property (livestock) owned by the family before and after the drought and famine

Stock species
Cattle
Sheep and goat
Camels
Donkeys
Others

before disaster

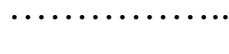

...............

.................

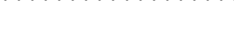

$\underline{\text { after disaster }}$

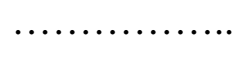

6. Was your livestock wealth enough to see you through the drought and famine period without asking for additional assistance from anybody? YES /NO

Reasons for answer.

7. During the $2005 / 2006$ drought and famine, were the Turkana of this locality alerted of its coming? How?

8. Did the people here take the warnings seriously? YES/NO

Reasons.

9. What livelihood strategies did the people use for fighting the problem of drought and famine?

Enumerate 1....

$$
2 .
$$


3.

10. How effective were these strategies in weathering the disaster?

11. In your case, when did you first learn that you were going to face acute food shortage?

12. What did you personally do to weather the drought and famine problem?

Enumerate starting with the one which came first:

1.

2.

3

13. How effective were these adjustments in your case?

14. What help did your family get from the bond-friends enumerated in Q.2 above? Name of the bond-friend Help received how frequently?

15. What help did you give out to your bond-friends? Name of the bond-friend how much given? how frequently?

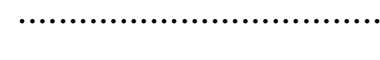

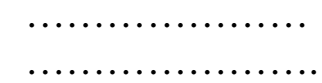

16. Were there any human losses in your family from drought and famine? YES/NO If yes, give the following details:

$\begin{array}{llcccc}\text { Name } & \text { Age } & \text { Sex } & \text { Mother (if child) } & \text { Date lost } & \text { Cause } \\ 1 \ldots \ldots \ldots \ldots . & \ldots \ldots & \text { M/F } & \ldots \ldots \ldots & \ldots \ldots & \ldots \ldots \\ 2 \ldots \ldots \ldots \ldots & \ldots \ldots & \text { M/F } & \ldots \ldots \ldots & \ldots \ldots & \ldots \ldots \\ 3 \ldots \ldots \ldots \ldots & \ldots \ldots & \text { M/F } & \ldots \ldots \ldots & \ldots \ldots & \ldots \ldots\end{array}$

17. Were there any human losses you know of due to drought and famine in the neighbourhood outside your family? YES/NO

If yes, give the following details:

$\begin{array}{lllll}\text { Name } & \text { Age } & \text { Sex } & \text { locality } & \text { cause of death } \\ 1 \ldots \ldots \ldots \ldots . & \ldots \ldots & \mathrm{M} / \mathrm{F} & \ldots \ldots & \ldots \ldots \\ 2 \ldots \ldots \ldots \ldots & \ldots \ldots & \mathrm{M} / \mathrm{F} & \ldots \ldots & \ldots \ldots \\ 3 \ldots \ldots \ldots \ldots & \ldots \ldots & \mathrm{M} / \mathrm{F} & \ldots \ldots & \ldots \ldots\end{array}$

18. Did you send any of your family members away to stay with relatives, friends or neighbours to ease the strain on domestic food resources? YES/NO

If yes give details as to whom, when and how long? 
19. Did any member of the family migrate to town, irrigation scheme, lakeshore etc in search of food or employment? YES/NO

If yes, give the following details:

Name of migrant Age sex where migrated to when returned

1.

$\ldots . . . \mathrm{M} / \mathrm{F}$

2.

$\ldots . . \mathrm{M} / \mathrm{F}$

20. Give details of what help the migrants in Q.19 above got from where they had gone?

What help found how much sent home?

1

2

3.
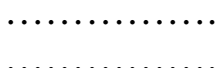

21. When was your name entered in the famine relief list?

22. Which of your family member remained in the countryside as you moved closer to the famine relief supply centre?

23. Who is now in-charge of your surviving livestock in the pasturelands?

24. What form of non-pastoral food aid did your family receive from anywhere/anybody before the Kenya government supplied food to this locality?

25. Considering what we have discussed, how would you describe the situation of household/other villagers now? Explain

- Do you consider yourself and/or them better than the way you were before drought or vice versa?

- What do you plan for your children in future, and what do you wish for your grandchildren? 


\section{Appendix 3: Key Informants Schedule}

1. Oral history and cultural interpretation of drought and famine by the Turkana elders.

2. In the past, who used to warn people of the impending outbreak of drought and famine?

3. In the past, were there any rituals or ceremonies related to drought and famine? Are they still being observed today by the Turkana people?

4. How effective were traditional means of wading off famine?

5. How effective are the cultural means for weathering drought and famine to be managed by the government?

6. How best would the Turkana themselves like drought and famine to be managed by them/ by the government?

7. Would you consider Turkana pastoralist more vulnerable to the devastating effects of drought and famine today than in the past?

Explain fully what factors are perceived to account for the changes in adaptive capacity if any?

8. Do you think the dispossessed Turkana fall off the reciprocal network during drought and famine as the recent/present one?

9. How does one re-enter pastoral life after a major drought like 2005-2006 0ne, and in the past?

10. In your view, would you say famine relief food as distributed in this famine relief camp reaches the needy? How are the people using their famine relief rations?

11. Considering what we have discussed, how would you describe your current situation and or/ that of other Turkana people in this village? Explain

- Do you consider yourself or them better than the way you were before drought or vice versa? 
Appendix 4: Mutually Intelligible Words in Ngaturkana and dholuo Languages

\begin{tabular}{|l|l|l|}
\hline Ngaturkana & dholuo & English \\
\hline Agulu & Agulu & Pot \\
\hline Akuru & Akuru & Dove \\
\hline Apor & Apuoyo & Rabbit (hare) \\
\hline Akinyang' & Nyang' & Crocodile \\
\hline Akipi & Pii & Water \\
\hline Akiring & Ring'o & Meat \\
\hline Etich & Tich & Work \\
\hline Arei & Ariyo & Two \\
\hline Ng'omon & Ang'uen & Four \\
\hline Kwe & Bwe & Jackal \\
\hline Ing'ok & Guok & Dog \\
\hline Edit & Matin & Small (Little) \\
\hline Apethe & Apisi & Nice girl \\
\hline
\end{tabular}

Source: Fieldwork 


\section{Appendix 5: Gender and the Division of Labour among the Turkana}

\begin{tabular}{|c|c|c|}
\hline Duties & Women & Men \\
\hline $\begin{array}{l}\text { Home management } \\
\text { and maintenance } \\
\text { roles }\end{array}$ & $\begin{array}{l}\text { - } \text { Fetching water for household use } \\
\text { - Preparing food and gathering wild } \\
\text { fruits for domestic consumption } \\
\text { - } \text { Fetching firewood } \\
\text { - Cleaning the compound and } \\
\text { construction of: } \\
-\quad \text { animal kraals ( (anok) } \\
-\quad \text { Main house (akai) } \\
-\quad \text { Children resting shelter }(\text { ekal }) \\
-\quad \text { Sleeping and cooking area } \\
(\text { atabo })\end{array}$ & 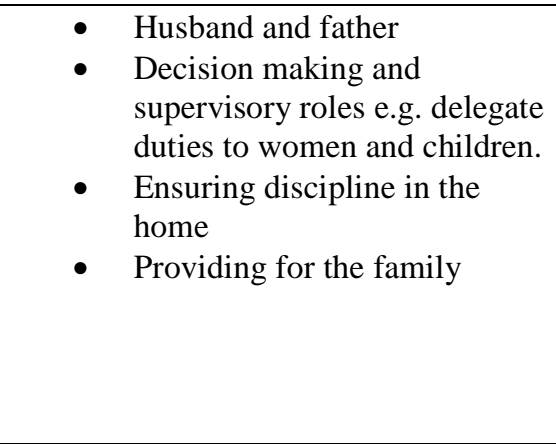 \\
\hline $\begin{array}{l}\text { Roles in livestock } \\
\text { production }\end{array}$ & $\begin{array}{l}\text { Watering the livestock other than cattle } \\
\text { (goats, donkeys and camels) by } \\
\text { scooping water from the wells into a } \\
\text { big calabash for the animals to drink } \\
\text { - } \quad \text { Preparation for migration to new } \\
\text { locations } \\
\text { - Milking the stock and positioning it out } \\
\text { into different uses for the household } \\
\text { - Herding small stock (goats). }\end{array}$ & $\begin{array}{l}\text { Ensuring that the livestock get } \\
\text { pasture } \\
\text { Exploring good grazing land } \\
\text { and water when the drought } \\
\text { sets in. } \\
\text { - Providing health services to } \\
\text { the animals in the form of } \\
\text { traditional herbs. } \\
\text { - Making decisions on the } \\
\text { slaughter and sale of animals } \\
\text { or when and where to migrate } \\
\text { Providing security to animals } \\
\text { and household members. }\end{array}$ \\
\hline $\begin{array}{l}\text { Roles in cultural } \\
\text { production }\end{array}$ & $\begin{array}{l}\text { - Socialization: bring forth children and } \\
\text { nurturing them as they grow. Socialize } \\
\text { the children into the Turkana way of } \\
\text { life. } \\
\text { - Supervise young girls when dowry is } \\
\text { being paid, and later prepare them as } \\
\text { brides on their wedding days. } \\
\text { - Older women and even younger ones } \\
\text { make skin clothes for girls and married } \\
\text { women. } \\
\text { Women prepare food and even sing } \\
\text { during rituals such as child-naming and } \\
\text { weddings }\end{array}$ & $\begin{array}{l}\text { - Organizing family meetings to } \\
\text { deliberate on matters relating } \\
\text { to the clan and family } \\
\text { Socialization of boys into } \\
\text { adult roles in the Turkana } \\
\text { society. They teach young } \\
\text { boys the skills in herding (how } \\
\text { to locate and identify good } \\
\text { pasture/water source, herbs to } \\
\text { cure diseases infecting herd), } \\
\text { social adults skills of being a } \\
\text { good husband and father and } \\
\text { protecting the herd and the } \\
\text { family. } \\
\text { Custodian of cultural values. } \\
\text { Men make all decisions related } \\
\text { to animal slaughter, migration, } \\
\text { marriage and dowry payment } \\
\text { and rituals and their } \\
\text { performance. }\end{array}$ \\
\hline $\begin{array}{l}\text { Non-pastoral } \\
\text { activities }\end{array}$ & - Weaving of mats, baskets and hats & $\begin{array}{l}\text { - } \quad \text { Start small business activities } \\
\text { such as charcoal selling and } \\
\text { kiosk ownership }\end{array}$ \\
\hline
\end{tabular}

Source: (Wawire 2003: 1-3) and Field data (2006) 


\begin{tabular}{l|l}
\hline TO & Richard Juma \\
\hline COPY TO & Professor Vijay Naidu \\
\hline FROM & Dr Allison Kirkman, Convener, Human Ethics Committee \\
\hline
\end{tabular}

\begin{tabular}{l|l}
\hline DATE & 17 December 2006 \\
\hline PAGES & 1 \\
\hline
\end{tabular}

\begin{tabular}{l|l}
\hline SUBJECT & $\begin{array}{l}\text { Ethics Approval: No 138/2006, Adaptation to drought in arid } \\
\text { areas in Kenya: a study of the livelihood strategies of Turkana } \\
\text { pastoralists. }\end{array}$ \\
\hline
\end{tabular}

Thank you for your application for ethical approval, which has now been considered by the Standing Committee of the Human Ethics Committee.

Your application has been approved and this approval continues until 30 July 2007. If your data collection is not completed by this date you should apply to the Human Ethics Committee for an extension to this approval.

Best wishes with the research.

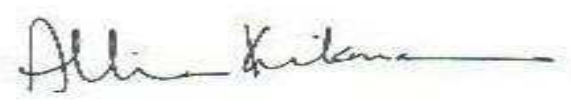

Allison Kirkman Convener 


\section{Appendix 7: Introductory Letter from Supervisor}

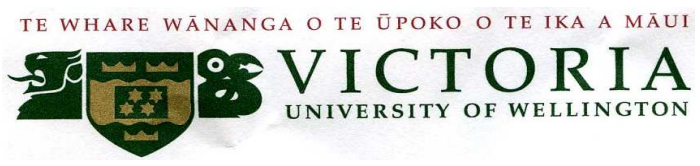

8 January, 2007

To whom it may concern,

I am writing to introduce to you Mr Richard Juma and to request your kind assistance to him.

Richard is currently a PhD student in Development Studies at the Victoria University of Wellington, New Zealand. He will be researching the topic of "Turkana Livelihood strategies and adaptation to drought in Kenya" over the next 6 months beginning in January.

Your assistance to him in his research work will contribute to his efforts at identifying how Turkana households are able to sustain livelihoods in increasingly arid conditions and the most appropriate ways in which their livelihood strategies can be enhanced.

It is likely that Richard's study will increase our understanding of Turkana livelihoods and identify sustainable strategies to reduce their vulnerability to droughts.

It is hoped that the findings of his research will be of benefit to Government, aid agencies, NGOs, community organisations and the wider Turkana community.

Yours faithfully

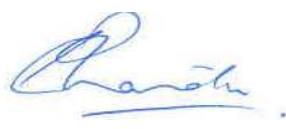

Professor Vijay Naidu

Director, Development Studies

Institute of Geography

School of Geography, Environment and Earth Sciences

Victoria University

PO Box 600

Wellington

Tel: +64-4-463-5281

Fax: +64-4-463-5186 


\section{Appendix 8: Information Sheet to Participants}

\section{RESEARCH PROJECT: TURKANA LIVELIHOOD STRATEGIES AND ADAPTATION TO DROUGHT IN KENYA.}

Dear

I am a PhD student in Development studies at Victoria University of Wellington, New Zealand. As part of this degree, I am undertaking a research project leading to a thesis. The project I am undertaking is investigating how the Turkana people in North West, Kenya adapt to an increasingly arid environment. The knowledge gained through this research will help to evaluate the appropriateness of the existing approach to drought impacts and whether enough effort has been put to identify alternative approaches to build resilience to drought in rural Turkana.

I would like to invite you and your (awi) to participate in my research to share insights on your practices, realities and observations regarding your livelihoods in the face of drought. Your observations will be tape recorded and transcribed. You will have the opportunity to review transcribes for accuracy. You are also free to withdraw at any time during your participation without any question.

Data will be safely stored during and after the research by me with reasonable security safeguards against loss, unauthorized access, use, modification or disclosure and other misuse. Only my three supervisors and I will have access to the information collected. That information will be kept by me for a period of 18 months to assist in data analysis and writing of thesis. After 18 months duration, all the information will be destroyed and electronically wiped out. Specific personal information will not be used and you will not be able to be identified in my report. I will strictly protect the confidentiality of the information you provide.

On completion of the project, I will present my findings to you in a comprehensive form. A $\mathrm{PhD}$ thesis will be prepared and subsequently published in part or as a whole.

I will greatly appreciate your cooperation in this important piece of research work for the Turkana people and our country as a whole. If you have any questions concerning this undertaking, please do not hesitate to address them to me or my principal supervisor Professor Vijay Naidu, Director Development studies, School of Geography, Environment and Earth Sciences, Victoria university, P.O Box 600, Wellington, Phone: +64-4-463-6108, Fax: +64-4-463 5186, Email vijay.naidu@vuw.ac.nz,

Thank You,

RICHARD OTIENO JUMA

Email: Richard.juma@vuw.ac.nz or juma_bandeko@yahoo.co.uk

Mobile:+254-724158971 
Appendix 9: Pre and Post the 2005-2006 Drought Family Herds at Morulem Village

\begin{tabular}{|c|c|c|c|c|c|c|c|c|c|c|}
\hline \multicolumn{11}{|c|}{ Morulem village } \\
\hline \multicolumn{6}{|c|}{ Pre-drought } & \multicolumn{5}{|c|}{ Post-drought } \\
\hline Household & Cattle & Goats and sheep & Camels & Donkeys & & Respondent & Cattle & Goats and sheep & Camels & Donkeys \\
\hline 1 & 8 & 15 & 0 & 0 & & 1 & 3 & 8 & 0 & 0 \\
\hline 2 & 30 & 20 & 3 & 7 & & 2 & 9 & 9 & 3 & 2 \\
\hline 3 & 4 & 31 & 1 & 4 & & 3 & 0 & 17 & 1 & 1 \\
\hline 4 & 4 & 27 & 1 & 1 & & 4 & 0 & 18 & 1 & 0 \\
\hline 5 & 15 & 60 & 3 & 7 & & 5 & 6 & 25 & 3 & 4 \\
\hline 6 & 3 & 7 & 5 & 11 & & 6 & 0 & 2 & 5 & 5 \\
\hline 7 & 9 & 30 & 0 & 1 & & 7 & 1 & 17 & 0 & 0 \\
\hline 8 & 14 & 17 & 0 & 0 & & 8 & 3 & 7 & 0 & 0 \\
\hline 9 & 5 & 0 & 0 & 0 & & 9 & 2 & 0 & 0 & 0 \\
\hline 10 & 8 & 5 & 0 & 4 & & 10 & 2 & 1 & 0 & 0 \\
\hline 11 & 16 & 19 & 0 & 1 & & 11 & 9 & 10 & 0 & 0 \\
\hline 12 & 8 & 13 & 9 & 1 & & 12 & 5 & 4 & 7 & 0 \\
\hline 13 & 4 & 3 & 0 & 0 & & 13 & 0 & 0 & 0 & 0 \\
\hline 14 & 22 & 5 & 6 & 2 & & 14 & 12 & 2 & 6 & 0 \\
\hline 15 & 8 & 1 & 2 & 0 & & 15 & 5 & 0 & 2 & 0 \\
\hline 16 & 4 & 7 & 0 & 0 & & 16 & 1 & 2 & 0 & 0 \\
\hline 17 & 8 & 1 & 0 & 0 & & 17 & 4 & 0 & 0 & 0 \\
\hline 18 & 7 & 1 & 1 & 1 & & 18 & 2 & 0 & 1 & 0 \\
\hline 19 & 13 & 0 & 1 & 0 & & 19 & 8 & 0 & 1 & 0 \\
\hline 20 & 5 & 1 & 0 & 0 & & 20 & 0 & 0 & 0 & 0 \\
\hline 21 & 4 & 3 & 0 & 0 & & 21 & 0 & 1 & 0 & 0 \\
\hline 22 & 24 & 4 & 6 & 0 & & 22 & 8 & 1 & 6 & 0 \\
\hline 23 & 7 & 1 & 0 & 1 & & 23 & 3 & 0 & 0 & 0 \\
\hline Total & 230 & 271 & 38 & 41 & & & 83 & 124 & 36 & 12 \\
\hline \multicolumn{5}{|l|}{ Sub-Total } & 580 & & & & & \\
\hline
\end{tabular}


Appendix 9 Continues

\begin{tabular}{|c|c|c|c|c|c|c|c|c|c|}
\hline \multicolumn{5}{|c|}{ Pre-drought } & \multicolumn{5}{|c|}{ Post-drought } \\
\hline Household & Cattle & $\begin{array}{c}\text { Goats and } \\
\text { sheep }\end{array}$ & Camels & Donkeys & Household & Cattle & $\begin{array}{c}\text { Goats and } \\
\text { sheep }\end{array}$ & Camels & Donkeys \\
\hline 24 & 3 & 18 & 1 & 3 & 24 & 1 & 7 & 1 & 1 \\
\hline 25 & 19 & 30 & 3 & 0 & 25 & 9 & 7 & 3 & 0 \\
\hline 26 & 4 & 5 & 0 & 0 & 26 & 3 & 1 & 0 & 0 \\
\hline 27 & 7 & 9 & 1 & 4 & 27 & 5 & 2 & 1 & 1 \\
\hline 28 & 8 & 4 & 1 & 1 & 28 & 2 & 0 & 1 & 0 \\
\hline 29 & 10 & 16 & 2 & 4 & 29 & 4 & 5 & 2 & 2 \\
\hline 30 & 11 & 26 & 6 & 2 & 30 & 6 & 12 & 6 & 1 \\
\hline 31 & 3 & 1 & 0 & 1 & 31 & 0 & 0 & 0 & 0 \\
\hline 32 & 5 & 6 & 0 & 2 & 32 & 1 & 0 & 0 & 0 \\
\hline 33 & 15 & 11 & 4 & 2 & 33 & 8 & 5 & 4 & 0 \\
\hline 34 & 6 & 1 & 0 & 4 & 34 & 2 & 0 & 0 & 1 \\
\hline 35 & 9 & 10 & 2 & 1 & 35 & 3 & 3 & 2 & 0 \\
\hline 36 & 1 & 7 & 0 & 2 & 36 & 0 & 1 & 0 & 0 \\
\hline 37 & 5 & 2 & 0 & 0 & 37 & 4 & 0 & 0 & 0 \\
\hline 38 & 11 & 2 & 1 & 1 & 38 & 8 & 0 & 1 & 1 \\
\hline 39 & 8 & 2 & 1 & 3 & 39 & 7 & 0 & 1 & 1 \\
\hline 40 & 24 & 10 & 5 & 4 & 40 & 10 & 2 & 5 & 1 \\
\hline 41 & 8 & 6 & 0 & 3 & 41 & 4 & 0 & 0 & 2 \\
\hline 42 & 2 & 7 & 0 & 3 & 42 & 1 & 2 & 0 & 0 \\
\hline 43 & 4 & 6 & 0 & 0 & 43 & 0 & 2 & 0 & 0 \\
\hline 44 & 10 & 9 & 1 & 1 & 44 & 4 & 1 & 1 & 0 \\
\hline 45 & 18 & 11 & 5 & 2 & 45 & 10 & 3 & 5 & 0 \\
\hline Total & 191 & 199 & 33 & 43 & & 92 & 53 & 33 & 11 \\
\hline Sub-Total & & & & 466 & & & & & $18 \subseteq$ \\
\hline
\end{tabular}


Appendix 10: Pre and Post the 2005-2006 Drought Family Herds at Lokichar Village

\begin{tabular}{|c|c|c|c|c|c|c|c|c|c|}
\hline \multicolumn{5}{|c|}{ Pre-drought } & \multicolumn{5}{|c|}{ Post-drought } \\
\hline Household & Cattle & Goats and sheep & Camels & Donkeys & Respondent & Cattle & Goats and sheep & Camels & Donkeys \\
\hline 1 & 3 & 24 & 6 & 1 & 1 & 2 & 15 & 6 & 0 \\
\hline 2 & 5 & 2 & 1 & 1 & 2 & 1 & 0 & 1 & 0 \\
\hline 3 & 18 & 36 & 9 & 7 & 3 & 10 & 24 & 9 & 3 \\
\hline 4 & 10 & 23 & 5 & 0 & 4 & 9 & 15 & 5 & 0 \\
\hline 5 & 9 & 52 & 11 & 12 & 5 & 7 & 30 & 11 & 7 \\
\hline 6 & 4 & 0 & 1 & 1 & 6 & 0 & 0 & 1 & 0 \\
\hline 7 & 17 & 14 & 3 & 5 & 7 & 11 & 7 & 3 & 1 \\
\hline 8 & 20 & 6 & 1 & 2 & 8 & 12 & 1 & 1 & 1 \\
\hline 9 & 24 & 12 & 6 & 1 & 9 & 14 & 6 & 6 & 0 \\
\hline 10 & 13 & 8 & 1 & 0 & 10 & 7 & 3 & 1 & 0 \\
\hline 11 & 10 & 9 & 1 & 0 & 11 & 4 & 5 & 1 & 0 \\
\hline 12 & 11 & 7 & 0 & 0 & 12 & 6 & 3 & 0 & 0 \\
\hline 13 & 9 & 5 & 1 & 2 & 13 & 3 & 1 & 1 & 0 \\
\hline 14 & 14 & 4 & 2 & 0 & 14 & 5 & 0 & 2 & 0 \\
\hline 15 & 27 & 17 & 12 & 10 & 15 & 15 & 11 & 12 & 8 \\
\hline 16 & 5 & 2 & 1 & 1 & 16 & 1 & 0 & 1 & 0 \\
\hline 17 & 8 & 0 & 1 & 1 & 17 & 2 & 0 & 1 & 0 \\
\hline 18 & 8 & 3 & 0 & 0 & 18 & 3 & 1 & 0 & 0 \\
\hline 19 & 7 & 2 & 0 & 1 & 19 & 2 & 0 & 0 & 0 \\
\hline 20 & 3 & 6 & 1 & 0 & 20 & 0 & 1 & 1 & 0 \\
\hline 21 & 10 & 1 & 1 & 1 & 21 & 1 & 0 & 1 & 0 \\
\hline 22 & 2 & 0 & 2 & 1 & 22 & 0 & 0 & 2 & 0 \\
\hline 23 & 35 & 60 & 8 & 8 & 23 & 25 & 22 & 8 & 5 \\
\hline Total & 272 & 293 & 74 & 55 & & 140 & 145 & 74 & 25 \\
\hline Sub-Total & & & & & & & & & 384 \\
\hline
\end{tabular}




\section{Appendix 10 Continues}

Pre-drought

Post-drought

\begin{tabular}{|c|c|c|c|c|c|c|c|c|c|}
\hline Household & Cattle & Goats and sheep & Camels & Donkeys & Household & Cattle & Goats and sheep & Camels & Donkeys \\
\hline 24 & 1 & 17 & 2 & 4 & 24 & 0 & 10 & 2 & 2 \\
\hline 25 & 12 & 20 & 4 & 2 & 25 & 0 & 15 & 4 & 0 \\
\hline 26 & 0 & 8 & 0 & 2 & 26 & 8 & 3 & 0 & 1 \\
\hline 27 & 4 & 10 & 0 & 1 & 27 & 1 & 7 & 0 & 0 \\
\hline 28 & 5 & 7 & 0 & 0 & 28 & 4 & 1 & 0 & 0 \\
\hline 29 & 0 & 2 & 0 & 0 & 29 & 0 & 0 & 0 & 0 \\
\hline 30 & 7 & 10 & 1 & 3 & 30 & 3 & 6 & 1 & 1 \\
\hline 31 & 0 & 2 & 0 & 1 & 31 & 0 & 0 & 0 & 0 \\
\hline 32 & 4 & 8 & 0 & 1 & 32 & 0 & 5 & 0 & 1 \\
\hline 33 & 12 & 20 & 1 & 2 & 33 & 10 & 8 & 1 & 0 \\
\hline 34 & 4 & 0 & 1 & 1 & 34 & 2 & 0 & 1 & 0 \\
\hline 35 & 0 & 2 & 0 & 0 & 35 & 0 & 0 & 0 & 0 \\
\hline Total & 49 & 106 & 9 & 17 & & 28 & 55 & 9 & 5 \\
\hline Sub-Total & & & & & & & & & 97 \\
\hline
\end{tabular}


